\title{
THE CULTURAL LIFE OF JAMIX BOND
}

(D)

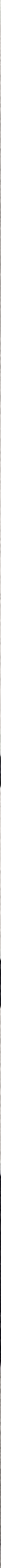


The Cultural Life of James Bond 



\title{
The Cultural Life of James Bond
}

Specters of 007

\author{
Edited by \\ Jaap Verheul
}


The publication of The Cultural Life ofJames Bond: Specters of oo 7 is made possible by a grant from The Faculty of Arts and Humanities at King's College London.

Cover illustration: Poster Art for Spectre (UK/USA/Austria/Mexico/Italy/Morocco: Sam Mendes, 2015) by Karolis Strautniekas. Commissioned by Human After All, United Kingdom, 2015 . Copyright of Karolis Strautniekas, Lithuania; and Folio Art Limited, United Kingdom.

Cover design: Coördesign, Leiden

Lay-out: Crius Group, Hulshout

$\begin{array}{ll}\text { ISBN } & 9789462982185 \\ \text { e-ISBN } & 9789048532117 \\ \text { DOI } & 10.5117 / 9789462982185 \\ \text { NUR } & 670\end{array}$

(c) The authors / Amsterdam University Press B.V., Amsterdam 2020

All rights reserved. Without limiting the rights under copyright reserved above, no part of this book may be reproduced, stored in or introduced into a retrieval system, or transmitted, in any form or by any means (electronic, mechanical, photocopying, recording or otherwise) without the written permission of both the copyright owner and the author of the book.

Every effort has been made to obtain permission to use all copyrighted illustrations reproduced in this book. Nonetheless, whosoever believes to have rights to this material is advised to contact the publisher. 
To my parents 



\section{Table of Contents}

Acknowledgements

Introduction: Specters of 007

Jaap Verheul

\section{Part I Beyond Britain: The Transnational Configuration of the James Bond Phenomenon}

1. The Forgotten Bond: The CBS production of Casino Royale (1954) 25 James Chapman

2. A Socialist 007: East European Spy Dramas in the Early James Bond Era Mikotaj Kunicki

3. From Indianization to Globalization: Tracking Bond in Bollywood 61 Ajay Gehlawat

4. The Dead Are Alive: The Exotic Non-Place of the Bondian Runaway Production

Melis Behlil, Ignacio M. Sánchez Prado, and Jaap Verheul

5. Bond Rebooted: The Transnational Appeal of the Daniel Craig James Bond Films

Huw D. Jones and Andrew Higson

\section{Part II Beyond The Hero: The Cultural Politics of 007}

6. Paradoxical Masculinity: James Bond, Icon of Failure

Toby Miller

7. Femininity, Seriality and Collectivity: Rethinking the Bond Girl Moya Luckett 
8. Market Forces: James Bond, Women of Color, and the Eastern Bazaar

Lorrie Palmer

9. Shaken, Not Stirred Britishness: James Bond, Race, and the Transnational Imaginary

Anna Everett

10. Global Agency between Bond and Bourne: Skyfall and James Bond in Comparison to the Jason Bourne Film Series

Seung-hoon Jeong

\section{Part III Beyond the Films: The Transmediality of the James Bond Franchise}

11. James Bond and Art Cinema

Christopher Holliday

12. Branding 007: Title Sequences in the James Bond Films Jan-Christopher Horak

13. "Unlike Men, The Diamonds Linger:" Bassey and Bond Beyond the Theme Song 269

Meenasarani Linde Murugan

14. Skyfall and Global Casino Culture 289 Joyce Goggin

15. Three Dimensions of Bond: Adaptive Fidelity and Fictional Coherence in the Videogame Adaptations of GoldenEye Ian Bryce Jones and Chris Carloy

Index 


\section{Acknowledgements}

The Cultural Life of James Bond: Specters of oo 7 emanates from an undergraduate course I taught on "Understanding 007" in the Department of Cinema Studies at New York University in 2014, which invited my students to identify potential gaps in existing scholarly debates on the James Bond franchise-especially in the wake of the unprecedented box office takings of Skyfall, the twenty-third Bond-feature from 2012. These in-class conversations shaped my inquiry into future directions for scholarship on 007, moving the debates beyond Ian Fleming's novels and the Eon film series in order to arrive at an understanding of Bond's literary and cinematic incarnations as contested sites of negotiation. This enterprise benefited significantly from my conversations with Meenasarani Linde Murugan, Seung-hoon Jeong, James Chapman, and Richard Allen. It may be something of a truism to conclude that The Cultural Life ofJames Bond would not have materialized without their sustained commitment to this project, but I owe these four eminent scholars my utmost gratitude.

Erika Balsom and Mark Shiel were generous mentors in the Department of Film Studies at King's College London, who helped to guide this collection through the publication process. Daniel Mann graciously offered feedback on my own, co-authored chapter with Melis Behlil and Ignacio M. Sánchez Prado on "The Dead Are Alive: The Exotic Non-Place of the Bondian Runaway Production." Robbie Mills was an astute editorial assistant on this journey and helped to see the project through to completion. The Faculty of Arts and Humanities at King's College London generously provided research funding that facilitated the publication of The Cultural Life ofJames Bond.

I would like to thank Anna McCarthy, Chris Straayer, Dan Streible, Antonia Lant, JungBong Choi, Robert Stam, and Toby Lee in the Department of Cinema Studies at New York University for their support for my inquiry into all things Bond, and for guiding me in my professional development. I have been particularly fortunate to teach a class on James Bond in the Department of Cinema Studies at NYU, which allowed me to conceptualize some of the critical interventions at the heart of this edited collection. The sharp, in-class contributions of my students consistently challenged my assumptions, and enabled me to consider some of the book's core arguments about the cultural life of James Bond.

I would not have been able to bring this project to fruition without the steady guidance from my academic community in Amsterdam. At the University of Amsterdam, I am particularly grateful to Joyce Goggin, Jaap 
Kooijman, and José Van Dijck for their confidence in my scholarly aspirations. I would like to express my deepest appreciation for my two thoughtful editors at the University of Amsterdam Press, Maryse Elliot and Jeroen Sondervan, who believed in The Cultural Life ofJames Bond from the very start and aptly shepherded the book through the many stages of its publication. Maryse and Jeroen were more than patient editors, who enabled this volume to reach its full potential. I would also like to thank the two peer-reviewers of the first draft of the book's manuscript. Their astute and detailed reflections helped us to improve and polish the final chapters.

A number of colleagues and friends deserve special thanks for their feedback, observations, and recommendations during our many conversations on all things Bond and beyond: in particular, Maria Vinogradova, Kartik Nair, Bruno Guaraná, Leo Goldsmith, Laliv Melamed, Diego Semerene, Gry Cecilie Rustad, Sonja Simonyi, Debashree Mukherjee, Jeff Scheible, Elena Gorfinkel, Victor Fan, Belén Vidal, Richard Dyer, Chris Berry, Mark Betz, Rosalind Galt, Lawrence Napper, Paul McDonald, Giorgio Bertellini, Christopher Holliday, Colin Burnett, Christoph Lindner, Jeremy Black, José Miguel Palacios, Linnéa Hussein, Neta Alexander, Hadi Gharabaghi, Sylvie Vitaglione, Cortland Rankin, Kristen Alfaro, Lucy Bolton, Julie Lobalzo Wright, Reem Hilu, Kristin Nicole Harper, Kim Khavar Fahlstedt, Chris Tedjasukmana, Max Holleran, Promiti Islam, Samira Farouk, Niels Van Tomme, Ishita Srivastava, Benjamin Holzman, Sarah Fajardo, Kris Graves, Yossi Capua, Kenneth Muylaert, Marina Wauters, Lonneke Verheul, Carolien Verheul, and Tom Omes.

Finally, my deepest debt is to my parents, Guus Verheul and Wilma Van Amerom, for their love and enthusiastic support for my academic endeavors. This book is dedicated to them. One of my most vivid childhood memories involves a rented VHS tape of Roger Moore's galactic-camp-fest Moonraker (1979), which remains one of my favorite Bond-adventures and is likely the genesis of The Cultural Life ofJames Bond: Specters of oo7. 


\title{
Introduction: Specters of 007
}

\author{
Jaap Verheul
}

The release of No Time To Die (UK/USA: Cary Joji Fukunaga, 2020) heralds the arrival of the twenty-fifth installment in the James Bond film series. Since the release of Dr. No (UK: Terence Young) in 1962, Eon Productions' first film adaptation of Ian Fleming's already-popular source novels, the cinematic James Bond has expedited the transformation of Fleming's literary creation into an icon of western popular culture that has captivated audiences across the globe by transcending barriers of ideology, nation, empire, gender, race, ethnicity, and generation in spite of its blatantly white, heteronormative, and Eurocentric worldview. The Cultural Life ofJames Bond: Specters of oo seeks to untangle the puzzling yet seemingly perpetual allure of the James Bond phenomenon by looking at the non-canonical texts and contexts that encompass the cultural life of James Bond. Chronicling the evolution of the British secret agent over half a century of political, social, and cultural permutations, the fifteen chapters examine the brand of Bond beyond the official Eon film series and across multiple media platforms while simultaneously understanding these ancillary texts and contexts as contested sites of negotiation with the twenty-five features that currently make up the Eon film franchise. In doing so, The Cultural Life ofJames Bond subscribes to what Christoph Lindner $(2010,1)$ has termed the "new wave of Bond criticism," which seeks to move scholarship on James Bond beyond a traditional emphasis on the Ian Fleming novels or the twenty-five Eon films in order to apply a range of methodologies to the interdisciplinary study of the cultural life of James Bond. The volume is thus as much concerned with Bond scholarship as it is with Bond himself.

The Cultural Life ofJames Bond pursues three strands of inquiry. The first section chronicles the increasingly transnational composition and myriad afterlives of the Eon film series. If 007 has often been understood as Britain's savior in an era of post-imperial decline, and if most of the earlier Eon-entries were produced in the United Kingdom, the franchise gradually transformed itself into a transnational if not global phenomenon,

Verheul, J. (ed.), The Cultural Life ofJames Bond: Specters of oo7. Amsterdam: Amsterdam University Press, 2020 DOI 10.5117/9789462982185_INTRO 
co-produced by different countries, inspiring endless spin-offs across the globe, and celebrating Bond as the quintessential cosmopolitan in order to enhance the character's appeal with international audiences. The first part, "Beyond Britain," analyzes Bond's influence on international filmmaking as well as his surrogate outings in the United States, Continental Europe, and India. The franchise's transnational configuration has influenced - and has itself been influenced by - the cultural politics of the Bond phenomenon. The second part of the volume, "Beyond the Hero," accordingly discusses the representation of race, ethnicity, citizenship, and gender in the Bond films, novels, and ancillary texts. In the wake of Tony Bennett and Janet Woollacott's (1987, 42-43) conceptualization of James Bond as a "mobile signifier" in their landmark study on Bond and Beyond: The Political Career of a Popular Hero, scholarship on James Bond has stressed the franchise's ability to adapt itself to continuously changing norms, values, ideologies, and practices. In spite of this malleability of signification, however, Bond's essentially white, male, heteronormative, and British identity continues to regulate the films' alternative and occasionally subversive articulations of Otherness. The chapters in the volume's second section explore these discrepancies as they examine the tension between the series' progressive and conservative elements, which are simultaneously in conflict and in dialogue with one another and thus constitute contested sites of negotiation. The third and final part, "Beyond the Films," moves away from the texts and contexts of the Eon film series as it chronicles the transmediality of the cultural life of James Bond beyond its cinematic outings. Over the span of fifty years, the brand of Bond has shaped and itself been affected by a range of articulations across multiple media platforms, encompassing literature, cinema, television, fashion, gambling, music, and, more recently, a digital existence in video games. The third section of this edited collection looks at Bond's transmediality in order to revisit and reexamine those features of the Bond phenomenon that have been produced and circulated on media platforms that transcend both the Ian Fleming novels and the Eon film series. In doing so, the chapters unravel how these non-literary and non-cinematic texts, contexts, and practices have contributed to the lasting appeal of her majesty's most well-known secret agent.

But why study Bond? The question has been asked before. For the inaugural issue of the International Journal ofJames Bond Studies (2017), Ian Kinane offers a rich intellectual history of scholarly writings on the James Bond phenomenon. Kinane (2017, 3-4) subscribes to Bennett and Woollacott's aforementioned understanding of the James Bond phenomenon as a mobile signifier, suggesting that "the Bond franchise provides a particular 
framework through which scholars may observe and address shifts that have occurred in British and international cultural politics from the post-war period through to the millennium and the immediate post-millennial period." He locates the genesis of critical inquiry into 007 in the publication of Kingsley Amis's The James Bond Dossier in 1965 (Amis 1965). Amis, an established novelist and literary critic, published his analysis at the height of what James Chapman $(2007,90)$ has referred to as a decade of "Bondmania," introducing a scholarly approach to popular spy fiction and to Ian Fleming's novels and short stories that had heretofore been reserved for the study of a more highbrow literary canon. Soon thereafter, Umberto Eco unveiled his structuralist inquiry into Fleming's novels in The Bond Affair, a collection of essays co-edited with Oreste del Buono and published in English in 1966 (Buono and Eco, 1966). In his contribution to the volume, "The Narrative Structure in Fleming," Eco famously provides the building blocks of the narrative structure of Fleming's tales of Cold War espionage as he examines a series of oppositional relationships - between Bond and the villain, girl, or $\mathrm{M}$; or between the West and the Soviet Bloc_-as well as the game-like "play situations" $-\mathrm{M}$ provides Bond with task; Bond is tortured by the villain; Bond conquers the girl — that drive the narrative of each Bond novel from Casino Royale (1953) up to The Man With the Golden Gun (1965).

The interventions by Amis and Eco set the stage for Tony Bennett and Janet Woollacott's Bond and Beyond: The Political Career of a Popular Hero (1987), a seminal addition to the nascent field of "Bond studies" that was published in 1987. Bennett and Woollacott untangle the cultural politics of the Bond phenomenon as they chronicle its evolution as a mobile signifier over the course of the "three moments of Bond." The first moment, around 1957, saw "the transformation of Bond from a character within a set of fictional texts into a household name" following the paperback publication of Casino Royale and Moonraker in 1955 and 1956, respectively, as well as the serialization of From Russia, with Love in the Daily Express in 1957 (Bennett and Woollacott 1987, 24). The second moment of Bond materialized in the mid-196os in the wake of the first four film adaptations of Fleming's Bond novels: Dr. No (UK: Terence Young, 1962), From Russia with Love (UK: Terence Young, 1963), Goldfinger (UK: Guy Hamilton, 1964), and Thunderball (UK: Terence Young, 1965). If oo7 had become a household name by 1957, the James Bond phenomenon nonetheless remained a mostly British affair that catered to lower middle class audiences. The first four film adaptations, by contrast, modernized Bond into a member of the "professional class," thereby widening his fanbase as they removed the connotation of 007 as an establishment figure - a trope still visible in David Niven's impersonation 
of the popular hero in the 1967 satire Casino Royale (UK/USA: Ken Hughes et al., 1967). In addition, the Eon films also expanded Bond's popularity beyond Britain, with Goldfinger's setting in the United States granting the franchise access to North-American audiences in particular. This second moment, then, may be considered as "the moment of Bond in the sense that his popularity was unrivalled by that of any other cultural figure," elevating the mobile signifier to "an established point of reference to which a wide range of cultural practices referred themselves in order to establish their own cultural location and identity" (Bennett and Woollacott 1987, 36). By the early 1970s, when the third moment of Bond arrived, the pinnacle of Bondmania had passed. In this third moment, the Bond phenomenon continued to be defined by "its selective and strategic activation of that currency [of 1960 sondmania] together with the more episodic and ritualistic nature of Bond's popularity" (Bennett and Woollacott 1987, 37). Henceforth, Bennet and Woollacott conclude, the mobile signifier of Bond would operate as an "institutionalized ritual" that could be reawakened with the release of each new Bond feature.

The turn of the twenty-first century coincided with a renewed scholarly interest in the Bond franchise and with the publication of four pivotal contributions in particular: two monographs, James Chapman's Licence to Thrill: A Cultural History of the James Bond Films in 1999 (with a Revised Edition in 2007) and Jeremy Black's The Politics of James Bond in 2001, and two edited collections, Christoph Lindner's The James Bond Phenomenon: A Critical Reader in 2003 (with a Second Edition in 2009) and Edward P. Comentale, Stephen Watt, and Skip Willman's Ian Fleming and James Bond: The Cultural Politics ofJames Bond in 2005. Chapman's and Black's monographs deepen Bennet and Woollacott's understanding of 007 as a mobile signifier in that they consider James Bond, as Kinane $(2017,5)$ observes, "not so much as a cinematic icon as he is a legitimate and authorized figure in and of cultural history; it is through Bond, these works assert, that much of the socio-political and cultural concerns of post-war Britain can be identified, assessed, and analyzed in original ways." Indeed, Chapman (2007, 19-20) explains, Licence to Thrill offers a cultural history of the James Bond films that examines "the various contexts of Bond" (and in particular the series' origins in the British film industry of the late 1950s and early 196os), analyzes the films' narrative ideologies, visual style, and politics of nation and gender, and chronicles their critical and popular reception in order to arrive at an understanding of "how they have responded over time to changes both in the film industry and in society at large." 
Christoph Lindner sustains this enterprise in his edited collection on The James Bond Phenomenon while introducing an interdisciplinary approach to the study of Bond. The volume also reflects on the current state of Bond scholarship in that it includes the by-now canonical works of Umberto Eco, Tony Bennett and Janet Woollacott, and James Chapman. Lindner's collection presents an array of scholarly methods and theoretical frameworks, ranging from Eco's aforementioned structuralist account to Ajay Gehlawat's postcolonial reading of the franchise's orientalism, Jeff Smith's industrial analysis of John Barry's soundtracks and theme songs as well as their pivotal role in promoting the films, and Elisabeth Ladenson's queer reading of the Bond Girl and Goldfinger's possibly “lesbian” Pussy Galore (Honor Blackman). In its interdisciplinary approach, The James Bond Phenomenon subscribes to Bennett and Woollacott's understanding of James Bond as a sliding signifier in that it demonstrates, as Lindner $(2009,5)$ suggests, "how and why the 007 films are successful not only in regenerating their social relevance and popular appeal, but also in sustaining the cultural mythology that has come to define the figure of James Bond." A similar rationale undergirds Edward P. Comentale, Stephen Watt, and Skip Willman's edited collection on Ian Fleming and James Bond: The Cultural Politics ofJames Bond, which emanated from a symposium dedicated to the literary legacy of Ian Fleming at Indiana University in Bloomington in 2003. Returning to the origins of the Bond phenomenon in Fleming's novels and short stories through the lens of critical theory, the editors (Comentale et al. 2005, xi) understand the figure of 007 as envisioned by Fleming as giving "expression to biases and anxieties that continue to shape our understandings of identity and belonging."

The ascendency of Daniel Craig to the role of 007 spurred further interest in the academic inquiry into all things Bond. The post-millennial renaissance in Bond scholarship occurred in two waves that followed the widespread impact and popularity of Craig's two most influential outings as the British superspy in Casino Royale (UK/Czech Republic/USA/Germany/Bahamas: Martin Campbell) in 2006 and Skyfall (UK/USA: Sam Mendes) in 2012. In the first phase, the commercial and critical success of Casino Royale engendered the publication of the revised editions of the aforementioned works by Chapman and Lindner, both of which now included chapters on Craig's first appearance as 007. Chapman $(2007,241)$ aptly refers to Casino Royale as the "revisionist Bond," understanding its "back to basics" approach as a response to developments in early-twenty-first century action-based spy thrillers on the one hand-noting in particular the influence of the more gritty, physical, and "psychologically realistic" Jason Bourne films — and 
the narrative structure and character arc of Fleming's source novel on the other. In addition, two edited collections were published in the wake of Chapman's and Lindner's revised editions. Christoph Lindner acknowledges the influence of Casino Royale on the materialization of his second volume on Revisioning oo7:James Bond and Casino Royale from 2010. While seeking new contributions for the second edition of The James Bond Phenomenon, Lindner received a considerable number of proposals pertaining to Craig's first film. Revisioning 007 represents the outcome of these submissions and thereby expresses "a recurring preoccupation with the film's manipulation of the established 007 formula and, in particular, the deliberate changes Casino Royale makes to Bond's character and identity" (Lindner 2010, 2). In 2011, Robert G. Weiner, B. Lynn Whitfield, and Jack Becker's mammoth volume on James Bond in World and Popular Culture: The Films Are Not Enough introduced 37 chapters that provide a comprehensive account of, among other subjects, the Bond phenomenon's multimediality, politics of race, class, and gender, and articulations of nationhood and empire.

The "second wave' in post-millennial Bond scholarship" occurred, as Kinane $(2017,6)$ has observed, in the wake of the release of Skyfall in 2012: the year in which the James Bond phenomenon thoroughly ingrained itself in the British cultural imagination. Coinciding with the year-long celebrations in honor of the Diamond Jubilee of Queen Elizabeth II, James Bond appeared, in the figure of Daniel Craig, alongside the British monarch in the opening ceremony of the London 2012 Summer Olympics. Directed by Danny Boyle - who would later helm the twenty-fifth installment in the Eon film series only to leave the franchise prematurely due to creative differences with Bond producers Barbara Broccoli and Michael G. Wilson-the opening ceremony evoked the iconic opening sequence of The Spy Who Loved Me (UK: Lewis Gilbert, 1977) as audiences worldwide watched 007 escorting the Queen to the Olympic Stadium, where the pair signaled their arrival by presumably jumping out of a helicopter while their parachutes displayed the Union Jack and Monty Norman's "James Bond Tune" reverberated throughout the arena. When Skyfall appeared in theaters only four months later, the Bond-signifier had firmly cemented its association with "Britishness" - which the film itself reinforced by centering the narrative and setting of the twenty-third Bond feature on the United Kingdom.

The unparalleled success of Skyfall at the global box office, where it earned $\$ 1,108,561,013$, engendered a surge in scholarly publications that sought to address the film's three significant interventions in the Bond phenomenon: its novel articulation of "Britishness," its newfound desire to bring the franchise's cultural politics of race and gender into the twenty-first 
century, and its recognition of the series' unprecedented and worldwide popular appeal. Lisa Funnell's collection of essays in For His Eyes Only: The Women of James Bond from 2015 scrutinizes the cultural politics of the brand of Bond and in particular its engagement with discourses of gender and femininity. In his "Foreword" to the volume, Christoph Lindner (2015, xvii) subscribes to Bennett and Woollacott's understanding of Bond as a floating signifier, reminding us of "just how much of that process of signification depends on Bond's relationship with women" while pointing out "the ways in which women in the 007 series also function as floating signifiers in their own right, reflecting but also sometimes anticipating or undermining mainstream constructions of identity, agency, and power." The Bond phenomenon's articulation of gender and femininity is also at the heart of Lisa Funnell and Klaus Dodd's co-authored monograph on Geographies, Genders, and the Geopolitics ofJames Bond (2017), Claire Hines' work on The Playboy Bond: oo7, Ian Fleming, and Playboy Magazine (2018), and Monica Germanà's study on Bond Girls: Body, Fashion and Gender (2019). Moreover, in her edited collection on Fan Phenomena:James Bond (2015), Claire Hines $(2015,5-6)$ arrives at an understanding of the seemingly lasting allure of the sliding 007 signifier by examining how Bond fans have approached, appreciated, and appropriated the "transmedia anomaly" and "intertextual phenomenon and cultural icon" that is James Bond. In like manner, Jeremy Strong's volume on James Bond Uncovered (2018) understands adaptation as pivotal to the intertextuality and intermediality of the Bond phenomenon.

As this hike in scholarship indicates, "James Bond studies" has, according to Kinane $(2017,7)$, "evolved out of the growing need for a sustained critical and discursive framework by which to examine Ian Fleming and James Bond specifically, as well the political and socio-cultural importance of Bond's position within the spy genre and within popular culture studies at large." The Cultural Life of James Bond: Specters of oo sustains this enterprise as it further develops Bennett and Woollacott's understanding of the James Bond phenomenon as a mobile signifier.

The collection's first part, "Beyond Britain," pays tribute to the phenomenon's increasingly transnational configuration while also tracing its historical origins in order to discern and deconstruct the conventional association of James Bond with imperial and masculinist "Britishness." James Chapman's reading of the often-ignored US television adaptation of Casino Royale (USA: William H. Brown Jr.) from 1954 reveals that the first reworking of Ian Fleming's source novel relocates its mostly European narrative and setting to a distinctly American context. Chapman accordingly questions the "Britishness" of the Bond phenomenon while acknowledging 
the televisual origins of adapting Fleming's tales of Cold War espionage for the screen. In like manner, the following two chapters understand the production of the mobile signifier of Bond beyond its exclusively British context. Akin to Chapman, Mikołaj Kunicki looks at early televisual adaptations of the Bond formula as he examines three spy series produced for television in Poland, the German Democratic Republic, and the Soviet Union during the 1960s and 70s. Kunicki posits that, at the height of the Cold War, the popular cultures of the Eastern bloc participated in a global network of cultural circulation that extended beyond the Iron Curtain, producing Bond-inspired spy dramas that mirrored their British counterpart in their emphasis on the escapist appeal of consumerism. Ajay Gehlawat's chapter chronicles the history of Bond "adaptations" in Bollywood in order to identify a shift from the "Indianization" of the Bond formula in the 1960 s and 1970s to its gradual erosion in the globalized Bollywood film industry of the twenty-first century. In doing so, Gehlawat demonstrates that Indian interpretations of the Bond phenomenon increasingly resemble the aesthetic and cultural markers of the contemporary Hollywood film form. The following two chapters understand the transnational composition of the Bond phenomenon in its industrial context. Melis Behlil, Ignacio M. Sánchez Prado, and Jaap Verheul dissect the opening sequences of Skyfall in Istanbul and Spectre in Mexico City in order to argue that the franchise's predilection for runaway productions has begun to influence the textual composition of the James Bond film series, fashioning a colonial imaginary of exotic non-places that has since long been a staple of the brand of Bond. Huw D. Jones and Andrew Higson argue that the transnational appeal of Daniel Craig's tenure as 007 is dependent on the textual qualities of the films on the one hand and the business of Bond on the other. While the ownership and distribution rights to the Bond films may facilitate their transnational circulation and remarkable box-office takings, Jones and Higsons industry and audience research reveals that European audiences do not a priori associate Bond with "Britishness" as the films' textual composition has started to resemble-in a vein similar to Gehlawat's reading of the Bond of global Bollywood - the formal qualities of the contemporary Hollywood blockbuster.

The Cultural Life ofJames Bond's second part, "Beyond the Hero," engages with ongoing debates on the cultural politics of the James Bond film series. Toby Miller deconstructs 007's masculinity as he understands the British superspy as an icon of failure. Miller argues that Bond's manhood rests on a paradox in which his commodified manliness compensates for his weakness by masking the gradual decline of hegemonic white and imperial British 
masculinity after the Second World War. Moya Luckett reminds us that the Eon film series obscures 007's failed manhood by positioning the women of Bond as second-class subjects. Luckett explores the seriality of the Bond Girl and situates it in relation to the "collectivity" at the heart of feminine and feminist cultures. While the Bond series falsely suggests that each Bond Girl operates as part of a larger "collective" of Bond Girls, the Bond phenomenon in fact relies on the individualized seriality of each Girl in order to atomize the women of Bond and render them replaceable as they hold little agency and lack the capacity to progress and develop. Lorrie Palmer furthers the conversation on the Bond Girl through the lens of race and ethnicity. Palmer looks at the encounters of Pierce Brosnan and Daniel Craig with women of color within in the specific setting of the eastern bazaar in Tomorrow Never Dies (UK/USA: Roger Spottiswoode, 1997) and Skyfall, respectively. Palmer understands the bazaar in these Bond films as both a social space and as a site for spectacle and consumption. If Brosnan's encounter with Michelle Yeoh (Wai Lin) in Saigon constructs the bazaar as a site of hybridity and open engagement with the Other, Craig's pairing with Naomie Harris (Eve Moneypenny) in Istanbul envisions the bazaar as an Orientalist space of colonial power relations in which "the civilized" seek to segregate themselves from the Other. Anna Everett understands race in the Bond films in terms of oo7's troubling "intersectional cosmopolitanism." Everett demonstrates how the Bond phenomenon cultivates what Susan Sontag has referred to as an "aesthetics of destruction" onto the bodies of black Bond Girls and black Bond villains. For Everett, the films indulge in a form of racialized and racist violence that articulates an anxiety and paranoia about the redefinition of hegemonic whiteness in the United Kingdom in the wake of its imperial decline and the arrival of new postcolonial subjects after the Second World War. Seung-hoon Jeong situates 007's tenuous cosmopolitanism in a context of the post-Cold War globalization of espionage. Comparing James Bond to Jason Bourne, Jeong understands both heroes in terms of their abjection from the twenty-first-century network of global surveillance. The millennial Bourne, however, departs from 007 in that his traumatic abjection subjects him to a bare life that lacks the hedonistic privileges of Bond's cosmopolitan adventures. If Bourne's attempt to regain his memory initiates a journey of self-discovery that in turn strengthens his resistance to the unethical system - the CIA — that trained him, the millennial Bond is internally excluded from his own agency-MI6 - with this abjection culminating in terrorist revenge and sovereign reaffirmation.

The third and final section of The Cultural Life ofJames Bond, "Beyond the Films," considers the transmediality of the Bond phenomenon by examining 
the signifier's mobility across such cinematic and non-cinematic media platforms as arthouse cinema, title sequences, theme songs, casino cultures, and video games. Christopher Holliday discusses the intersection of the early Bond films of the 196os with the modernist traditions of the post-war art cinemas of Britain, Europe, and North America. Holliday reveals that these Sean Connery entries eschewed both art cinema's social realist strand and popular film's escapist disposition in that they incorporated formal features that had heretofore been reserved for art cinema's modernist disposition, such as Ken Adam's production designs, Maurice Binder and Robert Brownjohn's title sequences, John Barry's electronic soundtracks, Peter Hunt's discontinuous editing, and the films' bold display of sex, sexuality and eroticism. Jan-Christopher Horak takes a closer look at the cultural politics of race and gender in the James Bond title sequences while arguing that Maurice Binder used his designs to promote the brand of Bond by repeating motifs and technologies associated with a modernist grid-based design that promoted the simplification of form. Moreover, Horak explains how the title sequences' digital shift in the 199os enabled their designers, Daniel Kleinman and MK12, to develop the films' themes and narrative patterns, thereby not just branding the film series but also individualizing each entry. Meenasarani Linde Murugan similarly explores the modernist legacies of the 1960 s Bond films by examining the lasting influence of Shirley Bassey on the sound of Bond. Murugan situates Bassey's theme songs in the transnational circulation of black musical performances across the Atlantic in order to expose a paradox at the heart of Bassey's impact on the Bond phenomenon. Bassey's voice, she elucidates, should not be understood exclusively as an act of gendered or racial resistance to the franchise's hegemonic white manliness because the Bond producers simultaneously enlisted her remarkable vocal performances in the service of both empire and patriarchy. Joyce Goggin examines the central position of the casino cultures of Las Vegas and Macau in Ian Fleming's novels and the Eon film series in order to argue that the franchise's reboot with Casino Royale in 2006 evoked broader currents in twenty-first-century blockbuster filmmaking as well as neoliberal economics. In particular, Goggin looks at Skyfall in order to unravel how its nostalgic revisionism renews the franchise's interest in gambling and casino culture by indulging in the card-playing logic at the heart of the brand of Bond. In the wake of the spectacular growth of entertainment and gambling industries after World War II, Goggin evinces that Bond's predilection for gambling mirrors a more general ideological shift toward an increasingly financialized economy of risk-taking and speculation. The intersection of Bond with gaming is further explored in 
the final chapter of this volume, in which Ian Bryce Jones and Chris Carloy revisit the videogame GoldenEye oo from 1997. They compare the landmark first-person-shooter and film-to-game adaptation of GoldenEye (USA/UK: Martin Campbell, 1995), which was designed exclusively for the Nintendo 64 console, to its re-adaptation GoldenEye from 2010 for the Nintendo Wii console in order to chronicle transformations in intellectual property on the one hand and conceptual developments in first-person-shooter-storytelling on the other. Jones and Carloy manifest that both videogames are less concerned with "adaptive fidelity," or the making of narrative contributions to the GoldenEye film, but instead privilege a "fictional coherence" in which the games' "interactive" components encourage the user to role-play as the character of 007 .

\section{Works Cited}

Amis, Kingsley. 1965. The James Bond Dossier. London: Jonathan Cape.

Bennett, Tony, and Janet Woollacott. 1987. Bond and Beyond: The Political Career of a Popular Hero. London: Routledge.

Black, Jeremy. 2001. The Politics ofJames Bond. London: Praeger.

Buono, Oreste del, and Umberto Eco. 1966. The Bond Affair. London: Macdonald. Chapman, James. 2007. Licence to Thrill: A Cultural History of the James Bond Films, Revised Edition. London: I.B. Tauris.

Comentale, Edward P., Stephen Watt, and Skip Willman. 2005. "Introduction." In Ian Fleming and James Bond: The Cultural Politics of oo7, edited by Edward P. Comentale, Stephen Watt, and Skip Willman, xi-xxiii. Bloomington: Indiana University Press.

Eco, Umberto. 1966. "The Narrative Structure in Fleming." In The Bond Affair, edited by Oreste del Buono and Umberto Eco, 35-75. London: Macdonald.

Funnell, Lisa. 2015. For His Eyes Only: The Women ofJames Bond, edited by Lisa Funnell. New York: Wallflower Press.

Funnell, Lisa, and Klaus Dodds. 2017. Geographies, Genders, and the Geopolitics of James Bond. London: Palgrave Macmillan.

Germanà, Monica. 2019. Bond Girls: Body, Fashion and Gender. London: Bloomsbury. Hines, Claire. 2015. “Introduction.” In Fan Phenomena:James Bond, edited by Claire Hines, 5-8. Bristol: Intellect.

Hines, Claire. 2018. The Playboy and James Bond: oo7, Ian Fleming and Playboy Magazine. Manchester: Manchester University Press.

Kinane, Ian. 2017. "James Bond Studies: Evolutions of a Critical Field." The International Journal of James Bond Studies 1, no. 1 (May): 1-11. 
Lindner, Christoph. 2009. "Introduction." In The James Bond Phenomenon: A Critical Reader, Second Edition, edited by Christoph Lindner, 1-10. Manchester: Manchester University Press.

Lindner, Christoph. 2010. "Introduction: Revisioning 007." In Revisioning 007:James Bond and Casino Royale, edited by Christoph Lindner, 1-7. London: Wallflower Press.

Lindner, Christoph. 2015. "Foreword." In For His Eyes Only: The Women ofJames Bond, edited by Lisa Funnell, xvii-xviii. New York: Wallflower Press.

Strong, Jeremy. 2018. James Bond Uncovered, edited by Jeremy Strong. Basingstoke:

Palgrave Macmillan.

Weiner, Robert G., Jack Becker, and Lynn Whitfield. 2011. "Introduction." In James

Bond in World and Popular Culture: The Films Are Not Enough, edited by Robert

G. Weiner, Jack Becker, and Lynn Whitfield, xvii-xix. Newcastle upon Tyne: Cambridge Scholars Publishing.

\section{About the Author}

Jaap Verheul is a Lecturer in Film Studies Education at King's College London, where his research focuses on transnational flows of cultural production and distribution in European media industries. He obtained his Ph.D. in Cinema Studies from New York University, and has been a visiting scholar at the École Normale Supérieure in Paris and the Freie Universität in Berlin. He has written on the dual monolingualism of contemporary Flemish cinema (in The Multilingual Screen, 2016), on the co-production of a European heritage brand for television (in Screening European Heritage, 2016), on the fluctuating stardom of various James Bond performers (in Lasting Screen Stars, 2016), and is currently completing his monograph on the formation of European film and television industries after 1989. 


\section{Part I}

\section{Beyond Britain:}

The Transnational Configuration of the James Bond Phenomenon 



\title{
1. The Forgotten Bond: The CBS production of Casino Royale (1954)
}

\author{
James Chapman
}

\begin{abstract}
In 1954, the US television network CBS broadcast a live studio dramatization of Casino Royale as an instalment of its drama anthology series Climax! Casino Royale was long thought to be "lost" and is still regarded as something of a curio item in the history of James Bond adaptations for the screen. This chapter offers a critical reassessment of the 1954 CBS production of Casino Royale by placing it in the institutional and aesthetic contexts of American television drama in the 1950s. In doing so, it argues that the Americanization of James Bond (played by American actor Barry Nelson) may be seen as part of a strategy of the cultural repositioning of the James Bond character for American consumption.
\end{abstract}

Keywords: Casino Royale; Climax!; CBS; tv-adaptation; Barry Nelson; Ian Fleming

The first screen adaptation of Ian Fleming's James Bond was not Eon Productions' film of Dr. No (UK: Terence Young) in 1962 but a live studio dramatization of Casino Royale broadcast on the American CBS television network on October 21, 1954. ${ }^{1}$ The one-hour drama was part of the network's anthology series Climax!, broadcast Thursday evenings at 8:30 pm Eastern Standard Time. For many years Casino Royale, in common with much live

1 Casino Royale. CBS (Columbia Broadcasting System). Producer: Bretaigne Windust. Director: William H. Brown. Written by: Antony Ellis and Charles Bennett. Associate producer: Elliott Lewis. Art direction: Robert Tyler Lee and James De Val. Cast: Barry Nelson (James Bond), Peter Lorre (Le Chiffre), Linda Christian (Valerie Mathis), Michael Pate (Clarence Leiter), Gene Roth (Basil), Kurt Kach (Zoltan), Eugene Borden (Chef de Partie), Jean Del Val (Croupier).

Verheul, J. (ed.), The Cultural Life ofJames Bond: Specters of oo7. Amsterdam: Amsterdam University Press, 2020 DOI 10.5117/9789462982185_CHO1 
television drama of the period, was thought to be "lost," but a kinescope recording was discovered in the early 1980 os and the "first James Bond film" again became available for public view. It was aired on the cable station TBS in 1992 and was subsequently released on VHS in the United States and Britain. ${ }^{2}$ While it is no longer "lost," however, the television Casino Royale remains a marginal text in James Bond and Ian Fleming related scholarship, despite the burgeoning academic interest both in adaptation studies and in Bond as a multi-media franchise.

On one level the critical neglect of Casino Royale might simply be due to the still widely-held perception that it was a cheaply-made and shoddy production. It would be fair to say that it is little regarded within the Bond fan culture. Steven Jay Rubin $(1981,2)$, for example, refers to it as "the feeble American television drama." Alan Barnes and Marcus Hearn $(1997,3)$ similarly dismiss it as "a creaking adaptation of the story." And David Giammarco $(2002,10)$ writes that "the hour-long pilot [sic] failed miserably. Hampered by an embarrassingly miniscule budget and ridiculous Americanization of the British agent, the October 1954 broadcast barely registered with critics or in the ratings." Sometimes the dismissive attitude towards the drama is compounded by misleading or even erroneous "facts," such as Giammarco's assertion that Casino Royale was produced as a pilot episode for a possible James Bond television series. Even Andrew Lycett's $(1995,265)$ otherwise authoritative and impeccably researched biography of Ian Fleming perpetuates the myth that "because of technical problems, the coast-to-coast audience saw Peter Lorre, the actor playing Le Chiffre, get up off the floor after his 'death' to walk to his dressing-room." In fact, the discussion between Fleming and CBS about a possible television series

2 Until the introduction of Ampex video tape machines in 1956, the only way of recording live television drama was by placing a film camera in front of a television monitor: a process known as a kinescope recording. The discovery of a 16 -millimeter film print of Casino Royale in the early 1980 s is credited to Chicago-based film collector Jim Shoenberger. There are press reports of Casino Royale being shown at the Strand Theater, Los Angeles in August 1981 (Parker 1981: $\mathrm{C}_{3}$ ) and at the University of Southern California's Norris Theater in May 1982 (London 1982: E1). It was broadcast on cable network TBS as part of its Bond thirtieth-anniversary season in 1992. In Britain Casino Royale was released on VHS by Retro Video in 1995 and by Visual Corporation Ltd in 1996: both feature the same recording in which the last two minutes (approximately) are missing. The most complete version, restoring the ending, is Casino Royale: The Collector's Edition, produced by Chris Anderson, Lee Pfeiffer and Ron Plesniarksi for SpyGuise/Cara Entertainment in 1997. At the time of writing there is no DVD release but Casino Royale can be viewed online via YouTube: the most complete version currently available is at http:/www.youtube.com/ watch? $=\mathrm{JH}_{5}$ Ryhao2PE (uploaded on April 24, 2015). 
happened four years later, in 1958, while the story of Lorre walking off set while still on camera is a fan myth: this does not happen in any extant version of the telecast.

The negative critical reputation of Casino Royale is no doubt to some extent a legacy of the program having been unavailable for many years: as it is now freely available on the Internet, however, there is no longer any reason for the continued perpetuation of errors and myths. In recent years there have been some indications of at least a partial critical rehabilitation of the "forgotten James Bond." "Given that it is all studio-bound, and in fuzzy black and white, and would have been broken up with endless advertisements for toothpaste," writes Sinclair McKay $(2008,5)$, "it is an inventive piece of adaptation." And Sean Egan (2016, 43-44) avers that "the adaptation is fairly faithful and adroit, and actually quite sophisticated in the way it convincingly portrays the pressures and tempo of the baccarat table. Although Bond is not in full tuxedo, his bow tie in the casino even provides a precursor to one of the trademarks of the cinema Bond, as does his snogging [sic] the girl as the closing music starts up." Even so these more sympathetic assessments still stop well short of a thoroughgoing critical re-evaluation of Casino Royale, which tends to be regarded as merely a curio item in the history of Bond screen adaptations. And the persistence of the traditional view is exemplified by Peter Debruge (2012) of Variety, who describes it as a "clumsy TV movie," suggests that "the whole thing seems to have been done on the cheap," and regards it as a "slipshod antecedent to the Bond oeuvre."

This chapter seeks to examine the television Casino Royale not as an antecedent of the James Bond films but rather to consider it in its own institutional and cultural contexts as an example of the live studio drama of the mid-195os. Casino Royale is about as far removed from the Eon Productions film series as it is possible to be: indeed it is so different from the films at every level—including its mode of production, formal conventions and visual style - that to compare it to the films is neither helpful nor appropriate. To appreciate the place of the Casino Royale telecast in the history of James Bond screen adaptations it is necessary to understand it on its own terms and in its own contexts: to analyze it as an example of what it was rather than comparing it to what came later and was produced under entirely different industrial and cultural conditions. This will involve placing Casino Royale in the institutional and aesthetic contexts of American television drama in the 1950s. In the first instance, however, it will be useful to consider the place of James Bond in popular culture in 1954. 


\section{Casino Royale in its Contexts}

At the time of the production of Casino Royale, Bond was far from being the popular cultural phenomenon with which we are now so familiar. For one thing only two Bond novels had been published-Casino Royale itself, in April 1953, followed by Live and Let Die a year later-and, while they had been favorably reviewed in the British press, their sales were steady rather than spectacular. In Britain, where it was published in hardback by Jonathan Cape, Casino Royale had sold 8000 copies in its first year-modest returns for a work of commercial fiction at the time-while in the United States, where it was published by Macmillan, it sold fewer than 4000 copies (Pearson 1966, 257). Thus, the first Bond book was very far from being "the best-seller by Ian Fleming" as host William Lundigan describes it in the introduction to the Casino Royale telecast. Indeed the initially disappointing sales might explain why Fleming was willing to sell the film and television rights for Casino Royale for what seem like quite paltry amounts: in May 1954 producer Gregory Ratoff paid $\$ 600$ for an option on the film rights (a further $\$ 6000$ would be payable if the film was made), while CBS paid $\$ 1000$ for the television rights (Lycett 1995, 264). As Fleming $(1963,14)$ later explained in an article for Books and Bookmen: "You don't make a great deal of money from royalties and translation rights and so forth [...] but if you sell the serial rights and film rights, you do very well."

CBS had bought Casino Royale for a new drama anthology series starting in the fall of 1954 under the title Climax! The 1950s have often been characterized as the "golden age" of television drama-largely on account of critically-acclaimed authored dramas such as Paddy Chayefsky's Marty (1953) and Rod Serling's Requiem for a Heavyweight (1956) — though like all golden ages this was perhaps more evident in hindsight than it necessarily was at the time. Most accounts of the US television industry in the 1950s present it as a period of rapid growth in the first half of the decade - the number of television stations in the United States increased from 108 in 1952, when the Federal Communications Commission lifted its freeze on the issue of new licenses, to 650 by 1960 - followed in the latter half of the decade by the institutionalization of oligopoly as the three main national networks, NBC, CBS and ABC, consolidated their power (Boddy 1990). It was also a period of transition in terms of the modes of television drama. Even by the mid-1950s, the days of the live studio drama were already numbered: the introduction of Ampex video machines from 1956 would allow the pre-recording and repeat broadcast of television plays. At the same time the expansion of the syndication market fueled demand for episodic 
series that could be scheduled according to local circumstances rather than single plays. This was the context for the production of action series such as Dragnet (1951-1958), Gunsmoke (1955-1975), Wagon Train (1957-1965) and The Untouchables (1959-1963), which were shot on film and which by the end of the decade would displace the live studio drama from primetime schedules.

Casino Royale can be seen as part of this transformation in the US television industry in the 1950s. It coincided with the shift of television production from New York to the West Coast - the broadcast came "live from Television City in Hollywood" - and exemplified the transformation of the drama anthology series from its early focus on Broadway adaptations, illustrated by the early years of series such as Kraft Television Theatre (1947-1958), Studio One (1948-1958) and Goodyear Television Playhouse (1951-1957), to what might be termed a second generation of anthology dramas such as Douglas Fairbanks Jr Presents (1953-1959) and Alfred Hitchcock Presents (1955-1962), which included original commissions for television as well as adaptations of popular fiction. CBS's Climax! (1954-1958) was a strand consisting of crime and thriller stories. Casino Royale was the third production of the first season in 1954: it followed adaptations of Raymond Chandler's The Long Goodbye on October 7 starring Dick Powell as Philip Marlowe-Powell had previously played Marlowe in RKO's film Murder, My Sweet (1944), based on Chandler's Farewell, My Lovely — and Bayard Veiller's mystery play The Thirteenth Chair on October 14 starring Ethel Barrymore (Crosby 1954, 33).

According to a contemporary case study in the trade press, Climax! was "illustrative of some of the functions of a network and some of its basic internal economics" (Anon. 1956, 28). Climax! was introduced as a one-hour drama series on Thursday evenings between 8:30 pm and 9:30 $\mathrm{pm}$ to replace two half-hour dramas that were underperforming in that slot. CBS's Program Department "felt that a half-hour time period, then commonly utilized for mystery dramas and melodramas, was insufficient for development of this type of program and hence after discussion it was decided to adopt the concept of an hour program" (Anon. 1956, 28). Climax! was sponsored by the Chrysler Corporation which paid CBS $\$ 43,287$ per week for one hour of airtime (Anon. 1956, 28). Casino Royale was one of the first batch of thirteen stories acquired-there was a standard fee of $\$ 1000$ for the purchase of rights to a book, magazine story or original script-of which "seven or eight" were developed into full scripts at a cost of $\$ 15,000$. Despite nearly a year in preparation, it was felt that Climax! initially "did not meet the network's expectations" and accordingly the production team was reorganized. Evidence that the overhaul was successful is to be seen in the fact that at the height of its popularity in 1956 Climax! was broadcast 
by 164 affiliates in the United States and Canada-local stations that took network content - and attracted over 26 million viewers, representing 45.9 percent of the total audience (Anon. 1956, 29).

Casino Royale had some impressive production credentials. It was adapted for television by Antony Ellis and Charles Bennett: the latter had extensive experience writing for film and television, including a successful collaboration with Alfred Hitchcock in Britain in the 193os. Bennett was a particularly apposite choice for Casino Royale as the films he had written for Hitchcock included five spy pictures: The Man Who Knew Too Much (1934), The 39 Steps (1935), Secret Agent (1936), Sabotage (1936) and Foreign Correspondent (1940). ${ }^{3}$ Its producer, Bretaigne Windust, was a theater producer who had turned his hand to film and television, his best-known film as a director being the Humphrey Bogart vehicle The Enforcer (1952). Barry Nelson, known predominantly as a theater actor, was cast as James Bond, with Hollywood starlet Linda Christian as heroine Valerie Mathis and veteran character actor Peter Lorre as villain Le Chiffre. Lorre had made his mark as the psychopathic child-murderer in Fritz Lang's $M$ (1931) and had been well used by Hitchcock in The Man Who Knew Too Much and Secret Agent before carving out a career in Hollywood, including memorable roles in such classics as The Maltese Falcon (1941), Casablanca (1942) and The Mask of Dimitrios (1944). The average budget per episode of Climax! was around $\$ 5^{2,000}$ (Anon. 1956, 29). This was in the upper half of the cost bracket of live network drama in the 1950s: the charge that Casino Royale was "done on the cheap" therefore does not stand up to scrutiny. ${ }^{4}$

The contemporary critical reception of Casino Royale was muted. It does not seem to have been widely reviewed in the major daily newspapers and the few reviews that did appear suggest that opinions were mixed. John Crosby $(1954,33)$ in The Washington Post was evidently disappointed: "The original book was a taught, slender volume about spying, counter-spying

3 The Man Who Knew Too Much, The 39 Steps, Secret Agent and Sabotage were all produced by the Gaumont-British Picture Corporation, while Foreign Correspondent was Hitchcock's second Hollywood film, for independent producer Walter Wanger. Bennett also worked with Hitchcock on Blackmail (1929), an adaptation of his own play, and the mystery melodrama Young and Innocent (1937).

4 CBS actually spent more on producing Climax! (an average of $\$ 5^{2}$,oog per episode) than it received from the sponsor as a program fee $(\$ 43,287$ per week). This sort of deficit was not in itself unusual, though for Climax! it was regarded as being "abnormally large." The network covered its costs from advertising revenue ("gross time charges"), which amounted to $\$ 93,720$ per week. After deducting delivery costs, payments to affiliates and discounts for week-to-week advertisers, CBS received an average net income of $\$ 5^{2}, 648$ for each episode of Climax! (Anon. 1956, 29). 
and assorted skullduggery [...]. But they got to messing around with it on television until it was unrecognizable and, apart from a few gambling scenes, remarkably tepid." In contrast Variety felt that it might have been too strong, especially for younger viewers:

Violence, gunplay, gambling and other dark deeds associated with Continental spy rings is tied here with Chrysler's "Forward Look," and providing further ammunition for crusades against grisly crime in the early evening hours while the small fry is still wide-eyed and setside. The dose is a heavy one, with torture thrown in to intensify the melodramatics. Even the elders might have found it a little strong to take ("Helm" 1954, 21).

While Casino Royale was broadcast across the CBS network, it is likely that its audience share would have varied between different locations depending on the local competition. In New York, for example, it was up against The Safe-Cracker (described as the "true story of a convict's struggle to go straight") at 8:30 pm, followed by the popular police series Dragnet at 9:00 pm (Anon. 1954b, 39). In Los Angeles, it competed with a documentary on Hollywood costume designer Edith Head and (again) Dragnet (Anon. 1954c, 34). The fact that Casino Royale did not excite much critical interest should not be taken as evidence of any lack of quality: it is more likely that it was regarded simply as a fairly routine production.

\section{Adapting Casino Royale for the Small Screen}

While the telecast of Casino Royale was necessarily condensed from the novel to fit into the one-hour time slot (including two commercial breaks) and to meet the logistics of live television drama with only three sets (the casino, hotel corridor and Bond's hotel room) and no costume changes, it maintains much of Fleming's plot. The main difference from the book is that Bond has become an American agent, working for the "Combined Intelligence Agency": his prowess at the gaming table has earned him the nickname "card-sense Jimmy Bond." Bond has been sent to beat Le Chiffre at baccarat: as in the novel Le Chiffre has been syphoning money supposedly for the payment of agents to fund his own gambling habit. Le Chiffre is referred to as "the chief Soviet agent for this area-controlled by Leningrad Section Three through Paris": hence the television Casino Royale locates itself within the same Cold War context as Fleming's novel. Bond makes contact with Clarence Leiter of the British Secret Service (Michael Pate), who takes the 
place of Fleming's CIA agent Felix Leiter. He also discovers that his former lover Valerie Mathis is now with Le Chiffre (In the novel the heroine is called Vesper Lynd: René Mathis is an agent of the Deuxième Bureau, the French Secret Service.). The following evening Bond takes on Le Chiffre at baccarat and, after a drawn-out game which swings to and fro, he wins. Bond survives an assassination attempt by one of Le Chiffre's henchmen armed with a gun disguised as a walking-stick (an incident from the novel) and converts his winnings into a cheque which (again as in the novel) he hides behind the number plate on the front of his hotel room door. Whereas in the book the girl had been kidnapped and Bond gives chase in his car, here Le Chiffre and his men arrive at Bond's room and threaten him and Valerie, who turns out to be an agent of the Deuxième Bureau. The novel's torture scene in which Le Chiffre flogs Bond's genitals with a carpet beater is here changed to Bond being bound in the bathtub while Le Chiffre pulls out his toenails with a pair of pliers. But Bond escapes while Le Chiffre and one of his heavies are searching the room. Bond knocks out the heavy, takes his gun and shoots Le Chiffre, who collapses into a chair. Le Chiffre recovers, gets to his feet and threatens Valerie with a razor blade. Bond shoots him again, this time killing him, before collapsing in Valerie's arms. ${ }^{5}$

Jonah Horwitz $(2008,39-40)$ has shown how in the early and mid-195os, CBS developed a "house style" of live drama that was distinct from the other networks: its anthology series, including Studio One (1948-1958), Danger (1950-1955) and Climax!, were "characterized by stylistic bravura, heightened visual expressivity and even a strain of formalism." In particular the network adopted what were sometimes known as "Miners' Laws" - after Worthingon Miner, the influential producer of Studio One - which emphasized staging in depth (or what Miner termed "vertical composition" to differentiate television from the theater where the staging was "lateral") and the use of a mobile camera (Horwitz 2008, 60). Consequently, CBS studio dramas-including early work by John Frankenheimer, Franklin Schaffner and George Roy Hill who all cut their teeth directing live television in the 1950s-were notable for their greater camera movement and their more "filmic" narration. Horwitz calculates that Marty — produced for NBC's Television Playhouse on May 24, 1953 and which has often been taken as exemplary of the studio

$5 \quad$ It might be the moment where Le Chiffre gets up after being shot gave rise to the story that Lorre can be seen getting up and walking off set: in the fullest extant version of Casino Royale - the NTSC VHS release by SpyGuise/Cara Entertainment - it is clear that Le Chiffre has only been injured by Bond's first bullet. His coming-back-to-life moment anticipates what has now become a cliché in horror movies such as Halloween (1978). 
drama-includes just over 100 shots in 49 minutes: this equates to an average shot length of around 28 seconds (Horwitz 2008, 43). In contrast, Casino Royale comprises 249 shots over its 49 minutes: its average shot length of just under 12 seconds is much less than the norm for television drama and comparable to the 11-second average of Hollywood films in the mid-1950s (Salt 1983, 322). Indeed, there as many shots (105) in the first act of Casino Royale as in the whole of Marty: evidence of the more "filmic" imperative in contrast to the "theatrical" style that is often seen as representative of the 1950s.

With its fluid, mobile camerawork, composition in depth and combination of long takes and montage, Casino Royale is entirely representative of the style of CBS live drama in the 1950s. Two sequences in particular demonstrate the "filmic" editing style and expressive mise-en-scène of the adaptation. The first is the set-piece baccarat game between Bond and Le Chiffre that takes up most of the second act of Casino Royale: this sequence builds up the tension through repeated pans between the silent, smirking Le Chiffre and an increasingly tense and agitated Bond (Nelson repeatedly frowns, sighs heavily and rubs his brow) as the game seems to be drifting away from him. The second act — comprising 94 shots in just under 14 minutes—has an even shorter average shot length (nine and a half seconds) than the drama as a whole: this is due mostly to the inclusion of short close-ups as the cards are turned over on the table. The second notable sequence is the torture scene: the camera remains at Bond's eye-level from the bathtub, while the menacing figure of Le Chiffre looms over him, Lorre's sheer physical bulk dominating the frame. While the act itself is not shown for obvious reasons, the reaction shots of Bond's face, contorted in pain, give a vivid indication of his suffering.

Of all the Bond novels, Casino Royale was the one that lent itself most easily to this treatment. Fleming's first book is the shortest and most realistic of the Bond novels: it is a taut, spare and more or less plausible story in contrast to the sensational melodramas that were to follow. The narrative sweep and movement that characterizes Live and Let Die, Moonraker, Diamonds Are Forever, From Russia, with Love, Dr. No, Goldfinger, Thunderball, On Her Majesty's Secret Service and You Only Live Twice are not present in Casino Royale, which is closer in style to the more existential thrillers of a writer such as Eric Ambler than it is to the adventure stories of John Buchan and "Sapper," to whom Fleming is more usually compared. ${ }^{6}$ Indeed, it might be

6 "Sapper" - the creator of Bulldog Drummond, often seen as a spiritual predecessor of Bond-was the pen name of H. C. McNeile, a former officer of the Royal Engineers, known as "Sappers." 
argued that Casino Royale is in fact the most faithful adaptation of an Ian Fleming story. It is certainly no further removed from its source text than the closest of the films to the book: On Her Majesty's Secret Service (UK: Peter Hunt, 1969). This fidelity is evident both on an ideological level—Casino Royale maintains the Cold War narrative of the book, whereas the early Bond films, Dr. No (1962) and From Russia with Love (UK: Terence Young, 1963), substituted Bond's enemy in those books, the Soviet counter-espionage agency SMERSH (Smiert Spionam - "Death to Spies"), for the international criminal syndicate SPECTRE (Special Executive for Counter-Intelligence, Terrorism, Revenge and Extortion) that Fleming had introduced in the novel of Thunderball - and in specific details such as the game of baccarat. In contrast, the Eon film of Casino Royale (UK/Czech Republic/USA/Germany/ Bahamas: Martin Campbell, 20o6) substitutes a variant of poker known as Texas Hold 'Em for Fleming's baccarat, presumably because it was thought more viewers would understand it. In some respects the adaptation even improves upon Fleming: the fact that Bond kills Le Chiffre rather than Le Chiffre dying at the hands of a Russian assassin removes a deus ex machina that is something of a dramatic flaw in the novel, while the adaptation also omits the whole of Fleming's anticlimactic last act, charting Bond's recovery and love affair with Vesper, leading to the revelation that she is "a double [agent], working for Redland" (Fleming 1953, 218). The fact that Valerie (in the telecast) is not a double agent may have been ideologically determined: the production of Casino Royale came only shortly after the height of McCarthyism in the United States, when the suggestion of internal treachery in the war against Communism would surely have been deemed unacceptable.

\section{The Americanization of James Bond}

The major change between Fleming's book and the Casino Royale telecast is to the character of Bond himself. For most Bond aficionados it is a matter of faith that Bond is and always should be British: US Bondologist Lee Pfeiffer (1997), for example, contends that the casting of Barry Nelson in Casino Royale demonstrates that CBS "had little understanding of the character." Nelson himself agreed with this assessment, later remarking that "I played Bond as an American, but I'm sure his eventual success came because he was so English" (Haining 1987, 80). If it is understood in context, however, the Americanization of Bond is perhaps not quite so unthinkable as most commentators believe. For one thing it was a matter of the production 
ecologies involved: Casino Royale was made for an American television audience and unlike telefilm series was not intended for export as well as domestic consumption. And for another thing the association between Bond and Britishness that has emerged in popular discourses around Bond was not so strong in 1954. It was not just that the Bond character was more or less unknown in America: at the time he was not even particularly well known in Britain. It was only following the publication of the Bond books in paperback-Casino Royale was the first in 1955-that Bond became a mass-market phenomenon in Britain. Tony Bennett and Janet Woollacott $(1987,24)$ identify 1957 - the year that From Russia, with Love was serialized in the mass-circulation newspaper the Daily Express and a "James Bond" strip cartoon began in the same paper-as "the first stage in the transformation of Bond from a character within a set of fictional texts into a household name."

It might even be argued that the Americanization of Bond in Casino Royale was consistent with Fleming's own attitude towards his creation. British critics usually tend to see Bond's place in popular fiction as belonging to the tradition of what Richard Usborne (1974) termed "clubland heroes": patriotic gentleman adventurers who serve the British Empire such as Buchan's Richard Hannay and Sapper's Bulldog Drummond. This, certainly, was the association made by contemporary reviewers. The Times Literary Supplement, for example, described Casino Royale as "an extremely engaging affair, dealing with espionage in the 'Sapper' manner, but with a hero who, although taking a great many cold showers and never letting sex interfere with his work, is somewhat more sophisticated" (Anon. 1953, 249). Simon Raven $(1953,695)$ labeled the same book "a kind of supersonic John Buchan." Fleming, however, sought to distance himself from the Buchan-Sapper tradition and instead claimed that his model had been the hard-boiled heroes of American crime fiction. As he told one interviewer: "I didn't believe in the heroic Bulldog Drummond types. I felt these types could no longer exist in literature. I wanted my character to more or less follow the pattern of Raymond Chandler and Dashiell Hammett's heroes, who are believable people, believable heroes" (Fishman 1965, 12-13).

In this context the CBS Casino Royale can be seen as part of a process whereby Bond was culturally repositioned for American consumption. It was perhaps just a coincidence that Casino Royale was produced for television as part of a strand that also included Raymond Chandler's The Long Goodbye. However, US reviews of Casino Royale associated it with the American "hard-boiled" school of detective fiction. Time, for example, suggested that Bond "might be [Philip] Marlowe's younger brother, except that he never 
takes coffee as a bracer, just a large Martini laced with vodka" (Anon. 1954a, u.p.). Anthony Boucher $(1954,27)$ in The New York Times also felt that Casino Royale belonged "pretty much to the private-eye school." When the Bond novels were published in paperback by the American Popular Library, the covers and advertising suggest that they were seen in the same tradition as Mickey Spillane's Mike Hammer: Hammer was a tough private-eye who first appeared in I, the Jury (1947). Casino Royale acquired a new title (You Asked For It) and a lurid "pulp-style" cover in which Bond, with a bottle of bourbon in hand, leers at a voluptuous female in the foreground, while Moonraker became Too Hot to Handle and featured a quotation from the Associated Press describing Fleming as "super-special [...] with blows below the belt the way Mickey Spillane delivers them" (Benson 1988, 12). The back-cover copy for You Asked For It might have had a more direct link to the telecast of Casino Royale:

If he hadn't been a tough operator, Jimmy Bond would never have risked a weekend with a woman who used her magnificent body as a weapon to destroy him [...]. But it was toughness that had landed Jimmy his job with the Secret Service - the job of smashing the ruthless Le Chiffre and his spy network - no matter how many women tried to stop him [...] (Benson 1988, 9).

The television Bond had also been called "Jimmy": both Valerie and Leiter refer to him as such, though Bond himself uses "James Bond" when answering the telephone. While there is no evidence to suggest a direct link, the packaging of You Asked For It and the Casino Royale telecast both exemplify the cultural repositioning of Bond for the American market.

The Americanization of Bond in Casino Royale - and the concomitant Anglicization of Leiter-also has significant ideological implications. Fleming's novels have typically been read as fantasies of British power: they present Britain - personified by Bond - in a position of global leadership and in the front line of the Cold War. While Fleming was writing against the background of Britain's decline as a world power and the retreat from empire, the Bond adventures construct an imaginary world in which the Pax Britannica still operates, and the decline of British power never took place. The professional alliance and personal friendship between Bond and his CIA colleague Felix Leiter configures the "Special Relationship" in terms that represent Britain as the dominant power and the United States in a subservient role as Britain's ally. As Kingsley Amis $(1965,70)$ astutely observed: 
The point of Felix Leiter, such a nonentity as a piece of characterization, is that he, the American, takes orders from Bond, the Britisher, and that Bond is constantly doing better than he, showing himself, not braver or more devoted, but smarter, wittier, tougher, more resourceful, the incarnation of little old England with her quiet ways and shoe-string budget wiping the eye of great big global-tentacled multi-billion-dollar-appropriating America.

In making Bond an American and Leiter British, however, Casino Royale not only reverses the power relationship of the books but also brings the narrative closer to the reality of the Anglo-American alliance by the 1950s. It was the United States that was the dominant power in NATO (the North Atlantic Treaty Organization) and that led the United Nations coalition during the Korean War (1950-1953). The Suez Crisis of 1956 - when the United States refused to support the Anglo-French military expedition to reclaim the Suez Canal following its nationalization by the Egyptian government-demonstrated that Britain was no longer able to act independently to protect its economic and strategic interests in the Middle East. To this extent, it might be argued that Casino Royale is rather closer to geopolitical realities than the novel on which it was based.

Casino Royale did not mark Fleming's last involvement with American television. In 1956, for example, Fleming wrote a treatment for a television series entitled James Gunn-Secret Agent for producer Henry Morgenthau III: the idea did not progress beyond a treatment, but Fleming used much of the plot for his next Bond novel, Dr. No (Lycett 1995, 297). In 1958, he was involved in negotiations with CBS for a James Bond television series: he wrote outlines for three half-hour episodes which he again reused as short stories in For Your Eyes Only when the series did not go ahead (Fleming $2015,210)$. Fleming's habit of reusing story material would notoriously land him in hot water when he based Thunderball on the unmade treatment for a film entitled James Bond of the Secret Service on which he worked with Kevin McClory and Jack Whittingham in 1959: McClory and Whittingham subsequently sued Fleming at the High Court in London (Sellers 2007, 109-22). Fleming's fullest involvement with television was in 1962 when he worked with producer Norman Felton in devising a secret agent adventure series for the NBC network: Fleming would bow out for a combination of personal and professional reasons - he was looking to reduce his work commitments due to his deteriorating health and was probably also mindful of being involved in other projects that might be seen as a rival to the Bond film series which had just begun with Dr. No - though the series, originally entitled Solo, would 
this time go ahead as The Man from U.N.C.L.E (1964-1968) (Walker 2010, 235-51). In light of these other projects, Casino Royale should be seen not as a one-off or an aberration but rather as part of Fleming's long-term ambition of finding a wider audience for Bond. He would achieve this ambition in 1961 when Albert R. "Cubby" Broccoli and Harry Saltzman acquired the rights to all the books (with the sole exception of Casino Royale, for which Gregory Ratoff still held the option) and formed Eon Productions to produce the Bond film series for United Artists.

\section{Conclusion}

The television Casino Royale has been so overshadowed by the success of the James Bond films that it has been relegated to a mere footnote in the history of the Bond franchise. Yet, as this chapter has shown, Casino Royale is not without its points of cultural and aesthetic interest: it may not have made any significant impact at the time but nevertheless it is rather better than its popular reputation as a "feeble" drama and "creaking adaptation" would allow. To place it in its historical and ideological contexts is to find a Bond adaptation that is different from the films but exemplary of the modes and style of live television. Historically it represents an alternative direction that Bond might have taken-as the other initiatives to launch Bond on television in the 1950 s demonstrate-but in the event did not. Ultimately the future of Bond as a popular cultural phenomenon and a global franchise lay elsewhere.

\section{Works Cited}

Amis, Kingsley. 1965. The James Bond Dossier. London: Jonathan Cape.

Anon. 1953. "An Extremely Engaging Affair." The Times Literary Supplement, April 17, 1953, 249.

Anon. 1954a. "Murder Is Their Business." Time, March 29, 1954, unpaginated.

Anon. 1954b. "On Television." The New York Times, October 21, 1954, 39.

Anon. 1954c. "Video-Radio Briefs.” The Los Angeles Times, October 21, 1954, 34.

Anon. 1956. "Evolution and Economics of One Network Show." Broadcasting Television, June 11, 1956, 28-32.

Barnes, Alan, and Marcus Hearn. 1997. Kiss Kiss Bang! Bang! The Unofficial James Bond Film Companion. London: B. T. Batsford. 
Bennett, Tony, and Janet Woollacott. 1987. Bond and Beyond: The Political Career of a Popular Hero. London: Macmillan.

Benson, Raymond. 1988. The James Bond Bedside Companion. London: Boxtree.

Boddy, William. 1990. Fifties Television: The Industry and Its Critics. Urbana: University of Illinois Press.

Boucher, Anthony. 1954. "Criminals at Large." The New York Times. April 25, 1954, 27.

Crosby, John. 1954. "Dusty Old Melodramas Are Dished Up in "Climax!.” The Washington Post, October 25, 1954, 33.

Debruge, Peter. 2012. “Revisiting 1954's “Casino Royale.” Variety, May 11, 2012. Accessed March 6, 2016, www.variety.com/ 2012/film/reviews/revisiting-1954-scasino-royale-1118053859.

Egan, Sean. 2016. James Bond: The Secret History. London: John Blake.

Fishman, Jack. 1965. “007 and Me, by Ian Fleming." In For Bond Lovers Only, edited by Sheldon Lane, 10-28. London: Panther.

Fleming, Ian. 1953. Casino Royale. London: Jonathan Cape.

Fleming, Ian. 1963. "How To Write A Thriller." Books and Bookmen. May, 1963, 14-19.

Fleming, Fergus, ed. 2015. The Man With the Golden Typewriter: Ian Fleming's James Bond Letters. London: Bloomsbury.

Giammarco, David. 2002. For Your Eyes Only: Behind the Scenes of the James Bond Films Toronto: ECW Press.

Haining, Peter. 1987. James Bond: A Celebration. London: W. H. Allen.

"Helm." 1954. “Telepix Reviews: Casino Royale.” Variety, October 26, 1954, 21.

Horwitz, Jonah. 2008. "Visual Style in the "Golden Age' Television Drama." Cinémas 22, no. 2-3: 39-6o.

Lycett, Andrew. 1995. Ian Fleming: The Man Who Created James Bond oo7. London: Weidenfeld \& Nicolson.

McKay, Sinclair. 2008. The Man With the Golden Touch: How the Bond Films Conquered the World. New York: Overlook Press.

London, Michael. 1982. "Bond Oldie to Screen Today." The Los Angeles Times, May 8, 1982, E1.

Parker, Paula. 1981. "James Bond Lives Again in Obscure 1954 TV Version." The Los Angeles Times, August 22, 1981, C3.

Pearson, John. 1966. The Life of Ian Fleming. London: Jonathan Cape.

Pfeiffer, Lee. 1997. Introduction to the VHS of Casino Royale: The Collector's Edition (SpyGuise/Cara Entertainment).

Raven, Simon. 1953. "Supersonic John Buchan.” The Listener. April 23, 1953, 695.

Rubin, Steven Jay. 1981. The James Bond Films: A Behind the Scenes History. London: Talisman Books.

Salt, Barry. 1983. Film Style and Technology: History and Analysis. London: Starword. 
Sellers, Robert. 2007. The Battle for Bond: The Genesis of Cinema's Greatest Hero. Sheffield: Tomahawk Press.

Usborne, Richard. 1974. Clubland Heroes: A Nostalgic Study of Some Recurrent Characters in the Romantic Fiction of Dornford Yates, John Buchan and Sapper, Revised Edition. London: Barrie and Jenkins.

Walker, Cynthia M. 2010. “The Man From U.N.C.L.E.: Ian Fleming's Other Spy.” In James Bond in World and Popular Culture: The Films are Not Enough, edited by Robert G. Weiner, B. Lynn Whitfield and Jack Becker, 235-51. Newcastle upon Tyne: Cambridge Scholars Publishing.

\section{About the Author}

James Chapman is Professor of Film Studies at the University of Leicester and editor of the Historical Journal of Film, Radio and Television. His research focuses on British cinema and television history. He is the author of Licence To Thrill: A Cultural History of the James Bond Films (I. B. Tauris, 1999; 2nd edition, 2007), while his other books include Hitchcock and the Spy Film (I. B. Tauris, 2018), Swashbucklers: The costume adventure series (Manchester University Press, 2015), Inside the Tardis: The Worlds of 'Doctor Who'-A Cultural History (I. B. Tauris, 2006; 2nd edition, 2013) and Saints and Avengers: British Adventure Series of the 1960 (I. B. Tauris, 2002). 


\title{
2. A Socialist 007: East European Spy Dramas in the Early James Bond Era
}

\author{
Mikotaj Kunicki
}

\begin{abstract}
If the James Bond films were officially unavailable to East European audiences until 1989, the Eastern Bloc did not escape the global reach of the Bond phenomenon. East European spy dramas began to appear during the late 1960 s, and they were mostly made for television and not all that distant in spirit from the Bond films. This chapter examines three television series: More Than Life at Stake (1967-1968) from Poland, The Invisible Gun Sight (1973-1979) from the German Democratic Republic, and Seventeen Moments of Spring (1972) from the Soviet Union. While these tales of espionage evince the projections of the west in the east during the Cold War, they reveal foremost the powerful appeal of consumerism behind the Iron Curtain.
\end{abstract}

Keywords:James Bond; East European spy series; Cold War; transnational film and television; Socialist consumerism

Until 1989, the Eon James Bond film series was officially unavailable to Eastern European cinema audiences. The only exception was former Yugoslavia, which saw the release of Diamonds Are Forever (UK: Guy Hamilton, 1973) in 1973. Yet, Central and Eastern Europe did not escape the global phenomenon of the Bond films. By the mid-198os, Polish, Hungarian and Yugoslav VHS markets, both underground and legal, boasted bootlegged Bond videos in circulation. Some East German viewers could watch West German TV channels which occasionally broadcast the adventures of oo7; others, particularly educated urbanites with exposure to Western popular culture, were no strangers to Bond, though not necessarily his fans. More importantly, East European filmmakers and policymakers were aware of

Verheul, J. (ed.), The Cultural Life ofJames Bond: Specters of oo7. Amsterdam: Amsterdam University Press, 2020 DOI 10.5117/9789462982185_CHO2 
the Bond phenomenon. Directors, script writers, film critics and cultural apparatchiks enjoyed access to the adaptations of Ian Fleming's novels during their visits to the West and at closed screenings in film schools and studios. However, the absence of 007 on East European movie screens meant that national film industries were not under strong pressure to come up with direct cinematic responses. Competing with the world of luxury, excess, and explicit sexuality that the Bond films projected was, in any case, out of question. Considering censorship, and the shabby, everyday reality of the People's Democracies, such rivalry was ideologically unacceptable and potentially laughable. Significantly, the first East European response to the Bond series was a spy thriller spoof, Konec agenta $W_{4} C$ prostřednictvím psa pana Foustky (The End of Agent W4 $W_{4}$; Czechoslovakia: Václav Vorliček, 1967) by Václav Vorliček, shot in Czechoslovakia during the period of cultural liberalization prior to the Prague Spring of 1968.

During the late 196os and early '70s, new spy dramas, made mostly for television and not all that distant in spirit from Bond, appeared across the Soviet Bloc. This chapter examines three television series: Stawka większa niż zycie (More Than Life at Stake; Poland:Janusz Morgenstern and Andrzej Konic, 1967-1968) from Poland, Semnadsat' mgnoveniy vesny (Seventeen Moments of Spring; Soviet Union: Tatyana Lioznova, 1972) from the Soviet Union, and Das unsichtbare Visier (The Invisible Gun Sight; GDR: Peter Hagen, 1973-1979) from the German Democratic Republic (GDR). Since their release, all three series have acquired a cult status and remain, to this day, some of the most successful productions in their respective countries, while their protagonists—Captain Hans Kloss (Stanisław Mikulski), Werner Bredebusch (Armin Mueller-Stahl) and Max Otto von Stirlitz (Viacheslav Tikhonov), respectively - have frequently been referred to as the Polish, East German, and Soviet Bonds. Not only do such generalizations diminish the three series and preclude their significance, they also ignore their historical and political contexts and cultural impact as well as the convoluted relationship between East European Socialist spy dramas and Western popular culture.

More Than Life at Stake was truly pioneering, especially if we consider the fact that most of its characters were Germans and fully-fledged figures rather than cartoons; no small feat in Władysław Gomułka’s Poland (1956-1970), where Germanophobia constituted one of the ideological pillars of the regime and where party propaganda projected the Federal Republic of Germany as a revanchist and Nazi-influenced state. Seventeen Moments of Spring followed this trend, "humanizing" Nazi functionaries and historical figures that inhabited the Soviet drama. As Stephen Lovell $(2013,314)$ observes, "It is hard to picture a British film of the 1970s, or even of the 2000s, making [Heinrich] 
Himmler, [Heinrich] Müller, and [Walter] Schellenberg so glamorous and sympathetic." The laborious and ascetic Stirlitz was "anti-Bond," whereas the Stasi agent Bredebusch was the East German response to the James Bond phenomenon. I argue that, while these tales evince the projections of the West in the East during the height of the Cold War, they reveal foremost the powerful appeal of consumerism behind the Iron Curtain. This is where I see the main link between these East European spy films and James Bond. With respect to differences, of crucial importance is the centrality of the experience of the Second World War in the founding myth of the People's Democracies: the struggle against Fascism. More Than Life at Stake and Seventeen Moments of Spring are World War II tales whereas Das unsichtbare Visier takes off in $195^{\circ}$ with the return of German prisoners of war from the Soviet Union. While the Polish series is a spy fairy tale, the Soviet and East German productions have a decisively anti-Western, Cold War flavor. In this regard, they differ greatly from the Bond movies, which toned down the anti-Communism of Ian Fleming's source novels.

Another difference concerns the double lives of the series' protagonists. While James Bond does not hide his identity — in fact, he emanates a powerful air of self-importance-Kloss, Stirlitz and Bredebusch are impostors, moles planted in enemy forces. Not only does the risk of unmasking their identity add more tension, it also forces them to make compromises which are necessary to avoid suspicion about their Fascist and anti-Communist credentials. While 007 operates openly, the three eastern spies are employees of the regimes they try to topple or weaken.

Finally, the three series testify to the more nuanced status of Socialist television than the western stereotype of the medium as a tool of party propaganda. As Anikó Imre (2016, 8-9) argues, Communist regimes were initially mystified by the political, social, and cultural potential of the new medium and developed central programming through the adoption of models used by West European broadcasters. By the end of the first decade of its existence - that is, the late 196os-Socialist TV had become a genuine mass medium, "a medium of leisure" which absorbed elements of "bourgeois," light entertainment. The lower cultural status of television opened the small screen to alternative, novel forms. I argue that, on the one hand, spy television dramas, which East Europeans initially considered inferior to feature films, were an "adequate" response to the James Bond film series, which were deemed "unserious:" the opposite of artistic and socially and politically engaged cinema. On the other hand, both filmmakers and Communist politicians quickly grasped the opportunity of oo7's global appeal to reach mass audiences. 
However, I do not endorse Imre's $(2016,9)$ observation that television's low prestige "kept away writers and actors" from associating with the new medium. In fact, the three dramas discussed in this chapter cast some of the most renowned actors of their respective countries. Furthermore, the three television series demonstrated the resourcefulness, innovation, and craft of Polish, Soviet and East German television productions during the allegedly dull and unimaginative years of the late Władysław Gomułka (Poland, 1956-1970), the mature Leonid Brezhnev (Soviet Union, 1964-1982) and the early Erich Honecker (German Democratic Republic, 1971-1989), respectively. In her seminal study on the history of Soviet television, Christine E. Evans (2016) successfully dispels the view that the Brezhnev era constituted a "zastoi" ("stagnation") in Soviet popular culture. My chapter confirms this observation and provides further evidence on the availability of high-end film and television under deep state Socialism.

\section{Captain Kloss: Empowerment, Impunity, and Indulgence in Nazi Germany and Gomułka's Poland}

Władysław Gomułka (1905-1982), the longest serving Communist leader in People's Poland, came to power in October 1956, riding the wave of deStalinization. Gomułka promoted the Polish road to Socialism that, instead of fully copying the Soviet model, considered such national specificities as the country's ethnic and religious homogeneity, the powerful position of the Catholic Church, and the predominantly private ownership of Polish agriculture. Gomułka's National Communism projected People's Poland as the apogee of nation-building and relied on ethnocentric, nationalist constructs of Germanophobia and, particularly in the late 196os, anti-Semitism. The October reforms completed the abandonment of the doctrine of Socialist Realism, which greatly affected the arts. The late 1950s saw the rise of the Polish School, which established Poland on the world's cinematic map.

The problem for the regime was that the Polish auteurs associated with this artistic formation-Andrzej Wajda and Andrzej Munk-were more interested in reflecting on the brutalized, politically confused, and demoralized war generation than in legitimizing the party state. Gomułka's resentment of "elitist" cinema led to a crackdown on the Polish School, which was condemned as pessimistic and anti-heroic in the notorious 1960 resolution of the Central Committee Secretariat of the Party (Haltof 2008, 103). The push for popular cinema received the support of Gomułka, who appealed for "cultural entertainment serving relaxation [and] meeting the 
cultural needs of millions of working people" (Gębicka 1994, 36, 38). The Polish leader lamented the overproduction of films made by, and addressed to, the intelligentsia as well as the absence of such pictures as High Noon (USA: Fred Zinnemann, 1952) (Kunicki 2017, 158).

This support for a politically acceptable popular culture also bolstered nascent Polish television, which began broadcasting Western TV series such as Dr. Kildare (USA:1961-1966), The Saint (UK: 1963-1969), and Bonanza (USA: 1959-1973). As for domestic shows, one of the trademarks of Polish TV was Teatr Sensacji "Kobra" (The Thriller Theatre "Cobra"), which began broadcasting live performances of plays in 1956. Aired on Thursdays at 8:00 pm, after the main television news, Kobra was a smash hit that familiarized Polish audiences with Western and Polish authors of detective stories and thrillers. In 1965, Illa Genachow, who oversaw Kobra, connected the two script writers, Zbigniew Safjan and Andrzej Szypulski, who, teaming up under the pen name of Andrzej Zbych, wrote episodes for a new play, More Than Life at Stake, about Stanisław Kolicki, a Polish spy working in the Abwehr (the German military intelligence) during World War II (Giza 2005, 163).

The play was so popular that two years later, Janusz Morgenstern and Andrzej Konic began shooting the film adaptation under the same title. Both directors complemented each other: Morgenstern, one of the most recognizable faces of 1960 s Polish cinema, easily moved between genre and art cinema, while Konic had worked as a full-time director on television shows since 1960. By 1968, they directed eighteen one-hour long episodes, which were broadcast from July 1967 until October 1969. More Than Life at Stake quickly gathered a mass audience, emptying the streets of Polish cities during its emission and transforming its lead actor, Stanisław Mikulski, into a national celebrity. Twelve episodes were also shown in cinemas in six two-episode segments. The series was immediately exported to the GDR, Hungary and Sweden, where it enjoyed critical acclaim and won numerous television awards. In Poland, it was followed by a comic book.

The plot follows the exciting and unbelievable war tales of Stanisław Kolicki, the Soviet and Polish superspy planted in the Abwehr following his escape from Germany to the Soviet Union shortly before the Nazi Invasion of June 1941. A patriotic Pole from north-western Poland and a student of the Danzig Politechnical University, Kolicki speaks perfect German and has Aryan looks (Mikulski, who was cast in the role, was tall, slim, and dark blond). Kolicki's defection to the Soviet side coincides with the Soviet People's Commissariat for Internal Affairs' (NKVD) arrest of the hard-boiled Nazi agent Hans Kloss. Due to a striking physical semblance, Kolicki impersonates 
Kloss and is placed in the German military intelligence. The audience is witness to his adventures in occupied Europe and the Third Reich, from Poland to France, from Berlin to Istanbul. Kloss's missions include blowing up a factory, obtaining information about Nazi fortifications in France, investigating betrayals in allied spy networks, liquidating double agents, and identifying Nazi war criminals. Kloss' comrades include members of resistance movements, especially Communists, German anti-Fascists and, following an initial confrontation or competition, British intelligence agents.

Although Kloss's bosses are in Moscow, he often refers to himself as an officer from the Polish intelligence, which strengthens his patriotic credentials but also puzzled some members of the Polish Commission of Film Approval (Komisje Kolaudacyjne) that evaluated films and television series and mandated their distribution. ${ }^{1}$ During the assessment of Episode 4, "Café Rose" (1968), which takes place in Istanbul, Colonel Jerzy Gonczarski, editor in chief of the Polish Army's daily Żotnierz Wolności, expressed doubts whether the Polish Communist underground could afford sending its agent to the shores of the Bosphorus. Other assessors quickly reminded Gonczarski that it was the Abwehr that dispatched Kloss and that he spied for the Soviets but collaborated with Western Allies (Filmoteka Narodowa, A-346 poz. 3).

It is surprising how quickly members of the Commission gave up on conducting a reality check and started to ignore the implausibility of some of the content of the series. Writer and film director Tadeusz Konwicki set the tone when he observed that More Than Life at Stake followed the conventions set up by western productions such as the James Bond franchise, and should therefore not be judged by the standards that applied to "realistic films." In fact, Konwicki advocated for more boldness in showing Kloss's incredible adventures because only then the series could rival the western spy thrillers broadcast by Polish TV and dominate the market for such productions in the Soviet Bloc. For the boss of Polish cinema, Tadeusz Zaorski, the story of Kloss delivered an optimistic message: Poles were not just victims but could successfully fight the Nazis as well (Filmoteka Narodowa, A-216 poz. 147).

In this respect, Captain Kloss is the opposite of the tragic or conflicted protagonist of the war films delivered by the auteurs of the Polish School. His world is populated by impeccably dressed men in Nazi uniforms who drink cognac, smoke Habana cigars, drive spacious cars, and spend their

1 The Commission was led by the chair of the Chief Board of Cinematography (Naczelny Zarzad Kinematografii) and populated by representatives of the film industry, party officials in charge of culture and propaganda, censors, movie critics, and directors and script writers of assessed films. 
evenings with beautiful women in restaurants, night clubs, and at parties. Thus, its setting in the Third Reich allows the series to mimic the glamour of the early James Bond films. While referring to Kloss's milieu, film critic and script writer Krzysztof Teodor Toeplitz $(1970,163)$ coined the term "elegant war zone" ("elegancka strefa wojny"), adding that "Europe conquered by Hitler reveals itself not as the world bound by barbed wire, but as a vast space available for comfortable travels of a (victorious) German officer, Hans Kloss." What Toeplitz did not want to see or reveal was that the aesthetics of luxury and glamour which More Than Life at Stake projects were foremost relevant for contemporary Polish audiences that watched the series twenty years after the end of the Second World War. Most of the citizens of the People's Poland under Gomułka's stringent rule could only dream about international travel, elegant cars, and polite, clean shaven waiters serving French wine and cognac.

Like 007, Kloss encounters attractive women, including refined and mysterious female spies, femmes fatales, and naïve starlets, all played by popular Polish actresses. Yet, with two exceptions, Major Hanna Bösel in the episode "A Double Nelson" (1968) and Edyta Lausch in the episode "Edyta" (1967), Kloss does not let a flirtation turn into a sexual encounter. The fact that most of women he meets are either German — which precludes any romantic interest on behalf of a Polish patriot — or resistance activists — who have more pressing duties to perform - testifies to the rather puritanical spirit of Polish television under Gomułka. At the same time, the sexist spirit of the spy films of the 196os mandated that Kloss should have a new female partner in crime in each episode. "I do not like when women play with guns”, Kloss tells Hanna Bösel. "German women look good with guns”, Hanna replies.

It is the portrayal of the Germans which constituted the ground-breaking novelty the series brought to Poland and the Soviet Bloc. Until that moment, Polish cinema, so fixated on the Second World War, portrayed Germans and Nazis as cruel killers, sadists, or automatons reminiscent of the Hollywood flicks of the 1940s. But in More Than Life at Stake, Kloss mingles with Germans and impersonates a German. It is significant that even his Polish collaborators refer to him as "Janek," the exact translation of Hans. The Germans that surround Kloss are prone to intrigues and crimes but also capable of sentimentality and decency. Of particular importance is the distinction between the Wehrmacht and the SS. While army officers are opportunists or doomed followers of the Prussian military tradition, SS and Gestapo functionaries are fanatical National Socialists, war criminals, and social upstarts. In this respect, the series borrowed Nazi stereotypes 
from West European and Hollywood movies that often juxtaposed noble Wehrmacht officers with sadistic SS officials. Stefan Olszowski, the propaganda chief of the Party in the late 196os, was frankly alarmed by what he perceived as the division between the "good Germans" from the Abwehr and the despicable SS officers. He was immediately countered by Stanisław Stefański from the Committee of Radio and Television, who defended the need for differences in the portrayal of the two organizations; after all, it was unfathomable that Kloss would wear a Gestapo uniform (Filmoteka Narodowa, A-346 poz. 4).

Indeed, SS membership was indicative of war crimes. For Krzysztof Teodor Toeplitz, it was clear that Kloss could never be an SS-officer because this would require some degree of complicity. Employment in the Abwehr, meanwhile, provides our hero with institutional protection and immunity. While Kloss's collaborators or fellow spies are occasionally killed, wounded, or tortured, he acts with complete impunity. According to Toeplitz (1970, $162,166-167)$, this solution removed any sense of tragedy from the adventures of Kloss and reduced the element of danger. Kloss's chief antagonist is Hermann Brunner (Emil Karewicz), an SS officer. Not particularly bright or fanatical, Brunner often provides a comic relief and is a likable villain. "I cannot look at a beaten man," Brunner muses over Kloss knocking down a Gestapo agent, "If someone else is beating."

Fifty years after its release, More Than Life at Stake may irritate by its predictability, theatrical acting, and technical shortages, but it continues to attract mass audiences, mostly due to the presence of some of the most popular Polish actors of their time. One disconcerting aspect concerns the period of the series' production and initial release, the years 1967-1968, which saw the anti-Semitic campaign and the crackdown on students and the liberal intelligentsia. It is true that the tale of Kloss contains only one veiled reference to the Holocaust (the episode "Edyta"). However, the series lacked any martyrologic subplots and should not be treated as part of the xenophobic and anti-intellectual drive of Gomułka's leadership.

For Mikulski, the role in More Than Life at Stake dominated the rest of his acting career-though he also enjoyed popularity in a string of popular Polish, Soviet, Hungarian, and Czechoslovak movies and television shows. ${ }^{2}$ The series even survived de-Communization after it was briefly removed from television screens on charges of historical inaccuracies and Communist propaganda. Above all, More Than Life at Stake made a significant impact

2 Popular in the Soviet Union, Mikulski held the position of director of the Polish Cultural and Information Centre in Moscow from 1988 to 1990. 
on spy dramas across the Soviet Bloc by lifting pre-existing taboos on the portrayal of Germans under Hitler and by depicting a glamorous lifestyle, spirit of adventure, and escape from martyrdom.

\section{Thinking and Sharing with Stirlitz: The Multiple Lives of Seventeen Moments of Spring}

"Stirlitz had a thought," a joke begins. "He liked it, so he had another one." Based on the novels by Iulian Semenov, Tatyana Lioznova's iconic spy series Seventeen Moments of Spring inspired numerous examples of deadpan humor that featured its protagonist, Soviet spy Colonel Maksim Isaev, better known as Standartenführer Otto von Stirlitz. The plot narrates Stirlitz's efforts to obstruct and expose the secret peace negotiations between Heinrich Himmler's emissaries and US representatives in February and March 1945. In her study on Soviet Central television during the Brezhnev years, Christine E. Evans $(2016,180)$ suggests that the creators of this multifaceted film aimed at engaging Soviet audiences in the active participation in Stirlitz's tale. Viewers wrote letters to the Soviet Central Television in support of the series and Stirlitz, while others showed their involvement by crafting "Stirlitz" jokes, a major subgenre of late Soviet humor.

I suggest that the abovementioned joke accurately captures the essence of the Soviet spy drama, which opposes the James Bond films and their shootouts, fist fights, car chases, and sexual promiscuity. Throughout the twelve-episode and fourteen-hour long series, Stirlitz assassinates one agent-provocateur, smashes a bottle of cognac on the head of a Gestapo officer, refuses to flirt with a beautiful girl and instead choses to play chess with a more senior female. Most of the time, he seats in the Reich Security Main Office (RSHA) and contemplates. The message of the series is spelled out in the first episode by the character of Ernst Kaltenbrunner, Chief of the RSHA. While scolding one of his officers who volunteers to be send to the front, Kaltenbrunner says, "It's easy to die for the Fatherland and our Führer on the frontline. It is much more difficult to work here [...] wiping filth out. [...] It takes brains, Kruger, a lot of brains!" The series is not about dynamic action but about a slow-burning intrigue with a rational, laborious, and ascetic hero at its center. The intelligent Stirlitz must face equally clever opponents such as Kaltenbrunner and Heinrich Müller, Chief of the Gestapo, portrayed memorably by Leonid Bronevoy. Lovell $(2013,316)$ even goes as far as to suggest that "Stirlitz's stream of thought is where the main action of Seventeen Moments takes place. There are two Stirlitzes: his face and body 
are that of Viacheslav Tikhonov, his soul lies in the interior monologues of Efim Kopelian's voice-over." And yet, the "anti-action” series was a stunning commercial and critical success, which has endured the collapse of the Soviet Union and continues to attract a mass following in present-day Russia.

Both Lovell and Evans agree that the series benefited from the introduction of a new genre, the fictional TV miniseries, in the late 1960 s and early ' 70 . There were two reasons for this intervention. Like its western counterparts, Soviet Central Television used TV series to tackle "the problem of obtaining films for TV broadcast" (Evans 2016, 154-55). Second, following the end of the Thaw and, especially, the Soviet invasion of Czechoslovakia in 1968, the Brezhnev regime aimed to reestablish a rapport with society and instill a national culture which would reinvigorate Soviet patriotism and imperial identity. Given the status of television as a mass medium, this "culture" ought to be "largely televisual" (Lovell 2013, 317). New historical miniseries, which usually focused on the Russian Civil War or World War II (referred to as the Great Patriotic War in Russia), were often aired each evening, requiring viewers to fully commit themselves for significant periods of time in order to avoid missing out on a new episode (Evans 2016, 156).

Although some of these films proved successful, none of them achieved a success comparable to Seventeen Moments. Lioznova's series blends several characteristics of multiple genres: a political thriller, which claims to be based on thorough historical research, psychological drama, and paradocumentary. Historical and fictitious figures, including Stirlitz, are often introduced with a brief audio-visual file, which assesses their career in the NSDAP and SS and lists racial profiles and personal characteristics. Another way of articulating "real" history is the insertion of Soviet wartime newsreels documenting the progress of the Red Army in the liberation of Europe, exposing Nazi crimes and providing a reality check for the claims made by Nazi leaders on the screen. Evans $(2016,165)$ rightly claims that the series made viewers into investigators and spiritual co-authors of the series.

The sense of engagement in Stirlitz's actions must have been thrilling. But so was the look at the Nazi elite portrayed in the series. Germans were fully-fledged characters, resourceful, intelligent, and even sympathetic. But unlike Kloss in More Than Life at Stake, the main protagonist and nearly all characters around him wore SS uniforms. How could this humanization of the most demonic enemy occur? The documents from the meeting of the arts council of Maksim Gor'kii Film Studio, where Seventeen Moments of Spring was filmed, testify that at least one speaker objected to depicting the Nazis as idiots because this "undermined the achievements of Soviet counterintelligence" (Lovell 2013, 316). 
This is a productive reading because it testifies to Stirlitz's mental powers. Yet, I posit that that there is also another explanation for this phenomenon: Nazis kept fascinating Russians and East Europeans. Not only did the war bring incredible loss and destruction to the region on a much greater scale than in Western Europe, it also led to the establishment of the Soviet empire. During the first two post-war decades, Soviet propaganda kept the dangers of Nazism alive by emphasizing German revanchism as well as the continuities between the Third Reich and the German Federal Republic. Used as a tool for mass mobilization and legitimization, Germanophobia and anti-Fascism, too, made a significant cultural impact. Nazi leaders, including Adolf Hitler, Joseph Goebbels and Hermann Göring had already been portrayed in Mikhail Chiaureli's The Fall of Berlin (Soviet Union: Mikhail Chiaureli, 1949), albeit as demonic and cartoonish figures. While the Polish producers of the Kloss series revealed a fascination with "Nazi glamour" (uniforms, weapons, and power), Lioznova and Semenov wanted to interrogate the "soul" and "mindset" of National Socialism.

Soviet television producers and directors knew that some viewers and actors objected to the humanization of Nazi characters. Stirlitz's past in the SS and SD is not fully revealed in the series. Was he useful for the SS apparatus? Clearly, acquiring the rank of Standartenführer (the equivalent of army colonel) and free access to Walter Schellenberg and Martin Bormann required some merits in the service of the SS. We only learn of Stirlitz's prior engagements off-camera, through the testimonies of other characters: Eismann, an ardent National Socialist, refers to Stirliz's exemplary service in Spain during the Civil War; Kruger mentions Stirlitz in the failed blowing up of the historical city of Krakow in Poland in $1945 .{ }^{3}$ Yet, these two examples only indicate two assignments our hero used to frustrate the rise of Fascism and its war atrocities. Again, viewers are asked to conduct their own investigation of Stirlitz by using the clues offered by his flashbacks to the 1930s. One thing we know for sure is that Stirlitz has been in Germany for so long that he refers to it as "home." On the other hand, while reflecting on his acts and service, which will ultimately benefit the German people, he bitterly adds, "I am doing just their job for them." It is "The Soviet Man's Burden." In this moment, reinforced by Soviet newsreels rejoicing the liberation of Hungary and other East European states, we can sense Soviet hegemony in Central and Eastern Europe.

The question is whether Seventeen Moments conveys any meaningful description of life in the Third Reich. When it comes to the Nazi security

3 This was a reference to another TV film based on Iulian Semenov's prose, Mayor Vikhr (Soviet Union: Major Whirlwind, 1967), directed by Yevgeny Tashkov. 
apparatus, it works well — in fact, too well for the "institutional anarchy" which characterized Hitler's Germany. The picture of the disciplined and competent SD may have more in common with the Soviet KGB. Since the narrative takes place mostly in Berlin (where it was shot on location), we see some evidence of allied bombing, but the city is mostly quiet and orderly. The anti-Fascist resistance networks are limited to Communists who cooperate with Stirlitz, to religiously motivated dissidents like a Catholic pacifist priest named Schlag, who is rescued and recruited by our hero, and to lonely middle-class figures. There is no reference to the July 20, 1944 plot to kill Adolf Hitler and dispose of the Nazi government. As far as the everyday is concerned, we can see the pleasures of middle-class life in the west. Stirlitz's occupies a spacious villa with a garden, owns a car, and enjoys his casual pint of beer or glass of cognac in The Elephant Inn, where he can also play chess with the elderly Frau Zaurich. Bits of glamour are particularly visible in Bern (filmed on location in Riga, Latvia): quiet and clean streets, charming hotels with well-stocked bars, and elegant guests dressed in the fashion of the 1960s. Swiss Alps (filmed on location in the Soviet Republic of Georgia) harmoniously coexist with good roads and trains that connect Switzerland and Germany. While driving with Schlag across the mountains, Stirlitz allows himself a moment of relaxation, listening on the radio to Edith Piaf's "Non, je ne regrette rien."

These anachronisms reinforce the contemporary spirit and appeal of Seventeen Moments, moving it toward the conflict Soviet audiences knew: the Cold War. It is worth mentioning that Evans' "spiritual co-authors" of the series include the KGB. Iurii Andropov, the KGB boss, had developed a close relationship with Iulian Semenov in the 1960s. He and his deputy Semen Tvisgun took a great interest in the series and provided KGB consultants (Lovell 2013, 309). Anti-Americanism is at the very center of the film because it is Stirlitz's mission to block a separate peace agreement, which would allow the Germans to redirect their armies from the western front against the Red Army. Operation Sunrise, the secret talks between US diplomat Allen Dulles and SS-Obergruppenführer Karl Wolff to negotiate a surrender of Nazi forces in Italy, did take place in late winter and early spring of 1945, producing friction between Western Allies and the Soviets. The film magnifies its significance. The scene of the negotiations between Dulles and Wolff features a group of CIA operatives dressed in contemporary, 1960 s fashion (white shirts and ties, the classic look of US officials). Soon thereafter, we see Soviet newsreels showing the victories of the Red Army. While the Soviets fight, Americans are negotiating with the enemy. It is all about the ensuing Cold War. "Nothing was over," Kopelian's voice-over ruminates in the epilogue. "Everything was just beginning." 


\section{Spying on Fascists While Dancing in Buenos Aires: The Exotic Adventures of a Stasi Spy in Das unsichtbare Visier}

Peter Hagen's Das unsichtbare Visier begins where Seventeen Moments of Spring ends, with the outbreak of the Cold War. The year is 1950. Among the group of German prisoners of war returning from Russia to the Federal Republic of Germany, we find Lieutenant Achim Detjen (Armin Mueller-Stahl), a former Luftwaffe pilot. However, his real name is Werner Bredebusch. He is a veteran of the National Committee for a Free Germany, an anti-Fascist organization set up by the Soviets after the battle of Stalingrad (1942-1943), and a Stasi agent. His mission is to infiltrate a secret network of former Nazi officers and war criminals active in Western Europe and South America. He later joins the Bundeswehr and unmasks various West German and CIA plots to destabilize the German Democratic Republic, launch a new war, and introduce weapons of mass destruction. During his adventures, Bredebusch traverses West Germany, Italy, Portugal, Norway, Argentina, and Paraguay (shot on location in Bulgaria, Czechoslovakia, and East Germany). He pilots planes, climbs the walls of castles, rides horses in the South American Pampas, and seduces attractive women.

The attributes of 007 that are missing are Bond's high-tech gadgets and the criminal masterminds who are set on controlling the world. The latter are replaced by hardened Nazis-turned-capitalist warmongers and American CIA agents. As Thomas Rodgers (2015) correctly observes, "Das Unsichtbare Visier didn't try very hard to hide its inspiration: like Bond, its opening credits showed a man walking down a rounded corridor, and today its theme song would be clear grounds for a copyright infringement lawsuit." Bredebusch and his Stasi supervisors are not only the defenders of the GDR but also the guardians of the peace-loving part of the world, and sworn enemies of neo-Fascism, colonialism and US-sponsored authoritarianism. As one East German spectator commented, "James [Bond] fuels wars, Detjen is preventing them" (Haller 2014, 91).

This representation is consistent with GDR propaganda, which equaled Fascism with capitalism and projected the German Federal Republic as the descendent of the Third Reich. To this end, Das unsichtbare Visier emphasizes the claim made by the governing Socialist Unity Party that the East German state was the only legitimate heir and embodiment of German anti-Fascism. As Sebastian Haller $(2014,73)$ suggests, the series should "be examined as a cultural artefact, which oscillates between the narrative of antifascism and the state-led development of an entertainment and popular culture in the 1970s." The series vilified the Konrad Adenauer 
era (1949-1963), the alleged militarism of the Federal Republic, and the subjugation of West Germany to American imperialism. Bredebusch remained the protagonist of the series for the first nine 75 -minute-long episodes shot between 1973 and 1976. Mueller-Stahl was dropped from the series in 1976 due to his protest against the forced expatriation of Wolf Biermann, an East German poet, singer, and dissident. Blacklisted in the GDR, the actor emigrated to West Germany in 1980 (Mueller-Stahl 2014). Ironically, Bredebusch makes his exit from the series while being flown to safety in the GDR at the time of the erection of the Berlin Wall. The remaining seven episodes saw two different main protagonists, stressed the collective effort of the Stasi espionage services, and covered the contemporary period as opposed to the 1950s and early '6os depicted in the first installment. My analysis focuses on the Bredebusch episodes, the series' political background, and the glamour of exoticism that tapped into the needs of the Wall-locked and travel-deprived East German people; a society that was, however, exposed to both the James Bond phenomenon and West German popular culture.

Like Seventeen Moments of Spring, Das unsichtbare vizier was very much the product of a modernized Socialist state television, the cultural policies of the Communist regime, and the cooperation between the security services and the filmmakers' community. First, GDR television occupied a unique position on the map of the Soviet Bloc as it had to compete with West German TV stations, which could reach most East German viewers. Second, the new Erich Honecker leadership (1971-1989), which abandoned the principle of two German states and one German nation in favor of two separate nations, invested in the mutual reinforcement of ideology and mass entertainment. Shortly after coming to power, Honecker famously complained about the "boredom" evoked by East German television. The answer was the production of shows that would dissuade GDR viewers from watching West German programming but which were nonetheless informed by western standards. Third, the Department of Agitation of the Ministry of State Security was engaged in the production of Das unsichtbare Visier and other spy films and television series as it supplied the DEFA (the state-owned film studio of the GDR) with feedback and consultations. Colonel Günter Halle from the Stasi co-authored the script of seven episodes shot from 1977 to 1979 (Haller 2014, 85-90).

One of the first results of the "television dialogue" between the German Democratic Republic and the Federal Republic of Germany was the launching of the police series Polizeiruf 110 (Police Dial 110, 1971-present) in 1971 as the East German response to the West German Tatort (1970 — present), 
which had premiered in 1970 . While answering to the Bond phenomenon, the East Germans had to go beyond the 196os Kundschafterfilme or "reconnaissance" espionage films such as János Veiczi's For Eyes Only (GDR: János Veiczi, 1963), which told the story of an East German spy, Hansen, infiltrating US intelligence and aborting the invasion of the GDR. Hansen was presented as a family man, abstaining from alcohol and other temptations from the western world (Rogers 2015). Das unsichtbare Visier, shot by the DEFA film studio - which testified to the prestigious status of the drama-for East German television, would provide an appropriate response to Bond and his world of excess, decadence, and sexual promiscuity. It did so by adding to the sexist aesthetics and colonial nostalgia of the Bond films a familiar, homegrown subculture of pop music hits-schlager musik - known for their romantic themes and holiday pleasures, and a taste of exoticism.

The first episode, "Der Römische Weg" ("The Roman Path," 1973), already contains numerous examples of this approach. Bredebusch finds his way to the ODESSA organization, which smuggles Nazi war criminals to South America via a Catholic monastery in Rome. Before this happens, he spends a night in a luxurious house where his caretakers conduct the last verifying test on him. Bredebusch is left with a beautiful former Nazi spy (Annekathrin Bürger) and a bottle of cognac in a bugged bedroom. He dispels any suspicion by drinking heavily and having intercourse with his companion. "There is nothing wrong with this man," declares the house owner who listens to the couple's encounter. Landing in Argentina, Bredebusch reunites with a group of former Luftwaffe pilots who, under the command of Colonel Krösing (Wilfried Ortmann), Detjen's former commanding officer, train the Argentinian air force of Juan Perón. The German officers are partying in a posh club, drinking champagne, and recalling anecdotes from the war service. The scene opens with a long tango piece performed by professional dancers. Suddenly, Bredebusch runs from the table and starts dancing with Carmela Morela (Czech actress and singer Milena Zahrynowská), who appears in blackface. Zahrynowská performs a typical schlager, "Sei ein Mann" ("Be a Man!"). ${ }^{4}$

In the second episode, "Das Nest im Urwald" ("The Nest in the Jungle," 1973), Bredebusch traverses between Argentina and Paraguay, where he visits a colony of Nazi war criminals who seek to take control of the future

4 Zahrynowská's makeup is often interpreted as evidence of the amateurism of the East German crew. I see it differently: blackface was commonly used by white performers in British and American dance and music clubs until the 1950s. 
Bundeswehr. While the German residents project the image of brutal colonial masters, the Argentinian and Paraguayan gauchos and peasants who Bredebusch encounters are the salt of their land, friendly, hardworking, and frequently engaging in melodic folk dances and songs. The depiction of indigenous people evokes the sentimental portrayals of the natives of the West Indies and other non-Europeans who cohabited the movie screen with 007 and other white protagonists of action films set in "the tropics." It was also compatible with the image of the "noble savages" that populated Karl May's westerns and the East German "Indianerfilme," anti-colonial and ideologically correct American frontier films set in the eighteenth and nineteenth centuries, and produced by the DEFA throughout the 1970s and '8os. Above all, Bredebusch's South American friends confirm the popular imagination of the merry, simple, and honest inhabitants of exotic locales promoted by popular literature and travel books; spatially distant peoples that average citizen of the GDR would never encounter. Still, East German viewers could find some consolation in the fact that these inhabitants of the Global South were befriended by a Stasi superspy.

Although laden with propaganda and factual inaccuracies, Das unsichtbare Visier does contain historical subplots that are plausible. Former Luftwaffe pilots and Nazi officers did train Juan Perón's aviators and acted as military advisors to South American governments. Members of the Roman Catholic Church did offer a haven to Nazi collaborators and war criminals. Some characters depicted in the series have much in common with former Nazis who occupied prominent positions in the Federal Republic and participated in the "alte kameraden" ("old comrades") networks of the SS and the Wehrmacht. Consider Colonel Krösing, Detjen's superior, whose story resembles the biography of Colonel Hans-Ulrich Rudel, a Nazi "war hero" and ace pilot who rendered his services to such Latin American dictators as Juan Perón, Augusto Pinochet, and Alfredo Stroessner. But what about the non-Germans? While CIA agent Wilson (Walter Niklaus) dons a thuggish leather jacket and displays the utter cynicism of American imperialists, the French characters in the series are quite sympathetic. The main reason for Bredebusch going underground after his return to West Germany is that the French military investigators genuinely seek to arrest Detjen for war crimes committed in France. French Nazi-hunting journalist Charles André collaborates with Bredenbusch, though this does not prevent Nazi thugs from murdering him. The warm portrayal of the French should not come as a surprise, as General Charles de Gaulle had removed the French army from the NATO-integrated command in 1966, and had expelled US troops from France in 1967. 
Subject to constant propaganda and political education, East German audiences were aware of these facts. Yet this does not explain the success of the series, which secured an audience rating of 50 to 60 percent in the GDR (Rogers 2015). I would like to propose several explanations for its widespread appeal. First, the series entered into a dialogue with both the Bond movies and West German productions, enriching them with familiar East German components and conventions. Second, the quality of the production surpassed all previous GDR spy and action television dramas and movies. Third, Das unsichtbare Visier was too prestigious to fail as it was the flagship of the revolution in mass entertainment that had been launched by the Honecker regime. Heinz Adamek, the chairman of the East German TV, acknowledged this shift: "A larger variety and a better balance of stories and genres, especially the increase of humorous, adventurous and exciting themes, is an essential task for our authors" (Haller 2014, 87).

\section{Conclusion}

The three television series discussed in this chapter demonstrate the osmotic relationship between the west and the Soviet Bloc; a relationship that confirmed that the Eastern European Socialist regimes were part of a global network of popular cultural circulation. In his influential article from 2004, György Péteri $(2004,114)$ proposed that, "Nylon rather than 'Iron Curtain' would be the appropriate metaphor to describe what was actually separating the worlds on the two sides of the Cold War front line." Transparent and technically more advanced than iron and coal (the primary resources for Soviet-style industrial production), nylon captured the nature of the transfer of knowledge, culture, and economy from the west to the east. It also referred to the package of consumer goods sought by populations from the Soviet sphere of influence. It is noteworthy that Péteri borrowed his metaphor from the American sociologist David Riesman's 1951 study on the "nylon war," which saw the US literally bombing the Soviet Union with consumer goods so that "the Russian people would not long tolerate masters who gave them tanks and spies instead of vacuum cleaners and beauty parlors" (Péteri 2004, 114-16).

Riesman's juxtaposition of spies and beauty parlors is highly symbolic and ironic in light of this chapter. I argue that the Polish, Russian, and East German creators and patrons of More Than Life at Stake, Seventeen Moments of Spring, and Das unsichtbare Visier crossed the "Nylon Curtain" in order to 
deliver spy stories that took the spectator on a cinematic journey of beauty parlors for political-cosmetic treatment. Milestones in the production of Socialist television, the three series had a limited impact on the "cinematic Cold War" - to use the title of Tony Shaw and Denise J. Youngblood's (2010) survey of film's role in the dissemination of American and Soviet ideologies. In Poland, the production of war films dramatically decreased after, firstly, the signing of the Treaty of Warsaw in December 1970, which normalized relations between People's Poland and the Federal Republic of Germany and recognized the Polish western borders, and, secondly, after the fall of Gomułka in the same month, following the massacre of striking workers on the Baltic Sea coast by the Polish army and security forces. Most of the films and television series produced in the 1970s, during the reign of the less nationalistic and more consumer-oriented Edward Gierek regime (1970-1980), tackled contemporary issues. This was the time of the birth of the "Cinema of Moral Angst," which engaged in a biting critique of corruption and of a society in crisis. Simultaneously, many TV series focused on Socialist technocrats and the everyday life of young professionals. In 1980, Poland plunged into the socio-political upheaval of the Solidarity Revolution.

While GDR television continued to produce ideologically correct, antiFascist action flicks, none of them matched the quality and success of Das unsichtbare Visier. It was West German broadcasters and the less flamboyant Polizeiruf 110 that continued to entertain East German audiences until the Fall of the Wall in 1989. The Soviet television screen, which had the capacity to provide Socialist blockbusters, continued to produce popular espionage series, among them the critically acclaimed Cold War thriller TASS upolnomochen zayavit (Tass is Authorized to Declare; Soviet Union: Vladimir Fokin, 1984), which was based on another Iulian Semenov spy novel and starred Tikhonov, the lead actor of Seventeen Moments. Yet the miniseries was released shortly before the ascent of Perestroika, which saw the elimination of anti-American movies. Furthermore, the aggressive anti-Communism and militarism of the Reagan-era produced anti-Soviet films which had little in common with the relatively subtle Socialist espionage flicks-Hollywood vehicles such as Red Dawn (USA: John Milius, 1984) and the Rambo film series (USA: Ted Kotcheff et al., 1982-1988) were truly loathed in the Soviet Union. "It's hard to imagine," the Soviet critic Nikolai Savitsky wrote, "that a viewer with aesthetic tastes could like Rambo II" (Shaw and Youngblood 2010, 57). Soon thereafter, the "Nylon Curtain" ceased to exist. 


\section{Works Cited}

\section{Unpublished documents}

Filmoteka Narodowa, Komisja Kolaudacyjna, A-346 poz. 3 (April 12, 1968), Stawka większa niż życie - "Hotel Excelsior" and "Café Rose".

Filmoteka Narodowa, Komisja Kolaudacyjna, A-216 poz. 147 (October 17, 1967), "Wiem kim jesteś" and "Wielka wsypa".

Filmoteka Narodowa, Komisja Kolaudacyjna, A-346 poz. 4 (November 18, 1968), "Bez instrukcji” and "Zdrada".

\section{Primary and secondary sources}

Evans, Christine E. 2016. Between Truth and Time: A History of Soviet Central Television. New Haven: Yale University Press.

Giza, Barbara. 2005. “Stawka większa niż życie'—narodziny subkultury fanów.” In 3o najważniejszych programów TVw Polsce, edited by Wiesław Godzic, 161-173. Warsaw: Trio.

Haller, Sebastian. 2014. "Diesem Film liegen Tatsachen... The Narrative of Antifascism and Its Appropriation in the East German Espionage Series Das unsichtbare Visier (1973-1979)." History of Communism in Europe 5: 72-105.

Haltof, Marek. 2008. Polish National Cinema. New York: Berghahn Books. Imre, Anikó. 2016. TV Socialism. Durham: Duke University Press.

Kunicki, Mikołaj. 2017. "Poland's Wild West and East: Polish Westerns of the 196os." In Popular Cinemas in East Central Europe: Film Cultures and Histories, edited by Dorota Ostrowska, Francesco Pittassio and Zsuzsanna Varga, 157-72. London: I.B. Tauris. Lovell, Stephen. 2013. "In Search of an Ending: Seventeen Moments and the Seventies." In The Socialist Sixties: Crossing Borders in the Second World, edited by Anne E. Gorsuch and Diane P. Koenker, 303-21. Bloomington: Indiana University Press.

Mueller-Stahl, Armin. 2014. Dreimal Deutschland und Zurück. Hamburg: Hoffmann and Campe.

Péteri, György. 2004. "Nylon Curtain-Transnational and Transsystemic Tendencies in the Cultural Life of State-Socialist Russia and East Central Europe." Slavonica 10, no. 2: 113-23.

Rogers, Thomas. 2015. “The James Bond of East." BBC-Culture, October 28, 2015, http://www.bbc.com/culture/story/20151028-the-james-bond-of-east-germany. Shaw, Tony, and Denise J. Youngblood. 2010. Cinematic Cold War: The American and Soviet Struggle for Hearts and Minds. Lawrence: University Press of Kansas. Toeplitz, Krzysztof T. 1970. Mieszkańcy masowej wyobraźni. Warsaw: PIW. 


\section{Selected Filmography}

Das unsichtbare Visier (The Invisible Gun Sight, 1973-79, GDR, Dir. Peter Hagen) Konec agenta $W_{4} C$ prostřednictvím psa pana Foustky (The End of Agent $W_{4} C, 1967$,

Czechoslovakia, Dir. Václav Vorliček)

Mayor Vikhr (Major Whirlwind, 1967, USSR, Dir. Yevgeny Tashkov)

Padenie Berlina (The Fall of Berlin, 1949, USSR, Dir. Mikhail Chiaureli)

Semnadsat'mgnoveniy vesny (Seventeen Moments of Spring, 1972, USSR, Dir. Tatjana Lioznova)

Stawka większa niż życie (More Than Life at Stake, 1967-68, Poland, Dir. Janusz Morgenstern and Andrzej Konic)

TASS upolnomochen zayavit (Tass is Authorized to Declare, 1984, USSR, Dir. Vladimir Fokin)

\section{About the Author}

Mikołaj Kunicki has been member of the Faculty of History at the University of Oxford since 2013. From 2013 to 2016, he was the director of Programme on Modern Poland and Senior Research Fellow at St Antony's College. Before coming to Oxford, he taught history at the University of Notre Dame and the University of California, Berkeley. Kunicki received his Ph.D. in History from Stanford University in 2004. He also holds MA degrees from the University of Warsaw, Central European University in Budapest, and School of Slavonic and East European Studies in London. He is the author of Between the Brown and the Red: Nationalism, Catholicism and Communism in Twentieth Century Poland (Ohio University Press, 2012) as well as articles and book chapters on twentieth-century Polish history, cinema, nationalism and contemporary politics. 


\title{
3. From Indianization to Globalization: Tracking Bond in Bollywood
}

\author{
Ajay Gehlawat
}

\begin{abstract}
This chapter uses Bollywood Bond "adaptations" to chart the shifting relationship between India and the West, from the Cold War era to the neoliberal present. It examines how elements of the Bond films were incorporated and "Indianized" in earlier films and how these elements, and the Bollywood film itself, subsequently became more globalized, as can be seen in contemporary Bond adaptations like Farhan Akhtar's Don (2006) and Don 2 (2011). Whereas previously the Bond figure was "Indianized" and elements of the Bond film similarly indigenized via the Bollywood masala formula, what one witnesses in the ensuing transition leading to the contemporary era is how the Bollywood film has become more aligned, both aesthetically and culturally, with contemporary Hollywood film forms.
\end{abstract}

Keywords: Bollywood; masala-Bond; Indianization; globalization

In 1983 James Bond, then played by the aging Roger Moore, arrived in India on what must have been the world's fastest helicopter, passing over the Taj Mahal in Agra in one shot before descending upon Lake Pichola in Udaipur in the next - a distance of some 600 kilometers in mere seconds. Mounting the steps of the ghat, Bond hears the tune of a snake charmer (played by none other than real-life Indian tennis star Vijay Amritraj) which suddenly segues into the Bond theme as he passes by. How is it that an Indian snake charmer knows this tune? Even before Octopussy (UK: John Glen, 1983), the influence of Bond was apparent in popular Hindi films of the 1960 s and 70 . In this chapter, I would like to use the figure of Bond, and the ensuing Bond "adaptations" made in Bollywood, to chart the shifting relationship between India and the West, from the Cold War era to the neoliberal present in which

Verheul, J. (ed.), The Cultural Life ofJames Bond: Specters of oo7. Amsterdam: Amsterdam University Press, 2020 DOI 10.5117/9789462982185_CHO3 
its economic and cultural policies have swung westward, with its films, in turn, increasingly reflecting this transition. This chapter will examine both how elements of the Bond films were incorporated and "Indianized" in earlier films, including Farz (India: Ravikant Nagaich, 1967), Ankhen (India: Ramanand Sagar, 1968), Keemat (India: Ravikant Nagaich, 1973) and Charas (India: Ramanand Sagar, 1976), as well as how these elements, and the Bollywood film itself, subsequently became more globalized following the advent of neoliberalization in the subcontinent, as can be seen in contemporary Bond adaptations such as Farhan Akhtar's Don (India: Farhan Akhtar, 2006) and Don 2 (India: Farhan Akhtar, 2011), as well as related film "updates" of earlier Bond-influenced narratives. Whereas previously the Bond figure was "Indianized" and elements of the Bond film similarly indigenized via the Bollywood masala formula - a culinary term used to describe the mixture of elements on display in the typical Bollywood film-what one witnesses in the ensuing transition leading to the contemporary era is how the Bollywood film itself has become more aligned, both aesthetically and culturally, with the contemporary Hollywood film form.

Tracking Bond in Bollywood via this latter film industry's multiple iterations of this cinematic figure becomes an effective way of charting both the gradual erosion of the masala form, which defined itself through a blending of multiple genres and generic elements, and the particular role that the Bond-influenced narrative has played in effecting such changes. Similarly, just as James Bond films underwent a shift from the comical Roger Moore capers of the 1970 s and early 8os to the nearly humorless, action-driven features of the twenty-first century starring Daniel Craig, this essay explores how Bollywood has also developed in several corresponding ways. While Indianized Bond characters of the 1970s, for instance, frequently engaged in both song and dance and the typical tongue-in-cheek humor associated with Moore's iterations of this figure, the contemporary Indian version of Bond, as personified by superstar Shah Rukh Khan in the two Don films of Farhan Akhtar, has nearly relinquished his sense of humor even as one sees a corresponding diminution of the earlier quintessential features of the Bollywood film, such as song and dance, in these modern updates. This chapter will closely examine not only the development of such changes but what they specifically entail within and for the "Bollywood ecumene" (Bhaumik 2007, 202), as well as what the resulting aesthetic and cultural shifts, aligned with the figure and figuration of Bond, signify for the contemporary iteration of Bollywood in a transnational era in which its agents, vamps and villains have increasingly come to resemble their western counterparts. 


\section{The Masala-Bond Blend, aka, The Singing and Dancing Agent}

One of the "first A list Bollywood films to capitalize on the James Bond craze" (Stadtman 2015, 205), Ravikant Nagaich's Farz (“Duty," 1967), begins with a very Bondian pre-credits sequence, in which Agent 303 is killed while trying to escape from villains whom he secretly photographed using a miniature camera. The music in this opening sequence is reminiscent of the James Bond theme, even as it is "Indianized" — that is, made to adhere to the Bollywood masala formula, in this case, including a blend of Western and Indian instrumentation. Such Indianization continues after the opening credits, when we are first introduced to our hero, Agent 116, aka Gopal (played by Bollywood star Jeetendra), who is to replace Agent 303. Agent 116 is introduced via a song, immediately following the opening credits and initial scene, in which the station chief tells his underling to find 116, wherever he may be. A cut immediately takes us to a Bollywood song and dance, featuring 116 cavorting and rolling around with a young woman, while wearing tight white pants, white shoes and a red sweater while lip-synching to the song's Hindi lyrics. 116 is repeatedly presented in freeze frames in the beginning of this song sequence as he jumps in the air or, indeed, over his female counterpart while emitting joyous "Ooh-oohs!" After this five minute sequence concludes, the understandably spent couple lie dormant on the ground before Gopal slowly begins whispering words of love in his female companion's ear. Even as he does so, however, he notices someone moving nearby, whose shadowy presence is also signified by ominous mood music on the soundtrack. As the earlier Bond-esque theme reemerges, 116 continues speaking words of love to his female friend while simultaneously creating a ruse to trap the unseen observer, who turns out to be the station chief's underling, Mohan, come to get him for his new mission. In this opening sequence-or, indeed, opening sequences—-we thus have a vivid instance of how the Bond narrative is adopted and Indianized via the quintessential element of the popular Hindi film: song and dance. Yet this opening also shows us how these two elements—-Bond and Bollywood-coexist somewhat awkwardly, with the film abruptly shifting registers from Bond-spy narrative to Bollywood song and dance. And while Agent 116,

1 This song, Mast Baharon Ka Main Aashiq ("I am the Lover of Blooming Pleasures"), is sung by legendary playback singer Mohammed Rafi. Jeetendra's energetic moves in this song sequence illuminate why he was subsequently given the moniker, "Jumping Jack of Bollywood," even as dancing in white pants and patent-leather shoes became his trademark (Jeetendra Biography; Rajadhyaksha and Willemen 1999, 114). 
like his western counterpart, balances his skills at amour with his equally formidable sleuthing prowess, the manner in which the former expresses his amorous desires is quintessentially aligned with the pathos of the Hindi film in its exuberance and over-the-top nature. ${ }^{2}$ In this way, one sees how the masala-Bond film engages in what Sumita Chakravarty $(1993,4-5)$ labels "imperso-nation," that is, "the play of/on surfaces" which, in turn, "implies a form of subversion," in this case, of the conventional (Western) Bond figure.

One sees a similar confluence of Bondian and Bollywood elements on display in the following year's Ankhen ("Eyes," 1968), in which Dharmendra plays Sunil, the son of an Army chief, who travels the world, visiting Tokyo, Beirut and Cochin in his pursuit of the villains. Sunil's female sidekick, Meenakshi (Mala Sinha), in a nod to the previous year's Bond film You Only Live Twice (UK: Lewis Gilbert, 1967), is a half-Japanese agent whom he first meets in Tokyo, where she is made up to look "Oriental." In the film's first song, set in Japan, Meenakshi switches from one Japanese-themed costume to the next while Sunil wears a beige overcoat and fedora. In a similar vein, and in a slight departure from the previous year's Farz, only Meenakshi sings in this first song sequence, with Dharmendra's Sunil forgoing Jeetendra's enthusiastic lip-synching (and dancing). ${ }^{4}$ Despite this lack of singing and dancing by the Indian agent, the film features several other instances of Indianization, detailed below, along with its several Bondian elements such as sliding partitions, hidden chambers and secret transmitters. A classic instance of such Indianization comes when Agent Sunil arrives in Beirut. While the Bond influence makes its presence felt via the electric guitar-heavy music that plays as he is trailed by villains from the airport, and in his subsequent discovery of an electronic bug (hidden inside a fake poodle) in his hotel room, it is when Sunil goes to a nearby café and places

2 Bond, on the other hand, as personified, e.g., by Sean Connery, tends to be more restrained in his displays of affection, as can be seen in the opening sequence of From Russia with Love (1963), in which it is his female friend who is more (sexually) aggressive and Bond who frequently slaps her exploring hands away. Similarly, for all his physical prowess, Bond never dances, much less in the manner of "Jumping Jack Jeetendra." All of these differences create essentially different forms of masculinity.

3 To some extent the masala-Bond film engages in the type of problematic Orientalism on display in several Bond films though to a lesser degree. For more regarding the Orientalism of Bond films, see Gehlawat (2009).

4 The subsequent shift to Dharmendra for the Bollywood Bond roles of the late 6os and early 70 may indeed reflect the fact that Jeetendra was "more suited to romances and musicals, while Dharmendra more fit the mold of the two-fisted man of action" (Stadtman 2015, 205). Nevertheless, Dharmendra also engaged in song and dance, despite his arguable proclivity for action sequences. 
an order that his cultural distinction (as Indian) becomes apparent. Rather than a shaken martini, Sunil orders chai. Similarly, upon meeting the villain's moll, Princess Zehnab, at a swanky dinner party later that evening, Agent Sunil, dressed in a tuxedo, declines Zehnab's offer of whisky, opting instead for a soft drink. Meanwhile the film's additional song and dance sequences, again primarily featuring Meenakshi and other female dancers, blend Bollywood and Bond elements by frequently using exotic foreign locales as backdrops for their numerous picturizations and, again in a nod to the conventions of popular Hindi cinema, the film ends with a reprise of one of these songs, featuring Sunil and Meenakshi walking hand in hand into the sunset, having defeated the enemy.

Dharmendra reprised his role as the Indian secret agent in Keemat ("Price," 1973), again directed by Nagaich. In this film, Dharmendra takes up the role originally played by Jeetendra, Agent 116, aka Gopal, and the film immediately signifies its adherence to the Bond aesthetic via its overtly cool opening credits sequence which features still images of characters and scenes with western-influenced, guitar-heavy music and breathy voices rhythmically intoning, "Hey! Hero!" Though Nagaich intended Keemat as a sequel to Farz, in the ensuing six years, Stadtman $(2015,205)$ surmises, some of the novelty of such films had most likely worn off, leading Nagaich, perhaps in a compensatory move, to "tak[e] advantage of the era's looser standards with racier content" in his new film. Yet though the film does feature such "racy" content-including the insertion of gratuitous item numbers in the villain's nightclub with women in outlandish and revealing, glittery costumes dancing before the assembled, leering men - most such song sequences still feature a more Indian style of dance choreography, thus articulating such films' cultural distinction from the prototypical Bond narrative which eschews such superfluous elements. ${ }^{5}$ Additional instances of Indianization of the ostensible Bond narrative-increasingly solidified by the "two-fisted" Dharmendra-are also on display throughout the film, particularly with regard to the secret agent's sexual proclivity (or lack thereof). When Gopal enters a woman's room, for instance, while she is showering and she subsequently calls for a towel, it looks like a classic Bond send-up. But then, when the woman realizes Gopal is in the room and shrinks back in embarrassment, the secret agent looks away even as he tosses her a robe and proclaims that he is a sharif ("noble") man and proceeds to lecture her about taking more care when exiting the bath. In a similar vein, when this woman starts removing her clothes in an attempt to seduce the 
secret agent, he asks her what the hurry is and, when she replies, "Business," demurs by noting that he doesn't engage in such "business" with girls. At the same time, when subsequently questioned about his meeting with this woman by another woman, Gopal replies, "When beautiful girls want to meet with me, I don't ask questions." Thus, we see how the Indian secret agent attempts to have it both ways (as does the masala-Bond film, even during this allegedly "looser" era), maintaining a veneer of sexual prowess while, in private, demurring from open sexual invitations.

This uneasy dynamic between Bondian and Indianized elements reaches its apotheosis in Charas ("Hashish," 1976), directed by Ankhen's director, Ramanand Sagar. In this convoluted story, Dharmendra plays Suraj, whose family is apparently killed off by villains in Uganda and who is subsequently recruited by the police as a secret agent to combat drug smugglers (including, as it turns out, those behind the attacks on his own family). As with Keemat, the film features a cool opening credits sequence, with lots of action and hip music, as well as a potpourri of evil villains including some of the era's most notorious, such as Ajit and Amjad Khan, with the former playing the lead villain and the latter, his henchman Robert who, in an "amplification of grotesquery," has an "oatmeal-y facial appliance and a seeming vat of pomade," along with lines, delivered in English, such as, "When I kill them, they stay dead" (Stadtman 2015, 201). At the same time, even as it includes such Bondian villains and Bond-esque trips to foreign locales including Malta, Charas features its fair share of lip-synched song and dance numbers. Similarly, as seen in both Ankhen and Keemat, Dharmendra and his female counterpart, Sudha, played by Hema Malini, display distinctly Indian sensibilities when confronted with stereotypically Western behavior. For instance, in a scene that recalls several others from this era of Hindi film, when Suraj points out a white couple kissing in a bar in Malta to Sudha, she replies, Sharam nahin aati hai? ("Don't they feel ashamed?") and proceeds to defend "Indian virtue" by turning down all of Suraj's subsequent suggestions and sexual innuendos, claiming that such actions only come "after marriage. ${ }^{6}$ Similarly, instead of a kiss, we get a song and dance sequence featuring Sudha and Suraj, cavorting about in their hotel rooms, singing (or, lip-synching) of their desire for one another but doing nothing more, even though Sudha does engage in a striptease of sorts for Suraj, changing into a sexy black negligee while he watches. Ultimately, however, he is pushed

6 Sharmila Tagore similarly rejects co-star Shammi Kapoor's request for a kiss in An Evening in Paris (1968), also set abroad, claiming that she is "an Indian girl" and that, according to Indian custom, "that... that's only after marriage" (Prasad 1998, 89). 
out of her room and sent back to his, empty-handed. Such moments not only provide vivid instances of the Indianization of the Bond sex scene (imagine Bond lip-synching of his desire but not fulfilling it) but also of the particular role that song and dance has historically played in sublimating such sexual desires. As Rini Bhattacharya Mehta $(2010,11)$ notes, such song sequences "enhanc[e] the suggestive yet minimal physicality of the love scenes' with poetic innuendos, but also ultimately steriliz[e] them; because nothing happens in full-view." Such "carefu[l] circumvent[ion] [of] the issue of sexual contact," in Mehta's (11) view, becomes "the most intriguing idiosyncrasy of Indian popular cinema" and, along with the thematization of the prohibition of public displays of affection (as cultural truth and duty), serve as quintessential markers of the otherwise Bondian film's essentially Indian formulation. As Madhava Prasad (1998, 90-91) notes regarding the Indian context of this era, "[T]he threat posed by a transgression of custom is not only to the family or the institution of marriage but to the nation itself, as if the expansion of the sphere of sexuality threatened to break open the national borders and destroy its identity." It is precisely such "breaking open" of sexual mores and national borders that the twenty-first-century Bollywood-Bond film engages in, as we shall see in the ensuing section, even as such an "opening up" allows for the importation, to some degree, of the cultural politics associated with Bond.

An additional key instance of the Bond narrative being made to fit the Procrustean bed of popular Hindi film conventions, meanwhile, can be seen in Charas's frequent back and forth from song to action to song, as well as in the ensuing ways that such failure to adhere to a more western-oriented linear narrative is almost casually forgiven. After engaging in a song and dance with Sudha upon arriving in Malta, for instance, in which several tourist locations are featured, Suraj arrives at the place where all of the police are waiting to ambush the main villain, casually stating, "Sorry, I got late." "No problem," the white police officer replies just as casually.7 Then, suddenly, in a nod to You Only Live Twice, the lead villain sees the assembled police force and, after leading them on a car chase, escapes when his car is lifted away by a helicopter. Just as suddenly the film cuts to Robert's nightclub, somewhere (else) in Malta, for yet another song and dance, this one featuring Suraj's long-lost sister performing a sexy item number. In such a way, even as one could argue song and dance numbers frequently interrupt the Bondian narrative, one could equally argue that it is the Bond narrative

7 The use of exotic foreign locales, replete with their local denizens, as backdrops for song and dance sequences is a Bollywood staple that continues up to this day. 
which is sandwiched between song and dance numbers, whether featuring the secret agent cavorting with his female lead in a hotel room or before various Maltan tourist locations, or featuring the secret agent's sister dancing in the villain's nightclub. As with the intense action and chase sequences taking place in most Bond films, such song and dances are arguably the most compelling visual attractions of the film. Yet these Bollywood-Bond films of the late 6os and 7os include both types of attractions-song and dance and intense fights and action - thus literally doubling the overall visual pleasure derived from such films. In the ensuing section, we shall see how this quintessential topos of the Bollywood-Bond narrative has (d)evolved, even as the Indian Bond figure has, in turn, grown increasingly globalized in both his outlook and look. While India remained essentially non-aligned during the Cold War era, one still witnesses a rather bellicose nationalism in the films of this era, particularly with regard to its neighbors, especially China, as one sees in the Chairman Mao-like villain of Farz. While the Bollywood-Bond films of the twenty-first century attenuate this earlier era's agonistic framing of Indian and Western cultural elements, they do retain - and to some extent heighten - the nationalism on display in the Cold War-era films. Similarly, even as the interim period-between the 1960s/70s and the twenty-first century — was marked by significant changes in the official Bond franchise, including with regard to both geopolitics (e.g., the end of the Cold War) and cultural dynamics (e.g., regarding gender and race), the Bollywood industry also underwent significant shifts during this period following the liberalization of the Indian economy in the 199os which, in turn, led to marked changes regarding the ensuing make-up of the Bollywood film.

\section{Remaking the Indian Bond}

If there is one actor who has constantly clamored to play James Bond, it is the so-called "King of Bollywood," Shah Rukh Khan (hereafter, SRK). ${ }^{8}$ SRK first had a chance to try out such a role in Farah Khan's directorial debut Main Hoon Na ("There Is Me, No;" India: Farah Khan, 2004), where he plays an army major who goes undercover at an Indian college to protect a general's daughter from attack by the villains. Khan's entry immediately conjures Bond, as his character, Ram Sharma, "literally drops in like a star from the

8 As, for instance, in an interview in The Scotsman, in which Khan stated, "Man, I want to be James Bond. Please make me the first Indian James Bond” (quoted in Dalton 2002). 
ceiling/sky in explosive sparks" (Gopinath 2017, 8) before "dangl[ing] from wires while killing hostage-takers, shoot[ing] henchmen in slow motion while seemingly flying through the air" (Denison 2010, 191). Even as this film was successful in developing Khan as "an action hero," however, one also witnesses the intrusion of melodrama on "the space of the truncated action performance" (191-92). Just as the film, in other words, "mix[es] the codes of melodrama and action," SRK provides "competing generic codes of performance" (192), engaging, like past Bollywood Bond figures such as Jeetendra and Dharmendra, in both fisticuffs and song and dance. Such a performance becomes a double role of sorts, mixing "action hero" with "romantic hero" (Gopinath 2017, 8) yet these roles remain segmented in a way that differs from the figure of Bond, in whom such elements (action, romance) are typically conflated. As Praseeda Gopinath $(2017,13)$ notes, the trope of the "standard heroic, confident action figure [...] wobbles when it comes to his interactions with the love interest." Even as the film more broadly mirrors this double role by engaging in a form of "genre blending" (185), combining elements of romance, song and dance and action, it also makes (parodic) allusions to contemporary Hollywood action blockbusters like The Matrix (USA: Lana Wachowski and Lilly Wachowski, 1999) and Mission: Impossible (USA: Brian De Palma, 1996) via its use of "Matrix-style 'bullet time'" (Stadtman 2015, 222), which in turn raises the question of whether such "Indian remaking" remains relegated to narrative content or indeed also affects the Bollywood film's "form and coding" (Wright 2015, 137). To come to a better understanding of this complex question and to see how SRK was finally able to play Bond, let us examine his subsequent film, Farhan Akhtar's Don (2006).

Akhtar's Don is itself a remake of an earlier Bollywood film of the same name, directed by Chandra Barot and released in 1978. Even more than Main Hoon $\mathrm{Na}$, this film — in both its original and remade versions - features the use of double role: "that of a dreaded don and that of a street performer who happens to resemble the don and is recruited by the police to penetrate the gang" (Chopra 2007, 220). Yet unlike the original version, which is more akin to the earlier masala-Bond films discussed in the first section of this chapter, the 2006 version of Don is a "Mission:Impossible-style thriller in which Shah Rukh plays an international criminal draped in guns, gadgets, drugs, and blondes" (220). ${ }^{9}$ Along with such quintessentially Bondian elements this remake, released the same year as Daniel Craig's Casino Royale, demonstrates

9 The original version is seen as epitomizing the Bollywood masala style of filmmaking (Dwyer 2005, 88), featuring a combination of song and dance, action sequences and melodrama. 
how the twenty-first-century Bollywood film has grown closer in "form and coding" to its Hollywood counterpart (Wright 2015, 137) even as SRK, like Craig, increasingly "attempts to fit into the 'hard body' masculinity of a new generation of male actors" (Gopinath 2017, 16). However, mirroring its title character's double role, Akhtar's 2006 remake still retains some degree of the original Bollywood masala formula even as it features "a high concentration of Hollywood/foreign film aesthetics" which, in some cases, lead to "abandoning traditional Bollywood conventions altogether" (Wright 2015, 173). Some of these changes - from a more Indianized palette to one more global in its contours-include a shift in settings (while the original Don, played by Amitabh Bachchan, was essentially relegated to Bombay/India, SRK's Don, like his Bondian counterpart, "exhibits an ease in moving between [...] Paris [...] Langkawi [...] Kuala Lumpur, as well as [...] Mumbai” [Seth and Fuchs $2015,71])$ as well as a more "slickly produced" film that adheres to the "song sequence formula" of erstwhile Bollywood yet presents its musical sequences "in the manner of an MTV pop video" (Wright 2015, 174). Similarly, SRK's Don, like his character in Main Hoon Na, still reflects an "imbalance" between his two roles- "cigarette smoking [...] and indestructible" on the one hand (176) and engaging in song and dance on the other-yet offers a fundamentally "harder" form of masculinity overall— "a man with a sense of humor," as SRK notes, "but very cold and very, very mean" ("Making of Don" DVD feature 2006). In a similar vein, the sexuality of the twenty-first-century Bollywood Bond is decidedly grimmer and less inclined towards the frivolity on display in the earlier masala-Bond films such as Farz.

The first song sequence from the film, Yeh Mera Dil ("This, my heart") aptly displays these shifts in form and content, both of which align this remake if not with a particularly Hollywoodian approach then with a "new globalized postmodern cinema aesthetic" (Wright 2015, 179). In the original version of this item song, the erstwhile queen of vamps, Helen, playing the sister of a man whom Don murdered, attempts to trap him via the use of song and dance as a delaying maneuver, distracting him until the police arrive. The updated version of this song, while adhering to the general contours of the original (employing the vamp figure, this time played by Kareena Kapoor, to utilize song and dance as a delaying tactic), features a much more densely layered audio track and techno beat, even as Sunidhi Chauhan's deeper timbre replaces Asha Bhosle's higher pitched voice for the playback. Similarly, the cinematic style of the remade song and dance sequence is rather different from the original and more analogous to an MTV aesthetic, featuring stutter edits that align audio track and image via a series of strobe-effect cuts. In a related vein, while Helen attempts to 
seduce Bachchan's Don in the original, he remains generally impervious or, at best, bemused by her attempts while SRK's Don displays a heightened sexuality, getting it on much more with Kapoor's vamp figure and even getting on top of her in bed near the end of the sequence (while maintaining his "hard" veneer ${ }^{10}$ ). Additionally, while the original sequence remains confined to the room in which Helen dances, the remake features a crosscut to the police arriving in their high-speed, siren-wailing entourage, even as the music continues playing, thus creating a sound bridge between these two simultaneous events. Such a postmodern cinema aesthetic is also on display in the updated version's other song sequences, which similarly employ MTV-style cinematography, remixed, bass-heavy techno beats, and are more closely interwoven with the surrounding narrative action. Thus, even as the remake of Don retains the quintessential elements of the Bollywood masala form (song and dance), their remixed iterations reflect this film form's increasingly globalized format.

Thanks to a plot twist revealed at the end of the Don remake, ${ }^{11}$ Akhtar brings the titular character back for a second installment five years later. This sequel, unlike either the original or its remake, both of which include five song and dance sequences, includes only one actual song sequence featuring dancing and lip-synching in the entire 153-minute film. This diminution of song and dance, signaling a closer alignment with the Hollywood film form, may also signify the sequel's attempt to be "more appealing internationally" (Ganti 2012, 341). Like the majority of songs in Akhtar's first Don, this sole song sequence hews to an MTV aesthetic, featuring Don's moll and a host of background dancers singing and dancing in a nightclub for the seated, smoking Don (again played by SRK) who, approximately midway through the song, also begins singing and dancing with the others. Other than this four minute sequence, the only other songs in this sequel are a song featured solely on the soundtrack, which plays while Don and his cohorts are seen preparing for a bank heist, and the end credits song sequence, featuring SRK

10 As in the original, Don ultimately kills this vamp figure, once the song ends and her subterfuge is revealed, showing little to no compunction in doing so. While in the original this death is alluded to by the police, in the remake we are actually shown Kapoor's lifeless body lying on the ground while elevator doors continue opening and closing against it. Thus, as with the protagonist's "harder" masculinity, the updated remake is starker in its depictions of violence, which also parallels the increased levels of violence on display in the contemporary Bond films of Craig.

11 Unlike the original Don, who is killed and replaced by his double, the remake reveals that the alleged "softer" double was actually the "harder" Don all along, having killed his double and taken his place. 
and co-star Priyanka Chopra singing and dancing amidst a bevy of CGI and VFX which, in many ways, recalls the opening credits sequences of several contemporary James Bond films. Along with a drastic reduction of the role of song and dance, Don 2 features a much "harder" SRK, whose muscular body is frequently put on display and whose sexuality is decidedly colder. Here, too, one can trace a parallel to Daniel Craig, whose hard and muscular body (and colder sexuality) is similarly put on display in the contemporary Bond films. Such bodies (and sexualities) stand in stark contrast to those of both former Bonds and Bollywood Bonds, including that of Dharmendra who, despite being more in the "two-fisted man of action" mold (Stadtman 2015, 205), rarely presents his (bared) body in such a manner and, in the rare instance when he does, as in an underwater sequence early on in Keemat, reveals a slight paunch. The premise of the Don sequel itself reflects Bollywood's larger aspiration in the twenty-first century as Don, having taken over the Asian (drug) market, now wants to conquer Europe. This westward shift is also signaled in the production crew of the new film, which included a British director of photography and a German action director and was largely shot on location in Germany, where the film premiered at the Berlin International Film Festival. This film, which was an even bigger hit worldwide than Akhtar's earlier Don, is much closer to a typical Bond film in its structuring, featuring a second half sans song and dance that is more concerned with Don's preparations for and implementation of a heist at the Deutsch Zentral Bank. Similarly, the film's convoluted plot hews more to the plot convolutions of a (western) Bond feature than to an erstwhile Bollywood feature, avoiding the type of plot "irrationalities" one still witnesses even in Akhtar's earlier Don remake (e.g., the numerous song and dance sequences).

In thus streamlining the Bollywood narrative, Akhtar creates a new type of Bollywood-Bond with Don 2, one which aptly reflects the changes in Indian cinematic culture, not only since the 1970s but even in the five years since the earlier remake. Along with minimizing or indeed eschewing the role of song and dance, the new film includes "extremely fast and 'realistic' martial arts scenes and stunts" and shifts from a nationalist rhetoric and milieu to one celebrating globalization (Seth and Fuchs 2015, 73-74). Similarly, even as critics have commented on the "darker" nature of Craig's Bond, SRK's Don, like Craig's Bond, "is not vilified;" rather, this anti-hero, like his western counterpart, is "presented as an 'achiever' enjoying a luxurious lifestyle that is only endangered by the multitude of his enemies"12 (74). One can

12 In another interesting parallel, both Craig and SRK serve as brand endorsers for luxury items frequently on display in their films: Omega watches (Craig) and Tag Heuer watches (SRK). The 
thus read the double role of Don as a synecdoche for the larger changes that have taken place in Bollywood and in India. Whereas the original Don features a local Indian (Vijay) who successfully impersonates Don while retaining his quintessentially Indian identity, the local Indian impersonator in Akhtar's remake is unable to survive "exposure to the modern world of globalized crime" (83) and is supplanted by the more global Don who, in turn, paradoxically thrives beneath the camouflaged veneer of an "Indian." Just as this more globalized Don sheds this veneer at the conclusion of Akhtar's first film (en route to taking over Europe), the follow-up makes little claim to any form of Indianness, save for the ostensible Indian nationality of its stars, many of whom more often speak in English, or "Hinglish," than in Hindi.

Such shifts are even more vividly on display in the following year's Agent Vinod (India: Sriram Raghavan, 2012), another "remake" of an earlier 70 era Bollywood-Bond film of the same name. While the director of the remake, Sriram Raghavan, unlike Farhan Akhtar, claimed that his film was not a remake and merely shared the name of the earlier film (IndiaFM 2007), in many ways, as is the case with Don and its remake (and sequel), this film—separated from its "original" by a period of thirty-five years—reflects the same move away from the masala aesthetic of 1970s era Bollywood (with its multiple discordant elements) towards the elimination of these "irrationalities" via the type of Hollywood-inflected sequencing apparent in the later Dons. While the 2012 version is slightly longer than the original 1977 version, it contains only three songs, compared with twice as many in the ' 77 version. Furthermore, while both the songs and the overall aesthetic of the original version are very much in keeping with the 1970s Bollywood aesthetic-including a high degree of spoofing and parabases, dishoom-dishoom fights ${ }^{13}$ and lip-synched song and dance sequences, including one which first introduces us to the title character - the 2012 version, starring Saif Ali Khan as the titular agent, eschews nearly all of these elements, replacing tongue-in-cheek humor and lip-synched songs with grim action sequences and extreme CGI violence. In many ways, one can trace a similar shift in the James Bond films, which went from the comical Roger Moore capers of the late 1970 s and early 80 s to the nearly humorless Daniel Craig action-driven features of the twenty-first century. Additionally, as in the case of Don 2, only one of the film's three song sequences features an actual dance performance and lip-synching; of the

ads for these products in turn frequently reference these films, resulting in symmetrical forms of synergy. For Don 2, Tag Heuer even produced a limited edition Don watch (Seth and Fuchs 2015, 77). 13 Dishoom-dishoom is the colloquial onomatopoeic term for the older Bollywood sound effect accompanying punches. 
remaining two songs, the first is set in a nightclub and interspersed with an action sequence which literally spills over into the song-dance space. The second song sequence in the 2012 Agent Vinod - "Raabta" - even more vividly highlights the growing shift away from the earlier space afforded to the song. In this sequence, while a woman plays a slow, romantic ballad on the piano, the title character shoots a series of villains, interspersed with the sound of silencer-suppressed pistol shots and the ensuing diegetic sounds of people falling over and crashing into various objects. Visually and aurally, this sequence is a far cry from the song sequences of the earlier Agent Vinod which, in keeping with the 7os Bollywood aesthetic, feature the title character lip-synching and cavorting with various women (without shooting them).

The 2012 Agent Vinod also signifies its globalized form in additional ways. Like SRK's Don, the title character, a RAW ${ }^{14}$ agent working for the Indian government, travels all around the world, including Afghanistan, Moscow, St. Petersburg, Morocco, Riga, London and Cape Town and, in keeping with the cosmopolitan nature of the Bond figure, is equally comfortable in all locations (despite frequently being in grave danger). As with Don 2, the pacing of the 2012 Agent Vinod is also more aligned with a western Bond film's itinerary, that is, moving logically from one (global) setting to the next while avoiding the random insertions of song and dance within or between these settings. Instead, as with contemporary Bond films and Don 2, the film is interspersed with intense action sequences though these, too, adhere more to a Hollywood model, forgoing the dishoom-dishoom aesthetics of the earlier Bollywood era. Khan, in playing the title agent, also conforms to the Bondian look, performing intense action and stunts while wearing a black tuxedo and bow tie; indeed, in some ways, one could say his look as the Indian Bond presages that of Craig in his most recent iteration as the secret agent. ${ }^{15}$

At the same time, "regardless of how much [it] may 'steal' from outside sources or stray from [its] own conventions," the 2012 Agent Vinod "cannot be experienced or labeled as [a] foreign, Western or non-Indian production" (Wright 2015, 174). The contemporary Bollywood-Bond remake, in other words, increasingly lacks a fixed cinematic identity, even as the identities of its secret agents have also grown less fixedly Indian, unlike, e.g., the

14 RAW stands for Research and Analysis Wing, the primary foreign intelligence agency of India.

15 One also sees an increased Hollywoodization on display in both the Craig and Bollywood Bond films of the twenty-first century, particularly with regard to the increasing amounts of CGI action sequences in both. In a related vein, even as these two types of Bonds increasingly look the same, the only type of clothing Agent Vinod never dons is Indian garb, thus reflecting the "disavowal of fixed identity" (Chakravarty 1993, 4). 


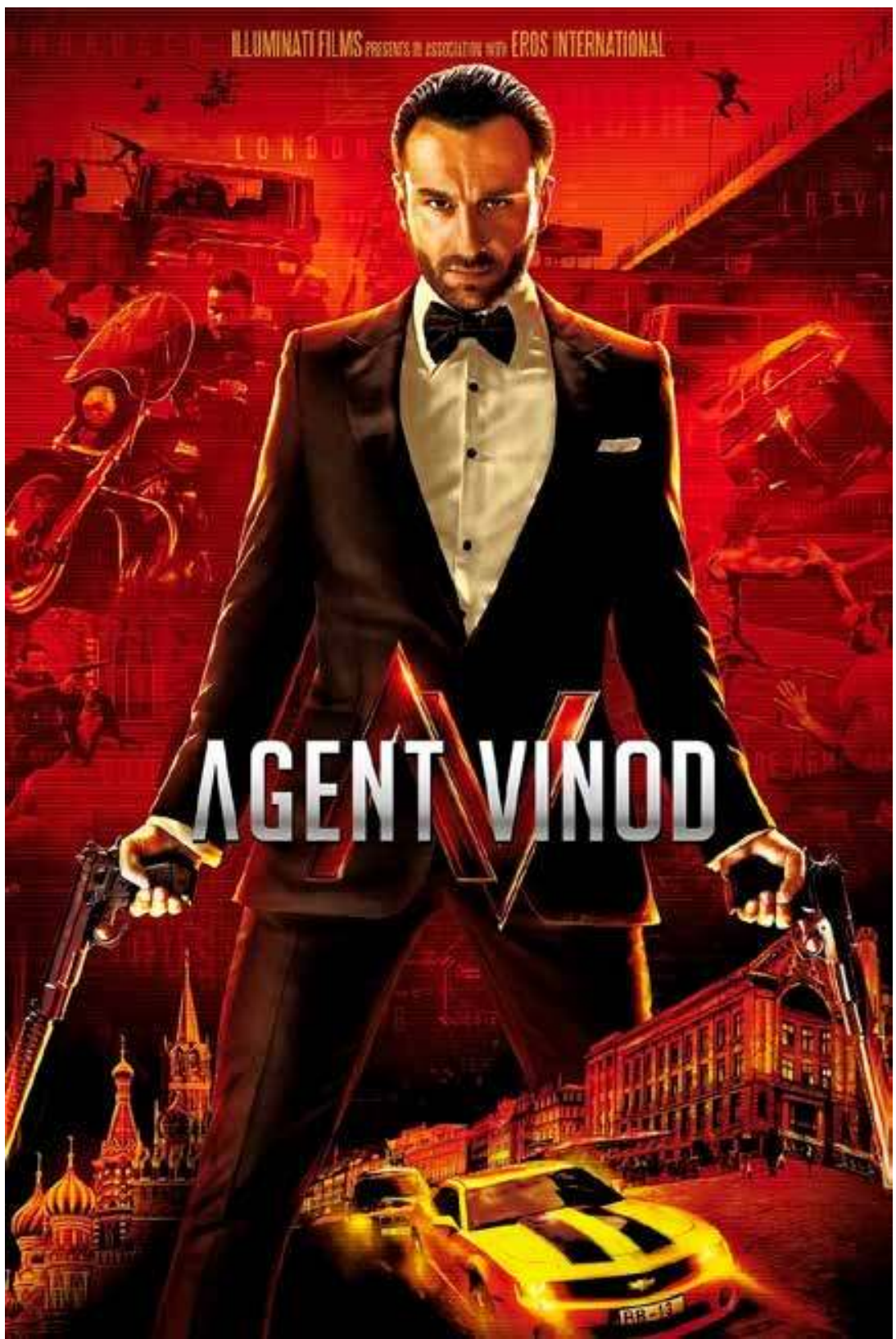

1: Saif Ali Khan as Agent Vinod (2012) in Agent Vinod (India: Sriram Raghavan, 2012). Copyright of Eros International, India. 
chai-drinking agent of Ankhen. A classic instance of this can be seen in the film's ending(s). The film first concludes with Agent Vinod, having completed his missions and newly shaven, approaching a white woman in a bikini on a Cape Town beach. As the woman flirtatiously asks him what his name is, Agent Vinod removes his sunglasses and smiles at her as the screen goes black. However this "Bondian" ending is immediately followed by a more "Bollywood" one, featuring an end credits song sequence, in which Khan goofily dances and playacts before a surveillance camera, while a woman, watching from the surveillance booth, grows increasingly turned on by his moves and joins him in an embrace as the two walk towards the camera together in slow motion. In such a way, the 2012 Agent Vinod pledges its (nominal) allegiance to both Hollywood and Bollywood ecumenes, providing endings that correspond to both film forms and, in the process, producing "a hybrid cinematic style that deviates from both Western and traditional Indian modes of filmmaking"16 (Wright 2015, 174).

\section{Conclusion: A Gentleman's Bond Fatigue?}

Even as the Bollywood film form has grown increasingly streamlined via its contemporary Bondian iterations, the James Bond films of Daniel Craig have increased in their overall length, with three of the last four Bond features clocking in at over 140 minutes. Such a temporal correspondence may belie the inner shifts underlying the internal dynamics of either film form yet it does point to shared tendencies, both in form and content, which are increasingly on display. Yet even as Bollywood has apparently embraced the harder, contemporary Bond aesthetic, a recent film seems to suggest at least a passing fatigue with the franchise. ${ }^{17} \mathrm{~A}$ Gentleman (India: Krishna D.K. and Raj Nidimoru, 2017) begins with Gaurav (Sidharth Malhotra), a nice but boring guy who resides in Miami and drives his minivan to and from work at precisely the speed limit. In a parallel narrative the film presents Rishi (also played by Malhotra), an Indian secret agent who sports tuxedos and a light beard and works for "Unit X," traveling to Bangkok to steal documents from the Chinese embassy and engaging in high speed chases and shootouts. At first glance, then, this appears to be yet another instance of the double role, with nice guy Gaurav and secret agent Rishi to switch identities. Yet when Rishi's motorcycle crashes after his opening 
mission, he sits on the ground in his disheveled tux, pulls out a cigarette and proclaims, "My life sucks." While Craig, too, has shown Bond-fatigue in his recent films, he invariably returns to the game, grimmer and more determined to "finish the job" each time. Rishi, meanwhile, decides to walk away from his life as a secret agent and, in an interesting twist, the film reveals that Rishi is actually Gaurav, having left his line of work to pursue his suburban dream. Needless to say, his former life pursues him and Gaurav soon finds himself reprising his alter identity in an attempt to thwart his former colleagues who have come to either reenlist or retire him. "There was a time you were like Bond," one of his former colleagues says, upon meeting the erstwhile secret agent in his suburban Florida home. "Now look how domesticated you've become." Bollywood has also engaged in such domestication (of Bond narratives) over the past half-century yet, like Gaurav, contemporary Bollywood is increasingly showing signs of repudiating its former identity, in favor of a more Hollywoodesque façade. However, just as Gaurav finds it hard to walk away from his life as a secret agent, contemporary Bollywood films like $A$ Gentleman demonstrate that, while it may be possible to transplant the Indian agent from his home country to the West, he ultimately remains a secret agent, that is, one who will always return. Even as the film concludes with Gaurav (or is it Rishi?) blowing up his suburban home and speeding away in a yellow convertible with his girlfriend, Bollywood returns via the end credits song sequence, featuring Gaurav and his girlfriend lip-synching and dancing to a song that has little, if anything, to do with the plot.

\section{Works Cited}

Bhaumik, Kaushik. 2007. "Lost in Translation: A Few Vagaries of the Alphabet Game Played Between Bombay Cinema and Hollywood." In World Cinema's 'Dialogues' with Hollywood, edited by Paul Cooke, 201-17. New York: Palgrave Macmillan.

Chakravarty, Sumita. 1993. National Identity in Indian Popular Cinema, 1947-1987. Austin: University of Texas Press.

Chopra, Anupama. 2007. King of Bollywood: Shah Rukh Khan and the Seductive World of Indian Cinema. New York: Warner Books.

Dalton, S. 2002. "Meet the Khan-Do Guy." The Scotsman, August 14, 2002, 5.

Denison, Rayna. 2010. "Bollywood Blends: Genre and Performance in Shahrukh Khan's Post Millennial Films." In Genre and Performance: Film and Television, edited by Christine Cornea, 184-204. Manchester: Manchester University Press.

Dwyer, Rachel. 2005. 100 Bollywood Films. London: British Film Institute. 
Ganti, Tejaswini. 2012. "No Longer a Frivolous Singing and Dancing Nation of Movie-Makers: The Hindi Film Industry and Its Quest for Global Distinction.” Visual Anthropology 25: 340-65.

Gehlawat, Ajay. 2009. "Kamasutra Bond-ing." In The James Bond Phenomenon: A Critical Reader, Second Edition, edited by Christoph Lindner, 268-84. Manchester: Manchester University Press.

Gehlawat, Ajay. 2017. "The Picture Is Not Yet Over!: The End Credits Song Sequence in Bollywood." South Asian Popular Culture 15, no. 2-3: 203-16.

Gopinath, Praseeda. 2017. "A Feeling You Cannot Resist': Shah Rukh Khan, Affect, and the Re-Scripting of Male Stardom in Hindi Cinema." Celebrity Studies 9, no. 1: 1-19.

IndiaFM News Bureau. 2007. "Agent Vinod is not a Remake of Rajshri Film." Bollywood Hungama, October 12, 2007, www.bollywoodhungama.com/movies/ features/type/view/id/3212.

Jeetendra Biography. n.d. Lifestyle Lounge. Accessed December 1, 2017, http:// lifestyle.iloveindia.com/lounge/jeetendra2935.html.

Mehta, Rini Bhattacharya. 2010. "Bollywood, Nation, Globalization: An Incomplete Introduction." In Bollywood and Globalization: Indian Popular Cinema, Nation, and Diaspora, edited by Mehta and Rajeshwari V. Pandharipande, 1-14. London: Anthem.

Prasad, M. Madhava. 1998. Ideology of the Hindi Film: A Historical Construction. New Delhi: Oxford University Press.

Rajadhyaksha, Ashish, and Paul Willemen. 1999. Encyclopaedia of Indian Cinema, Revised Edition. London: British Film Institute.

Seth, Aradhana, and Bernhard Fuchs. 2015. "The Don's World: Designing the Milieu of Shah Rukh Khan.” In SRK and Global Bollywood, edited by Rajinder Dudrah, Elke Mader, and Fuchs, 70-97. New Delhi: Oxford University Press.

Stadtman, Todd. 2015. Funky Bollywood: The Wild World of 1970 Indian Action Cinema: A Selective Guide. Godalming, Surrey: FAB Press.

Wright, Neelam Sidhar. 2015. Bollywood and Postmodernism: Popular Indian Cinema in the $27^{\text {st }}$ century. Edinburgh: Edinburgh University Press.

\section{Selected Filmography}

Agent Vinod. Dir. Deepak Bahry. India: Sargam Pictures, 1977.

Agent Vinod. Dir. Sriram Raghavan. India: Dreamaker Productions, 2012.

A Gentleman. Dir. Krishna D.K. and Raj Nidimoru. India: Fox Star Studios, 2017.

Ankhen. Dir. Ramanand Sagar. India: Sagar Art International, 1968.

Charas. Dir. Ramanand Sagar. India: Sagar Art International, 1976.

Don. Dir. Chandra Barot. India: DEI, 1978. 
Don. Dir. Farhan Akhtar. India: Excel Entertainment, 2006.

Don 2. Dir. Farhan Akhtar. India: Excel Entertainment, 2011.

Farz. Dir. Ravikant Nagaich. India: Vijayalakshmi Pictures, 1967.

Keemat. Dir. Ravikant Nagaich. India: Bharati International Films, 1973.

Main Hoon Na. Dir. Farah Khan. India: Eros International, 2004.

\section{About the Author}

Ajay Gehlawat is Professor of Theatre and Film at Sonoma State University. He is the author of Reframing Bollywood: Theories of Popular Hindi Cinema (2010) and Twenty-First Century Bollywood (2015), as well as editor of The Slumdog Phenomenon: A Critical Anthology (2013). Most recently, he co-edited The Evolution of Song and Dance in Hindi Cinema (2019), a special issue of the journal of South Asian Popular Culture. His previous work on Bond and Bollywood appears in the second edition of The James Bond Phenomenon: A Critical Reader (2009). 



\title{
4. The Dead Are Alive: The Exotic Non-Place of the Bondian Runaway Production
}

\author{
Melis Behlil, Ignacio M. Sánchez Prado, and Jaap Verheul
}

\begin{abstract}
This chapter dissects the opening sequences of Skyfall (2012) in Istanbul and Spectre (2015) in Mexico City in order to argue that Eon's predilection for runaway productions has begun began to influence the textual composition of the James Bond film series. Eon Productions often modifies the narratives and settings of its Bond features in order to exploit the increasingly global availability of funding schemes, tax incentives, and cheap labor, and to secure, on a global scale, profitable distribution deals, enhanced visibility, and greater revenues from merchandizing. In the process, the Bondian runaway production fashions a colonial imaginary of exotic non-places, which has since long been a staple of the brand of Bond.
\end{abstract}

Keywords: runaway production; Global South; exoticism; non-place; Mexico City; Istanbul

From the outset, the James Bond film series was conceived as a runaway production. Bond-producer Harry Saltzman, a Canadian born in Quebec, relocated to the United Kingdom in the mid-1950s, where he founded Woodfall Film Productions with director Tony Richardson and writer John Osborne in 1958, famously engendering a wave of British Kitchen Sink classics such as Look Back in Anger (UK: Tony Richardson, 1959). In 1961, while at Woodfall, Saltzman secured an option on nine Bond novels from Ian Fleming but struggled to complete the financing for the films. It is at this stage that the second producer of the Bond film series, Albert R. Broccoli, an Italian-American hailing from New York, entered the picture. Broccoli

Verheul, J. (ed.), The Cultural Life ofJames Bond: Specters of oo7. Amsterdam: Amsterdam University Press, 2020 DOI 10.5117/9789462982185_CHO4 
moved to the United Kingdom in the early 1950s, setting up Warwick Films with Irving Allen in 1951. Warwick's base in the UK granted Broccoli and Allen the distinct benefits of a "runaway production:" it enabled the duo to circumvent the British quota requirement; to tap into the resources of the Eady Levy, a British fund that subsidized domestic film production through a tax imposed on ticket sales; to bypass tax regulations in the United States; to hire high-skilled laborers that were considerably cheaper than those available in Hollywood; and to retain creative freedom in the production process. Although Warwick produced a string of profitable action films in the first half of the 1950s - including Bond-director Terence Young's The Red Beret (UK: 1953) — the studio's prospects were short-lived due to mounting financial difficulties on the one hand, and Broccoli's growing interest in the Bond novels on the other. When Broccoli learned that Saltzman had secured an option from Fleming but grappled with the financing of the films, he proposed a partnership (Chapman 2007, 39-43; Balio 2009, 254-55; Behlil 2016, 88-89; Walker 1974, 178-85; Woollacott 2009, 117-24).

Saltzman took up Broccoli's proposition, after which the duo entered into a series of prolonged negotiations with United Artists (UA) that lingered into the principal photography for the first Bond-feature, Dr. No (UK: Terence Young, 1962), and would not be completed until April 1962, when UA agreed to finance and distribute the film adaptations of seven Bond novels. In return, United Artists was allowed to proceed with the purchase of each new Fleming novel while it also acquired the films' exclusive distribution rights for a period of ten years and secured the copyright on many of the franchise's creative idiosyncrasies. The agreement between United Artists and Saltzman and Broccoli shaped what Janet Woollacott (2009, 119-20) has referred to as the "Bondian" formula, stipulating, as James Chapman $(2007,43)$ has observed, "the production arrangement for the Bond films for decades to come." If historians of the film series have stressed the pivotal influence of Saltzman and Broccoli on the brand of Bond, it is important to remember that United Artists, too, regulated the franchise's industrial and textual composition.

Indeed, United Artists endorsed Saltzman's and Broccoli's decision to produce the James Bond film series in the United Kingdom. In terms of the franchise's industrial configuration, Chapman $(2007,43-44)$ suggests that the Bond series corresponded to United Artists' "British production strategy" in the early 1960 , which facilitated the production of such classics as the The Beatles-vehicle A Hard Day's Night (UK: Richard Lester, 1964). The narrative, setting, and cultural politics of Fleming's Bond novels permitted UA to comfortably position the oo7-films in this lineage of "British" 
cultural production. Moreover, the decision to shoot the Bond films at the Pinewood Studios in Buckinghamshire must be understood, according to Woollacott $(2009,118)$, "in the context of the British film industry and its interrelationship with Hollywood" in the 195os and 196os, a liaison that was itself shaped by an "industrial context characterized by constant financial crisis" in both the United Kingdom and the United States. In Hollywood, the crisis of the studio system in the 1950s and 196os encouraged American producers to explore new opportunities for production overseas: the UK became, together with France, Italy, and Germany, one of the key sites for such American runaway productions in Western Europe.

While Hollywood, as Daniel Steinhardt $(2013,148)$ has argued, "certainly reaped the rewards of European financial incentives and cheap labor," it is equally true that the often-debilitated film industries of post-war Europe were eager to attract US film production, capital, labor, and know-how in order to bring European film industries "into contact with Hollywood firms and financing, creating opportunities for coproduction deals, and eliciting the rebuilding of an infrastructure that had suffered during the war." This was no less true in the United Kingdom, where, as Sue Harper and Vincent Porter $(2003,1-2)$ have observed, the 1950 s marked a period of transition for the British film industry. Induced in part by the structural under-capitalization of the film industry, post-war British film policy actively pursued the influx of inward investment from the United States, dismantling protectionist legislation in support of Britain's domestic film industry to such ends. The "distributors' quota," which required both distributors and exhibitors to account for a minimum of "British pictures" on British screens, was abolished, while the Board of Trade loosened its criteria for the definition of a "British film," enabling US studios to reap the benefits of British funding schemes and tax incentives. "Rather than heavily taxing the Americans' sterling earnings," Harper and Porter (2003, 6) elaborate, British film policy "now afforded them a strong financial incentive to invest in the production of British films" (Harper and Porter 2003, 114-36; Chapman 2007, 39-40).

The benefits of a runaway production persuaded the North American producers of the Bond series to launch the film franchise in the United Kingdom in the early 196os. The assets of the Eady Levy were evident to Broccoli, who ("Britain" 1978, 4; quoted in Chapman 2007, 40) claimed that the British film fund "was the carrot that induced American production to come here [to the UK]." In line with United Artists' British production strategy and the financial and logistical perks of producing Bond in Britain, Broccoli and Saltzman established the production company Eon Productions 
in London in 1961, followed by the inauguration of Danjaq S.A. in Lausanne, Switzerland, in 1962, which subsequently became the parent company of Eon, now its subsidiary. Eon would produce all films in the "official" James Bond series, operating predominantly from its headquarters in London as well as the Pinewood Studios in Buckinghamshire. Danjaq was established as the holding company that would regulate the copyright and trademarks of the cinematic brand of Bond. With the operations of the Bond franchise split between the United Kingdom (Eon, Pinewood), Switzerland (Danjaq), and the United States (United Artists and, later, Danjaq), the Bond series was, from its inception, a truly transnational enterprise; an early articulation of what Toby Miller and Marie Claire Leger $(2001,103)$ have referred to as the "New International Division of Cultural Labor" (NICL) in which the production of the Bond films signified "the close historic relationship between the film industry and finance capital" that encouraged investors in film production to explore opportunities abroad in order to "spread risk and investment as widely as possible." This transnational, post-Fordist mode of film production in the 1960 s gradually evolved into what Camille Johnson-Yale $(2017,14)$ has identified as the global, "late capitalist" runaway venture in the early twenty-first century, in which the James Bond film series has become a pivotal node in a worldwide network of conglomerate competition (Chapman 2007, 43-44; Balio 2009, 258-59; Behlil 2016, 89; Storper 1994, 203-15).

This chapter argues that film financing began to influence the textual composition of the Bond films in this "late capitalist" context. The Bondian runaway production encapsulated both of these dimensions: Eon often modified the narratives and settings of its Bond features in order to exploit the increasingly global availability of funding schemes, tax incentives, and cheap labor, and to secure, on a global scale, profitable distribution deals, enhanced visibility, and greater revenues from merchandizing. In the process, the Bondian runaway production fashioned an exotic imaginary of the Global South that had since long been a staple of the brand of Bond. While the series' second instalment, From Russia with Love (UK: Terence Young, 1963), was predominantly set in Istanbul, Eastern Europe, and the Balkans, the majority of its scenes were in fact in fact shot at the Pinewood Studios and in other locations across the United Kingdom in order to qualify the production for the Eady Levy, which required at least 70 percent of the film to be shot in Great Britain or the Commonwealth - as had been the case with the first feature in the series, $\mathrm{Dr}$. No, a blatantly colonial venture that was set in Jamaica and shot on location only months before Jamaica gained its independence from the United Kingdom in August 1962. From the 
outset, then, the Bond films bred a peculiar exoticism: a colonial imaginary of the Global South dreamed up, written, and produced in a Britain at the twilight of Empire.

A change occurred in 1967 with the release of You Only Live Twice (UK: Lewis Gilbert, 1967), the first Bond feature to be shot almost entirely on location - in Japan. James Bond would return to East and Southeast Asia for the production of The Man With the Golden Gun (UK: Guy Hamilton, 1974). Although Fleming's source novel had been set in Jamaica, Saltzman favored a more orientalist flavor after the tropical exoticism of Roger Moore's first outing as 007 in Live and Let Die (UK: Guy Hamilton, 1973), which was set and shot on location in Louisiana and Jamaica. The Bondian runaway production entered yet another stage in the late 1970s when Broccoli produced Moonraker (UK/France: Lewis Gilbert, 1979) under the auspices of the Anglo-French co-production treaty, signed between the UK and France in 1979 in order to pool resources, facilitate international distribution, and collaborate in the face of the increasingly global hegemony of Hollywood (Jäckel 1996, 87-88). Never before had the textual composition of a Bond film been altered so capaciously: filmed at the Pinewood and Shepperton studios near London as well as the Boulogne, Billancourt, and Epinay studios near Paris, Moonraker's Californian iconography had in fact been prefabricated in France, with the Chateau de Vaux-le-Vicomte standing in for the Californian lair of Bond-villain Hugo Drex (Michael Londsdale). Moonraker signaled the end of an era in which the Bond films could have been identified as "British;" henceforth, the Bond films would be co-financed, produced, and distributed by Eon's partners in the US By the late 1980s, Licence to Kill (UK/Mexico/ USA: John Glen, 1989) had become the first Bond feature to relocate its production from Pinewood to an offshore location. The producers decided to shoot the film at the Churubusco Studios in Mexico City because the Eady Levy had been dismantled in 1985 while the exchange rate and cheap labor in Mexico also proved lucrative. Conveniently, the production of Licence to Kill in Mexico allowed the franchise to tap into the tropical exoticism of its Caribbean imaginary while adding a distinct Latin American flavor, thus aligning the film's textual composition with the economic benefits of the Bondian runaway production.

This chapter demonstrates, firstly, that we must understand the appearance of these Bondian exotic spaces as a consequence of the franchise's long-standing predilection for runaway productions. It suggests, secondly, that the Bondian runaway production constructs these "othered spaces" as "non-places" in order to advance an exotic imaginary of the Global South that sustains the colonial world of Bond as dreamed up by Fleming. The chapter 
dissects the opening sequences of two recent Bond entries, Skyfall(UK/USA: Sam Mendes, 2012) in Istanbul and Spectre (UK/USA/Austria/Mexico/Italy/ Morocco: Sam Mendes, 2015) in Mexico City, in order to argue that the Bond features of the twenty-first century reflect a broader trend in which the offshore runaway venture increasingly shapes the cultural politics of the late-capitalist film franchise. This imperial imaginary corresponds, in turn, to the financial, economic, and logistic perks of the runaway production, often relegating national film crews to second-tier cinematic labor while allocating them limited levels of creative input in the imagination of their local geographies on the western screen.

\section{Skyfall and the Grand Bazaar of Istanbul}

James Bond is no stranger to Istanbul. Long before Skyfall, From Russia with Love was set and shot in Turkey's largest city at the height of the Cold War, while The World Is Not Enough (UK/USA: Michael Apted, 1999) returned Bond to Istanbul at the end of the twentieth century. Istanbul's popularity grew in the following decade, when the city became an attractive backdrop for a number of international productions that over time grew in size: from the independent espionage thriller Fay Grim (USA/Germany: Hal Hartley, 2006) and two Bollywood films to such increasingly more lavish features such as Tinker Tailor Soldier Spy (UK/France/Germany: Thomas Alfredson, 2011) and Ben Affleck's Academy Award-winning Argo (USA: Ben Affleck, 2012), which chose Istanbul both as the backdrop for some of its scenes and as a stand-in for the Iranian capital of Tehran. Looking at these films, one notices that many of them are action-adventure flicks with a spy-twist. Yet while the city is rather conveniently distinguished by its narrow streets and dark alleys and by a history of Cold War espionage, Bond may have helped to set the tone for these runaway espionage thrillers with From Russia with Love in the sixties.

When Skyfall returned to Istanbul in April 2012 for the shooting of its opening sequence in which 007 crosses the city's rooftops by motorcycle, the production infringed on Istanbul's civic life while imposing itself on its urban spaces. Eminönü, one of the biggest squares of the old city-where the two main waterways of Istanbul (the Golden Horn and the Bosphorus) meet along the Spice Bazaar and (slightly below) the Grand Bazaar-, was closed off to vehicular and pedestrian traffic, generating some inconvenience and much curiosity. Shoppers and tourists dwell the area during the day while it also accommodates heavy traffic, both of which remain invisible in 
the film presumably because these urban markers failed to answer to the exotic image of a "Middle Eastern marketplace." The production also used the rooftop of the Grand Bazaar for its elaborately choreographed chase sequence, which ends with Bond's motorcycle crashing spectacularly into the Bazaar. While shooting this scene, the windowpane of a jewelry store inside the Bazaar was destroyed when a stuntman smashed it, igniting a heated debate in the local press on the film's production in the city.

The choice of Istanbul as the backdrop for the always-spectacular opening sequence of a new Bond film nonetheless generated excitement among the city's inhabitants and was covered extensively and with considerable pride in local media outlets. Yet the secrecy surrounding the shoot, aggravated by the sealing off of such a bustling area of the city and the destruction of the jeweler's windowpane, turned the press against Bond. There were reports of substantial damage to the Bazaar and concerns about its roof being destroyed by the motorbikes. A few days after the news on the stuntman's window-crash had emerged, Bond producer Michael G. Wilson and Turkish line producer Ali Akdeniz (2017) held a joint press conference in order to reassure the public that everything was under control, that none of the original tiles on the roof were being driven on, and that the only damage caused had not been to the Bazaar but to the jeweler's window, which they were eager to compensate. There were also reports that the Cultural Protection Agency, which is responsible for the classification and protection of the city's cultural and natural resources, was going to evaluate the situation and that "Bond might have to go to jail" (Çalık 2012) for the damage inflicted, but ultimately there was no civil court against 007 .

The production of Skyfall required substantial logistical planning and support, and the Turkish state intervened only at this level. Municipalities collaborated with the production team by closing off streets for principal photography while providing the permits required to do so. Although the Ministry for Culture and Tourism regularly states its intention to attract productions from around the globe, the Turkish state does not offer tax incentives to international productions, and little is done in terms of actual policy change. The only tax rebate applies to the Value Added Tax (VAT), which is a rather limited scheme. The producers of Skyfall thus approached Turkish Airlines, a national company, in their search for alternative forms of support, but no deal was reached as Turkish Airlines demanded significant product placement.

During the production in Turkey, both the above-the-line crew and most of the employees in the one tier below were either British or American, while much of the equipment was shipped in from the UK and the US as 
well. The production team hired about 150 employees from the local film industry, and several hundred more for such services as security and driving. According to one below-the-line member of the local film crew, the working conditions were good, especially in terms of the transfer of know-how. Doruk Yavuz (2017), in charge of the vehicles used on set, testified that the Bond production team cooperated fully with local employees while granting them significant responsibilities as well. The second unit worked in Turkey for eleven weeks, shooting the film's opening sequence in Istanbul and Adana, where 007 presumably falls to his death after having been shot from the Varda Bridge, as well as in Fethiye, where Bond is seen recovering on the beach. According to line producer Ali Akdeniz (2017), it was the Varda Bridge that convinced the producers to relocate the opening sequence to Turkey, as it called for an imposing railroad bridge. Turkey, then, became a runaway site for Skyfall not because Istanbul was seen as a desirable backdrop or because of Bond's historical ties to the city, but because there happened to be a conveniently located bridge nearby.

When Skyfall was released in Turkey in November 2012, its promotion did not rely on the film's opening sequence in Istanbul. The first emails to local critics from the publicity coordinator at Warner Bros., the film's distributor, were translations of a global advertising campaign highlighting the fiftieth anniversary of the first Bond film, 1962's Dr. No. There was just one sentence reminding press delegates that parts of Skyfall had been shot "in our country" (Kutlu 2012). While the press picked up on this rather peculiar omission, it failed to cover it extensively. And although Skyfall had the highest box office earnings of all of Daniel Craig's outings as 007 in Turkey-its success on the Turkish market should not be overestimated as it corresponded to the film's global box office takings-public criticism on social media scrutinized the market scene and lamented how Istanbul was shown only very briefly and made to look like an imaginary "Middle Eastern city." Many critics also compared this portrayal with that of Shanghai later in the film, which it depicts as modern, sleek, and polished.

Indeed, the representation of Istanbul in Skyfall turned out to be a rather exoticizing affair. The opening sequence takes place in an "oriental-looking" market that does not exist and had been constructed exclusively for the film on Eminönü Square. It then moves seamlessly and within seconds from the narrow streets of Istanbul to a highway and then to the Adana railroad, while Istanbul and Adana are 900 kilometers apart and Fethiye is another 800 kilometers to the west. The following scenes in Fethiye, moreover, lack local markers and the location is simply presented as an idealized exotic beach. The film's depiction of the Grand Bazaar, meanwhile, follows an orientalist 
iconography that has, in turn, been strategically exploited by the Bazaar's store owners, eroding the appeal of the Bazaar for Istanbul's inhabitants while transforming the site into a leading tourist destination. Indeed, the branding of Istanbul and its promotion abroad often capitalizes on this image of the city as "the capital of the Orient." Criticized for contributing to such "self-orientalization" (Uysal 2013), promotional videos for the city as well as the music video for Turkey's 2003 Eurovision winner "Every Way that I Can" - shot in a Turkish bath and replete with belly dancers-all partook in this exoticizing trend. Skyfall, by contrast, manages to deviate its orientalizing aesthetics away from such sexist clichés, marking some progress in comparison to 1963's From Russia with Love and its exoticist depiction of Gypsy women engaged in a catfight, and of the belly dancer who dominates Robert Brownjohn's credit sequence for the film.

\section{Spectre and the Day of the Dead in Mexico City}

It is hard to tell how often western media have imagined a holiday tradition in a foreign country, but Spectre accomplished such a feat. On November 1, 2016, Mexico City held its first Día de los Muertos (Day of the Dead) parade, recreating a fictional event featured in the opening sequence of Spectre, in which James Bond (Daniel Craig) chases Marco Schiarra (Alessandro Cremona) through an intricate maze of Day of the Dead festivities. From the very beginning, Mexico City's Board of Tourism, which only rarely finances cinema, acknowledged the singular opportunity provided by the arrival of 007 in Mexico. "When this movie hit the big screen and was seen by millions and millions of people in 67 countries," the board's CEO (Stevenson 2016) declared, "that started to create expectations that we would have something." Yet this was an opportunity that had itself been manufactured. The Mexico City government had offered twenty million dollars in tax incentives to the Bond franchise, an amount that exceeds the budget of nearly any Mexican production, allegedly demanding a positive portrayal of the country and the city in return. According to reports based on the emails that were leaked as a result of the hack of Sony Pictures in 2014, Mexico City secured a number of concessions in the script, such as the removal of a cage match, the casting of the first Mexican Bond Girl (Stephanie Sigman as Estrella, who was added at a later stage and only has one line of dialogue), the demand that film's villain would not be Mexican, and the elimination of a scene in which the city's mayor would be assassinated (Young 2015). The city, then, sought the removal of western, exotic elements that might have depicted the country 
as violent, and promoted instead such Mexican-approved stereotypes as the now-famous iconography of the skull.

While the exuberant sum of the tax credit would outrage anyone familiar with the dire straits of the Mexican film industry, it is important to acknowledge the strides made by city officials in stipulating such stringent demands for the textual composition of Spectre. The Bond franchise had used Mexico City as an exotic location before: historical buildings such as the National Post Office, the Grand Hotel, the City Theater, and the Spanish Casino all substituted as fictional settings for the imaginary Latin American Republic of Isthmus in Licence to Kill, for which many scenes were also shot at the Churubusco Studios in Mexico City as well as in Acapulco and the Otomí Ceremonial Center in Temoaya. Iconic Mexican actors like Claudio Brook, Juan Peláez, and Jorge Russek appeared only in minor roles, while Pedro Armendáriz Jr., at the time the most visible Mexican actor in Hollywood, starred as Isthmus's Latin American dictator, President Hector Lopez. Licence to Kill's faux Latin America is corny exoticism at its worst: a tropical paradise with absurd urban undertones that masks the culture and society of the country where the film was shot. The Timothy Dalton vehicle erased Mexico completely, burying the country's rich architecture and national talent under an exotic imaginary of Latin America in which its corrupt citizens and officials must be put in place by a civilized British spy.

Spectre's opening sequence is, by contrast, perhaps the least dire and offensive portrayal of Mexico City in contemporary Euro-American cinema. Following the release of Licence to Kill in 1989, Mexico City was transformed into a key runaway site for Hollywood's dystopian imagination. Total Recall (USA/Mexico: Paul Verhoeven, 1990) used such urban landmarks as the Mexico City subway system and the Military College for the visualization of its futurist dystopia, while Romeo+Juliet (USA/Mexico/Australia: Baz Luhrman, 1996) deployed a multitude of locations in Mexico City and the port city of Veracruz to envision its violence-ridden, vertiginous Verona Beach. In the twenty-first century, western representations of Mexico City began to acknowledge the city as its own urban space but were still not free of derision. One may recall the dizzying Man on Fire (USA/UK/Mexico/ Switzerland: Tony Scott, 2004) or Amores Perros (Mexico: Alejandro González Iñárritu, 200o), which addressed urban crime and economic inequality in a way that the foreign gaze could readily exoticize. Spectre, on the other hand, allowed Mexico City to partially construct a counterimage to the generally demeaning representation of Mexico on the western screen. If the politics of luring Bond to Mexico City were somewhat questionable because the film participated in the Mexican state's whitewashing of endemic social and 
political concerns - such as the concurrent waves of feminicide and the widely-covered disappearance of 43 students in Iguala-, it is equally true that many Mexicans considered the carefully crafted image of downtown Mexico City a necessary counterpoint to the Speedy-González aesthetic associated with films as recent as The Mexican (USA/Mexico: Gore Verbinski, 2001), and to the anti-Mexican rhetoric that would crystallize in the United States only a few months later during the presidential campaign of then Republican candidate Donald Trump.

It remains difficult to ascertain why Mexicans became so taken with this fictional image of themselves, but the premiere of Spectre in Mexico City - which, scheduled on the Day of the Dead (November 2) in 2015, granted the city the film's first official screening in the Americas-received an overwhelmingly positive response in Mexico. In addition, the production of the opening sequence became itself a source of both fascination and controversy. The front page of Reforma, one of Mexico's most important newspapers, covered the daily shoot of Spectre and reported on the discontent of local business owners in a series of stories that chronicled the compensation they received for closures and lost revenues as well as for the restoration of Mexico City's iconic Zócalo square, which had been damaged during the shoot of the helicopter skirmish that closes the sequence. By the time of Spectre's premiere, such controversies were by and large forgotten while the opening sequence, which has limited narrative purpose in relation to the rest of the plot, was lauded by most Mexican spectators.

Unlike Licence to Kill, which had featured recognizable Mexican actors in small parts with dialogue, Spectre awards little screen time to Mexican performers. Tenoch Huerta and Adriana Paz, two actors with a significant career, are credited as "Mexican Man in Lift" and "Mexican Woman in Lift" for the cameo in which we can spot them kissing behind Bond and Estrella in a hotel elevator. Stephanie Sigman is one of the most influential Latin American actors of her generation, but the perfunctory role she performs in Spectre turns her into one of the franchise's most forgettable Bond Girls. Although Sigman's career outside of Mexico seems to have benefited little from her cameo in Spectre, she was nonetheless instrumental for the promotion and marketing of the film in Spanish language markets. Moreover, one could also point out - as The Hollywood Reporter (Giardina 2015) did — that the opening sequence's use of the long take is stylistically indebted to the aesthetics of such renowned Mexican auteurs as Alejandro González Iñárritu and Emmanuel Lubezki. This process of cultural appropriation would account for the lack of continuity in the film's representation of the urban geography of Mexico City, in which Bond and Estrella walk for half a block from the Tolsá 
Square to the Grand Hotel (a location also used in Licence to Kill), which are almost seven blocks apart. To appropriate a cinematic style popularized by well-known Mexican filmmakers speaks volumes about the ways in which western blockbusters territorialize symbolic capital and intellectual labor originating from alternative cinemas and national traditions.

The painstaking labor that went into the cinematic imagining of the Day of the Dead parade benefited from the contribution of a local collective of arts majors and artisans, who were able to render the imaginary of the Día de los Muertos in a contemporary and non-exoticist fashion. The extras who occupied the streets of Mexico City were subject to careful dressing and make-up and were modelled on the Catrina figure, a skeleton character created in the late-nineteenth century by graphic artist José Guadalupe Posada, who devised the bony structure to mock the upper classes. The Catrina figure, which has become a globally recognized symbol of the Day of the Dead since the release of Spectre, enabled the artists and craftsmen- and women to create a parade that appeared modern - the Catrina figure was meant to represent an urban character - while mostly shunning the folkloric typecasting or the trite exoticism that had hampered earlier depictions of Latin America in the Bond franchise. It is noteworthy that the significant creative and aesthetic input of local Mexican talent in the creation of the parade's iconography engendered one of the least exoticist portrayals of a Latin American nation in contemporary western filmmaking. Spectre's Day of the Dead opts for a modern depiction of the holiday, which is usually celebrated in cemeteries and relies on older styles of craft. The film's opening scene signals a departure from, for example, the animated feature The Book of Life (USA: 2014), in which animator-director Jorge Gutiérrez and producer Guillermo del Toro advance a more traditionalist approach that relies on a small-town and folkloric imaginary. Spectre, by contrast, develops an urban aesthetic for the Day of the Dead that brings the festivities to Mexico City by replicating its blend of folklore and modernity: a musically vertiginous procession of stylized Catrinas parading against the backdrop of the city's nineteenth-century colonial architecture.

\section{The Global South in James Bond}

In spite of these representational strides and the creative input of local talent, the Bondian tourist gaze of Istanbul and Mexico City subscribes to a mode of exoticism that, according to Graham Huggan (2001, 44-45), operates as a "semiotic circuit that oscillates between the opposite poles of strangeness 
and familiarity [...], a particular mode of aesthetic description [that] renders people, objects and places strange even as it domesticates them, and which effectively manufactures otherness even as it claims to surrender to its imminent mystery." Daniel Craig's twenty-first century exploits sustain the semiotic circuit of the Ian Fleming novels from the 1950s, which themselves, as Sam Goodman $(2015,145-47)$ has demonstrated, sought to preserve an Edwardian fantasy of an ordered, hierarchical, and benevolent Empire at the turn of the twentieth century. Fleming's tales of Cold War espionage consolidated the late-Victorian literary genres of the crime fiction and the imperial adventure novel while tapping into an instantly identifiable image of exoticized otherness in order to construct an 'empty stage' of colonial space [which had been] prefigured as an arena for adventure, excitement, and leisure only for the 'best' people" (150). In like manner, Skyfall and Spectre construct Istanbul and Mexico City as empty stages for oo7's neo-imperial ventures in the twenty-first century, offering a tourist imaginary of these urban geographies which otherwise lack a sense of narrative, emotional, ideological, or geopolitical purpose.

This lack of purpose differentiates Skyfall and Spectre from earlier entries in the series. Published in 1957, Fleming's From Russia, with Love appeared at a time when Cold War tensions were mounting and public interest in espionage had increased due to a series of spy scandals in the early 1950s, most notably the widely-covered defection of two British spies, Guy Burgess and Donald Maclean, to the Soviet Union in 1951. This backdrop of Cold War espionage allowed Fleming to devise a spy adventure that offered a topical and a slightly satirical take on Britain's increasingly antagonistic relationship with the Soviet Union. The novel articulated a strong anti-Soviet sentiment, as evinced in the reappearance of the Soviet counterintelligence agency SMERSH, which seeks to take revenge on Bond and MI6 for the killing of its agents by luring 007 to Istanbul. "The use of Istanbul as a locale for much of the action," Jeremy Black $(2001,29)$ argues, "both presented the reality of a location of East-West intelligence operations and confrontation and offered the opportunity of describing a place that could be gritty and exotic." In 1952, Turkey had joined the North Atlantic Treaty Organization (NATO), further aligning itself with the United Kingdom in 1955 when it signed the Baghdad Pact, a military alliance between Turkey, Iran, Iraq, and Pakistan who, backed by the United Kingdom, sought to create a protectionist umbrella against both Soviet expansionism and Arab nationalism. Henceforth, the West considered Turkey a pivotal ally in its Soviet "containment strategy," regarding Istanbul as a central node in the increasingly global web of Cold War espionage because its central position on the Bosphorus enabled western 
intelligence services to surveil Soviet naval operations and missile tests (Dodds 2003, 137). Fleming's 1957 novel reflected these topical concerns and exploited them to enhance the story's appeal, famously eliciting US President John F. Kennedy to include it in his top-ten-list of favorite novels in a 1961 interview for Life magazine.

The film adaptation of From Russia, with Love, released in 1963, played down the anti-Soviet stance of Fleming's novel by replacing SMERSH with the rogue syndicate SPECTRE, enabling the films to introduce, according to Klaus Dodds (2005, 281), a dual vision of political space in which the world of Bond is "dominated by territorial nation-states in the midst of a Cold War and a second global system infiltrated by a trans-boundary network of criminals using nation-states merely as bases for their activities." In this geopolitical mirage, Chapman (2007,74-75) reminds us that 007 is still very much engaged in a conflict with Russia-especially in comparison to From Russia with Love's predecessor, the blatantly colonial $\mathrm{Dr}$. No, as well as any subsequent entry in the series until the 1980s, when films such as For Your Eyes Only (UK: John Glen, 1981) and The Living Daylights (UK: John Glen, 1987) once again positioned oo7's exploits in a setting of Cold War espionage. As Rosa Klebb (Lotte Lenya), From Russia with Love's iconic Bond-villain, proclaims in the film's opening act, "Who can the Russians suspect but the British? The Cold War in Istanbul won't remain cold very much longer." Indeed, when 007 roams the Grand Bazaar and its adjacent alleys, the film's picturesque rendition of Istanbul is very much tapping into a popular fantasy of glamorous espionage on the Bosphorus.

In like manner, the franchise's latent desire for imperial salience established Mexico City as an expedient production site for the exotization of a faux Latin America in Licence to Kill. Although the second Timothy Dalton vehicle did not attribute any geopolitical or narrative significance to Mexico itself, the film nonetheless reflected the thaw in Soviet-NATO relations at the end of the 1980 s while it also reciprocated the longstanding tropical exoticism at the heart of Fleming's worldview. As Vivian Halloran has persuasively argued, Fleming structured his web of global espionage on an idea of Caribbean space centered on Nassau, the Cayman Islands, Haiti, Cuba, the Bahamas, and Jamaica while adding the US states of New York, Louisiana, and Florida to this tropical amalgam. In this staunchly imperial realm, Halloran $(2005,176)$ posits, Fleming "pits the ghosts of England's colonial past against the specters of international communism; it serves as a meeting point for Old and New Worlds as well as a place from which to articulate a hybrid cultural identity." Fleming's imaginary of the Caribbean-evinced most clearly in Live and Let Die (1954) and Dr. No 
(1958), which are both set in Jamaica - thus articulates a dual geopolitical topicality. First, Fleming's Caribbean sphere is, as Goodman $(2015,147)$ suggests, reflective of Britain's imperial decline after World War II and of its reciprocal desire to develop a new and "special" relationship with the United States in order to reimagine its own position in the twentieth-century version of the Great Game. Second, Dr. No and Live and Let Die allowed Fleming to envisage a Caribbean realm under British rule, thereby disavowing both the liberation of British overseas territories and, as Cynthia Baron (2009, 164) has observed, the postcolonial migration from the West Indies, India, and Pakistan to the United Kingdom in the 1940s, 50s, and 6os.

Fleming's personal connection to Jamaica and the West Indies-he was involved in intelligence-operations in the region during World War II and wrote most of the Bond novels at his Goldeneye estate in Jamaica-enabled him to imbue his tropical exoticism with these two colonial fantasies of British imperial prowess. In doing so, Goodman (2015, 152-53) claims, Fleming revitalized a colonial vision of Jamaica — and by extension, the Caribbean-as "a way of combining Cold War political objectives and contemporaneous British industrial recovery" in order to "reinvigorate the relevance of colonial space in the Cold War." Licence to Kill sustains this desire. The film's faux "Latin American" setting allowed the producers to circumvent the imminent disintegration of the Soviet Union in the late 1980 s, thereby propelling 007 into the post-Cold War world that would come to define the film series from 1995's GoldenEye (UK/USA: Martin Campbell) onward. Licence to Kill, then, carries considerable geopolitical weight because it seeks to disavow the backdrop of the Cold War that had still featured eminently in the earlier Bond films of the 1980 .

In terms of the film's tropical exoticism, moreover, Black (2001, 151) observes that the fictional Isthmus City operates as a surrogate for a renewed Anglo-American interest in Latin America during the 1980s. For American audiences, the drug empire of Franz Sanchez (Robert Davi), the film's villain, reverberated with the military dictatorship of Manuel Antonio Noriega Moreno (1983-1989) in Panama. Noriega had come to power in 1983 with support from the Central Intelligence Agency (CIA) because the US government considered the General a pivotal ally in its policing of Nicaragua and its renewed commitment to the War on Drugs. After Noriega fell out of favor, the United States invaded Panama in 1989 and convicted him for drug trafficking after a trial in Miami in 1992. For British audiences, meanwhile, the plot and setting of Licence to Kill carried echoes of the Falklands War of 1982, during which the Argentinian military junta (1976-1983) occupied the Falkland Islands and the South Georgia and South Sandwich Islands, 
which provoked a military response from the British government of Margaret Thatcher. Although the islands were eventually returned to British control, the war had awakened nationalist sentiments in the United Kingdom while reviving interest in Latin American politics in the process.

The production of Licence to Kill in Mexico "made sense," then, because it reflected the geopolitical role of Latin America in East-West relations on the one hand while sustaining the tropical imaginary at the heart of Fleming's worldview on the other. In Skyfall and Spectre, by contrast, such geopolitical justifications for narrative or ideological space are absent. The tourist imaginary of their opening sequences abandons Fleming's exoticism in favor of a postcard aesthetics devoid of the urgency that marked the franchise's prior exploits in Turkey and Mexico. In the Craig-era, oo7 has little interest in the Global South as he rampages through Istanbul and Mexico City before returning to the United Kingdom: the only space that holds any geopolitical and emotional significance in both films, thereby establishing Skyfall and Spectre as two of the most unapologetically "British texts" in the franchise. Istanbul and Mexico City, however, serve little purpose-narrative or geopolitical or ideological or emotional or otherwise-and are accordingly reduced to exotic non-places.

\section{The Exotic Non-Place of the Bondian Runaway Production}

The perception of place as a "natural category" shapes human subjectivity in that civil society constructs individual and collective identities-indeed, imagined communities - through place, whether, as Elena Gorfinkel and John David Rhodes (2011, ix) put it, "by our embrace of a place, our inhabitation of a particular point in space, or by our rejection of and departure from a given place and our movement toward, adoption and inhabitation of, another." At the same time, place also operates discursively in that it serves a myriad of human interests, cultural formations, and ideological applications. It is therefore actively worked upon and in a permanent state of transformation. At the level of representation, moreover, place operates as a mobile signifier that connotes not just a singular geography-be it "natural" or "discursive" — but also a secondary set of meanings, practices, ideas, and values associated with the place.

The Bondian non-places of Skyfall and Spectre offer the spectator an instantly recognizable tourist gaze of Istanbul and Mexico City that unfolds beyond the diegetic world of the film frame. Unlike the dreamed-up exoticism of Isthmus City in Licence to Kill, part of the appeal of these 
opening sequences is that the audience immediately identifies their material presence in some of the key heritage sites of Turkey and Mexico. At the same time, this postcard aesthetics also operates in a discursive register in which these depictions of Istanbul and Mexico City articulate a longstanding imperial fantasy of what these "other" geographies signify to western audiences. In doing so, they sustain the restorative colonial world as dreamed up by Fleming in his Cold War novels from the mid-twentieth century. In the exotic non-places of Skyfall and Spectre, the urban diegesis is constructed from this tourist mapping of both cities, expressed most clearly in the recreation of the fictional Día de los Muertos parade in Mexico City in November 2016 - which has since come to transcend the profilmic world of Spectre in that the procession has now become a recognizable symbol for the growing popularity of Day of the Dead celebrations across the globe.

For Marc Augé (1995), non-places emerged in a specifically late-capitalist context in which subjects find themselves in a state of transit, passing anonymously through spaces that are outside of the spatial-temporal continuum of modernity and consequently lack historical subjectivity. In the non-places of the postcolonial world, Sandra Ponzanesi $(2012,689)$ argues, "people are trapped by their anonymity, immobilized in a time without events, stripped of their humanity." In the process, she elucidates (667-78), "regimes of otherness are organized and enforced, creating a laboratory for what the perfected society at home should be, far away from the center but imprinted with its model of inclusion and exclusion." The Bondian non-place regulates otherness and difference in a similar fashion, positioning the Global South outside of modernity, which, as Homi K. Bhabha $(1991,205)$ has argued, has historically delineated colonial space as, on the one hand, "the empty or wasted land whose history has to be begun" and, on the other hand, as "space without places, time without duration." In the exotic non-places of the Bond films - often former colonies of Britain - the Global South is governed either by rogue organizations such as SPECTRE or by renegade entrepreneurs such as Franz Sanchez. In doing so, the world of Bond forges an imaginary of the Global South in which, as Black (2004, 300) has observed, "these countries are ungoverned, ripe for exploitation by international megalomaniacs, and waiting for the order [...] brought by Western intervention in the shape of Bond." The opening sequences of Skyfall and Spectre sustain this tradition. Skyfall lacks noteworthy characters and actors of Turkish origin altogether, while Spectre reduces its noteworthy Mexican performers to exotic ornaments that decorate Sam Mendes's elaborate, four-minute tracking shot which opens the film. Moreover, these 
sequences perpetuate the exotic iconography of Istanbul and Mexico City, thereby deepening this erasure of otherness and difference as both cities find themselves trapped in time, outside of history, and under the subjugation of a British modernity in the figure of Bond.

The franchise's late-capitalist predilection for runaway productions augments the on-screen visibility of the Bondian non-place. The setting of so many Bond adventures - be they literary or cinematic - in the Global South reflects what Stephanie Hemelryk Donald $(2005,140)$ has referred to as a "thin cosmopolitanism" that, in the case of the Bond brand, suggests a globally inclusive narrative realm while effectively reducing the heterogeneity of culture, location, and character to a façade in the service of a British nostalgia for imperial order. The runaway production, Hemelryk Donald elucidates, sustains this eurocentric status quo because the local meaning of place is subsumed to the economic, financial, and ideological interests of conglomerated movie studios, production houses, and film distributors such as Eon, Danjaq, MGM, Sony, and Universal — which exploit the global reach of Bond in order to benefit from the international division of cultural labor. The Bondian runaway production thus merges its thin cosmopolitanism with the outsourcing of studio space, locations, post-production facilities, and high-skilled personnel in the film industries of the Global South in order to consummate the series' lavish opening sequences, which in turn seek to restore the exotic worldview that has demarcated the brand of Bond since Fleming's tropical, mid-twentieth-century fantasy of the Caribbean. "This is the point," Hemelryk Donald (2005, 141-42) explains, "at which outsourcing fundamentally alters the meaning of location, as the phenomenology of a place is de-specified to the financial benefits of producing [elsewhere]."

Skyfall and Spectre, then, engender a process of resignification in which the exotization of Istanbul and Mexico City operates as a semiotic circuit that oscillates between strangeness and familiarity in order to construct a lateimperial fantasy that reaffirms Britain's continued relevance on the world stage. Both cities are reduced to exotic non-places because economically, Barbara Selznick $(2005,157)$ explains, "it makes sense that the easiest path is to abandon specificity of place and remain vague." The thin cosmopolitanism of the Bond franchise maps Istanbul and Mexico City as spaces that 007 must traverse in order to allow the hero to keep "his sights on finding or returning to his place: a home or a community that helps to define him and motivate his actions" (165). Indeed, it is the maternal womb of the nation that bestows a sense of purpose upon Skyfall and Spectre, which restoratively imagine the United Kingdom as the only place that holds meaning in the world of Bond, thereby going against the grain of all previous Bond features which, as we 
have seen, had worked so arduously to soften the "Britishness" of the brand. In Skyfall, London and the Scottish Highlands operate as oedipal sites for 007's maternal histrionics with M (Judi Dench) in order to articulate Bond's loyalty to queen and country. In Spectre, 007 travels across Europe and Northern Africa only to return to the headquarters of MI6 by the Thames for his penultimate showdown with Ernst Stavro Blofeld (Christoph Waltz), his oedipal nemesis, on Westminster Bridge. Initially considered as Daniel Craig's swansong to the franchise, Spectre sees 007 drive off into the sunrise in his immaculately restored Aston Martin-destroyed so symbolically in the finale of Skyfall - with the Houses of Parliament looming on the horizon, thus going at great lengths to assure its audience that the millennial Bond is still very much on her majesty's secret service.

\section{Works Cited}

Akdeniz, Ali. 2017. Interview with the author, March 13, 2017.

Augé, Marc. 1995. Non-Places: An Introduction to an Anthropology of Supermodernity. London: Verso.

Balio, Tino. 2009. United Artists, Volume 2, 1951-1978. Madison, WI: University of Wisconsin Press.

Baron, Cynthia. 2009. "Doctor No: Bonding Britishness to Racial Sovereignty.” In The James Bond Phenomenon: A Critical Reader (Second Edition), edited by Christoph Lindner, 153-68. Manchester, UK: Manchester University Press.

Behlil, Melis. 2016. Hollywood is Everywhere: Global Directors in the Blockbuster Era. Amsterdam: Amsterdam University Press.

Bhabha, Homi K. 1991. "'Race,' Time and the Revision of Modernity." Oxford Literary Review 13 , no. 1/2, Neocolonialism: 193-219.

Black, Jeremy. 2001. The Politics ofJames Bond. London: Praeger.

Black, Jeremy. 2004. “The Geopolitics of James Bond." Intelligence and National Security 19, no. 2 (Summer): 290-303.

"Britain 'Turning People Out' Says Bond Producer." 1978. Screen International, September 9, 1978.

Çalık, Burcu. 2012. “Kapalıçarşı'yı Tahrip Eden o07'ye Hapis Yolu." Sabah, May 27, 2012, http://www.sabah.com.tr/yasam/2012/05/27/kapalicarsiyi-tahrip-edenoo7ye-hapis-yolu.

Chapman, James. 2007. Licence to Thrill: A Cultural History of the James Bond Films, Revised Edition. London: I.B. Tauris.

Dodds, Klaus. 2003. "Licensed to Stereotype: Popular Geopolitics, James Bond and the Spectre of Balkanism." Geopolitics 8, no. 2 (Summer): 125-56. 
Dodds, Klaus. 2005. "Screening Geopolitics: James Bond and the Early Cold War Films (1962-1967)." Geopolitics 10, no. 2 (Summer): 266-89.

Donald, Stephanie Hemelryk. 2005. "The Ice Storm: Ang Lee, Cosmopolitanism, and the Global Audience." In Contracting Out Hollywood:Runaway Productions and Foreign Location Shooting, edited by Greg Elmer and Mike Gasher, 140-56. Lanham, MD: Rowman \& Littlefield.

Giardina, Carolyn. 2015. "How Spectre's Opening Scene Pulled Off the Birdman Effect." The Hollywood Reporter, November 6, 2015, http://www.hollywoodreporter. com/behind-screen/how-spectres-opening-scene-pulled-836200.

Goodman, Sam. 2016. British Spy Fiction and the End of Empire. New York: Routledge. Gorfinkel, Elena, and John David Rhodes. 2011. "Introduction: The Matter of Places." In Taking Place: Location and the Moving Image, edited by John David Rhodes and Elena Gorfinkel, vii-xxix. Minneapolis: University of Minnesota Press.

Harper, Sue, and Vincent Porter. 2003. British Cinema of the 1950s: The Decline of Deference. Oxford, UK: Oxford University Press.

Halloran, Vivian. 2005. “Tropical Bond.” In Ian Fleming and James Bond: The Cultural Politics of oo7, edited by Edward P. Comentale, Stephen Watt, and Skip Willman, 158-177. Bloomington, IN: Indiana University Press.

Huggan, Graham. 2001. The Postcolonial Exotic: Marketing the Margins. London: Routledge.

Jäckel, Anne. 1996. "European Co-Production Strategies: The Case of France and Britain." In Film Policy: International, National, and Regional Perspectives, edited by Albert Moran, 85-96. London: Routledge.

Johnson-Yale, Camille. 2017. A History of Hollywood's Outsourcing Debate: Runaway Production. London: Lexington Books.

Kutlu, Duygu. 2012. E-mail message to author, October 3, 2012.

Miller, Toby, and Marie Claire Leger. 2001. "Runaway Production, Runaway Consumption, Runaway Citizenship: The New International Division of Cultural Labor." Emergences:Journal for the Study of Media \& Composite Cultures 11, no. 1 (May): 89-115.

Ponzanesi, Sandra. 2012. “The Non-Places of Migrant Cinema in Europe.” Third Text 26, no. 6 (November): 675-90.

Selznick, Barbara. 2005. "World-Class Budgets and Big-Name Casts: The Miniseries and International Coproductions." In Contracting Out Hollywood: Runaway Productions and Foreign Location Shooting, edited by Greg Elmer and Mike Gasher, 157-76. Lanham, MD: Rowman \& Littlefield.

Steinhardt, Daniel. 2013. "A Flexible Mode of Production: Internationalizing Hollywood Filmmaking in Postwar Europe.” In Behind the Screen:Inside European Production Cultures, edited by Petr Szczepanik and Patrick Vonderau, 135-51. New York: Palgrave Macmillan. 
Stevenson, Mark. 2016. "Mexico City's First Day of the Dead Parade Inspired by James Bond Film Spectre." The Hollywood Reporter, November 1, 2016, http://www. hollywoodreporter.com/news/mexico-citys-first-day-dead-parade-inspired-byjames-bond-film-spectre-94288.

Storper, Michael. 1994. "The Transition to Flexible Specialisation in the US Film Industry: External Economies, the Division of Labour and the Crossing of Industrial Divides." In Post-Fordism: A Reader, edited by Ash Amin, 195-226. Malden, MA: Blackwell.

Uysal, Ülke Evrim. 2013. "Branding Istanbul: Representations of Religion in Promoting Tourism." Place Branding and Public Diplomacy 9 (4): 223-35.

Walker, Alexander. 1974. Hollywood in the UK: The British Film Industry in the Sixties. London: Stein and Day.

Woollacott, Janet. 2009. "The James Bond Films: Conditions of Production." In The James Bond Phenomenon: A Critical Reader, Second Edition, edited by Christoph Lindner, 117-35. Manchester, UK: Manchester University Press.

Yavuz, Doruk. 2017. Interview with the author, May 6, 2017.

Young, James. 2015. "Mexico Reportedly Paid Millions to Hollywood for Better Portrayal in Upcoming 007 Film." Vice News, March 23, 2015, https://news.vice. com/article/mexico-reportedly-paid-millions-to-hollywood-for-better-portrayalin-upcoming-007-film.

\section{About the Authors}

Melis Behlil is an Associate Professor of Cinema Studies and Chair of Radio, Television and Cinema Department at Kadir Has University in Istanbul, Turkey. She has been a visiting scholar at Massachusetts Institute of Technology, a Research Associate at Stockholm University, and a member of the Global Women's Cinema Network. Her book, Hollywood is Everywhere: Global Directors in the Blockbuster Era was published with Amsterdam University Press in 2016. In addition to teaching and other academic duties, she writes film reviews for various publications, co-hosts a weekly radio show, and is a member of the Turkish Film Critics Association.

Ignacio M. Sánchez Prado is Jarvis Thurston and Mona Van Duyn Professor in the Humanities at Washington University in St. Louis, and President of the Association for the Study of the Arts of the Present. He is the author of seven books, including Screening Neoliberalism: Transforming Mexican Cinema (1988-2012) (2014) and Strategic Occidentalism: On Mexican Fiction, the Neoliberal Book Market and the Question of World Literature (2018). He is 
currently completing a book tentatively entitled The Transnational Paradox: Mexican Film and the International Division of Cinematic Labor. He has edited thirteen collections, including Pierre Bourdieu in Hispanic Literature and Culture (2018) and Mexican Literature in Theory (2018). He has published over one hundred scholarly articles on Mexican and Latin American literature, cinema and gastronomy, as well as on cultural and literary theory.

Jaap Verheul is a Lecturer in Film Studies Education at King's College London, where his research focuses on transnational flows of cultural production and distribution in European media industries. He obtained his Ph.D. in Cinema Studies from New York University, and has been a visiting scholar at the École Normale Supérieure in Paris and the Freie Universität in Berlin. He has written on the dual monolingualism of contemporary Flemish cinema (in The Multilingual Screen, 2016), on the co-production of a European heritage brand for television (in Screening European Heritage, 2016), on the fluctuating stardom of various James Bond performers (in Lasting Screen Stars, 2016), and is currently completing his monograph on the formation of European film and television industries after 1989. 


\title{
5. Bond Rebooted: The Transnational Appeal of the Daniel Craig James Bond Films
}

\author{
Huw D. Jones and Andrew Higson
}

\begin{abstract}
The James Bond films starring Daniel Craig are amongst the most globally successful films of the twenty-first century. The transnational appeal of these films can only be partly explained by their textual attractions, such as the way they play out ideas of British identity. Much of their success depends on the business of Bond, from rights ownership to distribution. Focus group interviews with audiences in continental Europe also reveal an ambivalence about whether the Bond character and the Bond films are perceived as British or American. This ambivalence extends the appeal of the films to different audiences. This chapter therefore provides new insights into Bond's enduring transnational appeal.
\end{abstract}

Keywords: James Bond, audience research, British national identity, film distribution, film industry

James Bond may be a British agent, but the Bond film franchise is by any definition a global phenomenon. It is one of the longest running movie franchises, with 24 films dating back to the first release in 1962, and the second most lucrative franchise, amassing some $\$ 7$ billion at box-offices around the world (The Numbers 2016a). According to the American Statistical Association, “20\% of the world's population has seen at least one Bond film" (Young 2014).

The four most recent Bond films starring Daniel Craig as Agent $007-\mathrm{Ca}$ sino Royale (UK/Czech Republic/USA/Germany/Bahamas: Martin Campbell 2006), Quantum of Solace (UK/USA: Marc Foster 2008), Skyfall (UK/USA: Sam

Verheul, J. (ed.), The Cultural Life ofJames Bond: Specters of oo7. Amsterdam: Amsterdam University Press, 2020 DOI 10.5117/9789462982185_CHO5 
Mendes 2012) and Spectre (UK/USA/Austria/Mexico/Italy/Morocco: Sam Mendes 2015) — continue the pattern of global success. Skyfall grossed \$1.1 billion worldwide, making it the fifteenth most successful film of all time in terms of worldwide box office revenue (Box Office Mojo 2016a), and the most successful Bond film ever (The Numbers 2016b). Between them, the four Craig Bonds have taken over $\$ 3$ billion at the worldwide box office, with all of them in the 125 highest-grossing films of all time (Box Office Mojo 2016a).

The Craig Bond films were conceived as a "reboot" of the Bond film franchise. Casino Royale is set at the beginning of Bond's career as Agent 007, and the story arc continues across Quantum of Solace, Skyfall and Spectre. At the time of writing, Craig is due to appear in one more Bond film-No Time To Die (UK/USA: Cary Joji Fukunaga, 2020), the twenty-fifth in the franchise, with a 2020 release - so that story arc is clearly not yet complete. There is a wealth of scholarly commentary on the Craig Bond reboot, but most of it is in the form of theory-led textual readings (Lindner 2010; Cox 2014; Hasian 2014; Dodds 2014; Anderson 2017; Murray 2017). This chapter sets out to do something different, to explore why this particular cycle of Bond films has been such a global success.

There is of course nothing particularly new about this success, since the Bond franchise has always achieved impressive international distribution and box-office success. What is new is the research about European distribution arrangements and audience reception on which we draw for this study of the most recent entries in the Bond franchise. We explain the transnational appeal of these films partly through their textual attractions, including their high production values, their formal and generic qualities, the way they play out ideas of British national identity, and the balance between continuity and change. We also consider how the appeal of the films depends on the business of Bond, from the ownership of the rights, to the distribution of the films. We focus in particular on how the Craig Bond film were distributed in Europe - a market which, as box-office figures demonstrate, represents about one third of the worldwide revenue for the Bond films, but also one which presents particular challenges in terms of negotiating access to different national and linguistic territories. Finally, we examine how the films have been received by audiences in Europe through the analysis of survey data and focus groups conducted in Germany, Italy and Bulgaria. Audience research of this kind is still relatively rare within film studies and (to our knowledge) has not previously been used in work on the Bond film franchise. One of the points that emerges from this research is an ambivalence about whether the Bond character and the Bond films are British or American-an ambivalence which actually extends the 
appeal of the films to different audiences. This chapter therefore provides new insights into Bond's enduring transnational appeal in a global context, but especially within the context of Europe's changing film market and its diverse social, cultural and political landscape.

\section{Bond's Formula for Global Success}

Bond historian James Chapman (2003) suggested four key reasons for the sustained success of the Bond film franchise over several decades: consistently high production values; spectacular visual qualities-notably fast-paced action, dramatic stunts and special effects; the play on British national identity; and, most importantly for Chapman, the ability of the producers to "find the right balance between repetition and variation, between continuity and change." As Chapman explains, this process of both maintaining and renewing the formula means that each film "provide[s] the sort of entertainment pattern which audiences expect while at the same time providing new thrills, new set pieces, new variations on old situations" (Chapman 2003, 94). The success of the rebooted Bond of the Daniel Craig era has depended precisely on this ability to update the formula, but also on the fact that, for all its apparent "Britishness," the franchise is an integral part of the global business that is Hollywood.

With an average production budget of about $\$ 200$ million (26 times the budget of the first Bond film, even after taking inflation into account), the production values of the Craig Bond films have remained high (The Numbers 2016b). Both Casino Royale and Skyfall won the Art Directors Guild "Excellence in Production Design Award," one of Hollywood's top creative prizes. Visual qualities also remain a key feature. From the free-running chase across the roof-tops and building sites of the Madagascan capital in the opening sequence of Casino Royale, to Bond's extended fist-fight with the mercenary Patrice on top of a speeding train at the start of Skyfall, the Craig Bond films are still packed with fast-paced action, special effects and sheer spectacle. As another Bond chronicler, John Brosnan (cited in Chapman 2003, 92), observed, such qualities have the capacity to appeal to "a large international audience because they are able to bypass language and cultural barriers and appeal directly to people of various nationalities and age groups."

Chapman $(2003,95)$ argues that Bond's Britishness is an important part of his international appeal, partly because it serves as "a means of differentiating Bond from the all-American action heroes" that feature in so 
many other Hollywood films. This illustrates Andrew Higson's (2010, 71) argument that "banal markers of national identity" can "become exotic signifiers of difference in the global marketplace.” As Chapman $(2003,97)$ further notes, Bond's Britishness is "carefully packaged for the international market" through combining Britishness with elements of internationalism and cosmopolitanism. Thus, Bond is not parochially British, but "very much the Englishman [sic] abroad, a professional tourist whose job (saving the world from diabolical masterminds) takes him to exotic foreign locations" (Chapman 2003, 97).

In the Craig Bond films, Bond remains identifiably British-and indeed English. In Skyfall, for instance, during the psychological word association test which Bond must complete before his return to the field, he resolutely replies "England" in response to the prompt "country." And at the end of the film Bond appears on the rooftop of the MI6 building, facing the British flag, with the Houses of Parliament and Big Ben prominently positioned in the London skyline behind, visually symbolizing the British nation-state. At the same time, Bond remains a global, cosmopolitan traveler, and an imperialist adventurer: across the four films he visits Uganda, Madagascar, the Bahamas, the USA, Montenegro and Italy (Casino Royale); Haiti, Austria, Italy, Bolivia and Russia (Quantum of Solace); Turkey, Bali and China (Skyfall); and Mexico, Italy, Austria and Morocco (Spectre).

Bond's Britishness was further underlined when Daniel Craig appeared as Bond alongside Queen Elizabeth II in the short spoof film made for the opening ceremony of the London Olympics in 2012. The film culminated with the Queen appearing in person at the Olympic stadium after apparently descending from a helicopter with a British flag parachute in a scene which parodied the iconic opening sequence to The Spy Who Loved Me (UK/USA: Lewis Gilbert, 1977). As part of the build-up to the Olympics, Bond also appeared prominently within the government-backed "Britain Is GREAT" promotional campaign, which aimed to encourage tourism and inward investment to the UK (BBC News 2011).

According to the UK Government's (2014, 8-9) review of the campaign, "Over 20 Embassies and High Commissions held Bond-themed receptions and screenings to promote Britain as a world-class tourism destination to influential local audiences and highlight the strengths of the British film-making industry and Bond-related British products such as the new Jaguar." While it is beyond the scope of this chapter to explore the values associated with these "hypotextual" materials in any detail, they nevertheless demonstrate the way in which Bond has become an important instrument of soft power, projecting an image of Britain to the world. 
In presenting the Craig Bond films as a reboot, the process of renewing the franchise, balancing out continuity and change, became very evident. A key part of that reboot was the casting of a new actor, Daniel Craig, in the role of Bond, a decision which initially raised eyebrows when it was first announced in October 2005-Craig was chiefly criticized for not fitting Fleming's original portrait of Bond as "tall, dark and suave." The decision was eventually vindicated when critics widely praised Craig's performance in Casino Royale for combining "Sean Connery's athleticism and cocksure swagger with Timothy Dalton's thrilling undercurrent of stone-cold cruelty" (The Times, cited in BBC News 2006). The casting of Craig thus represented both a sense of continuity with previous Bond actors, and innovation, as a new actor who didn't initially seem to meet Fleming's requirements.

The reboot also took Bond back to the beginning of his spy career, thereby removing some aspects of narrative continuity with previous Bond films. But in other respects, the narratives of the Craig Bonds adhered to the well-established traditions of the franchise. Thus, they still feature many of the familiar Bondian plot elements-briefings at Headquarters from $\mathrm{M}$ and $Q$, numerous seduction scenes with often incidental female characters, high-octane chase sequences and fights, the showdown with the villain, and so on. Many of the same characters reappear across the Craig Bonds, including M, Q and Miss Moneypenny, as well as Bond's occasional CIA ally Felix Leiter and a series of more or less stereotypical "Bond girls" and villains. They also contain references to earlier Bond films, such as the Aston Martin $\mathrm{DB}_{5}$ that is bought back into service at the end of Skyfall, or the scene in Casino Royale in which an impressively muscled Bond emerges from the sea wearing a very snug pair of swimming trucks, an apparently "accidental" pastiche of the moment when Ursula Andress stepped out of the sea in Dr. No (UK: Terence Young 1962) (Singh 2008).

Other key characters have also received a makeover. Miss Moneypenny, for example, is reintroduced in Skyfall as a field agent played by Naomie Harris, a black female character with much more narrative agency than the desk-bound secretary who appears in the earlier Bond films. Similarly, Q, the MI6 Quartermaster, returns in Skyfall as a young computer "geek" played by Ben Whishaw - in an era of teenage hackers, perhaps a more apt depiction of the twenty-first-century technical expert than the ageing white-coated laboratory "boffin" played for many years by Desmond Llewellyn.

Another key aspect of the Bond "reboot" is the way in which the Craig films have brought what commentators have observed as a "more serious tone" to the franchise (Eisenberg 2014). This is not to suggest that earlier Bond films should not be taken seriously_as the academic literature on Bond 
makes clear, the Bond films have always raised big questions about gender, sexuality, national identity, geopolitics, the film industry and so on (Lindner 2010; Chapman 2007). What is distinctive about the Craig Bond films is that they feature elements that, within contemporary film culture, are more often associated with character-based dramas and auteur-driven films within the arthouse market than with popular, mainstream action-adventure movies. In particular, the films explore Bond's character and psychology in greater depth than earlier films in the franchise. As Variety's Todd McCarthy (2006) put it in a review of Casino Royale, "Dialogue requires Bond to acknowledge his mistakes and reflect on the soul-killing nature of his job, self-searching unimaginable in the more fanciful Bond universes inhabited by Brosnan and Roger Moore." The Craig Bonds also feature a number of actors more associated with "serious" drama or non-English language films, including Danish actor Mads Mikkelsen (as the villain Le Chiffre in Casino Royale); the Oscar-winning Spanish actor Javier Bardem (as the ex-MI6-operativeturned-cyberterrorist Raul Silva in Skyfall); and the Palme d'Or-winning French actor Léa Seydoux (as the "Bond girl" Madeleine Swann in Spectre). In addition, Skyfall and Spectre were directed by Oscar-winning director Sam Mendes, a recognized "auteur" also more associated with "serious" dramas than action-adventure movies. Once again, there is a complex process of repetition of elements associated with previous Bond films and the difference of the re-boot.

These attempts to make Bond appear more "serious" can be seen as a response to developments within the international film market, recalling Chapman's $(2003,95)$ observation that the Bond franchise has consistently "responded to and survived changes in the film industry, film culture and society at large," keeping pace with changing tastes and attitudes. The 1990s and early 20oos saw a series of highly successful comic films-most notably the Austin Powers movies and the Johnny English films-which lampooned the spy genre and the Bond franchise in particular (the Johnny English character was actually created by Neal Purvis and Robert Wade, the writers of the most recent Bond films). Meanwhile, action spy thrillers had begun to take on a more intelligent and realistic tone with the equally successful Jason Bourne films, directed by former journalist and documentary filmmaker, Paul Greengrass. The Jason Bourne franchise, which to date has grossed $\$ 1.6$ billion worldwide over the course of five films, an average of \$327 million per film (Box Office Mojo 2016b), featured a more complex and flawed hero and less of the jokey, tongue-in-cheek irony associated with the Bond films. The Craig Bonds seem to draw on some of the qualities of the Bourne films (e.g. the hero's soul-searching 
vulnerability) while avoiding the clichés lampooned by the Austin Powers and Johnny English films.

To be sure, the Craig Bond films are still littered with spectacularly implausible and fantastic set-pieces, along with equally spectacular scenery and locations, copious sequences featuring violent masculine aggression, moments of tongue-in-cheek humor and overt displays of the conventionally beautiful bodies of a series of "Bond girls" who one way or another succumb to Bond's charm. There is also nothing new about attempts to give Bond a more serious tone. As one 007 observer recalls, John Glen's first outing as director of For Your Eyes Only (UK: John Glen, 1981) in 1981 was seen as "a turning point in the series," introducing "a more serious side of Bond" (007 James 2016). Nevertheless, the Craig Bond films have gone much further than previous Bond films in terms of re-positioning them as "serious" drama, thereby seeking to renew the appeal of the franchise.

\section{The Business of Bond: Exploiting the Rights in Europe}

What this analysis of the films suggests is that the success of the Craig Bond films can certainly be put down in part to what we see on screen-the production values, the action and spectacle, the relationship between British national identity and global tourism, and the continuity and reinvention of characters, themes and scenarios. At the same time, the success of the Craig Bond films is also due in part to the business strategies exploiting the franchise.

The Craig Bond films were co-produced by London-based Eon Productions and the Hollywood studio Metro-Goldwyn-Mayer (MGM). Eon is a private company created in 1961 by two North American film producers, Albert "Cubby" Broccoli and Harry Saltzman, both by then resident in the UK and involved in the UK film industry. Eon is still owned and run by Broccoli's daughter, Barbara Broccoli, and his stepson, Michael G. Wilson. MGM acquired a share of the copyright to the Bond film franchise from the United Artists Corporation in 1981, who themselves bought these rights from Saltzman after he sold his shares in Eon's holding company, Danjaq, in 1975. The Craig Bond films also involved Japanese-owned Sony Pictures Entertainment, which acquired a 20 percent stake in MGM in 2005, and Sony's studio subsidiary, Columbia Pictures, which co-produced Skyfall and Spectre with Eon after MGM's bankruptcy in 2011. The twenty-fifth installment, No Time To Die (2020), will be a joint venture between Eon, MGM, Annapurna Pictures, and Universal, who will take over international 
distribution. With the exception of Casino Royale (which was mainly shot in the Czech Republic), the films themselves were primarily produced in the UK, where they were able to gain additional financing through Britain's film tax relief system, which offers a 25 percent cash rebate on qualifying UK expenditure. They were also able to exploit production support in many other countries, notably the Bahamas. Thus, while Bond and many of the people who work on the films are British, the films are essentially transnational productions, formally registered as UK/US inward investment features, with 50 percent of the funding coming from Hollywood (Fritz 2011).

The distribution of the Craig Bond films also speaks to the extraordinary complexity of the global film business. Between 1997 and 2005, MGM owned the distribution rights for the Bond films. However, in purchasing a 20 percent stake in MGM in 2005, Sony secured the distribution rights for the Craig Bond films (Mendelson 2016). In the United States, the films were distributed by Sony's studio subsidiary, Columbia. In the rest of the world, distribution involved a veritable network of corporate subsidiaries, regional powerhouses and even small independents. Meanwhile, the home entertainment (DVD and BluRay) release was handled by Sony Pictures Home Entertainment for Casino Royale, and 2oth Century Fox Home Entertainment in the case of the other three Craig Bond films.

The European market, which generated about a third of the global revenue for the recent Bond films, presents a particular challenge for the Bond franchise, as with all other Hollywood-affiliated films. Whereas the United States (which together with Canada forms the "North American" market) is treated as a single domestic market with one language, Europe is a highly fragmented market made up of numerous different territories and language groups, in some of which there are strong local or regional distribution companies. Within Europe, the theatrical release of the four Craig Bonds was handled by national branches of Sony Pictures Releasing in around eight territories, including the big five European markets of the UK, Germany, France, Spain and Italy. However, there were some exceptions: Casino Royale was released in France by Gaumont Columbia TriStar, while Skyfall and Spectre were released in Italy by Warner Bros. (Table 1). Sony also released all four films in Austria and Belgium, countries that share a language with one of the "big five" European countries (Germany and France respectively); for less obvious reasons, they also distributed three of the films in the Netherlands, two of them in Sweden, Estonia and Croatia, and one in Russia (jointly with Walt Disney).

By far, the majority of the European box-office income was derived from the territories where Sony released the Bond films (in particular the "big five"). In 
Table 1. Cinema admissions and distributors for Skyfall in Europe.

Source: LUMIERE 2016.

\begin{tabular}{|c|c|c|c|c|}
\hline Market & Distributor & $\begin{array}{l}\text { Release } \\
\text { date }\end{array}$ & Admissions & $\begin{array}{l}\text { Penetration } \\
\text { rate }\end{array}$ \\
\hline Austria & Sony Pictures (AT) & 01/11/2012 & 792,022 & $9.77 \%$ \\
\hline Belgium & Sony Pictures Releasing (BE) & $26 / 10 / 2012$ & $1,081,429$ & $10.56 \%$ \\
\hline Bulgaria & Forum Film (BG) & 19/10/2012 & 158,653 & $1.94 \%$ \\
\hline Croatia & Sony Pictures Releasing (HR) & $01 / 11 / 2012$ & 152,507 & $3.56 \%$ \\
\hline $\begin{array}{l}\text { Czech } \\
\text { Republic }\end{array}$ & Forum Film (CZ) & $26 / 10 / 2012$ & 489,653 & $4.76 \%$ \\
\hline Denmark & SF Film (DK) & $26 / 10 / 2012$ & 943,627 & $17.70 \%$ \\
\hline Estonia & Acme (EE) & $02 / 11 / 2012$ & 99,023 & $6.88 \%$ \\
\hline Finland & SF Film Finland [FS Film] & $26 / 10 / 2012$ & 647,440 & $12.51 \%$ \\
\hline France & Sony Pictures Releasing (FR) & $24 / 10 / 2012$ & $7,005,962$ & $11.83 \%$ \\
\hline Germany & Sony Pictures Releasing (DE) & $01 / 11 / 2012$ & $7,779,852$ & $9.47 \%$ \\
\hline Greece & Feelgood & & 581,553 & $5.51 \%$ \\
\hline Hungary & Forum-Hungary & $25 / 10 / 2012$ & 398,786 & $3.97 \%$ \\
\hline Italy & Warner Bros. (IT) & $31 / 10 / 2012$ & $1,900,284$ & $3.30 \%$ \\
\hline Latvia & Forum Cinemas (LV) & $02 / 11 / 2012$ & 84,114 & $3.47 \%$ \\
\hline Norway & SF Norway & $26 / 10 / 2012$ & 742,765 & $16.58 \%$ \\
\hline Poland & Forum Film (PL) & $26 / 10 / 2012$ & $1,672,893$ & $4.39 \%$ \\
\hline Portugal & ZON Lusomundo Audiovisuais & $25 / 10 / 2012$ & 474,720 & $4.75 \%$ \\
\hline Romania & Forum Film Romania & $26 / 10 / 2012$ & 305,445 & $1.36 \%$ \\
\hline Russia & $\begin{array}{l}\text { Walt Disney Studios Sony } \\
\text { Pictures Releasing }\end{array}$ & $26 / 10 / 2012$ & $3,241,165$ & $2.22 \%$ \\
\hline Slovakia & Forum Film Slovakia & $26 / 10 / 2012$ & 155,612 & $2.88 \%$ \\
\hline Slovenia & Continental Film (SI) & $31 / 10 / 2012$ & 111,929 & $5.63 \%$ \\
\hline Spain & $\begin{array}{l}\text { Sony Pictures Releasing De } \\
\text { Espana }\end{array}$ & $30 / 10 / 2012$ & $1,486,293$ & $3.77 \%$ \\
\hline Sweden & SF Film (SE) & $26 / 10 / 2012$ & $1,087,546$ & $12.27 \%$ \\
\hline Switzerland & Walt Disney $(\mathrm{CH})$ & $27 / 10 / 2012$ & $1,186,874$ & $16.57 \%$ \\
\hline $\begin{array}{l}\text { The } \\
\text { Netherlands }\end{array}$ & Sony Pictures Releasing (NL) & $01 / 11 / 2012$ & 288,367 & $1.81 \%$ \\
\hline Turkey & Warner Bros. (TR) & $02 / 11 / 2012$ & 635,649 & $0.99 \%$ \\
\hline UK & Sony Pictures Releasing (GB) & $26 / 10 / 2012$ & $16,147,235$ & $25.66 \%$ \\
\hline EUREU & & & $43,692,438$ & \\
\hline EUR OBS(36) & & & $49,651,405$ & \\
\hline
\end{tabular}

other, less lucrative European markets, distribution was handled by a plethora of other companies, including other major Hollywood studio subsidiaries (e.g. Walt Disney/Buena Vista, Columbia TriStar Warner, UIP and Universal) and independent distributors (e.g. Sena, Nordisk, Itafilm, Continental, Falcon, Intercom, Acme, SF, Feelgood, Myndform and Lusomundo). The distribution of the Craig Bond films in Central and Eastern Europe (CEE) makes for an 
interesting case study. Forum Films started out releasing the first two films in Bulgaria but, for the last two films, they also distributed to cinemas in the Czech Republic, Hungary, Poland, Romania and Slovakia. Forum Films has strong ties with Hollywood majors and is the distribution subsidiary of Cinema City International, the largest cinema chain in the seven CEE countries. Cinema City is itself part of Global City Holdings, which was absorbed into Cineworld in 2014, making it the second largest cinema chain in Europe, with a substantial share of the UK market, as well as Ireland, Israel and CEE. This is then no small local firm but a major regional and now European player with extensive interests and capital (Cineworld Group Plc 2016).

This set of arrangements demonstrates a number of key features of the global film business, including its complexity, but also the various ways in which the Hollywood majors maintain control over that business. Sometimes this is through their own direct actions, sometimes through subsidiaries and sometimes through arms-length arrangements with other large corporations but also with much smaller independent companies, especially in less lucrative markets such as Central and Eastern Europe. The success of the Craig Bond films is in large part due to the involvement of Hollywood majors that are able to tap into this network of distribution agents.

Despite the variety of different companies involved in the distribution of the Craig Bond films, the marketing campaign for these films had remarkable consistency across Europe and North America. The same trailers, posters and other publicity material were used in the majority of territories. One noticeable difference, though, was the language Bond spoke. In large non-English-speaking countries such as Germany, France, Spain and Italy, for example, the Craig Bond films were dubbed into local languages. In other non-English-speaking territories, the films were shown in their original version but with local language subtitles. Thus, to a degree, the Craig Bond films-like all major Hollywood films, including inward investment "British" blockbusters-were adapted to suit local preferences.

\section{The Audience Reception of Bond in Europe}

The success of the Bond film franchise is dependent not only on negotiating the complexities of the global film industry, but also on its ability to speak to audiences of different ages, genders, nationalities and socio-economic backgrounds. In terms of reviews, responses to the Craig Bond films were mixed. According to the Rotten Tomatoes website, which aggregates film reviews in the English-language press, 95 percent of the reviews for Casino 
Royale (out of a sample of 246) and 93 percent of the reviews for Skyfall (out of a sample of 347) were positive (Rotten Tomatoes 2006; 2012). However, in the case Quantum of Solace and Spectre, only 65 percent of reviews (out of a sample of 280) and 65 percent of reviews (out of a sample of 311) respectively were positive (Rotten Tomatoes 2008; 2015). Critics seemed to prefer the films when they delved into Bond's character and psychology rather than focus on the fast-paced action and humor generally associated with the Bond franchise. Thus Casino Royale was praised for "dispos[ing] of the silliness and gadgetry that plagued recent James Bond outings, and deliver[ing] what fans and critics have been waiting for: a caustic, haunted, intense reinvention of 007 " (Rotten Tomatoes 2006), whereas Spectre was criticized for being "reliant on the established 007 formula" (Rotten Tomatoes 2015).

The "Audience Scores" on Rotten Tomatoes mirror the critics. Thus Casino Royale and Skyfall performed best with a 89 percent positive rating (out of a sample of 701,447) and a 86 percent positive rating (out of a sample of 371,828 ) respectively, compared with only a 58 percent positive rating (out of a sample of 431,021) for Quantum of Solace and 62 percent (out of a sample of 104, 678) for Spectre. However, these responses are restricted to internet users who choose to engage with a film website that is most prominent in the US and the UK, and do not necessarily represent the views of the cinemagoing population as a whole.

A more representative sample of the European audience for the Craig Bond films can be found in a recent report by the European Commission (2014) on film audiences in Europe. The survey polled 4,608 people aged 4-50 in 10 European countries (Croatia, Denmark, France, Germany, Italy, Lithuania, Poland, Romania, Spain and the United Kingdom) about their film viewing habits and interests. Respondents were asked whether they had "seen," "liked" or "heard of" a list of recent films, including Skyfall. Having secured access to the original survey data (some of which was not included in the final report), we have been able to build up a detailed profile of the European audience for one of the Craig Bond films.

Skyfall was one of the most well-known recent films included in the European Commission survey. It had been "seen" by 43 percent of respondents (the third most recognized title overall) and was "liked" by 38 percent of respondents (the fourth most popular title). Skyfall was most popular amongst British respondents ( 56 percent of whom said they liked the film), followed by French (46 percent), Croatian (50 percent) and Romanian respondents (45 percent) (Table 2). It was least popular amongst Italian respondents (26 percent of whom said they liked the film), Spanish (29 percent) and Polish respondents (35 percent). To a certain degree, this reflects the film's 
Table 2. Proportion of Europeans ( $\mathrm{N}=4608$ ) who "have seen and liked" Skyfall by various social demographic variable. Z-scores indicate the amount each variable differs from the mean value (38\%).

Source: European Commission 2014.

\begin{tabular}{|c|c|c|}
\hline Social demographic variable & $\begin{array}{l}\text { Liked } \\
\text { "Skyfall" }\end{array}$ & Z score \\
\hline British & $56 \%$ & $18 \%$ \\
\hline Male & $46 \%$ & $8 \%$ \\
\hline Watched many 'US films' in the last 12 months & $44 \%$ & $6 \%$ \\
\hline Earns $€ 2000$ euros net per month or more & $42 \%$ & $4 \%$ \\
\hline French & $42 \%$ & $4 \%$ \\
\hline $16-25$ year old & $42 \%$ & $4 \%$ \\
\hline Movie addicts & $42 \%$ & $4 \%$ \\
\hline Movie selectives & $41 \%$ & $3 \%$ \\
\hline Croatian & $41 \%$ & $3 \%$ \\
\hline Romanian & $41 \%$ & $3 \%$ \\
\hline Blockbuster lovers & $41 \%$ & $3 \%$ \\
\hline Watched many films from 'any other origin' in last 12 months & $40 \%$ & $2 \%$ \\
\hline Urban-dweller & $40 \%$ & $2 \%$ \\
\hline Watched many 'European films' in the last 12 months & $39 \%$ & $1 \%$ \\
\hline Earns $€ 1000-1499$ net per month or more & $39 \%$ & $1 \%$ \\
\hline Danish & $39 \%$ & $1 \%$ \\
\hline Graduate & $39 \%$ & $1 \%$ \\
\hline 26-34 year old & $39 \%$ & $1 \%$ \\
\hline Watched many 'country language films' in the last 12 months & $39 \%$ & $1 \%$ \\
\hline Mean value & $38 \%$ & $0 \%$ \\
\hline Post-graduate & $37 \%$ & $-1 \%$ \\
\hline Primary or Basic education & $37 \%$ & $-1 \%$ \\
\hline Semi-urban dweller & $37 \%$ & $-1 \%$ \\
\hline German & $36 \%$ & $-2 \%$ \\
\hline Lithuanian & $36 \%$ & $-2 \%$ \\
\hline Earns $€ 1500-1999$ euros net per month & $35 \%$ & $-3 \%$ \\
\hline Polish & $35 \%$ & $-3 \%$ \\
\hline $35-50$ year old & $35 \%$ & $-3 \%$ \\
\hline Earns less than 1000 euros net per month & $35 \%$ & $-3 \%$ \\
\hline Movie indifferents & $34 \%$ & $-4 \%$ \\
\hline Rural-dweller & $33 \%$ & $-5 \%$ \\
\hline Hit grazers & $30 \%$ & $-8 \%$ \\
\hline Female & $29 \%$ & $-9 \%$ \\
\hline Spanish & $29 \%$ & $-9 \%$ \\
\hline Italian & $26 \%$ & $-12 \%$ \\
\hline
\end{tabular}


box office performance. In the UK, for example, Skyfall had a 26 percent rate of penetration (in terms of admissions per head of population); in France, the rate of penetration was 12 percent and in Spain and Italy the rates were 4 percent and 3 percent, respectively (LUMIERE 2016).

The high popularity of $S k y f a l l$ amongst British respondents seems to corroborate Chapman's (2003) suggestion that British audiences are especially drawn to Bond because of the way the films patriotically celebrate a particular notion of Britishness. In a broader sense, it also confirms the cultural proximity thesis that audiences tend to prefer national stories and characters with which they are culturally familiar (Hoskins and Mirus 1988). The lower enthusiasm for Skyfall in Italy and Spain is harder to explain, but may be partly due to the fact that both countries have a strong market for their own domestic productions (e.g. Italy's Benvenuti al nord (“Welcome to the North"; Italy: Lucia Miniero 2012) or Spain's Tengo ganas de ti ("I Want You"; Spain: Fernando Gonzalez Monlina, 2012)), which occasionally outperform US blockbusters.

The survey confirms that Skyfall is significantly more popular amongst men than women ( 46 percent of men said they liked the film, compared with 25 percent of women) and also more popular with young people than older people (42 percent of 16-25 year olds said they liked the film, compared with 35 percent of $35-50$ year olds). Higher earners (with a net income of $€_{2,000}$ or more per month) tend to prefer $S k y f a l l$ to lower earners, while the level of educational qualifications makes no difference one way or the other. Again, this seems to confirm the notion that the Bond films continue to appeal to "wild adolescent fantasies" about a "world of beautiful women, easy sex and consumer affluence" (Chapman 2003, 95).

In terms of their taste in films, Skyfall fans tend to watch a high amount of US films and are most likely to be what the pollsters call "movie addicts" (42 percent) or "movie selectives" (41 percent). The former are described as "the heaviest consumers of film and media" who "watch all sorts of film" (European Commission 2014, 69). The latter "watch carefully selected films, on the more 'sophisticated' end of the spectrum, rather than Hollywood blockbusters which they see as too stereotypical, or big-hit National comedies that they see as too commercial and sometimes lacking the intellectual sophistication that they are after" (European Commission 2014, 69). This suggests that the Craig Bond films appeal to not only fans of fast-paced action films and special effects, but also audiences who prefer more "serious" drama-which was apparently was precisely what the producers had hoped to achieve.

While the data from the European Commission report allows us to identify to whom Skyfall appeals (and to a certain degree why), it tells us little about what audiences actually think about the film. To learn more about how 
European audiences have made sense of $S k y f a l l$, we conducted a series of focus groups involving 82 participants (23 in Germany, 17 in Bulgaria and 42 in Italy) from a range of different ages, genders, educational qualifications and (to a lesser degree) socio-economic backgrounds. Participants were recruited to discuss attitudes to contemporary European film in general rather than Skyfall in particular (the film was one of six "European films" discussed in each focus group). As such, their responses were not necessarily representative of the wider cinemagoing population. However, if we accept that fans of contemporary European cinema are more likely to identify with "serious" drama than most cinemagoers, then the focus groups do provide an opportunity to assess the appeal of the film's more "serious" elements.

Skyfall was very well-known across all the focus groups. About half ( 52 percent) had seen the film while another quarter (27 percent) had heard of it but not seen it. The film was most well-known amongst the Bulgarian focus group participants ( 76 percent had seen it and 18 percent had heard of it) and least well-known amongst the Italian participants (40 percent had seen it and 29 percent had heard of it), which to some extent mirrors the findings of the European Commission survey. Most of the focus group participants were also aware of earlier Bond films. Even in Bulgaria, where the archetypal Bond films of the 1960 s and 1970 s were not officially available until the post-Communist era, there was a strong recognition of the Bond franchise.

Despite its high-level of recognition, only around two in every five focus group participants said they liked Skyfall. As with the European Commission survey, the proportion was higher amongst men than women, though older participants tended to be more enthusiastic about the film than younger ones, which may reflect the fact that the focus groups were less representative of the population as a whole.

Most fans of the film said they liked Skyfall because it took Bond "back to its origins" (Italian male aged 45-54), thus confirming the argument that a key part of the appeal of the Bond films is their sense of continuity. As another Italian participant put it, "What I really liked was that, in comparison with the other 007 films, which are always full of technological stuff, this one was like vintage, simple" (Italian male aged 25-34). For older audiences who were more familiar with the early Bond films of the 196os and 1970s, Daniel Craig was seen as a worthy successor to Sean Connery, the first person to play Bond in the cinema. However, for younger audiences, whose main reference point was Pierce Brosnan, Craig was seen as a disappointment. As one German participant in his early 2os put it, "I don't like the new James Bond. Our generation just grew up with Pierce Brosnan as James Bond. For me personally that annoyed me the most" (German male aged 18-24). 
Others were drawn to Skyfall less by its elements of continuity and more by the newer aspects of the film. Thus, a handful of focus group participants suggested they liked the film because of its more "serious" tone. Often these participants (most of whom were Italians with a high level of knowledge of and interest in European film) were keen to stress they did not normally watch Bond films or action blockbusters in general. However, they made an exception with Skyfall because of the involvement of director Sam Mendes, whose films were described as "beautiful" (Italian male aged $65^{+}$) and "very well made" (Italian male aged 25-34). The involvement of the actor Javier Bardem (as Bond-villain Raoul Silva) was another reason for some audiences to watch the film, since he was seen as a "very good actor" (Italian female aged 35-44) and recognized for his Oscar-winning performance in No Country for Old Men (USA: Ethan and Joel Coen, 2007) (Italian male aged 25-34). Some also praised the emphasis which the film placed on Bond's character development and psychology. As another Italian participant put it:

I have to admit that, apart from special effects, the shootings, the explosions, the bombings, which I hate, I found that the theme was very interesting. Actually the story is about a retired 007 [sic], so it's a different angle on the character. He's not the usual super cool oo7, he's retired and shows a more human, tender side of his character (Italian female, aged 35-44).

Thus, by introducing a more serious tone, Skyfall was to a certain extent able to cross over from a mainstream audience to a more middlebrow or even arthouse audience. However, the majority of focus group participants (most of whom were fans of middlebrow dramas and arthouse films rather than of blockbuster action films) said they disliked Skyfall, because they regarded Bond films as too predictable or formulaic. This attitude was particularly common among the Bulgarian focus group participants, and seemed to exemplify a wider cynicism towards Hollywood films. As one Bulgarian respondent put it, "It's all the same, the [Bond] chick, the explosions" (Bulgarian male, aged 25-34). Others simply disregarded Bond as an "action movie," a genre described as "exaggerated," "stupid," and "unrealistic." As one Italian respondent put it, "I don't like the genre. It's all based on fantastic, imagined stories. There's no link to reality" (Italian female aged $55^{-64}$ ). This would seem to indicate that, despite moves to add a greater degree of seriousness to the recent Bond films, there remains a lingering "un-seriousness" about the franchise in the use of fast-faced action and special effects that undermines their appeal with audiences who identify with "serious" drama. 
The emphasis on action also affected how audiences perceived the national identity of the Bond films and, by implication, the Bond character. Many of the focus group participants suggested Skyfall "looks very American with all the action." For one Italian participant, the film was described as "typical americanata, a film full of special effects that costs millions of dollars" (Italian female, aged 18-34). Another (Italian male, aged 25-34), who described Skyfall as "one of my favorite films ever" and a film he had seen "fifteen times," said that he "totally forgot" that Bond was British until he was reminded by the interviewer of that fact. Even though some focus group participants recognized that "oo7 is British," they still felt the film "looks American." As one participant put it, "I know James Bond is English, but in terms of structure, and the presence of special effects, it's really in the American style" (Italian female, aged 35-44).

The suggestion that $S k y f a l l$ is an American film was particularly common amongst Italian and German focus group participants, for whom the film dialogue was dubbed into their local language, thereby erasing elements of Britishness (e.g. accents) that might have served to distinguish the film from other Hollywood imports. By contrast, Bulgarian focus group participants, who watched the film in English with Bulgarian subtitles, were more likely to regard the film as British. Nevertheless, they suggested the story and action was too far removed from reality to be seen as a realistic portrayal of British life. As one Bulgarian participant put it, "it's a fantasy" (Bulgarian male, aged 18-24).

This would suggest that Bond's national identity—even within a film like Skyfall, with its strong emphasis on British imagery and iconography-is not entirely clear from the perspective of mainland European audiences. For some audiences, especially UK audiences, Bond is clearly understood as British, and that is one of the appeals of the character and films for those audiences. For other audiences, Bond's appeal to them (or his lack of appeal) is that, contrary to Chapman's $(2003,95)$ assertion, he is not so easily differentiated in the international film market from "all-American action heroes incarnated by the likes of Mel Gibson, Bruce Willis and Sylvester Stallone." To that extent, the apparent lack of cultural specificity, or at least the ability to read the recent Bond films as both British and American, and their frequent translation into local languages, enables the films to appeal to a wide range of mainstream audiences with an equally wide range of tastes and expectations. But that same aspect of the films also makes it harder for them to appeal to arthouse audiences, who tend to prefer films with a clear sense of identity. 


\section{Conclusion}

As previous work on the Bond film franchise has argued (Chapman 2003), the appeal of Bond lies partly in the textual attractions of the films, their high production values, and their ability constantly to renew a well-established formula. While these are key features of the appeal of the Craig Bond films, it is clear that the business behind the Bond franchise is also absolutely vital to the success of the films. The involvement of Sony in particular ensured that the films not only benefited from huge budgets and heavy marketing, but were also able to negotiate access to the numerous national and linguistic territories which make up the global film market, as our case-study on the distribution of the films in Europe demonstrates.

As our audience research shows, the considerable box-office success of the Craig Bond films does not mean they were universally popular. They tended to appeal more to British audiences than film viewers in the rest of Europe, and were more popular amongst men, young people and high earners than women, older audiences and low earners. Moreover, while the films featured more "serious" elements than previous Bond films, this did not necessarily mean they appealed to audiences who tend to identify with "serious" dramas. Our focus group research also shows that, despite the numerous references to Bond's British national identity in films like Skyfall, audiences in mainland Europe do not necessarily see Bond as a British character. The use of fast-paced action and special effects, qualities many associate with American blockbusters, and the fact that the Bond films are often dubbed into local languages, serve to dilute Bond's Britishness. This would seem to undermine efforts such as the "Britain is GREAT" campaign" to use Bond as a way of projecting British national identity on the global stage. It also serves to remind us that audiences often read media texts in ways which are very different to their intended meanings.

\section{Acknowledgements}

This chapter arises from the "Mediating Cultural Encounters through European Screens" (MeCETES) project (www.mecetes.co.uk). MeCETES received funding from the Humanities in the European Research Area (HERA) Joint Research Programme (www.heranet.info) [grant number 291827]. The authors would like to thank Jessica Van Roye, Martina Lovascio and Maya Nedyalkova for their help with the focus groups, including the transcription and translation of interview transcripts. 


\section{Works Cited}

o07 James. 2016. “Top 10 James Bond Movies.” oo7 James, Accessed December 22, 2016, http://www.o07james.com/articles/top_10_james_bond_movies.php.

Anderson, Patrick. 2017. "Neocon Bond: The Cultural Politics of Skyfall." Quarterly Review of Film and Video 34, no.1: 66-92.

BBC News. 2006. “'Brilliant' Bond Seduces Critics.” BBC News, November 4, 2006, http://news.bbc.co.uk/1/hi/entertainment/6116286.stm?ls.

BBC News. 2011. "London 2012: David Cameron Launches 'Great' Campaign.” BBC News, September 22, 2011, http://www.bbc.co.uk/news/uk-15019587.

Box Office Mojo. 2016a. "All Time Box Office: Worldwide Grosses.” Accessed December 22, 2016, http://www.boxofficemojo.com/alltime/world/.

Box Office Mojo. 2016b. "Franchises: Bourne." Accessed December 22, 2016, http:// www.boxofficemojo.com/franchises/chart/?id=bourne.htm.

Chapman, James. 2003. "A Licence to Thrill." In The James Bond Phenomenon: A Critical Reader, edited by Christoph Lindner, 91-98. Manchester: Manchester University Press.

Chapman, James. 2007. Licence to Thrill: A Cultural History of the James Bond Films, Revised Edition. London: I. B. Tauris.

Cineworld Group Plc. 2016. Annual Report and Accounts 2015. Accessed December 22, 2016, http://www.cineworldplc.com/ /media/Files/C/Cineworld-PLC/reportsand-presentations/cineworld-ar15.pdf.

Cox, Katharine. 2014. "Becoming James Bond: Daniel Craig, Rebirth, and Refashioning Masculinity in Casino Royale (2006)." Journal of Gender Studies 23, no. 2:184-96.

Dodds, Klaus. 2014. "Shaking and Stirring James Bond: Age, Gender, and Resilience in Skyfall (2012)." Journal of Popular Film and Television 42, no. 3: 116-30.

Eisenberg, Eric. 2014. "Why The James Bond Franchise Isn't Goofy Anymore.” CinemaBlend, Accessed December 22, 2016, http://www.cinemablend.com/new/ Why-James-Bond-Franchise-Isn-t-Goofy-Anymore-68491.html.

European Commission. 2014. A Profile of Current and Future Audiovisual Audiences. Luxembourg: Publications Office of the European Union.

Fritz, Ben. 2011. "Sony and MGM Finalize James Bond, Co-Financing Partnership.” The Los Angeles Times, April 13, 2011, http://latimesblogs.latimes.com/ entertainmentnewsbuzz/2011/o4/sony-and-mgm-finalize-bond-co-financingpartnership.html.

Hasian, Jr., Marouf. 2014. “Skyfall, James Bond's Resurrection, and 21st-Century Anglo-American Imperial Nostalgia." Communication Quarterly 62, no. 5: 569-88.

Higson, Andrew. 2010. Film England: Culturally English Filmmaking Since 1990. London: I.B. Tauris.

Hoskins, Colin and Rolf Mirus. 1988. "US Dominance of the International Trade in Television Programmes." Media, Culture and Society 10: 499-515. 
Lindner, Christoph, ed. 2009. The James Bond Phenomenon: A Critical Reader. Manchester: Manchester University Press.

Lindner, Christoph, ed. 2010. Revisioning oo7:James Bond and Casino Royale. New York: Wallflower Press.

LUMIERE database. 2016. “Skyfall.” Accessed December 22, 2016, http://lumiere. obs.coe.int/web/film_info/?id=40163\&graphics $=$ on

McCarthy, Todd. 2006. "New US Release: Casino Royale (UK-Czech Republic-Germany-US)." Variety, November 6, 2006, https://web.archive.org/web/20070126070659/ http://www.variety.com/VE1117932077.html.

Mendelson, Scott. 2016. “The 'James Bond' Series Will Thrive With or Without Daniel Craig”. Forbes, September 6, 2016, http://www.forbes.com/sites/scottmendelson/2016/og/o6/daniel-craig-isnt-worth-15om-for-two-james-bondmovies/\#6a1d463a494c.

Murray, Jonathan. 2017. "Containing the Spectre of the Past: The Evolution of the James Bond Franchise during the Daniel Craig Era." Visual Culture in Britain 18, no. 2 : $247-73$.

Rotten Tomatoes. 2006. “Casino Royale.” Accessed December 22, 2016, https:// www.rottentomatoes.com/m/casino_royale/.

Rotten Tomatoes. 2008. "Quantum of Solace." Accessed December 22, 2016, https:// www.rottentomatoes.com/m/quantum_of_solace/

Rotten Tomatoes. 2012. "Skyfall." Accessed December 22, 2016, https://www.rottentomatoes.com $/ \mathrm{m} /$ skyfall $/$.

Rotten Tomatoes. 2015. "Spectre." Accessed December 22, 2016, https://www.rottentomatoes.com/m/spectre_2015/.

Singh, Anita. 2008. "James Bond: Daniel Craig's Most Famous Scene Was 'An Accident.” The Daily Telegraph, October 17, 2008, http://www.telegraph.co.uk/ culture/film/3562206/James-Bond-Daniel-Craigs-most-famous-scene-wasan-accident.html.

The Numbers. 2016a. "Movie Franchises." Accessed December 22, 2016, http://www. the-numbers.com/movies/franchises/.

The Numbers 2016b. "Box Office History for James Bond Movies." Accessed December 22, 2016, http://www.the-numbers.com/movies/franchise/JamesBond\#tab=summary.

UK Government. 2014. "Government Response to the House of Lords Select Committee of Soft Power and the UK's Influence. Report of Session 2013-13 (HL150)." Accessed December 22, 2016, https://www.parliament.uk/documents/ lords-committees/soft-power-uk-influence/Lords-Soft-Power-GovernmentResponse.pdf.

Young, Derek S. 2014. "Bond. James Bond. A Statistical Look at Cinema's Most Famous Spy." CHANCE, April 16, 2014, http://chance.amstat.org/2014/04/james-bond/. 


\section{About the Authors}

Huw D. Jones is a Lecturer in Film Studies at the University of Southampton. He previously worked at the University of York as a Postdoctoral Research Associate on the HERA-funded Mediating Cultural Encounters through European Screens (MeCETES) project (www.mecetes.co.uk), an international project on the transnational production, distribution and audience reception of European film and television drama. He has published in The Routledge Companion to World Cinema, Transnational Cinemas, Comunicazioni Sociali, Journal of British Cinema and Television, and Cultural Trends. He also edited the book The Media in Europe's Small Nations (CSP, 2014) and is currently working on a monograph on the cross-border circulation and reception of European film.

Andrew Higson is Greg Dyke Professor of Film and Television at the University of York, UK. He has published widely on British cinema history, national and transnational cinema, and heritage cinema, and is co-editor of the Palgrave European Film and Media Studies series. He was Project Leader of Mediating Cultural Encounters through European Screens (www. mecetes.co.uk), an international project on the transnational production, distribution and audience reception of European film and television drama. He is currently Director of Screen Industries Growth Network, funded by Research England, and Co-Director of XR Stories (www.xrstories.co.uk), funded by the AHRC. His books include Film England: Culturally English Filmmaking Since the 199os (I.B. Tauris, 2011); and European Cinema and Television: Cultural Policy and Everyday Life, co-edited with Ib Bondebjerg and Eva Novrup Redvall (Palgrave Macmillan, 2015). 


\section{Part II}

\section{Beyond The Hero:}

\section{The Cultural Politics of 007}





\title{
6. Paradoxical Masculinity: James Bond, Icon of Failure
}

\author{
Toby Miller
}

\begin{abstract}
The James Bond films enact dilemmas posed by the paradoxical, split subjectivity of male spies under capitalism. Success and failure, sophistication and ignorance, knowledge and class, gender and sexuality, commercial targeting and viewing pleasure jumble together in a complex amalgam. A weird mix of hyper-bourgeois individualist, technocrat, and empty signifier, 007 can never relax, never truly know who he is, beyond being a shifting sign of impermanent state labor. His masculinity incarnates these paradoxes: often derided and celebrated for his brutality, Bond exemplifies less-than-conventional forms of life in his sexuality and identity.
\end{abstract}

Keywords: James Bond; masculinity; capitalism; hegemony; metrosexual; split subjectivity

This chapter contends that far from being the alpha and omega of the latter-day Hollywood macho man, James Bond has been in the vanguard of weak, commodified male beauty, and compensation for its loss: a mythic imbrication of sex, secrets, and the risible but welcome slide from an Empire to a Commonwealth of Nations. It is odd to suggest that Bond's masculinity is a paradox - that he might be an icon of failure. After all, we are told that 007 is "fit, sensual, technical, memorializing, and calculating [...] thrilling audiences in sensual stories of seduction, revelation, and calculation" (Funnell and Dodds 2015, 123). Ian Fleming boasted that he wrote the novels

1 Consider Clint Eastwood, Charles Bronson, Bruce Lee, Sylvester Stallone, Arnold Schwarzenegger, Jet Li, Vin Diesel, Bruce Willis, Chris Hemsworth, Tom Cruise, Matt Damon, Chris Evans, Chuck Norris, Jackie Chan, Jean-Claude Van Damme, Harrison Ford, Keanu Reeves, Steven Seagal, Wesley Snipes, Liam Neeson, Dwayne Johnson, or Jason Statham.

Verheul, J. (ed.), The Cultural Life ofJames Bond: Specters of oo7. Amsterdam: Amsterdam University Press, 2020 DOI 10.5117/9789462982185_CHO6 
for "red-blooded, heterosexual adults" (South Bank Show 2008) and that "all history is sex and violence" (Desert Island Discs 1963). The story lines have led latter-day statistical mavens to count the number of women 007 sleeps with in each film (described as "conquests") alongside the number of martinis downed by each lead actor (Young 2019). And consider the instructions that Roald Dahl received for the screenplay to You Only Live Twice (UK: Lewis Gilbert, 1967):

Three girls. No more and no less. Girl number one is pre-Bond. She stays around roughly through the first reel of the picture. Then she is bumped off by the enemy, preferably in Bond's arms. [...] Girl number two is antiBond. She works for the enemy and stays throughout the middle third of the picture. She must capture Bond, and Bond must save himself by bowling her over with sheer sexual magnetism. The girl should also be bumped off, preferably in an original fashion. [...] Girl number three is violently pro-Bond. She occupies the final third of the picture, and she must on no account be killed (Dahl 1967).

Asian Adventure magazine's August 1967 front cover featured a triptych representing three countries: an elderly man with tightly-squeezed features headlined as "Borneo Head-Hunters House Guest;" a stone-chiseled face on a wall signifying "Lost Cities of Cambodia;" and a still photograph from You Only Live Twice of Sean Connery in a Japanese hot tub surrounded by four women in bikini tops and briefs, one talking to him and three soaking his body. Further articulating such Orientalism, Esquire admired the film's "diving girls" and "massage girls" from the "Mysterious Orient" (Adams 1967). The Los Angeles Herald-Examiner thought its sex scenes would be "wonderful for Asian relations" ("Killing Off" 1967; Loynd 1967).

But for all that we might now construct a lineage of Bond as the first in a lengthening line of mostly Western muscle-bound action-adventure heroes, he was seen as quite another figure from the 196os onward. When Esquire (Bilmes 2015) announced in 2015 that Daniel Craig "redefined the once cartoonish secret agent as a symbol of masculinity for the modern age: embattled, conflicted, but still standing, still ready to take on the world," it was actually reiterating a venerable trope. Indeed, the ahistorical idea of Craig as the first beefcake Bond, designed for straight female and gay male spectators, is unsustainable (Williams and Flynn 2006; Cox 2015; Manganas 2019). Eva Green, Bond Girl Vesper Lynd in Casino Royale (UK/ Czech Republic/USA/Germany/Bahamas: Martin Campbell, 20o6), may have spoken truth to power in avowing that "He's the Bond Girl, Not Me" 
(quoted in Jeffries 2007), but Roger Ebert (1999) is correct that "Bond is consistently Bond: He remains recognizably the same man he was in 1962." My contention is that during that period, and indeed ever since, 007 has expressed significant changes in the political economy of masculinity, as beauty and precariousness have dueled with toil and certainty.

The seemingly irresistible, everlasting desire to extrapolate from 007 onto the world we live in is a sign that Bond exhibits that rarest of capacities: an ability to cross the normal frontiers of the semiosphere, to transcend the screen and become a mass icon of the everyday (Lotman 1996). Eduardo Galeano (2004) illustrates his classic account of and from the Global South with the observation that multinational corporations "seat and unseat kings and presidents, finance palace plots and coups d'etat courtesy of innumerable generals, ministers, and James Bonds under their command [my translation]." For Jean Baudrillard $(1998,171)$, the mythic hyper-competent US businessman is "part James Bond, part Henry Ford." Roger Moore opened the 1992 United Nations Conference on Environment and Development ("the Earth Summit") in Rio de Janeiro by saying that as per his time as Bond, he was opposed to "evil men trying to destroy our planet" (quoted in Harré et al. 1999, 17). For Ralph Miliband (1969, 226), Bond was one of the quintessential "paragons of anti-Communist virtues," and MI6 reportedly delights in the franchise's free advertising, which assists in recruitment (Cain 2019).

Such reference points in real life are legitimized by Fleming's work in wartime intelligence and later drawing-room liaisons with trans-Atlantic security elites (Moran and McCricken 2019). And in his travel writing and fiction, nothing but the 'finest' actual tobacco, coffee, and cars sufficed. The obsession with prestigious brands so evident in the novels and films - one to develop character, the other to defray production costs—and the books' grief over the advent of a welfare state and the decline of empire, are profound (Bennett and Woollacott 1987). Perhaps only Alvin Toffler (1971) regarded the series as an empty fad, destined for the trash. How wrong could a lapsed Trot/Reagan fanatic be?

On the left, both the books and the films are routinely—and rightly—-held up as significant contributors to, and symptoms of, imperialism, sexism, Orientalism, class hierarchy, and jingoism; even as the first form of mass pornography (Baron 1994, 69-70; Bold 1993; Drummond 1986, 66-67; Moniot 1976, 29; Denning 1992, 225; Funnell 2015). He was berated for displaying "the sadism of a schoolboy bully, the mechanical two-dimensional sex-longings of a frustrated adolescent, and the crude snob-cravings of a suburban adult" (Johnson 1958). John le Carré (Intimations 1966) called Bond an "international gangster" lacking "all political context" and driven by a "consumer-goods 
ethic:" a person for whom ordinary objects were transformed by the magic of espionage to induce materialistic pleasure. Penelope Gilliatt (1963) worried that the films' "brutal flippancy" was "a new voice of the age." For Pauline Kael (1966), they summed up Hollywood: a successful but empty place; technology without art. Warming to the theme of hyper-consumerism and snobbery, Manny Farber $(1971,161)$ referred to Thunderball (UK: Terence Young, 1965) as "a catalogue of posh-vulgar items for licentious living." Theodore Roszak $(1969,216)$ regarded 007 as the embodiment of technocracy, maintaining a "clinical cool while dealing out prodigious sex or sadistic violence." For Stuart Hall (2010, 303), Bond villains represented a casual yet marked and purposive racism. And looking back on 007's first half-century on film, Jane Martinson (2012) said feminists were "sick of a long-running multibillion-pound franchise that left a series of beautiful women as little more than roadkill in the path of the spy we never loved."

Reactionary critics see things differently. Vincent Canby (1971) adored this "steadfast agent for the military-industrial complex, a friend to the C.I.A. and a triumphant sexist." His latter-day fellow-travelers lament that the US is not a nation of Bonds. Breitbart is relieved that 007 can "survive a miserable trend of male feminization" (Meyers 2014) and horrified by "the truly awful idea of a female or gay James Bond" (Nolte 2019). The American Conservative luxuriates that "Bond's Britain is relevant, wealthy, and influential, still a beacon of Western ingenuity," regretting that "today's man, coerced into believing in his own emasculation, would introduce himself to a lesbian named Pussy Galore by saying: 'I respect your lifestyle choice.' When James Bond met a lesbian named Pussy Galore, he slept with her" (Tippins 2012). The Federalist glorifies 007 as "the quintessential alpha male" who "is all about guarding the perimeter and protecting the group" and deems it "exhilarating for a woman to bring the alpha male to his knees through her feminine wiles." This is apparently "the height of eroticism" (McAllister 2017). The magazine is horrified by the prospect of what it calls "a lefty's dream and a Bond fan's nightmare: a female-helmed James Bond” (Enck 2019), preferring hyper-masculine "decisiveness, his willingness to take a life without remorse in the cause of queen and country" (Tracinski 2015). The Telegraph lauds Bond as "masculinity's last Hollywood outpost" (Daubney 2015) while the Daily Mail avows that " 007 may be a sexist dinosaur, but I still prefer it when a granite-tough alpha male saves the world" (Epstein 2017).

I think something else has been going on, beyond what these accounts allow; something more contested and complex. Returning to the right's reactions, the libertarian Cold War pop philosopher and idol of contemporary US conservatism Ayn Rand $(1975,138)$ adored the 007 books for their unabashed 
Romanticism and inspirational transcendence. But she was troubled that the film franchise was laced with "humor intended to undercut Bond's stature, to make him ridiculous." Her concerns were in keeping with Fleming's lament for the passing of "real" heroism (Hellman 1962), itself a typical complaint of the "war bores" so prevalent among upper-crust Englishmen after 1945 ("War Bores" 2004). It is significant in this regard that the Bond actors were some distance from the image of a highly-educated scion of the ruling class. The box below shows that none of them were the upper-crust Englishman of official fantasies. Put another way, there has routinely been a publicly visible, audible, and even widely-promoted, gap between the ideal they embodied and the men they were (Cox 2014).

Sean Connery: A working-class Scot who was a barrow and dairy transport worker and junior horseman at the Corstorphine Dairy, sailor, naked male model, and bodybuilder ("Connery's Milkman" 2005; "Before" 2007; http:// picphotos.net/sean-connery-as-a-bodybuilder-http-www-ebay-com-itmsean-connery/).

George Lazenby: A working-class, rural Australian whose mother worked in a department store and father on the railways, he rose to prominence in 1961 by getting a speeding ticket in Canberra (" $£ 45$ Fine" 1961), and became a used-car salesman and male model (https://www.youtube.com/ watch?v=WQxcoGOhnts). Co-star Diana Rigg described him as "ill-equipped" (https://www.youtube.com/watch?v=QiRaiidtTYQ).

Roger Moore: The son of an English policeman (McGrath 2012) who matriculated into modeling knitwear and portraying a wide-eyed gambler on network television (https://www.pinterest.com/pin/109001253455220364/; https://lapancetadehojita.blogspot.co.uk/2011/10/roger-moore-maverick-serie-tv.html).

Timothy Dalton: A Welshman whose father was an advertising man and mother an Irish-Italian American ("Timothy" 2013).

Pierce Brosnan: The Irish immigrant son of a carpenter and nurse who became a flame-eating busker ("Pierce" 2003).

Daniel Craig: A middle-class Englishman of aristocratic lineage whose mother was an art teacher and father a publican (La Monica 2006; “John” 2016).

In keeping with the style revolution of the 1960 s and a new generation formed from youth culture rather than tradition, some progressive voices find pleasure as well as pain in Bond. Ken Adam (South Bank Show 2008) recalls this as a time "when the British took off their handcuffs and said: 'Fuck, the Empire doesn't exist any longer. Now, we will take over.'” Janet Thumim (1992) interprets Goldfinger (UK: Guy Hamilton, 1964) as a paean 
to "personal liberation [...] privileging the young and the new" by blurring espionage with comedy; unpacking secrets is less important than the work of spectacle. And the equal legitimacy of male and female extra-marital desire lives contradictorily within Bond's violent patriarchal attitudes. Despite his sexism, the series opened a world for some women where sex was about pleasure, not commitment; fun, not family; action, not inertia; taking, not waiting (Douglas 1994; Miller 2001; Cox 2015). These paradoxical responses from both left and right are present throughout espionage fiction.

\section{Espionage}

Espionage involves surreptitiously conveying information about a country, company, or union to its enemy or rival. It is to do with theft, secrecy, trust, and lies. Espionage fiction's nexus of spectacle and violence has led to accusations that it models anti-social conduct, heroizes the capitalist state, delights in base consumerism, and endorses covert government action. Loyalty, patriotism, and the mundanity of public employment are re-forged as plays with death, doom, and style. The mystery concerns the enemy's reasons, allies, and methods-plans devised and executed by a geopolitical opponent that are foiled in the lonely hour of the last instance by a lone operative, thanks to superior beauty, physique, ingenuity, and technology.

Ernest Mandel $(1984,61-62,65)$ ties the genre's popularity to the split subjectivity produced by mass-consumption capitalism. Superheroes emerge with the development of a bourgeoisie: mounting mechanization, diverse commodity production, hyper-consumerism, and increasingly alienated populations. He argues that the search for identity is a necessary process for fiction produced in such societies, where individuals are divided amongst a variety of selves: workers, buyers, and capitalists. As proprietors of homes and consumables, they uphold and even materialize laws of ownership, of both objects and people. But as citizens, they are concerned with the general good rather than their own. And as sexual subjects, they are driven by needs that take them beyond reason, the family, and property.

Spy stories enact the dilemmas posed by this contradictory subjectivity and reference law and order, the where and why of sovereignty, in a physical, material way, via the daily actions of secret agents acting as delegates of a people, monarchy, or military. The arbitrariness of this delegation, and its reliance on instant decision and action, is paradoxical. Loading up clandestine operatives with power and responsibility, and hence signing away the right to democracy, makes the myth of bourgeois society-popular 
endorsement of overt governmental processes through the publicly-ratified rule of law - unsustainable. Binary divisions between good and evil, police and felon, spy and counter-spy, West and East, become unstable, and a grudging respect and recognition of mutuality and doubling may even appear (Mandel 1984, 65, 122). How hegemonic is Bond, given varying responses to him from left and right, the slide between his on- and off-screen personae, and Mandel's account? Is he a hegemonic figure?

\section{The Paradoxes}

The intellectual lineage of hegemony lies in Antonio Gramsci's account of a contest of meaning in which a ruling class secures approval of the social order by making its power appear normal and natural. Ordinary people give "spontaneous' consent" to the "general direction imposed on social life by the dominant fundamental group." Each society contains old cultural meanings and practices, no longer dominant but still influential, and emergent ones (Gramsci 1978, 12). Raewyn Connell (1995, 185-99; 1993, 6o2) applies this notion of consent-through-incorporation to gender, articulating the expansion of North Atlantic commercial republics across the world to contemporary ethnography and political economy. The resultant hegemonic masculinity makes Western-European and North-American white male sexuality isomorphic with power: dominant men seek global dominion and desire, orchestrated to oppress women and marginal men. One might regard espionage fiction as part of obtaining Gramscian consent, because it glamorizes the work of spies as entertainment, patriotism, and raison d'état, while Bond's image as an unquestioningly loyal Englishman, serial philanderer, gadget man, and fanatic for the high life appears to fit Connell's analysis.

The series is definitely guilty as charged (and valorized) for its sexism, racism, imperialism, and consumerism - but frequently in a chaotic manner that is more complex and contradictory than critical or welcoming accounts of a colonialist, snobbish, or phallic hero will allow. In conversation with Raymond Chandler, Fleming disclosed that he thought of Bond as a "blunt instrument wielded by a government department who would get into bizarre and fantastic situations [...] he's always referred to as my hero. I don't see him as a hero myself. On the whole I think he's a rather unattractive man" (Fleming and Chandler 2014, 31). Alexander Cockburn $(1987,30-31)$ suggests that 007 incarnates a "postimperial fantasy:" the first screen action hero to embody and address the new, fragile pleasure of the 
commodity, an environment in which both Bond and those he encounters are "mundane objects of desire." Small wonder that Christopher Hitchens (2006) discerned "the penis envy of a declining power" and Eric Hobsbawm (1995) saw characters "compensating for their country's decline." As Ernst Stavro Blofeld rather wonderfully tells 007 in Diamonds Are Forever (UK: Guy Hamilton, 1971), "Your pitiful little island hasn't even been threatened."

A frequently stricken figure, Bond's emotions are intense, his drinking dipsomaniacal, and his body routinely reduced. That body-so often both shaken and stirred, by people, technologies, and events beyond his ken-is a perilous means of being known and of losing authority, a site of the potentially abject that must be objectified as a sign of self-control and autotelic satisfaction. Its stark movements between patriarchal power and limp failure embody the long crisis of a seemingly victorious Atlantic masculinity that began after 1945 with soldiers' return from the front to a crumbling economy and empire in Britain and new gender relations in the US, occasioned by the wartime economic mobilization of women followed by peacetime's suburbanization of the population. Such movements intensified in the face of both countries' progressive deindustrialization from the 196os onward, the rise of the services sector, and new developments in the political economy of looking (Miller 2008). Those social, economic, and cultural shifts impelled the slow move that has made the male body the object of routine public ocular dissection. They have also increased options for toying with its symbolism. Commodification through niche targeting has increasingly identified men as objects of desire for gay male and straight female viewers (Miller 2001). I hope to illustrate this paradox by focusing on two of the long-lasting Bonds, Sean Connery and Pierce Brosnan.

\section{Connery}

As the splendidly-named Product Digest put it at the time, Connery was chosen after a thorough "search for the exciting figure who was designed to set masculine pulses hammering and feminine hearts throbbing" ("Dr. No" 1963). The filmmakers cast him knowing full-well that he was not the ruling-class figure of the novels, in the hope that he would appeal to straight women and encourage cross-class identification by men (Broccoli with Zec 1998, 171). Producer Albert Broccoli (quoted in Barnes and Hearn 1998, 20) called this "sadism for the family." Connery signaled the end of traditional ruling-class British confidence and a new cross-class allure and masculinity. This was part of an emergent style: the first Sunday Times magazine color supplement (1962) featured Mary Quant clothing, worn by Jean Shrimpton 
and photographed by David Bailey; a state-of-the-nation essay on Britain; and a Bond short story. The inaugural Observer equivalent included fashion from France and stills from the forthcoming 007 movie (Booker 1969, 49, 238). Connery's Bond, then, offers a complex transcendence from the ties of origin via commodities and sex, without any drive towards accumulating power and authority. He is the drifter in a tux that rarely remains pristine for long. His body bears the signs of social stratification, but never remains stable or in one place long enough to adopt the mantle of patriarchy through soil, blood, or home. Connery was frequently criticized as a wuss, in keeping with the notion that he embodied the welfare state's weak-kneed, decadent cosseting that was supposedly losing an empire (Anez 1992). Cyril Connolly's 1963 spoof "Bond Strikes Camp" found M coming out as gay and Bond a cross-dresser. ${ }^{2}$

Following a "short, sharp exploitation campaign" (Houston 1964b, 176), Dr. No (UK: Terence Young, 1962) proved extremely popular. Critics, however, were mostly negative. Monthly Film Bulletin complained that the film "misses the genuine sadistic, sybaritic relish" of the novels and deemed Connery "wooden and boorish" ("Dr. No" 1962), while there was also controversy over Bond's callous execution of Professor Dent (Anthony Dawson) and his casual sexual encounter with Miss Taro (Zena Marshall) (Yule 1992, 106). As the film begins, of course, Connery hands his card to a woman (Eunice Gayson as Sylvia Trench) he meets in a club, suggesting she come up and see him some time. This is an invitation for Trench to exercise her desire-which she does, astonishing him by breaking into his apartment within the hour. He encounters her practicing golf in his rooms, attired in just a shirt. No wonder that for Susan Douglas $(1994,72)$ growing up, Dr. No was a sign that "sex for single women [could be] glamorous and satisfying."

Such sexual agency and pleasure came at a certain cost to the image of 007. Bosley Crowther (1964) suggested five decades ago that:

Mr. Bond's off-handed conquests were always open to a certain amount of doubt, a certain amount of skepticism as to how much of a Lothario he actually is. Indeed, they have often intimated a bland contempt for, or, at least, a slippery spoof of the whole notion of masculine prowess. One might question whether Bond really likes girls.

Time magazine labeled Connery a "used-up gigolo" in the wake of $\mathrm{Dr}$. No (quoted in Barnes and Hearn 1998, 16), Newsweek condemned him as of

2 When asked whether James Bond would sleep with another man in the line of duty, Daniel Craig replied: "No. Kill him and then seduce him" (quoted in Orr, 2008). 
interest solely to "cultivated sado-masochists" (quoted in Anez 1992, 314), and many US magazines objectified him mercilessly by listing his bodily measurements (Dore 1996, 11). As far as the New Republic was concerned, Bond was "stupid. [...] His only genius lies in an infinite capacity for taking pain" (Grella 1964, 17). Connery was frequently mauled for his lack of vim and vigor, the very departures from muscular Christianity and white leadership supposedly afflicting the Britain that Fleming abjured.

Across ideological and geographical spectra came commensurate critiques from the German Democratic Republic's Communist Party youth paper, Junge Welt, and the Vatican City's L'Osservatore Romano, which discerned "a dangerous mixture of violence, vulgarity, sadism and sex" (Sann 1967, 34; L'Osservatore quoted in "Church Says" 1965). Britain's Daily Worker noted an "appeal to the filmgoer's basest instincts" and "perversion." The Spectator deemed the film "pernicious." Films and Filming called the "sex and sadism" a "brutally potent intoxicant," deriding Bond as a "monstrously overblown sex fantasy of nightmarish proportions" who was "morally [...] indefensible" and liable to produce "kinky families" (quoted in Barnes and Hearn 1998, 16-17, 26-27; Smith and Lavington 2002, 22).

But Penelope Houston (1964a) suggested that Goldfinger "converts Bond into a human equivalent of the cat in the Tom and Jerry cartoons, with the same ghastly resilience." In short, it was obviously a joke, not least thanks to Ken Adam's enormous, lovingly-detailed, excessive set designs. Steel, concrete, and gold organized life through power in monumental form-virtual memorials to authority and control that always end in pieces. And the jokes undermined 007. "Why do you always wear that thing?," inquires a woman of Connery's shoulder-holster in the pre-credits sequence of Goldfinger. His reply, "I have a slight inferiority complex," illustrates the mutability of his sexuality. And the exchange bespeaks a gratuitous self-confidence: he lets go of the gun and is subsequently exposed to peril. Variety rather straightforwardly called this "making an arrogant pass at a chick" ("Review: Goldfinger" 1963); but it was more than that.

Goldfinger puts Connery's body on display, notably in a rather alarming terry-toweling jump-suit. This is "major beefcake," retrospectively described by the Guardian as akin to the "revenge" of a "feminist art director" for the film's almost-casual sexism (Bradshaw 2007). For the New York Daily News' Wanda Hale (1964), Connery exuded "animal magnetism with that graceful panther walk and baring of the teeth in that slow smile" but was a "joke superman" ("Goldfinger" 1964). A sequence in bed with Jill Masterson (Shirley Eaton) is initially characterized by smart-ass conduct during a phone call where Bond tells a CIA agent that he cannot meet immediately because 
"something big's come up." But this is followed by defeat- -007 is knocked senseless just as he shows he's an old fogey by deriding The Beatles. Then Masterson is drowned in gold paint. Baudrillard $(1993,105)$ interprets her dead body as the triumph of the phallus over femininity through the blocking of her pores. But it was equally a sign of Bond's repeated, hapless failure.

His "masculinity" is directly at risk in the near-castration scene, when Connery is taunted by Auric Goldfinger (Gert Fröbe) while an industrial laser cuts through wood and metal towards his spread legs. 007's muscles visibly tense, the two men engage in some badinage, and a close-up on Bond's face evidences further concern. He looks between his legs and across the room in a series of reverse shots with Goldfinger. John Barry's three-minute musical sequence sustains and repeats, "with characteristic punctuation from the xylophone, an F-minor added-second chord." As the laser heads for 007's groin, violins provide "an eight-note motif, harmonized by the same chord" that crescendos many times before returning to the opening two notes of the previous motif, which also repeats itself (Brown 1994, 46-47). All this instability leaves Connery "a direct object of desire," caught between power, passivity, beauty, bondage, invulnerability, and fallibility (Bennett and Woollacott 1987, 162).

Thunderball finds Connery chided by Fiona Volpe (Luciana Paluzzi):

I forgot your ego, Mister Bond. James Bond, who only has to make love to a woman and she starts to hear heavenly choirs singing. She repents, then immediately returns to the side of right and virtue. But not this one. What a blow it must have been-you, having a failure.

Connery was routinely the object of the gaze in publicity for Thunderball, posing in 1966 be-suited for $G Q$ and bare-cleavaged for Life. The harbinger of a new male body on display, he showed that sexiness did not require a choice between ruggedness and style (McInerney 1996, 26, 32). But that equilibrium was contingent. Pauline Kael (1967) described Connery as "a paunchy, rather bemused spectator" in You Only Live Twice. Stephen Farber (1967) thought he looked "embalmed," while the New Yorker said Connery "seems deflated. Once dashing in himself, he has become the instrument of dashing production ideas" ("Nether" 1967). Crowther (1967) lamented in the New York Times that " $[\mathrm{t}]$ he sex is minimal. But, then, Bond is getting old," while Houston (1967) called 007 "an over-worked legend." Four decades later, the Guardian likened Connery's performance to "a slouching Burt Reynolds" (O'Neill 2012). As per Cockburn, Hitchens, and Hobsbawm, while You Only Live Twice is a high point of Orientalism, with Bond's body wiped 
clean by Japanese women, it is also the moment of Britain's withdrawal from East of Suez (announced in early 1968), and hence a certain recognition of a dream (and tyranny) that had faded and failed: the nation's begrudging acceptance of middle-power status, in keeping with the disasters of Suez, Kenya, Malaya, and Cyprus; the erosion of its manufacturing base; and the desire to increase domestic social spending.

By the time of Connery's return to the role in Diamonds Are Forever four years later, a homology was clearly in place between imperial decline and his own. Critics deemed 007's body too bloated and his hair piece too obvious: he "shuffles through the motions like some ageing heavyweight showboater, flirting with disaster, his toupee slipping" (Brooks 2012). Retrospectively, Empire magazine lamented the sight of "Connery ageing quickly, his hairline indeterminately assisted" (Nathan 200o). Is this an all-powerful ruling-class scion at work, with women cowering defensively? I think not. Connery's prior careers as Scottish Mr. Universe, Carnaby Street model, and Royal Court Shakespearian instance the risky, contingent intersection of body, style, action, and performance. He showed that the look of a man could transcend his class background and politesse: a postmodern figure of beautiful male commodification avant la lettre (Synnott 199o; Manning 1990, 3). But the currency of such beauty was subject to rapid depreciation.

Ever since Connery, there has been a discourse each time a new screen Bond is announced -in advertising, promotion, and the films themselvesabout returning to the darkness of the novels and the real spirit of the original 007 , of a figure troubled by the fate of Britain at home and abroad as a nation supposedly coarsened by the welfare state and humiliated by the loss of empire. Bond, in other words, has always been a sign of the end of British confidence and a newly pleasurable display of masculinity, by turns weak and strong, flaccid and erect, commonwealth and imperial, institutionalized and autonomous. This is nostalgia for a lost world of colonialism; dismay at its decayed vestiges; signage of the power of cultural imperialism; and a marker of a newly objectified, available masculinity. Connery's trajectory said it all.

\section{Brosnan}

For Cedric Robinson $(1984,86)$, Bond's Cold War spy adventures signified a distinctly modern realm:

Bond dealt with a world which was geometric in form, brightly illuminated, aseptic, technologically advanced. It situated evil in an arena of civility. 
Evil was never reduced to brute force. It was intellectual, technically advanced and imaginative, scientific, architecturally innovative and capable of a global presence. Its phenomenology was the paraphernalia of the modern world.

That modernity was rocked by the erosion of the Cold War's binary oppositions and its proxy struggles that had given contour to decolonization. The 007 series actually decentered Cold War tensions - the Soviets or Chinese were there or thereabouts, and provided context, but the main enemy was always a criminal capitalist or rogue operative. Nevertheless, the fall of the Eastern bloc would have presented some dilemmas had it not coincided with intellectual property disputes over the franchise. As a consequence of that legal crisis, the James Bond film series lay dormant from 1989 to 1995 . Skepticism as to its future was rife: the series' supposed animating power was spent. What could 007 now offer (Harney 2002)?

While Brosnan had the same fitful, fateful task of others - to walk in Connery's shadow - he also needed to broker a shift from Soviet severity to Russian lawlessness. Arriving almost a quarter of century after Diamonds Are Forever, Brosnan's Bond was said to combine stylishness with an understated but ever-ready violence. This led to his celebration within hegemonic masculinity; as, for example, in the JamezBond animutations, where to be other than 007 was to be queer-and "lame" (Kendall 2007). But Brosnan was up for grabs as a sexual object. In its review of GoldenEye (UK/USA: Martin Campbell, 1995), the Washington Post named him a "programmed cover boy" (Howe 1995), while Rolling Stone advised readers that Tomorrow Never Dies (UK/USA: Roger Spottiswoode, 1997) featured "[l] ess an actor than a model" (Travers 1997). Janet Maslin (1999) thought he barely "entered the land of the living" but CNN avowed that "he'll have the ladies turning out in swooning droves" (Buckland 1995) and the Seattle Times' Moira Macdonald (2002) found him "so devilishly handsome he really should come with a warning label."

Brosnan's 007 and his "permanent come-hither squint" (Morris 1999) coincided with the emergence of the "metrosexual," a term coined in the mid-1990s by queer critic Mark Simpson (1998), who encountered "the real future" and found "it had moisturized." Historically, male desire for women has been over-legitimized and female and male desire for men under-legitimized. ${ }^{3}$ The advent of metrosexuality represented a major shift in power relations, with men subjected to new forms of governance and 
commodification. Metrosexuals endorsed equal-opportunity vanity through cosmetics, softness, women, hair-care products, wine bars, gyms, designer fashion, wealth, the culture industries, finance, cities, cosmetic surgery, and deodorants. Happy to be the object of queer eroticism and committed to exfoliation and web surfing, these newly feminized males blurred the visual style of straight and gay - and were supposed to be every fifth man in major US cities. Single straight men embarked on what the New York Times called "man dates," nights out together without the alibis of work and sport or the props of televisions and bar stools - although Yanquis shied away from ordering bottles of wine together (Miller 2008). Metrosexuality was embraced by Western European, Australian, South Asian, Latin American, East Asian, and US marketers, who regarded the emergent creature as "having the strength to be true to oneself" rather than simply being a vain cat. Based on its rapid diffusion, acceptance, and national usage, "metrosexual" was declared word of the year for 2003 by the American Dialect Society—ahead of "weapons of," "embed," and "pre-emptive self-defense." Euromonitor's 2006 report on the phenomenon was entitled The Male Shopping Giant Awakes. ${ }^{4}$

Brosnan was often taken to represent just such politically-correct masculinity: polished, witty, well-dressed, and finely-groomed. Publicity shots generally showed him looking boldly into the camera in a tuxedo, with not a hair out of place. His narrow emotional range could be interpreted as coolness. Janet Maslin (1995) welcomed Brosnan as a "coffee-bar James Bond: mild, fashionable and nice in a very go's way [...]. The best-moussed Bond [...] a fabulous clothing model." There are obvious connections to Connery's paradoxical mixture of beauty, vulnerability, and violence. Although Brosnan supposedly epitomized metrosexuality through his "italicized good looks" and "restrained air of machismo" (Ellen 2002), given the softness of his beauty, the elegance of his approach, and the style of his habiliments, he was also hailed as the opposite of the metrosexual in his devil-may-care attitude. I have found debates about Brosnan as metrosexual versus non-metrosexual in sources stretching from Britain to Malaysia to Ecuador to the US to Spain to Ireland to Mexico to India. Some ask whether he was the first metrosexual Bond; others categorize him as the last hold-out before Craig took over (Torregrossa 2007; Khoo 2006; Harris 2005; Majors 2005; "Los ubersexuales" 2007; Ruiz and Santander 2006; Reynolds 2007; Guevara 2006; Zakaria 2004; Tippins 2012). In the UK, the Daily Mirror, a working-class leftist paper, plumped for Brosnan as anti-metrosexual (Moodie and Lawler 2008), while the Daily Mail, a working-class conservative rival nationally and gossipy T\&A 
web site globally, saw him as the acme of metrosexuality (Newland 2006). Meanwhile, the Daily Telegraph, a ruling-class conservative paper, defined him as post-metrosexual (Goswami 2005). In the tradition of bourgeois Yanqui journalism, the New York Times bet each way (Menkess 2006).

But Brosnan's time came to an end, as all such commodified beauty must do. Maitland McDonagh (1996) predicted he would "last a good half-dozen films before his waist thickens and his solid good looks begin to slide." And with The World is Not Enough (UK/USA: Michael Apted, 1999), the Guardian warned that Brosnan was "ageing and cragging up" (Bradshaw 1999), the New York Post said "his boyish face ages and his frame fills out" (Foreman 1999), and the Washington Post observed that he was "starting to look a tad long in the tooth" (Howe 1999). Manohla Dargis (2002) felt obliged to note that in Die Another Day (UK/USA: Lee Tamahori, 2002), Brosnan was "a very fit 49 year-old actor who's nonetheless 49." Then it was over. The Daily Mail explained that the decision to end his time in the role was made following "pictures taken at a family barbecue [...] in which he betrayed signs of middle-age spread" ("Is Brosnan" 2004). This is the kind of cruel bodily scrutiny supposedly reserved for patriarchal surveillance and misogyny. In time, it happens to every Bond.

\section{Conclusion}

As embodied by Sean Connery and Pierce Brosnan, 007's masculinity enacts dilemmas posed by the paradoxical, split subjectivity identified by Mandel. Success and failure, sophistication and ignorance, knowledge and class, gender and sexuality, commercial targeting and viewing pleasure jumble together in a complex amalgam that is more conflictual than theories of hegemonic masculinity perhaps allow. A weird mix of hyper-bourgeois individualist, technocrat, and empty signifier, 007 can never relax, never truly know who he is, beyond being a shifting sign of impermanent state labor.

The secret agent is a member of the precariat, that latest breed of postindustrial person, with high levels of educational attainment, great facility with cultural and communications technologies and genres - and a very uncertain future. Spies are protean, pacey, and problematic, from their alpha to their omega. They are the ultimate flexible subjects: empty and ready to obey, depthless and prepared to innovate. That model is reworked time and again, but is far from being a straightforward assertion of brute maleness or elite taste. Rather, it encompasses Mandel's split subject, the vulnerable beauty of traditional femininity, and the uncertain membership of the precariat. And its name is Bond. 


\section{Works Cited}

“£45 Fine in Traffic Case Re-Hearing." 1961. Canberra Times, December 15, 61.

"Before He was Bond: Semi-Nude Portrait of Sean Connery Reveals His Early Promise." 2007. The Daily Mail, October 25, http://www.dailymail.co.uk/tvshowbiz/ article-489617/Before-Bond-Semi-nude-portrait-Sean-Connery-reveals-earlypromise.html.

"Church Says No, No to “No"." 1965. Los Angeles Times, May 19.

“Connery's Milkman Wages Revealed.” 2005. BBC News, November 21, http://news. bbc.co.uk/1/hi/scotland/4457708.stm.

"Dr. No." 1962. Monthly Film Bulletin, October, 135.

“Dr. No." 1963. Product Digest, April 3, 785.

"Goldfinger." 1964. Monthly Film Bulletin, October, 149.

"Is Brosnan Too Old to Be 007?." 2004. The Daily Mail, February 9, http://www. dailymail.co.uk/tvshowbiz/article-207653/Is-Brosnan-old-oo7.html.

“John Cleese Declares Daniel Craig Too Short for James Bond." 2016. The Daily Telegraph, February 22, http://www.dailytelegraph.com.au/entertainment/sydneyconfidential/john-cleese-declares-daniel-craig-too-short-for-james-bond/ news-story/b4de208ao4feb254adb9514246e56of6.

"Killing Off Bond." 1967. Esquire, March, 74-85.

"Los ubersexuales jubilan a los metrosexuales en el mundo." 2007. El Comercio, July 29.

"Nether Villainy." 1967. The New Yorker, June 24, 74.

"Pierce Brosnan: Questions from the Floor." 2003. The Guardian, March 18, https:// www.theguardian.com/film/2003/mar/18/features1.

“Review: Goldfinger." 1963. Variety, December 31, http://variety.com/1963/film/ reviews/goldfinger-1200420642/.

“Timothy Dalton: The Bond of Colwyn Bay." 2013. The Daily Post, April 19, http:// www.dailypost.co.uk/news/north-wales-news/timothy-dalton-bond-colwynbay-2765248.

"War Bores." 2004. The Economist, October 28, http://www.economist.com/ node/3331095.

Adams, Andy. 1967. “Bond Kicks Up Furore in Japan.” Asian Adventure, August, 8-15. Anez, Nicholas. 1992. "James Bond." Films in Review 43, nos. 9-10: 310-19.

Barnes, Alan, and Marcus Hearn. 1998. Kiss Kiss Bang! Bang! The Unofficial James Bond Film Companion. Woodstock: Overlook Press.

Baron, Cynthia. 1994. "Doctor No: Bonding Britishness to Racial Sovereignty." Spectator 14, no. 2: 68-81.

Baudrillard, Jean. 1993. Symbolic Exchange and Death, translated by Ian Hamilton Grant. London: Sage. 
Baudrillard, Jean. 1998. The Consumer Society: Myths and Structures, translated by C. T. London: Sage.

Bennett, Tony and Janet Woollacott. 1987. Bond and Beyond: The Political Career of a Popular Hero. Basingstoke: Macmillan.

Bilmes, Alex. 2015. "Daniel Craig is Esquire's October Cover Star." Esquire, October 21, http://www.esquire.co.uk/culture/film/news/a8782/daniel-craig-interview/.

Bold, Christine. 1993. “'Under the Very Skirts of Britannia:' Re-reading Women in the James Bond Novels." Queen's Quarterly 100, no. 2: 310-27.

Booker, Christopher. 1969. The Neophiliacs: A Study of the Revolution in English Life in the Fifties and Sixties. London: Collins.

Bradshaw, Peter. 1999. "You're Stuck in the 5os, Mr Bond." The Guardian, November 26, https://www.theguardian.com/culture/1999/nov/26/jamesbond.

Bradshaw, Peter. 2007. "Goldfinger.” The Guardian, July 27, https://www.theguardian. com/film/2007/jul/27/jamesbond.actionandadventure.

Broccoli, Albert, with Donald Zec. 1998. When the Snow Melts: The Autobiography of Cubby Broccoli. London: Boxtree.

Brooks, Xan. 2012. "My Favourite Bond Film: Diamonds Are Forever.” The Guardian, September 27, https://www.theguardian.com/film/filmblog/2012/sep/27/ favourite-bond-diamonds-are-forever.

Brown, Royal S. 1994. Overtones and Undertones: Reading Film Music. Berkeley: University of California Press.

Buckland Carol. 1995. “'GoldenEye:' 007's License to Thrill Renewed.” CNN, November 21, http://edition.cnn.com/SHOWBIZ/Movies/9511/GoldenEye/review.html.

Cain, Sian. 2019. 'James Bond Still a Strong 'Recruitment Sergeant' for MI6, Says Expert.” The Guardian, May 30, https://www.theguardian.com/books/2019/ may/3o/james-bond-still-a-strong-recruitment-sergeant-for-mi6-says-expert.

Canby, Vincent. 1971. “A Benign Bond.” The New York Times, December 18, http://


A669EDE\&partner=Rotten\%2520Tomatoes.

Connell, R. W. 1993. "The Big Picture: Masculinities in Recent World History." Theory and Society 22, no. 5: 597-623.

Connell, R. W. 1995. Masculinities. Berkeley: University of California Press.

Cockburn, Alexander. 1987. "James Bond at 25." American Film 12, no. 9: 26-31, 59.

Connolly, Cyril. 1963. Previous Convictions. New York: Harper \& Row.

Cox, Katharine. 2014. "Becoming James Bond: Daniel Craig, Rebirth, and Refashioning Masculinity in Casino Royale (2006)." Journal of Gender Studies 23, no. 2:184-96.

Cox, Tracey. 2015. “Every Woman Wants One Night With Bond.” The Daily Mail, October 26, http://www.dailymail.co.uk/femail/article-3288436/Every-womanwants-one-night-Bond-Tracey-Cox-Daniel-Craig-s-0o7-s-cheesy-chat-linessteamy-bedroom-antics-leave-shaken-stirred.html. 
Crowther, Bosley. 1964. "Goldfinger." The New York Times, December 22, http:// www.nytimes.com/movie/review?res=EE05 $\mathrm{E}_{7} \mathrm{DF}_{173} \mathrm{DE}_{46}{ }_{4} \mathrm{BC}_{4} \mathrm{~A}_{51} \mathrm{DFB}_{4} 6783$ 8F679EDE\&partner=Rotten\%2520Tomatoes.

Crowther, Bosley. 1967. "Sayonara, 007: Connery is at it Again as Whatshisname." The New York Times, June 14, http://www.nytimes.com/movie/review?res=9Co7 $\mathrm{E}_{5} \mathrm{DE} 173 \mathrm{FE}_{53} \mathrm{BBC}_{4} \mathrm{C}_{52} \mathrm{DFB} 666838 \mathrm{C6} 79 \mathrm{EDE} \&$ partner=Rotten\%2520Tomatoes.

Dahl, Roald. 1967. “007's Oriental Eyefuls." Playboy, June, 86-91.

Dargis, Manohla. 2002. "Bond's 40 But Refuses to Leave." Los Angeles Times, November 22, http://articles.latimes.com/2002/nov/22/entertainment/et-dargis22.

Daubney, Martin. 2015. “James Bond: You're a Sexist, But We Love You for It." The Telegraph, September 1, http://www.telegraph.co.uk/men/thinking-man/1183646o/ James-Bond-youre-a-sexist-but-we-love-you-for-it.html.

Denning, Michael. 1992. "Licensed to Look: James Bond and the Heroism of Consumption." In Contemporary Marxist Literary Criticism, edited by Francis Mulhern, 211-29. London: Longman.

Desert Island Discs. 1963. "Ian Fleming," https://www.youtube.com/watch?v=JFSEBeOEVo.

Dore, Katherine. 1996. "Public School Playboy: The Image of James Bond in America in the Sixties." Unpublished ms.

Douglas, Susan J. 1994. Where the Girls Are: Growing Up Female with the Mass Media. New York: Times Books.

Drummond, Lee. 1986. “The Story of Bond.” In Symbolizing America, edited by Hervé Varenne, 66-89. Lincoln: University of Nebraska Press.

Ebert, Roger. 1999. “Goldfinger.” Roger Ebert, January 31, http://www.rogerebert. com/reviews/great-movie-goldfinger-1964.

Ellen, Barbara. 2002. "I am the Sexiest Man in the World! I Know I Am. I Read it.” The Observer, January 13, https:/www.theguardian.com/film/2002/jan/13/ features.magazine.

Enck, Paulina. 2019. "A Female 007 Leaves Bond Fans Shaken (Not Stirred), and for Good Reason.” The Federalist, July 22, https://thefederalist.com/2019/07/22/afemale-007-leaves-bond-fans-shaken-not-stirred-and-for-good-reason/.

Epstein, Angela. 2017. "I Hate to Admit it, but Women Pilots Make Me Nervous." The Daily Mail, August 16, http://www.dailymail.co.uk/femail/article-4797202/Ihate-admit-women-pilots-make-nervous.html.

Farber, Manny. 1971. Movies. New York: Hillstone.

Farber, Stephen. 1967. “Review." Film Quarterly 21, no. 1: 62.

Fleming, Ian, and Raymond Chandler. 2014. "'You Want Me to Describe How It's Done?'" Five Dials 7, 30-33.

Foreman, Jonathan. 1999. “A Strong Bond.” The New York Post, November 19, http:// nypost.com/1999/11/19/a-strong-bond-brosnan-finds-his-footing-in-o07s-world/. 
Funnell, Lisa, and Klaus Dodds. 2015. “'The Man with the Midas Touch:' The Haptic Geographies of James Bond's Body." Journal of Popular Film and Television 43, no. 3: 121-35.

Funnell, Lisa. 2015. For His Eyes Only: The Women ofJames Bond. London: Wallflower Press.

Galeano, Eduardo. 2004. Las venas abiertas de América Latina. Mexico City: Siglo XXI Ediciones.

Gilliatt, Penelope. 1963. "Laughing It Off with Bond.” The Observer, October 13, https://www.mi6-hq.com/sections/articles/history_press_frwl_observer. php3?id=03595.

Goswami, Nina. 2005. "Ken Counts on a Make-Over to Win Back Barbie." The Telegraph, October 23, http://www.telegraph.co.uk/news/worldnews/northamerica/ usa/1501322/Ken-counts-on-a-make-over-to-win-back-Barbie.html.

Gramsci, Antonio. 1978. Selections from the Prison Notebooks of Antonio Gramsci, translated and edited by Quentin Hoare and Geoffrey Nowell-Smith. New York: International Publishers.

Grella, George. 1964. "James Bond: Culture Hero." New Republic, May 30, 17-20.

Guevara, Beatriz. 2006. "Hay de hombres ... a HOMBRES." El Expreso.

Hale, Wanda. 1964. “'Goldfinger' Exudes Fun and Sex Galore.” The Daily News, December 22, http://www.nydailynews.com/entertainment/movies/ goldfinger-better-previous-bonds-1964-review-article-1.2444241.

Hall, Stuart. 2010. Sin garantías: Trayectorias y problemáticas en estudios culturales, edited by Eduardo Restrepo, Catherine Walsh, and Victor Vich. Popayán: Envión; Lima: Instituto de Estudios Peruanos; Bogotá: Instituto de Estudios Sociales y Culturales.

Harney, Stefano. 2002. State Work: Public Administration and Mass Intellectuality. Durham: Duke University Press.

Harré, Rom, Jens Brockmeier, and Peter Mühlhäuser. 1999. Greenspeak: A Study of Environmental Discourse. Thousand Oaks: Sage.

Harris, Paul. 2005. "Metrosexual Man Bows to Red-Blooded Übersexuals." The Observer, October 23, https://www.theguardian.com/world/2005/oct/23/gender. books.

Hellman, Geoffrey T. 1962. "Bond's Creator." The New Yorker, April 21, 32.

Hitchens, Christopher. 2006. "Bottoms Up." The Atlantic, March, https://www. theatlantic.com/magazine/archive/2006/o4/bottoms-up/304719/.

Hobsbawm, Eric. 1995. The Age of Extremes: The Short Twentieth Century, 1914-1991. London: Michael Joseph.

Houston, Penelope. 1964a. “007." Sight and Sound 34, no. 1: 14-16.

Houston, Penelope. 1964b. The Contemporary Cinema. Harmondsworth: Penguin. Houston, Penelope. 1967. "Bond Dishonoured." Spectator, April 21, 26. 
Howe, Desson. 1995. “'GoldenEye:' Bona Fide Bond.” The Washington Post, November 17, http://www.washingtonpost.com/wp-srv/style/longterm/movies/videos/ GoldenEye.htm\#howe.

Howe, Desson. 1999. “'World:' Bond Without End.” The Washington Post, November 19, http://www.washingtonpost.com/wp-srv/entertainment/movies/reviews/ worldisnotenoughhowe.htm.

Intimations - A Question of Influences. 1966. "Malcolm Muggeridge and John le Carré.” Produced by Margaret McCall. BBC, http://www.bbc.co.uk/iplayer/ episode/poonwitb/intimations-10-john-le-carre\#.

Jeffries, Stuart. 2007. "'He's the Bond Girl, Not Me." The Guardian, January 26, https://www.theguardian.com/film/2007/jan/26/jamesbond.

Johnson, Paul. 1958. "Sex, Snobbery and Sadism." New Statesman, April 5, 430-32. Kael, Pauline. 1966. "Marlon Brando: An American Hero." The Atlantic Monthly, March, http://www.theatlantic.com/past/docs/unbound/aandc/movies/movies4. htm.

Kael, Pauline. 1967. “Consumer Guidance.” New Republic, July 15, 27-28.

Kendall, Lori. 2007. "Colin Mochrie vs. Jesus H. Christ: Messages About Masculinities and Fame in Online Video Conversations." Proceedings of the $40^{\text {th }}$ Hawaii International Conference on System Sciences, https://www.ideals.illinois.edu/ bitstream/handle/2142/705/co?sequence $=2$.

Khoo, Rubin. 2006. "Mirl of the Moment." Star, August 8.

La Monica, Paul R. 2006. "Blond, James Blond." CNN Money, November 17, http:// money.cnn.com/2006/11/o8/commentary/mediabiz/index.htm.

Lotman, Iuri M. 1996. La semiosfera, translated and edited by Desiderio Navarro. Madrid: Ediciones Cátedra.

Loynd, Ray. 1967. "Bond-san Oriental Hijinks." Los Angeles Herald-Examiner, June 15 .

Macdonald, Moira. 2002. "James Bond is Back in 'Die Another Day.” Seattle Times, November 22, http://community.seattletimes.nwsource.com/archive/?slug=di e22\&date $=20021122$.

Majors, Dan. 2005. “Trend Watchers Have a New Label for a Refined Man's Man: Ubersexual." Pittsburgh Post-Gazette, November 26.

Mandel, Ernest. 1984. Delightful Murder: A Social History of the Crime Story. London: Pluto Press.

Manganas, Nicholas. 2019. "Real Men: Sam Smith's Emasculation of the James Bond Theme." Celebrity Studies 10, no. 3: 436-40.

Manning, Maria. 1990. "Futile Attraction." New Statesman and Society: 12-13.

Martinson, Jane. 2012. "Is Skyfall a Less Sexist Bond Film?” The Guardian, October 30, https://www.theguardian.com/film/the-womens-blog-with-janemartinson/2012/oct/3o/skyfall-less-sexist-bond-film. 
Maslin, Janet. 1995. “That 'Sexist, Misogynist Dinosaur' James Bond.” The New York Times, November 17, C17.

Maslin, Janet. 1999. "The World is Not Enough.” The New York Times, November 19, http://www.nytimes.com/library/film/111999enough-film-review.html.

McAllister, D. C. 2017. "Why James Bond Should Never be a Woman." The Federalist, July 24, http://thefederalist.com/2017/07/24/james-bond-never-woman/.

McDonagh, Maitland. 1996. “GoldenEye.” TV Guide, January 14, http://www.tvguide. com/movies/GoldenEye/review/130384/.

McGrath, Nick. 2012. "Roger Moore: My Family Values." The Guardian, September 29, https://www.theguardian.com/lifeandstyle/2012/sep/29/roger-moore-my-familyvalues.

McInerney, Jay. 1996. “How Bond Saved America-And Me.” In Dressed to Kill:James Bond the Suited Hero, edited by Jay McInerney, Nick Foulkes, Neil Norman, and Nick Sullivan, 13-37. Paris: Flammarion.

Menkess, Suzy. 2006. "Past Present; Secret Agent Man.” The New York Times, March 12, http://query.nytimes.com/gst/abstract.html?res=9Fo5EoDA113EF9 31A2575oCoA96ogC8B63\&legacy=true.

Meyers, Lawrence. 2014. "James Bond: Super Spy. Franchise Anchor. Icon of Masculinity." Breitbart, July 2, http://www.breitbart.com/big-hollywood/2014/o7/o2/ james-bond-masculine-icon/.

Miliband, Ralph. 1969. The State in Capitalist Society. New York: Basic Books.

Miller, Toby. 2001. SportSex. Philadelphia: Temple University Press.

Miller, Toby. 2008. Madeover Nation: The United States of Reinvention. Columbus: Ohio State University Press.

Moniot, Drew. 1976. "James Bond and America in the Sixties: An Investigation of the Formula Film in Popular Culture." Journal of the University Film Association 28, no. 3: 25-33.

Moodie, Clemmie, and Danielle Lawler. 2008. "James Bond in Metrosexual Makeover Shock." The Daily Mirror, April 17, http://www.mirror.co.uk/3am/celebrity-news/ james-bond-in-metrosexual-makeover-shock-303132.

Moran, Christopher R. and Trevor McCrisken. 2019. "The Secret Life of Ian Fleming: Spies, Lies and Social Ties." Contemporary British History 33, no. 3: 336-56.

Morris, Wesley. 1999. "New Bond Not Quite Enough." The San Francisco Examiner, November 19, http://www.sfgate.com/news/article/New-Bond-not-quiteenough-3057334.php.

Nathan, Ian. 2000. “Diamonds Are Forever Review.” Empire Magazine, January 1, http://www.empireonline.com/movies/diamonds-forever/review/.

Newland, Martin. 2006. “'Bond' Heralds the Return of 'Pure Pecs' Appeal.” The Daily Mail, November 23, http://www.dailymail.co.uk/femail/article-418054/ Bond-heralds-return-pure-pecs-appeal.html. 
Nolte, John. 2019. “Daniel Craig Endorses Terrible Idea of Female James Bond.” Breitbart, April 29, https://www.breitbart.com/entertainment/2019/04/29/ daniel-craig-endorses-terrible-idea-of-female-james-bond/.

O'Neill, Phelim. 2012. "My Favourite Bond Film: You Only Live Twice." The Guardian, October 4, https://www.theguardian.com/film/filmblog/2012/oct/o4/ favourite-bond-you-only-live-twice.

Orr, Christopher. 2008. "James Bond, Necrophiliac." New Republic, September 21, https://newrepublic.com/article/44525/james-bond-necrophiliac.

Rand, Ayn. 1975. The Romantic Manifesto: A Philosophy of Literature, rev. ed. New York: Signet.

Reynolds, Deidre. 2007. "It's the Last Stop for Metro Man." Independent Ireland, June 21. Robinson, Cedric. 1984. "Indiana Jones, The Third World and American Foreign Policy: A Review Essay." Race \& Class 26, no. 2: 83-92.

Roszak, Theodore. 1969. The Making of a Counterculture: Reflections on Technocratic Society and Its Youthful Opposition. New York: Anchor Books.

Ruiz, Alfonso, and S. E. Santander. 2006. "Y tú de quién eres?” El Diario Montañés, May 7 .

Sann, Paul. 1967. Fads, Follies and Delusions of the American People. New York: Crown. Simpson, Mark. 1998. It's a Queer World: Deviant Adventures in Pop Culture. London: Harrington Park.

Smith, Jim, and Stephen Lavington. 2002. Bond Films. London: Virgin Books.

South Bank Show. 2008. "James Bond Special," https://www.youtube.com/ watch?v=KxtgAuyırmA.

Synnott, Anthony. 1990. "The Beauty Mystique: Ethics and Aesthetics in the Bond Genre." International Journal of Politics, Culture and Society 3, no. 3: 407-26.

Thumim, Janet. 1992. Celluloid Sisters: Women and Popular Cinema. New York: St. Martin's Press.

Tippins, Stephen B., Jr. 2012. “o07's Masculine Mystique.” American Conservative, October 17, http://www.theamericanconservative.com/articles/oo7s-masculinemystique/.

Toffler, Alvin. 1971. Future Shock. New York: Bantam.

Torregrossa, Richard. 2007. "The New Gentleman." The San Francisco Chronicle, February 25, http://www.sfgate.com/living/article/The-New-Gentleman-Stepaside-Mr-Metrosexual-2646133.php.

Tracinski, Robert. 2015. "Why We Need James Bond.” The Federalist, November 6, https://thefederalist.com/2015/11/o6/why-we-need-james-bond/.

Travers, Peter. 1997. “Tomorrow Never Dies." Rolling Stone, December 19, http:// www.rollingstone.com/movies/reviews/tomorrow-never-dies-19971219.

The Unlovable James Bond (2016). BFI Films http://www.bfi.org.uk/films-tvpeople/569ce283od26b. 
Williams, Zoe, and Paul Flynn. 2006. "The Spy Who Buffed Up." The Guardian, November 16, https://www.theguardian.com/film/2006/nov/16/jamesbond. features.

Young, Derek S. 2019. “Bond. James Bond. A Statistical Look at Cinema's Most Famous Spy." CHANCE 32, no. 1: 27-35.

Yule, Andrew. 1992. Sean Connery: From ooz to Hollywood Icon. New York: Pinnacle. Zakaria, Namrata Sharma. 2004. “The Female Gaze.” Express India, July 4.

\section{About the Author}

Toby Miller is Research Professor of the Graduate Division, University of California, Riverside; Stuart Hall Profesor de Estudios Culturales, Universidad Autónoma Metropolitana-Cuajimalpa; and Professor in the Institute for Media and Creative Industries, Loughborough University London. The author and editor of over forty books, his work has been translated into Spanish, Chinese, Portuguese, Japanese, Turkish, German, Italian, Farsi, French, Urdu, and Swedish. His most recent volumes are How Green Is Your Smartphone? (co-authored, 2020), El Trabajo Cultural (2018), Greenwashing Culture (2018), Greenwashing Sport (2018), The Routledge Companion to Global Cultural Policy (co-edited, 2018), Global Media Studies (co-authored, 2016), The Sage Companion to Television Studies (co-edited, 2015), The Routledge Companion to Global Popular Culture (edited, 2015), Greening the Media (co-authored, 2012), and Blow Up the Humanities (2012). The Persistence of Violence: Colombian Popular Culture is in press. 



\title{
7. Femininity, Seriality and Collectivity: Rethinking the Bond Girl
}

\author{
Moya Luckett
}

\begin{abstract}
Bond Girls are often used to index fifty years of popular assumptions about feminism and femininity. This chapter considers how the Bond Girl's particular position as part of this collective moderates her individuality and limits her agency even as it imbues her with historical and historiographic value. I argue that the Bond Girl's collective identity is allied more to seriality, with its forward-looking regulation of femininity allied to replacement, atomization and substitution rather than the more utopian relational ideals of the female group linked to difference, possibility and growth. Drawing on selected films, reception and marketing discourse, I will trace how the Bond Girl's femininity is caught up in a serial identity that both flaunts and forecloses agency and possibility.
\end{abstract}

Keywords: Bond Girl; femininity; fashion; postfeminism; serial; female group

Easily recognized and sometimes iconic, Bond Girls are used to index over fifty years of popular assumptions about feminism and femininity, spanning 196o's sex symbols, 1970's quasi-feminists and postfeminist sparring partners. Although individual Girls have come close to full narrative subjectivityunderstood in the series and by its critics as parity with o07's professional expertise, control over space, activity and sexuality-Bond Girls' serial quality positions them as second-class subjects. While Bond unifies different actors via a single, ever-developing, if discontinuous, identity that gives him an unusual capacity to adjust to social change and public taste, Bond Girls are usually contained within a single film, framed as creatures of their time with limited capacity to progress and develop. Moneypenny and,

Verheul, J. (ed.), The Cultural Life ofJames Bond: Specters of oo7. Amsterdam: Amsterdam University Press, 2020 DOI 10.5117/9789462982185_CHO7 
latterly, Judi Dench's M (1995-2012) remain franchise constants despite being played by different actors, but they bear a tenuous relationship to the Bond Girl-typically older, these long-term colleagues are not sexually involved with 007. ${ }^{1}$ Often defined in terms of their relationship to 007, Bond Girls also help define Bond: "The difference [...] is that Bond is named, identified, singularized, whereas women remain generic, interchangeable, dependent" (Lindner 2015, xvii).

This chapter explores the Bond Girl's distinctive seriality, examining its vexed relationship to the collective identities and female connections central to femininity while considering the implications for feminism, female agency and popular feminine historiography. Drawing on selected films, their reception, marketing discourse and social/institutional contexts, I trace the Bond Girl's problematic intersection with feminine and feminist cultures, framed here within concepts of the collective and the serial. Whereas most feminine collectives link diversity to femininity's complexity and highlight women's presumed desires for female connection, the Bond Girl's seriality both atomizes her and renders her replaceable. Even roles intended to challenge this archetype fail as novel treatments of femininity and/or feminism because they are enmeshed in the formal and cultural repetition, recycling and seriality inherent in a character function played out across 24 films, each with multiple Bond Girls. Marketing and the cultural imagination nevertheless link Bond Girls with their predecessors and those who will follow, helping forge a putative Bond Girl archive that, in turn, points to an inescapable collectivity with marked implications for feminism, itself a topic central to the Bond universe.

Both a reference to individual girls and their collective identity, the term "Bond Girl" operates as a catch-all for every young women in the franchise and as something more nuanced. Some academics and critics consider only love interests or professional partners Bond Girls despite publicity and post-release commentaries including a panoply of minor characters and bit part players (Mills 2015, 110-19. Caplen 2010, 125, 346). For example, Lisa Funnell identifies a mere twenty-two Bond Girls, each a lead in a single film, setting them apart from franchise villains, helpers, lovers, "Bond Women" and "secondary girls," effectively reserving the designation for those who are sexually, romantically and/or professionally aligned with 007 (Funnell 2008, 63; Funnell 2011a, 199-212). Accordingly, one of the Bond

1 Naomie Harris's appearance and youth initially led some to include her as a Bond Girl. Her subsequent outing as Eve Moneypenny instead allied her with other continuing members of the ensemble. 
Girl's distinctive qualities is her intimate knowledge of and suitability for 007, a man whose profession she sometimes shares (Funnell 2011b, 464; Burnette 2015, 61). Depending on the film (and the critics' own perspective), this resemblance potentially individualizes the Bond Girl, enhancing her powers, or renders her a facsimile of the male original, undermining her agency. Another dominant approach analyses Bond Girls in relation to their female counterparts (within and across films), raising the potential of the Bond Girl as archive (Ulfedotter 2015, 7-17; Funnell 2015, 79-87). But while these studies point to the Bond Girl as a collective, they rarely examine its significance, instead tracing individual Girls' feminist credentials. I opt here for the broadest and most inclusive definition of the "Bond Girl" in order to trace popular understandings of the archetype's cultural and historical significance.

A spectacular part of the Bond universe and its promotional machinery, these young or youthful-looking women are renowned for embodying period trends. Their looks, dress, personal and professional characteristics therefore index period pop culture in ways that Bond often does not, placing him in that conventionally masculine role of seemingly stable, unchanging subject. While often allied to novelty-each Bond Girl has to be "new" even as she recycles and reworks the core archetype - these women often tame the formerly radical, as seen with Grace Jones (May Day), whose image had become tired by A View to a Kill's (UK: John Glen) 1985 release. A contemporary rather than cutting edge figure, the Bond Girl's associations with period popular culture both embed her in history and simultaneously configure her as ephemeral.

\section{Seriality and Collectivity}

The serial's two major aspects inform the workings of the Bond Girl as cultural, textual and promotional category: the narrative and the mathematicalpolitical. The former refers to ongoing sagas that are primarily modernist constructs designed to manage and respond to the very mass production of which they are a part. Refusing closure, these serials often deal with issues that are too substantial or troubling for any self-contained text: for Bond, these include threats to the UK in a reconfigured world (post-empire, then post-Cold War and the current global/digital economy) as well as challenges to white masculine power associated with the rise of feminism (Bennett and Woollacott 1987, 93-142, 211-30). Such ongoing dilemmas lead to the serial's profusion producing a narrative world whereby characters replace each 
other as they enact parallel and affiliated situations_-just like the different Bond Girls who find themselves in similar positions across the franchise, straddling different times and spaces. Serials encourage anticipation while cycling back to earlier narratives, just like the Bond Girls who move the franchise forwards through replacement and substitution but often fail to benefit from any potential "progress."

While the narrative serial looks forward, reflects upon prior events but never reaches a successful apotheosis, the mathematical serial is predictive and consistent, always structured by its internal logic. As Benedict Anderson has shown, it is consequently attractive to the modern state and governmentality, promising order by identifying subjects and putting them in their place via names, Social Security and National Insurance numbers. Hierarchical and sequential, this serial logic is rooted in comparison, making it innately competitive, something seen in commentary on Bond Girls across the franchise (Anderson 1998,19-25). Inherently passive, as Jean-Paul Sartre and Iris Marion Young have pointed out, both forms of the serial present collectives of weakly connected individuals subjected to power who lack the group's capacity for action or resistance. For example, Bond Girls are almost always individualized and rarely work together (exceptions include villains like Pussy Galore's Flying Circus, whose members are essentially interchangeable). Most cannot collaborate as they appear sequentially over many years and do not constitute what Sartre would consider a group.

Following Sartre, Young has called for the reconceptualization of social groups in terms of "serial collectivity [...]. Such a way of thinking [...] allows us to see women as a collective without identifying common attributes [...] or implying that all women have a common identity" (Young 2008, 201). Sartre's series is unselfconscious and fluid, a form of constraint that operates amidst "structures that have been created by the unintended collective result of past actions" (213). It does not define individual identities even as it restricts possibilities for action, with members finding themselves "powerless to alter this material milieu, and they understand that others in the series are equally constrained" (215). Linking figures like Bond Girls without shared characteristics or goals, the serial is both more diverse and more passive than the group.

Central to popular feminine culture, the all-female group typically constitutes one of its more utopian features. It presents femininity as relational, linking female friendship to self-actualization while attesting to the emotional literacy demanded from women. Unlike second wave feminism's group consciousness, however, postfeminist collectivity is inherently individualistic. Configured in terms of self-care, it presents the group 
in terms of its potential personal, affective, professional and economic, but tellingly not political, rewards.

As an atomized collective lacking the close interpersonal relationships of the female group, Bond Girls have a contentious relationship to these feminine ideals, attesting to their status as both male fantasy figures and possible sites for feminine identification and emulation. A serial construct rather than a group, they link weakly connected characters across several decades. Even as members proliferate, they do not gain power, partly because they replace each other, making collaboration uncommon, if not impossible. Instead, the franchise standardizes female experience as all these women, regardless of their morality, ethics, and motivation, will be replaced and thereby expelled from this narrative world. So forgettable are some that they can even reappear as another character: From Russia with Love's (UK: Terence Young, 1963) Zora (Martine Beswick) resurfaces in 1965's Thunderball (UK: Terence Young, 1965) as the no more memorable Paula Caplan. Even those who linger across films, like Bond's (would-be) girlfriend Sylvia Trench (Eunice Gayson) in the first two installments, link seriality to failure or even death. Trench never secures Bond and her role is quickly dropped. Later films reveal Bond's continued feelings for Tracy di Vicenzo and Vesper Lynd after their death, transforming them into memories that motivate his actions.

Perhaps unsurprisingly, popular media usually do not present Bond Girls as a mutually beneficial collective, instead isolating and ranking individual members. Some are singled out as "firsts," exemplars of the kinds of female "progress" the franchise allows- the first Bond Girl (Dr. No's Ursula Andress/ Honey Ryder; UK: Terence Young, 1962), the first black Bond Girl (1971's Diamonds Are Forever's Trina Parks/Thumper; UK: Guy Hamilton, 1971), the first American (Diamond's Jill St. John/Tiffany Case), the first Mexican Bond Girl (Stephanie Sigman/Estrella in Spectre [UK/USA/Austria/Mexico/ Italy/Morocco: Sam Mendes, 2015]), the first villainess/Bond Girl hybrid (Dr. No's Zena Marshall/Miss Taro), the first Bond Girl in her 5os (Spectre's Monica Bellucci/Lucia Sciarra) and the only one to marry o07 (1969's On Her Majesty's Secret Service's Diana Rigg/Tracy di Vicenzo; UK: Peter Hunt, 1969). Rather than female camaraderie, this framing presents the Girls battling for Bond's - and the viewer's - attention. Accordingly, features ranking Bond Girls - the most attractive or memorable, best or worst, most or least intelligent-have surrounded each release since at least 2002's Die Another Day (UK/USA: Lee Tamahori, 2002). Social media has further showcased the different ways in which Bond Girls can be ordered and reshuffled-a practice with implications for both history and feminism. Reinforcing the 
logic of progress - the first, the best, the worst, the most beautiful, the most stupid, the most unnecessary - history is presented as events organized in a predominantly linear, chronological fashion. The films and their reception/ publicity discourse then use this historiography to secure the evaluation of Bond Girls - and by extension women outside the text - in terms of their putative emancipation and/or the degree to which they embody or divert from patriarchal male fantasies (something seen in discussions of the franchise's earlier installments). Feminism(s) are consequently embedded within the consumerist logic of progress (Packer and Sharma 2009, 95-98; Radner 1999, 8-9). Through

this evolutionary tale of feminism, which is in large part the product of a revisionist history that treats feminism as a linear achievement of women's progress through the years, the Bond Girl becomes only more and more feministic [sic] to the point where she becomes a postfeminist, bypassing altogether the label of feminist. In fact, feminism is not necessarily acknowledged as a worthy social struggle that has had any effect on the lives of the women discussing their lives as Bond Girls, instead it is something that happened outside of the text that exerted pressure on the filmmakers to re-represent the Bond Girl (Packer and Sharma 2009, 97).

Even as it subsumes female diversity and racial, sexual, ethnic or professional difference into aesthetics, this historical narrative foregrounds Bond's growth and social awareness, both as character and franchise, tracing his migration from British agent to increasingly global figure.

The Bond Girl, then, is simultaneously category, brand, historiography, mode of evaluation and archive of (largely recycled) images of women. While this recycling potentially disturbs the franchise's progress narrative, it is nevertheless widely associated with populist images of female liberation. As Yvonne Tasker points out, Bond Girls coopt period ideals of female strength and independence, moving, for example, from the 196o's fascination with sexual liberation to the 1970's "figure of fun-if you think of the ads at the time that celebrate that independence, like Charlie, they're very similar to the [era's] Bond Girl" (Rothman 2012). This progress narrative and the practice of recycling (including the self-cannibalization involved in the franchise's allusions to its earlier incarnations) further signify the Bond Girl's inherent seriality. These practices, in turn, evoke temporalities that coexist within this Bondian articulation of history: the franchise reboots itself each time a new actor plays James Bond, while 
each new unveiling of the Bond Girl [...] is always also an unveiling of a more "evolved" feminist role model [...]. The unveiling begins a long term (for some of the actresses more than forty years) public relations campaign of exploiting the notion of "the new" to denote female advancement. Ultimately, within this discourse her power lies in the fact that she needs neither Bond nor the feminist movement (Packer and Sharma 2009, 92).

Being new also means that Bond Girls risk rapid obsolescence, their value embedded in a temporality that quickly assigns them to history, just like Bond's other accessories.

Embedded in progress rhetoric, practices of replacement and substitution are found within each film as well as across the franchise's broader history. In refusing closure, the serial has an asymptotic logic: it moves close to its goals but cannot achieve them. Final installments usually fail to convince, largely because serials engage fundamentally irresolvable problems that encourage us to return and reflect back on earlier dilemmas. As a serial construct, the Bond Girl simultaneously attests to the ways in which these women are brought together, usually not for their own benefit or for a broader feminist cause, as well as to the problematic status of female emancipation within the franchise. Framing the Bond Girl since her inception, this appropriation of feminism continuously molds reception practices and discourses.

While each film's Bond Girl must be unaware of her status, it is now almost compulsory for actresses like Jane Seymour, Maryam D'Abo, Halle Berry, Olga Kurylenko, Monica Bellucci and Léa Seydoux to reflect on their place in franchise history when promoting each new installment. Here each Girl measures herself against the others as cultural memory precludes them existing in isolation. Interviews either argue for the exceptional, progressive nature of each new Bond Girl or celebrate what they see as the neglected feminist qualities of their predecessors - even as actors try to distinguish their characters from those who came before. For example, in promotional interviews for 2006's Casino Royale (UK/Czech Republic/ USA/Germany/Bahamas: Martin Campbell, 2006), Eva Green (Vesper Lynd) argued that she was not a Bond Girl and that she was "less iconic, more human [...] rather than just beautiful and sexy [...]. Far from feeling part of a glamorous pantheon, she dismisses most of the Bond Girl archive as chauvinist fantasies - with the notable exception of Honor Blackman's [...] Pussy Galore" (Sachs 2006). On the other hand, 2012's Skyfall's (UK/USA: Sam Mendes, 2012) Berenice Lim Marlohe (Sévérine) and Naomie Harris (Moneypenny) frame Bond Girls as strong and progressive, with Marlohe describing her character as having "all of the classic components of a Bond 
girl: voluptuous, sexy, a woman and not a girl, a mystery and a survivor" ("Skyfall Bond Girls", n.d.). While she later critiqued her role and vowed not to appear in the franchise again, Gemma Arterton initially praised her forbears in promotional interviews for 2008's Quantum of Solace's (UK/USA: Mark Forster, 2008): "My character [Strawberry Fields] is an homage to the 196os original Fleming-type Bond girl and definitely the way she looks. She is just fun and lovely [...]. It's brilliant [...]. Just to be known as a Bond girl is an incredible thing for me [...] even as I don't really think my character is Bond-girly" (Laufer-Krebs, n.d.). Despite distinguishing herself from her predecessors, noting that, amongst other things, she survives to the end of the film, Spectre's Léa Seydoux does not diminish them: "I don't mind the cliché of the Bond girl, it's a choice. A statement. I'm not the typical Bond girl" (Coren 2015).

\section{Postfeminism and the Bond Girl}

Seydoux's use of "choice" recalls the postfeminist sensibility that tries to reclaim Bond Girls as desiring women in charge of their own lives, unconstrained by monogamy and reproduction as they seek pleasure and adventure outside the home. Often problematic, such efforts overlook individual girls' struggles to retain agency even as they validate their collective accomplishments. Often dubbed "choice feminism," signifying its relationship to consumerism and its neoliberal investment in individuality, postfeminism departs from the women's movement's collective social responsibilities and free market critiques. Instead, as Angela McRobbie has shown, it uses feminism's mainstream acceptance to position it as unnecessary, part of a less enlightened historical moment (McRobbie 2004, 255-64; McRobbie 2009, 1-12, 24-40, 66). Simultaneously a historical development (post- second and third wave feminism), a sensibility found in mass media and popular culture, and a form of backlash, postfeminism positions women as ideal neoliberal subjects by making them responsible for their own fate (Gill 2007, 218-71). Maintaining that battles for equality have been won, postfeminism positions class, race, age, national origin, sexuality and other inequities as easily overcome with the "correct" attitude. Heralding women's capacity to do anything as long as they want it enough, work hard and make the "right" choices, postfeminism gives rise to Anita Harris's two archetypes- the "can-do girl" and her "at-risk" counterpart, signifying its privileging of white, middle-class, upwardly mobile youth as well as neoliberalism's emphasis on individual responsibility (Harris 2004, 13-36). 
Young women invested in self-improvement who self-monitor their body, professional skills and emotions constitute postfeminism's ideal. Entirely self-reliant, they aim to have it all. More a market- and media-driven sensibility than a political or social movement, postfeminism is distinctly populist, emphasizing pleasure and success. It restores the primacy of the body, annexing it to an "essential" femininity that has to be cared for and nurtured lest it becomes undisciplined or decays, producing social marginalization, the loss of status and pleasure. Even as it heralds "the girl" and suggests aging can be overcome, postfeminism is, as Diane Negra points out, acutely time-conscious, measuring female success against myriad deadlines that often signify disappointment and failure (Negra 2008, 45-78). Despite ostensibly celebrating feminine pleasure and power, postfeminism instead circulates fantasies of largely inaccessible privilege, although its utopian emphasis and insistence on pleasurable self-improvement make it deceptively attractive.

Radner's reading of cinema's first Bond Girls highlights their postfeminist orientation (although she does not use the term): "Her body and her sexuality are the implicit rather than the explicit measure of her value, most important, it is she herself who reaps the benefits of her well-invested capital" (Radner 1999, 7). As she points out, the Bond Girl's ostensible sexual and gendered liberation serves the needs of consumer culture in the guise of a feminine "independence" that ultimately binds her to the necessity of physical and sexual self-improvement. Rather than feminists, then, the first Bond Girls might be seen as postfeminist antecedents, participating in both mid-twentieth century swinging bachelor culture and Cosmopolitan magazine's 196os light feminism. Associated with Helen Gurley Brown and centered on the figure of the working girl, this archetype focuses on glamour, work, self-improvement and the explicitly self-referential self-construction that Radner $(1999,8)$ links to "a slow evolution toward an economic and social structure in which the individual rather than the family became the primary locus of identity". Tracing the historical logic espoused by Lynn Spigel, postfeminism thus finds its antecedents in popular representations of an illusory past lacking feminism but filled with independent, young, beautiful working women who, like the early Bond Girl, seemingly achieved liberation on their own, rendering feminism unnecessary (Spigel 2013, 270-78).

Radner's analysis is important in tracing postfeminism's roots-its combination of hyper-individuality, self-reliance, female professionalism and self-construction-and linking them to the consumer culture the Bond Girl embodies. Within the films, however, the desire to consume 
often has negative consequences, tempting Girls into crime or putting them in danger even as it also facilitates their meetings with Bond. For example, Diamonds Are Forever's Tiffany Case and Plenty O'Toole so covet high-end consumption that they relinquish morality with the latter losing her life. For today's critics, bloggers and fans, the Bond Girl's retro-glamour, seeming liberation and life outside marriage and motherhood support utopian, postfeminist readings that are often based on images removed from their narrative contexts: beautiful, well dressed young women fight antagonists, almost overwhelm Bond and still find time for romance and sexual pleasure. But this ideal is often undermined in its execution: many Bond Girls show no real evidence of their professional skills (like Denise Richards' nuclear physicist Christmas Jones in 1999's The World Is Not Enough [UK/USA: Michael Apted]) and their activities often result in death or disappointment.

\section{How to Be a Bond Girl: Fashion, Beauty and the Postfeminist (Collective) Self}

In keeping with postfeminism's investment in self-surveillance and selfcreation, stories about how to be - that is, look like - a Bond girl proliferate, linking appearance to the Bond Girl's purported agency. In 2015, British Vogue released a glossy one-minute film to mark Spectre's release. Starring Léa Seydoux, How to Be a Bond Girl (Jeremie Rozan, 2015, style.com) used the high fashion magazine's consumerist female gaze in an effort to reclaim the Bond Girl as an icon of postfeminist style and independence. Positioned at the center of its diegesis, Seydoux is narrator, agent, object and subject (associations underlined by its title). The Bond theme plays as she stands at the bar of a high-end restaurant, enunciating the following rules, ones whose elusive quality evokes high fashion's connections to fantasy and the possibility of crafting multiple feminine selves:

\footnotetext{
Always make a bold entrance [...], remember to assess your environment, look out for glitches in the matrix. Danger usually comes from the most unexpected places. Neglect no options, never put all your eggs in one basket. I don't gamble but I like a little flutter now and then [...] but at all times keep your guard up. As a Bond Girl I've got be able to swim with sharks. It is part of the learning curve [as she says this camera traces the curve of her waist, simultaneously showing us the details of her black jacket]. Seydoux, Léa Seydoux.
} 
This monologue links high fashion and the well-honed fantasy of replacing 007 with an eminently feminine agent seemingly in control of her environment. As she surveys space, the camera foregrounds the female gaze's capacity to register and recall detail via a series of cutaways that embed her advice and vision in franchise history, each reference more explicit than the last. First a gadget is surreptitiously passed between two men, then a Faberge egg opened, evoking 1983's Octopussy (UK: John Glen). A poker chip points to the importance of casino gambling, particularly in Goldfinger (UK: Guy Hamilton, 1964), while the reference to sharks is accompanied by close-ups of a handsome young man whose metal teeth recall Jaws in The Spy Who Loved Me (UK: Lewis Gilbert, 1977) and Moonraker (UK/France: Lewis Gilbert, 1979). Finally, fashion is linked to fantasies of the empowered female subject as the film reveals Seydoux is wearing red dagger shoes inspired by From Russia with Love. Hyper-feminine, they merge the adult and childlike, explicitly referencing The Wizard of $\mathrm{Oz}^{\prime}$ 's (USA: Victor Fleming, 1939) ruby slippers as she clicks her heels to bring us back to "reality" while uttering the final words: "Seydoux, Léa Seydoux."

This short's structure is telling. It starts by individualizing Seydoux-alone by the bar, she directs the camera and scans space. Her look signifies her secret agent skills via references to franchise history, producing a backwards vision that recycles the past to suggest the difficulty of imagining a feminine future. Even as the film nods to the possibility of other powerful women through a cut to an older, stylish woman whose designer bag might contain a bomb, her counterpart's grey hair points to the problematic future facing all beautiful women. Their eye contact nevertheless signifies mutual feminine understanding, shifting the discourse to gender. Next, a trio of handsome young men (the sharks) stare back at Seydoux, linking female sexual desire to mortal danger. From here we move to fashion - at last something seemingly within female control as the camera traces its "learning curve" around Seydoux's waist, allowing (female) viewers to take in the details of her jacket before moving to her shoes and then back to her beautiful face. In keeping with Radner's observations, the voice-over positions her body, clothing and accessories as locus of her identity and central to her value. The film ends on a reflexive and self-aware note that both infantilizes Seydoux and links fashion's capacity for roleplaying to childhood fantasy. As she clicks her red heels, bringing together Bond and Dorothy Gale (Judy Garland), Seydoux's pigeon-toed stance and innocent face render her childlike while references to The Wizard of $\mathrm{Oz}$ highlight fashion's innate irrationality, positioning her Bond-like agency as just another dream - an unoriginal and heavily recycled one at that (Wilson 2003, 47-66). 
This film links Seydoux's self-surveillance, careful consumption and physical perfection not to espionage but to the ultimate (post)feminist fantasy of reversing the gaze, so central to femininity and the structure of fashion magazines. Her presentation of successful individualism is nevertheless undercut by the logic of substitutability - the audience hopes to take her place at the center of attention and as the apogee of beauty. We also know she will be replaced; such is the logic of both the Bond franchise and the magazine cover girl, another serial construct. Mired in fashion's need for constant change, she thus shares its capacity to index history without full participation. Even the film's title, How to Be a Bond Girl positions Seydoux as a type not an individual, reframing her as part of a well-known brand and inviting viewers to take up similar positions in this potentially unending serial or chain. Standing alone, she is ultimately isolated: connected to others only via threats, whether sexual, mortal or the ultimate menace, aging.

Mass market and high-end cosmetic brands like Avon (oo7 perfume) and Charlotte Tilbury (Bond Girl lipstick) offer a more utopian take on the Bond Girl's seriality, promising women who carefully manage their own self-presentation access to an idealized form of this collective identity, one that is only inspired by and therefore somewhat divorced from the films. Many of these fashion and beauty tie-ups and tutorials adopt the Bondian notion of history - linear progress combined with recycling and returnechoing Spigel's points about postfeminist histories that deny feminism (Spigel 2013, 270-78). A style blog, couturing.com proclaims, "The 'Bond Girl' image is rooted in the 196o's look of the original Bond films. Although throughout the decades Bond Girls have modernized the premise is still the same. Classic, sophisticated and extremely sexy" (Walsh 2012). A vintage website, Go Retro, recommended their readers emulate the Bond Girl's classic makeup and touchable, long hair, advocating exercise while shunning more contemporary activewear or tattoos (Pam 2015). Meanwhile, myriad online features discuss how to replicate the likes of Vesper Lynd's gowns, Solitaire's bohemian dresses, Pussy Galore's wrap blouses or Lois Chiles' and Tracy di Vicenzo's jumpsuits (Doupnik 2012; Nguyen 2015; Walker 2015).

Like Bond Girls, fashion exists in the dialectic between individuality and collectivity, promising a distinctive self while enforcing group social and aesthetic norms and inviting comparison with others. But Bond Girl fashion is ultimately problematic, pointing to shared collective features rather than individuating its members. This can be seen, for example, in a promotional poster featuring the "most memorable" Bond Girl outfits which highlights the difference between passive seriality and the greater variation the group allows. 


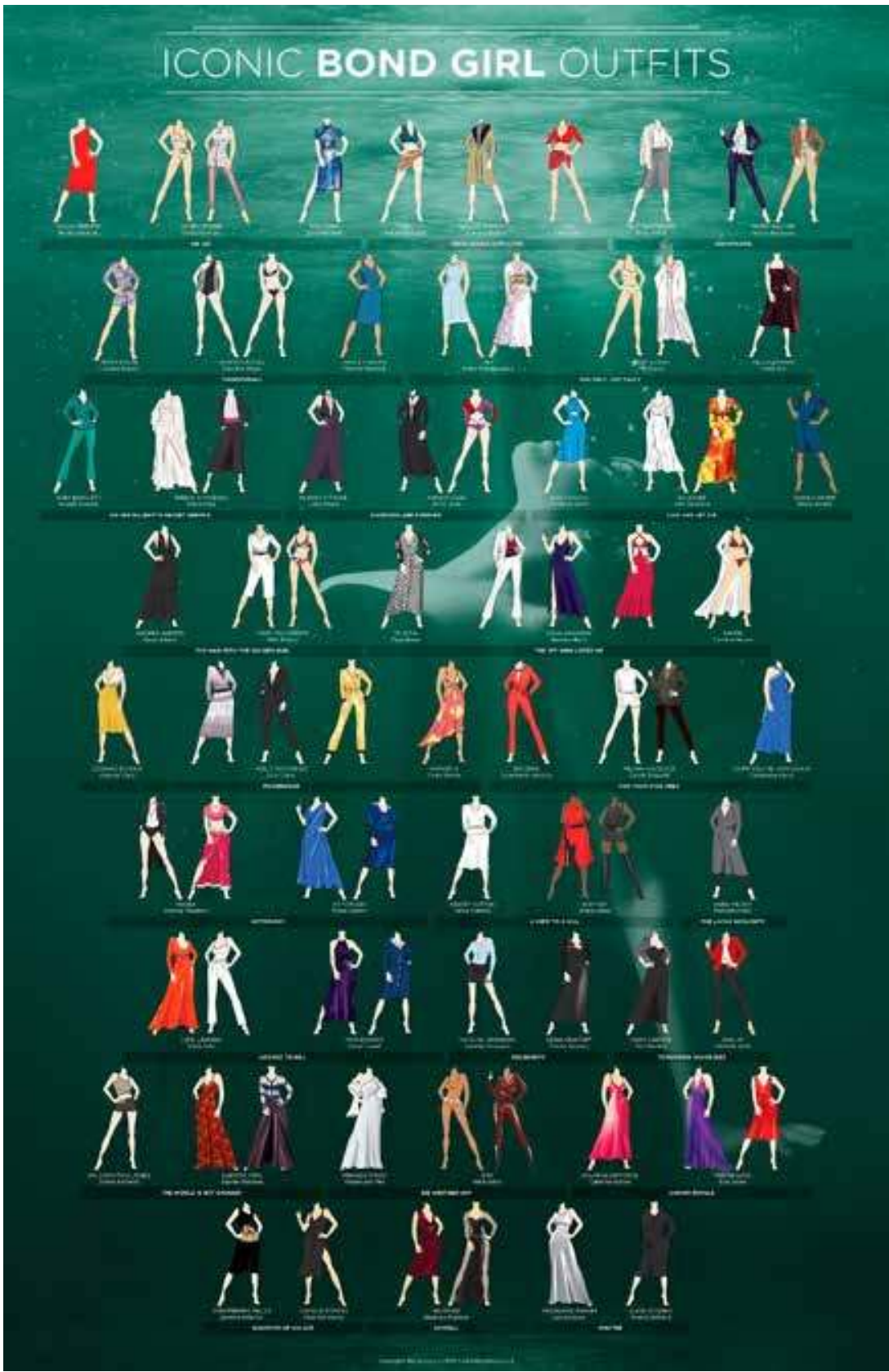

2. Promotional poster (2015) for the "most memorable" Bond Girl outfits, produced in anticipation of the release of Spectre (2015). Copyright of the London-based marketing company The Big Group Limited, United Kingdom. 
Designed by the London marketing company Big Group to mark Spectre's 2015 release, its drawings of headless bodies wearing key outfits from each film are organized in chronological order. Identical save skin color and dress, the overall effect is of one girl's wardrobe, a strategy that further recasts race as style. The repetition of certain items-bikinis, slinky evening gowns, jumpsuits, men's shirts/jackets-coalesces into a Bond Girl look that reduces historical variations, binding these women together over time. Similar recycling occurs across films, most famously in images of Ursula Andress (Dr. No) and Halle Berry (Die Another Day) wearing similar bikinis that point to the franchise's shared history while flattening the gap between the 1960's Swiss blonde and Berry's millennial mixed-race American Girl. A franchise characteristic, recycled fashions are used in 2006's Casino Royale to evoke "the history and glamour of the Bond films to create [sic] a timeless effect [...] that connects it to the earlier films," rather than to foreground feminine individuality (Severson 2015, 180).

Besides binding actresses to this collective, Bond Girl attire distances them from their other roles and off-screen identities. One iconic outfit, Diana Rigg's low-cut white lace wedding jumpsuit from On Her Majesty's Secret Service, contrasts with her more streamlined The Avengers (UK: Sydney Newman, 1961-1969) garb, suggesting a retreat away from modernity and independence that is further compounded by her character Tracy di Vicenzo's mental instability, marriage to Bond, and subsequent death. As one journalist points out, "the role of helpless heiress feels like a step backward after the smart and karate-kicking Mrs. Peel" (Kurchack 2015). Although Emma Peel's wardrobe was more varied than her iconic catsuits and streamlined jersey mini dresses suggest, Tracy's fluid and decorative fashions are emblematically feminine, featuring white lace blouses, cleavage and lots of girlish curled hair. This departure from Rigg's established style suggests efforts to rework her image away from her progressive, strong-willed and independent Avengers alter-ego.

A View to a Kill's May Day (Grace Jones) presents an interesting counterpoint to Rigg as the film uses Jones' well-known masculine image to signify villainy, capitalizing on her 1980 os fashion credentials with her black, red and yellow snoods, bat-winged leather jackets, padded shoulders, thigh high boots, and bright red jersey dresses. By this point, however, Jones had lost her power to shock. Cartoonish rather than cutting-edge, her costumes were as lacking in high fashion credibility as Moonraker's naïve futurism or the Caucasian Girls of the 196os aping exoticism with their cheongsams (Dr. No) and sarongs (From Russia with Love). Jones' clothes remind us that the Bond Girl style is populist, not high fashion with its glory days always slightly in the 
past - the early films' 1960 outfits arguably retain their fashion credibility because of the transformations wrought by time. Historical distance erases the specificities of period dress, transforms kitsch into style and permits the evocations of agency seen in feminist-oriented vintage aesthetics-conscious reworkings that exhibit some of the strategies postfeminist audiences use to recuperate the Bond Girl. Designed not for high fashion's female gaze but to capture male attention, the Bond Girls' attire ultimately undermines fashion's feminine knowledge, literacy and female address. Vogue's video speaks to this ambivalence, with its difficulty imagining a plausible future for its Bond Girl even as it celebrates her appearance, self-control and ability to master the gaze.

\section{Independence and the Female Group}

Critical considerations of independence, agency and individuality are central to feminist media criticism, spanning varied methodologies and concerns with text, context and audience. Similar issues shape the Bond Girl's marketing and popular reception. I do not want to suggest that individuality is more progressive, powerful or feminist than collectivity—indeed the question is often moot, given the diverse ideologies both terms encompass. Feminists may laud individuality and its close relative, agency, but both are also central to postfeminism's free market imperatives. Like individuality, collectivity is not inherently progressive but rather an ideal that is up for grabs. While feminism has historically embraced collective action, popular media typically misrepresent collectivity as homogeneous and dull, restricting social mobility (here seen as a reward for idealized forms of individuality) and eliminating pleasure. Other forms of collective femininity are seen as more "traditional," linked to the family, emphasizing relationships over work and even lauding the value of submission. Presentations of the female group often capture this ambivalence: it operates both as a sign of women's idealized relationality and encapsulates purported feminine limitations that foreclose agency and entry into public life.

Promotional images for the 1960's and 1970's films present Bond Girls as part of another regressive group: the harem. Roger Moore is pictured flanked by eleven swimsuit clad beauties for For Your Eyes Only (UK: John Glen, 1981), four young Asian women in pink bikinis wash Sean Connery in a hot tub for You Only Live Twice (UK: Lewis Gilbert, 1967) while George Lazenby sits amidst nine or ten ethnically and racially diverse starlets, several in different national dress (Blofeld's Angels of Death) for On Her Majesty's 
Secret Service. These images simultaneously point to and erase something powerful and attractive: the possibility of a public life oriented not just around self-betterment and self-display, but one that facilitates feminine camaraderie, something principal Bond Girls usually cannot access. As the female group and feminine connectivity become more central to millennial popular culture, the franchise has moved away from such scenes, which may now appear simultaneously more repressive and more difficult to reclaim for the male gaze. Pointing to the ambivalence of the female group in this cinematic universe (and others), the films favor seriality instead as it brings women together on terms that often preclude relationality while redirecting femininity's comparative gaze.

In most films, the Girl's allegiance to Bond limits her capacity to maintain relationships with other women. Groups of women working together are usually presented in a negative light, usually as villains in the 196os and

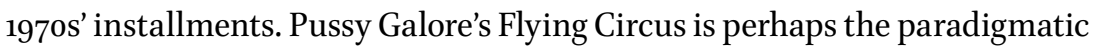
example of the visually undifferentiated female group: each (conventionally attractive) pilot wears an identical black catsuit, white belt, headband and ankle boots and styles her hair in a loose, curled bob. Their leader, Galore (Honor Blackman, an established actress who will be reclaimed from the group) wears a variation on this theme, pointing to her nascent individuality and subsequent redemption. Besides their lesbian implications, the Flying Circus are linked to death-Goldfinger orders them to spray nerve gas on Fort Knox, an activity Galore foils after Bond seduces her. On Her Majesty's Secret Service features another deathly female group, Blofeld's Angels of Death, who spray bacterial agents to spread infertility in plants and animals. Their dress presents them as exoticized representatives of racial and national difference, distinguishing them not as individuals but as types, with the film's credits bracketing most of them together as "The Girls" (Caplen 2010, 222). Other production decisions flatten female difference with German actress Nikki van der Zyl voicing at least thirteen Bond Girls in ten Bond films between 1962-1978, including Ursula Andress, Eunice Gayson and most of the actresses in Dr. No (Funnell 2008, 63-65; Roberts 2015). Such practices depart from feminine or feminist ideals of the female group as a positive, empowering or nurturing entity, reinforcing widespread interpretations of the Bond Girl as eminently replaceable or "entirely disposable" (Caplen 2010, 82).

The Bond title sequence displays perhaps the franchise's most reductive image of women with its serial profusion of different, barely identifiable hypersexualized girls, starting with the second film, From Russia with Love, whose credits are projected onto a bikini clad belly dancer's writhing thighs 
and torso. ${ }^{2} 1965$ 's Thunderball introduces the now-characteristic motif of the disposable and proliferating girl when one of its anonymous female silhouettes shoots another as they swim. This action produces more girls as a second, then a third optically printed figure materializes, with this series of cloned women effectively voiding each other's identity. More reflexive and tongue-in-cheek, On Her Majesty's Secret Service highlights her disposability as a range of Bond Girls (and a couple of male villains) pass through martini and wine glasses like sand through a timer, consciously indexing franchise history. Tomorrow Never Dies (UK/USA: Roger Spottiswoode, 1997) uses code to connect the Girl to the logic of the endless digital copy while transparent bullets containing nude women update the earlier films' girl-gun-bullet motif that signifies female danger. Despite hints at female authorship—For Your Eyes Only features Sheena Easton singing the title song while Licence to Kill (UK/Mexico/USA: John Glen, 1989) opens with a woman holding a camera, then a still image of another girl holding a gun - the franchise's established logic of proliferating silhouettes, abstracted nudes, and dancing figures shot from guns consistently foregrounds the Bond Girl's seriality and replaceability. A rare deviation from this pattern, Casino Royale, features no women other than a brief shot of Eva Green as the Queen from a deck of cards, rebooting the franchise and returning to $\mathrm{Dr}$. No's opening salvo of a gun targeting Bond. Female bodies return for Quantum of Solace, first via sandscapes that echo female curves and then through the arching back of a female nude, progressing to a zoetrope-like scene of dancing figures. Credits for Craig's films are generally more abstract: their Bond is more vulnerable, hard to read, and less in control of what are increasingly complicated global spaces. Possibly attesting more to changes in technology and music videos than in Bond and the Bond Girl, the credits nevertheless share their predecessor's logic of female replacement and proliferation. Although Bond Girls "progress" - they develop careers, become more multiracial, stand up for themselves, experience sexual pleasure and, in the Craig films, have increasingly technologized bodies - the franchise's title sequences present them as mass-produced figures who risk obsolescence. Rather than a single individual, the Bond Girl is here envisaged as part of a proliferating sequence, framed as a nodal point on the route to change, readily bypassed in the transition to the next new thing.

2 Sabrina Planka suggests that many of these women "lack coherent identities [...] [, envisaged] as two dimensional figures [...] or as fragments." Planka, Sabrina, 2015, "Female Bodies in James Bond Title Sequences," in For His Eyes Only, 142-43. 


\section{Conclusion}

Considering the Bond Girl as collective entity demands examination of the ways these women are brought together by the franchise, its audiences and popular culture. Largely kept separate in the films, posed as antagonists or replacements who perform the same limited range of functions-decoration, distraction, love interests, collaborators or threats - they are bracketed together in publicity and made part of a Bond Girl archive. Postfeminist efforts to reclaim the Bond Girl as a feminine icon likewise bring Bond Girls together to create historically impossible female groups that contest serial logic. Some actors use similar strategies to foster "real" connections and camaraderie, with Jane Seymour lauding "an interesting sorority. We all share about our Bonds [...]. We may as well be in high school" (McKay 2012). But this might be wishful thinking: differences in actresses' age and languages limit opportunities for socializing, making this collective more imaginary than real.

As replaceable, disposable figures in a franchise that shows no sign of ending, who serve and undermine narratives of progress, Bond Girls function as serial constructs: they follow each other but do not necessarily coexist, with each proposing a somewhat different approach to related core dilemmas. Connecting texts and the issues they raise, from sexual mores and gender ideals to geopolitics, the Bond Girl is unable to escape her own time and its limitations and conventions even as she invites comparisons with other Girls and other possible worlds. Her position is therefore essentially symbolic. Existing both in and across texts, she forms part of a network that fractures the linearity that she also serves.

Framing the Bond Girl in serial terms nevertheless foregrounds her vexed position with regards to feminism and feminist historiography: she may or may not seek female emancipation or work for the good of other women, but her actions are framed in terms of an agenda she does not-and cannot-set. She is delimited by the innate passivity of her seriality, even as she points towards greater feminine emancipation and agency. Here, the concept of the serial encapsulates some of the contradictions that make the Bond Girl so marketable, so promising and yet so limited a model for feminist possibility. She derives her force and cultural significance from being part of a group that frames her actions, positions her historically and yet traps her in its temporal logic, always folding back as it moves forward, never reaching its denouement. As such, she shares the serial's other pivotal characteristic: she does not make sense on her own. Her identity, meaning, and cultural significance all depend on a collective of which she can only be a part and whose future she cannot determine. 


\section{Works Cited}

Anderson, Benedict. 1998. The Spectre of Comparisons: Nationalism, South East Asia and the World. London: Verso.

Bennett, Tony, and Janet Woollacott. 1987. Bond and Beyond: The Political Career of a Popular Hero. London: Macmillan.

Burnette, Charles. 2015. "Bond's Bit on the Side: Race, Exoticism and the Bond 'Fluffer' Character." In For His Eyes Only: The Women ofJames Bond, edited by Lisa Funnell, 6o-69. London: Wallflower Press.

Caplen, Robert A. 2010. Shaken and Stirred: The Feminism ofJames Bond. Xlibiris. Coren, Giles. 2015. "Léa Seydoux: The Bond Girl Interview," Vogue (UK), November 6, http://www.vogue.co.uk/article/lea-seydoux-vogue-cover-interview.

Doupnik, Liz. 2012. "10 of the Most Fabulous Bond Girl Fashion Moments of All Time," Stylecaster, http://stylecaster.com/10-fabulous-bond-girl-fashion-moments-years/.

Funnell, Lisa. 2008. "From English Partner to American Action Hero: The Heroic Identity and Transnational Appeal of the Bond Girl." In Heroes and Heroines: Symbolism, Embodiment, Narrative and Popular Identity, edited by Christopher Hart, 61-8o. Kingswinford: Midrash Press.

Funnell, Lisa. 2011(a). "Negotiating Shifts in Feminism: The Bad Girls of James Bond." In Women on Screen: Feminism and Femininity in Visual Culture edited by Melanie Waters, 199-212. Basingstoke: Palgrave Macmillan.

Funnell, Lisa. 2011(b). “'I Know Where You Keep Your Gun:' Daniel Craig as the Bond-Bond Girl Hybrid in Casino Royale." Journal of Popular Culture 44, no. 3: 455-72.

Funnell, Lisa. 2015. "Objects of White Desire: (D)Evolving Representations of Asian Women in Bond Films." In For His Eyes Only: The Women ofJames Bond, edited by Lisa Funnell, 79-87. New York: Wallflower.

Gill, Rosalind M. 2007. Gender and the Media. Cambridge: Polity.

Harris, Anita. 2004. Future Girl: Young Women in the Twenty-First Century. London: Routledge.

Kurchack, Sarah. 2015. 'A Brief History of the Bond Girl Through the Ages.' Consequence of Sound, November 3, https://consequenceofsound.net/2015/11/ bond-girls-through-the-ages/.

Laufer-Krebs, Bonnie. n.d. “Gemma Arterton Interview: James Bond-ing.” Tribute.ca, Accessed July 15, 2017, http://quantumofsolace.tribute.ca/gemma_arterton.asp. Lindner, Christoph. 2015. "Foreword." In For His Eyes Only: The Women ofJames Bond, edited by Lisa Funnell, xvii-xviii. New York: Wallflower.

McKay, Hollie. 2012. "Bond Turns 50: Jane Seymour on being a Bond Girl." Fox News, September 17, http://www.foxnews.com/entertainment/2012/o9/17/janeseymour-on-being-bond-girl-was-meant-to-look-like-virgin.html. 
McRobbie, Angela. 2004. "Postfeminism and Popular Culture." Feminist Media Studies 4, no. 3: 255-64.

McRobbie, Angela. 2009. The Aftermath of Feminism: Gender, Culture and Social Change. Thousand Oaks: Sage.

Mills, Dan. 2015. “'What really went on up there, James?' Bond's Wife, Blofeld's Patients and Empowered Bond Women.' In For His Eyes Only: The Women of James Bond, edited by Lisa Funnell, 110-19. New York: Wallflower.

"Skyfall Bond Girls Berenice Lim Marlohe \& Naomie Harris Interview." MoviesOnline. ca, n.d., Accessed June 31, 2017, http://www.moviesonline.ca/skyfall-bond-girls/.

Negra, Diane. 2008. What a Girl Wants: Fantasizing the Reclamation of Self in Postfeminism. London: Routledge.

Nguyen, Kelsey. 2015. “7 'Bond Girl' Style Moments to Get You Hyped for Spectre.” Bustle, November 6, https://www.bustle.com/articles/122114-7-bond-girl-stylemoments-to-get-you-hyped-for-spectre-photos.

Packer, Jeremy, and Sara Sharma. 2009. "Postfeminism Galore: The Bond Girl as Weapon of Mass Consumption.” In Secret Agents: Popular Icons beyond James Bond, edited by Jeremy Packer, 89-110. New York: Peter Lang.

Pam. 2015. "How to Be a Bond Girl." Go Retro, November 4, http://www.goretro. com/2015/11/how-to-be-bond-girl.html.

Planka, Sabrina. 2015. "Female Bodies in James Bond Title Sequences." In For His Eyes Only: The Women ofJames Bond, edited by Lisa Funnell, 139-47. New York: Wallflower.

Radner, Hilary. 1999. "Introduction: Queering the Girl.” In Swinging Single: Representing Sexuality in the 196os, edited by Hilary Radner and Moya Luckett, 1-35. Minneapolis: University of Minnesota Press.

Roberts, Andrew. 2015. "Nikki van der Zyl: The Bond Girl You've Never Seen Who Voiced Some of the Films' Best-known Heroines." The Independent, October 11, https://www.independent.co.uk/arts-entertainment/music/features/nikkivan-der-zyl-the-bond-girl-youve-never-seen-who-voiced-some-of-the-filmsbest-known-heroines-a6689701.html.

Rothman, Lily. 2012. "Fighting, Flirting, Feminism: The Bond Girl Evolution. How has the Bond Girl changed between Dr. No and Skyfall?" Time, November 9, http://entertainment.time.com/2012/11/og/fighting-flirting-feminism-thebond-girl-evolution/.

Sachs, Ethan. 2006. "Actress Eva Green Makes for a Reluctant Bond Girl.” New York Daily News, November 16, reprinted in popmatters.com, http://www.popmatters. com/article/actress-eva-green-makes-for-a-reluctant-bond-girl/

Severson, Andrea J. 2015. "Designing Character: Costume, Bond Girls, and Negotiating Representation." In For His Eyes Only: The Women ofJames Bond, edited by Lisa Funnell, 176-84. New York: Wallflower. 
Spigel, Lynn. 2013. "Postfeminist Nostalgia for a Prefeminist Future." Screen, 54, no. 2 (June): 270-78.

Ulfedotter, Boel. 2015. "The Bond Girl Who Is Not There: The Tiffany Case." In For His Eyes Only: The Women ofJames Bond, edited by Lisa Funnell, 7-17. New York: Wallflower.

Walker, Harriet. 2015. "How to Dress Like a Bond Girl." The Times, October 15, https://www.thetimes.co.uk/article/how-to-dress-like-a-bond-girl-xglzojc2sg5.

Walsh, Georgia. 2012. "Get the Skyfall Look: How to be a Bond Girl Makeup 101." Couturing, November 22, http://www.couturing.com/get-the-skyfall-look-howto-be-a-bond-girl-makeup-101/.

Wilson, Elizabeth. 2003. Adorned in Dreams: Fashion and Modernity. New Brunswick: Rutgers University Press.

Young, Iris Marion. 2008. "Gender as Seriality." In Feminist Interpretations ofJean Paul Sartre, edited by Julien S. Murphy, 200-28. University Park, PA: Penn State University Press.

\section{Selected Filmography}

How to Be a Bond Girl (Jeremie Rozan, 2015, style.com) https://www.youtube.com/ watch?v=nLlVQnPWilU.

\section{About the Author}

Moya Luckett is the author of Cinema and Community: Progressivism, Exhibition and Film Culture in Chicago, 1907-1917 (Wayne State University Press, 2014) and coeditor of Swinging Single: Representing Sexuality in the 196os (University of Minnesota Press, 1999). She is currently writing two books, one on the relationship between celebrity, economic recession and foreclosed social mobility, the other on femininity and popular media. She has published essays and chapters on feminism and femininity in popular media, fashion, 196o's popular culture, British film and television, early cinema and celebrity culture. She teaches Media Studies in the Gallatin School of Individualized Study at New York University. 



\title{
8. Market Forces: James Bond, Women of Color, and the Eastern Bazaar
}

\author{
Lorrie Palmer
}

\begin{abstract}
This chapter examines the chase sequences in Tomorrow Never Dies (1997) and in Skyfall (2012) in order to argue that 007's varying relationships with women of color may be seen through the Otherness evoked by the Eastern bazaar: a site of visuality and mobility as well as a social space where both hybrid identity and cultural tourism are made visible. The earlier film (with Pierce Brosnan and Hong Kong action star, Michelle Yeoh) reflects what Mikhail Bakhtin casts as carnival, where inverted roles challenge social and cultural norms. In contrast, the later Bond (with Daniel Craig and a new Moneypenny, Naomie Harris), regresses to the Orientalist expression of an East-West relationship predicated on the colonial exercise of power based on exclusion and domination.
\end{abstract}

Keywords: James Bond, women of color, Eastern bazaar, carnival, Orientalism

When it comes to the exotic East in the James Bond franchise, 007 is frequently immersed in the chaotic spaces of the Eastern city and, in the films under discussion here, their mainstream movie centerpiece: the street market or bazaar. Across actors (Connery, Moore, Brosnan, Craig) and global cities, the super spy has brought his West-meets-East action to metropolitan locales from Tokyo (You Only Live Twice), to Hong Kong (Die Another Day, The Man with the Golden Gun, You Only Live Twice), to Istanbul (From Russia with Love, The World is Not Enough, Skyfall), to Saigon (Tomorrow Never Dies). As a public commercial district, the Eastern bazaar is a site of spectacle, display, and consumption as well as a social space where both hybrid identity and cultural tourism are made visible. The bazaar is where an encounter with Otherness

Verheul, J. (ed.), The Cultural Life ofJames Bond: Specters of oo7. Amsterdam: Amsterdam University Press, 2020 DOI 10.5117/9789462982185_CH08 
is a certainty and, like other urban zones, is a contested space between the traditional and the contemporary. "It represents the sensuous, the 'raw', the down to earth, the possibilities of sensory stimulation, and intrigue" (Vicdan and Firat 2015, 13). These characteristics are not unlike James Bond himself.

The Bond of our two most recent eras - those played by Pierce Brosnan and Daniel Craig - encounter the Eastern bazaar and they each do so in the company of a woman of color in Tomorrow Never Dies (UK/USA: Roger Spottiswoode, 1997) and in Skyfall (UK/USA: Sam Mendes, 2012), respectively. In the earlier film, Bond and Chinese intelligence officer, Wai Lin (played by established Hong Kong action star, Michelle Yeoh), are pursued through the street markets of Saigon; the white British man and the Asian woman share a motorcycle in a cooperative choreography between two professionals. In the latter film, Bond is paired with a fellow MI6 agent he knows only as "Eve" (Naomie Harris) as they chase a suspect through Istanbul, Turkey. Bond eventually separates from Eve to go at it alone, racing after their man on a motorcycle across the rooftop of the Grand Bazaar and, finally, through the interior spaces of the market stalls below. I contend that it is unity with or distance from his female partner, as staged at these sites, which effectively distinguishes the two Bonds. We can read the Brosnan Bond through the lens of what Russian philosopher and literary critic, Mikhail Bakhtin, casts as carnival in which hybridity and inversion challenge the social and cultural norms of the day. The Craig Bond, on the other hand, reflects the Orientalist mode outlined by Edward W. Said (1978) as an EastWest relationship predicated on the colonial exercise of power based on exclusion and domination.

In their study of contemporary globalization and the social practices of encountering Otherness in the context of the Turkish bazaar, Handan Vicdan and A. Fuat Firat offer a helpful framework for my analysis here. They explore the conflicting modes of being within the bazaar-one way is open to experiencing the Other and the other seeks segregation of the civilized from the unruly and heterogeneous. This perspective helps make the distinction between the two Bonds in these signature bazaar action sequences, with and/or without their respective Bond Girls. Vicdan and Firat explain that there is "a conflict between the global modern market and the local markets, the bazaars" $(2015,5)$, which corresponds to "the Orientalist approach where the encounter in this consumption space is sought [by the Western or westernized] as a 'tourist,' a somewhat distant observer" in contrast to a very different impulse in which a "willingness to accept 'otherness' is expressed" $(2013,17)$. The authors call attention to "issues of identity and the construction of otherness in the observed global consumer sensibilities" 
and find that people in this context "prefer not to be constrained within any single mode of being or experiencing life," instead wishing to experience difference, to "immerse in others' mode of being rather than stand detached and be a distanced observer" (Vicdan and Frrat 2015, 2). While these street market and bazaar settings function in the Bond canon as all foreign shooting locations have functioned throughout the franchise - to ideologically and iconographically situate Bond's specific masculine Britishness against the exotic, the foreign, the feminine, the uncivilized, and the threatening - they offer a unique perspective of 007 as a "variable and mobile signifier," reflecting shifting social attitudes that Tony Bennett and Janet Woollacott $(1987,42)$ have attributed to the character of James Bond over time. That the bazaar can do this through the spatial, social, and racial contexts associated with these urban sites simultaneously reveals that such social shifts are not always fixed or linear — and likewise the Bond franchise.

\section{The Bonds of Difference: Carnival / Orientalism}

What animates the carnivalesque aspects of the bazaar is "freedom, the freedom that, according to M.M. Bakhtin, issues from a suspension of 'laws, prohibitions, and restrictions"' (Zahlan 1988, 34). Carnival disrupts privileges and hierarchies in a city space of "many fusions" where "every extreme of race and habit can meet and marry" freely "on grand avenues and in narrow alleyways, in bazaars and cafés, on beaches and balconies" (Zahlan 1988, 35) as people encounter one another in close physical proximity and constant motion. Vicdan and Furat trace the increased acceptance of traditional neighborhood bazaars in Turkey by high-society patrons as well as how they enable a form of escape to women of both upper and lower classes. "The patriarchal ordering of modern commercial spaces" such as high-end shopping malls is inverted in the bazaar, where women can step outside the private domestic sphere and learn to master and "navigate a space that is not pre-ordered" and in so doing "experience a new public self" (Vicdan and Firat 2015, 18). In the Tomorrow Never Dies motorcycle chase, the new public self that is created is - for those moments and in that space-a hybrid self, erasing the distance between East-West as well as between male-female. Vicdan and Firat note that the bazaar "gives participants a sense of license to not simply be in a space but to negotiate its organization as well as their identities" (20), thereby "construct[ing] new spaces that permit new forms of being" (23). The environment itself mirrors the transformed body on the motorcycle. 
Elsewhere, the potential for such immersive encounters with otherness is resisted as global capital and corporate commodification permeate the local as well as the international markets. Istanbul, for example, has sought to re-package its bazaars with an eye toward cultural tourism and gentrification. Öz and Eder (2012, 298) describe these spaces of controlled commodification as "more capitalist, and less inclusive." Similarly, one of the key textual conventions of the Bond franchise and its Eastern locales- the exotic - has its roots in the commodity market of the British Empire's Victorian colonialist practices on the home front. Nineteenth-century London department stores (Whiteleys, Liberty, and Debenhams), although the very anti-thesis of the Eastern bazaar, nevertheless harnessed the power of European nostalgia for the Orient. The exotic, in this context, reflects the separateness of Craig's Bond within the commodified spaces of the Grand Bazaar in Skyfall's Istanbul chase sequence-and that separateness may be conceptualized alongside his detachment from the woman of color with whom he is initially paired in the film. Britain's Victorian-era nostalgia associated with the spectacle and consumption of Oriental goods resulted in the "naturalization of both sexual and cultural differences" as these sites "positioned the Other beyond the confines of Western 'civilization"' (Cheang 2007,3 ) in the mid-1880s. So, while Bond himself (as well as the filmmakers and fans of the series) are inexorably attracted to the exotic, it is still the liminal space of the Other by which Bond sets himself apart. Ross Karlan $(2015,198)$ observes that "Bond offers a contemporary manifestation of the Victorian self/Other dichotomy." This distanced relationship is physicalized into the separate trajectories of Bond and his female partner around and through the Eastern bazaar in Skyfall.

\section{To Bed or not to Bed: Bond and Women of Color}

Naomie Harris, as a black female MI6 agent representing the government institution of the British Secret Service, is initially presented as an active partner potentially on par with James Bond but the film quickly reorients her to a supportive role. Although her late reveal as the new Moneypenny is preceded by the action sequence that opens the film and serves to establish that her character is not the "desexualized mothering figure or desperate and doting admirer of Bond" played by Lois Maxwell in the Connery and Moore eras, it still falls short of the more progressive portrayal by Samantha Bond in the Brosnan films (Shaw 2015, 77). Kristen Shaw $(2015,77)$ points to this later version of the character "as a strong and attractive yet sexually 
unattainable woman capable of calling out Bond on his misogynistic antics" and adds that the Craig-era Moneypenny has not been nearly so "reimagined" as the Craig-era Bond. However, through her identity as a British agent and the centrality of her screen time in the opening of Skyfall and in light of her professional and sexual independence from Bond in Spectre (UK/ USA/Austria/Mexico/Italy/Morocco: Sam Mendes, 2015), Naomie Harris does deliver a character that diverges from the raced/gendered Otherness of previous black women in the series. For example, in A View to a Kill (UK: John Glen, 1985), May Day (Grace Jones) is depicted as physically powerful and sexually dominant toward Roger Moore's Bond, but her identity and actions are ultimately in service to her wealthy white male boss and lover, Zorin (Christopher Walken), allowing her to be read as a "postcolonial subaltern Other" (Wagner 2015, 56). Elsewhere, Jinx Johnson (Halle Berry), in Die Another Day (UK/USA: Lee Tamahori, 2002), quickly becomes an exotic object, memorably engaging with Brosnan's Bond in one of "the most graphic sex scenes in the franchise" (Wagner 2015, 57). In contrast, Naomie Harris' Eve/Moneypenny enters the series as a platonic peer to 007, particularly in the Istanbul sequence; however, her Otherness eventually becomes a destabilizing, even dangerous, force for Bond until she is safely relegated to the bureaucratic margins of MI6 by film's end. There are additional expressions for women of color in the franchise.

Shaw $(2015,75)$ describes the dual mode of Otherness in which "representations of Asian women in the franchise alternate between Bond Girl helpers and passive servers," while Lisa Funnell $(2015,83)$ similarly identifies these characters within their Orientalist soft-hard Asian stereotypes as either the Lotus Blossom or the Dragon Lady, each denoting an "Asian femininity [that] is defined in relation to James Bond," especially visible in the Connery era. To wit, Funnell $(2015,82)$ examines Aki and Kissy Suzuki in You Only Live Twice (UK: Lewis Gilbert, 1967) in the context of the "infamous bathhouse scene" in which Bond and a male Japanese agent are "bathed by a bevy of semi-nude Asian women" who are entirely submissive to the men as befits their traditional roles. This limited frame of reference is reinforced more recently from the insider perspective of Michelle Yeoh. The actor/producer/ martial artist remarks that, even with her work in Tomorrow Never Dies and in the global crossover hit, Crouching Tiger Hidden Dragon (China/Hong Kong/Taiwan/USA: Ang Lee, 200o), she has always had to "fight clichéd roles - the Suzie Wong type, the Chinatown waitress, the Chinatownwhatever" and that "[e]ven 10 years ago, they were the only roles available" (Gilbey 2008). Her distinction from previous Asian women in the Bond series is driven by her international stature as a marquee star from a national 
film industry-Hong Kong - that stands on the powerful tradition of its landmark 1980 s and 'yos action cinema. These bona fides have earned her a place in an action franchise like Bond (with its mission statement deeply invested in the international marketplace) while simultaneously making her an anomaly. "As an Asian woman in her mid-forties, her every appearance on screen defies mainstream cinema's bias towards the youthful, and the Caucasian" (Gilbey 2008). Therefore, Yeoh's presence as Colonel Wai Lin in Tomorrow Never Dies is a departure from Bond Girl (and action movie) conventions while, during its Saigon ${ }^{1}$ motorcycle chase, also embodies a hybrid identity through her professional and physical interchangeability with Bond's white Western maleness. Shaw $(2015,72)$ remarks that, although "women and people of color are not necessarily barred from this sphere, they are fundamentally conceptualized as 'out of place" and must be restored to the margins of that dominance. This dichotomy of open and closed systems is visible in the chase sequences in Tomorrow Never Dies and in Skyfall. Specifically, it is the Eastern bazaar and its social practices of spectacle, consumption, and mobility constituted through the act of looking and the navigational trajectories within it that distinguish the diverse approaches of the two films. It is how the pairings of Bond-Moneypenny and Bond-Lin interact with each other and with these site-specific locales that reveal the ways in which 007's varying relationships with women of color may be framed in association with the Otherness evoked by the Eastern bazaar.

\section{Skyfall: Moneypenny and the Detached Bond}

In pursuit of a stolen list that identifies covert NATO agents, Bond and Eve Moneypenny chase Patrice (Ola Rapace) through Istanbul in a Land Rover with Eve behind the wheel. Almost immediately, their quarry spots them and makes a sudden turn. This foreshadows the "problem" of Moneypenny in her capacity as a field agent. Her performance is contrasted throughout with Bond's superior skills at seeing and moving through the spaces of the street market they will soon enter and, subsequently, with his separate pursuit on and through Istanbul's famed Grand Bazaar. This divergence of their respective skillsets is conveyed through the relative cleanness of their trajectories, in the obstacles and architecture they encounter, and in the camerawork itself. When Moneypenny turns the wheel to follow the Audi

1 Due to last-minute visa difficulties, the production had to shoot this Ho Chi Minh City (Saigon) motorcycle chase in Bangkok, Thailand. 
ahead, she knocks off the vehicle's passenger side mirror, to which Bond responds, “It's alright, you weren't using it." This critique by Bond of her driving skills in the middle of a high-speed chase, establishes his dominance and exclusion of Moneypenny from the action arena.

The pursuit enters an extensive network of street market stalls as the Audi and the Land Rover race through it. The camera frames the action with rough-hewn bags of nuts and spices, stacks of bright oranges, silvery mass-produced samovars, fluttering scarves and other colorful textiles, and ornately-patterned Turkish rugs, situating these within the mise-en-scène on the sides and background of the shots as well as in the foreground. These are the exoticized objects associated with the touristic gaze of the Eastern bazaar. Subsequently, we see a shot of Moneypenny driving the Rover as Bond reaches across to take hold of the steering wheel, overriding her control of the vehicle. He steers them into the other car with enough force to send it banking vertically into a violent rollover. This chase-and-pursuit opening to Skyfall fortifies Bond's skills as a field agent in marked contrast to Moneypenny's abilities, which are highlighted as unreliable—in seeing, driving, and shooting - throughout the sequence.

Patrice emerges from the crashed Audi with gun in hand, firing off a volley of bullets at the MI6 agents, as Bond leaps out of the car to track him on foot. Each man grabs an unattended motorcycle and continues the chase with these more nimble and maneuverable vehicles while Moneypenny resumes driving the ponderous Land Rover. Without Bond in the car, Moneypenny is depicted as both disruptive and ineffective in her passage through the streets (and street markets) of Istanbul.

In spatial contrast, Bond and his quarry steer their motorcycles up a flight of stone steps to the open expanse of the Grand Bazaar's rooftop. Long shots and elegant, swooping camera movements capture the high-speed motorcycle chase across the flat roof tiles with the iconic Hagia Sophia as a dramatic backdrop. Crashing their motorcycles through a massive window to land in the interior spaces of the bazaar, the men make a short run past bright stalls of tourist items (mosaic ceiling lamps, fridge magnets, luggage, and more Turkish rugs) until they emerge back out on the streets. Moneypenny, in the meantime, is stopped dead by a traffic jam. To extricate herself, she reverses gears into the car behind her, crumpling its hood, then angles her vehicle diagonally and accelerates forward, hitting the car in the next lane. Finally clear, she drives over the grass divider into oncoming traffic where she hits the first car she encounters. In each of these collisions, the camerawork emphasizes Moneypenny as a chaotic force: using subjective angles from the point-of-view of the vehicles that she hits, the camera is put 
in the Land Rover's path to capture the assault of flying debris from each impact, shaking violently in close-up, at oblique angles, resulting in visual and spatial disorientation. From here, the film cuts to a smooth tracking shot at a clean right angle to Bond's motorcycle, which is moving unimpeded at high speed toward a bridge-while Moneypenny drives "the wrong way" into traffic. She screeches to a halt and leaps from the vehicle to shoot at Patrice, who has vaulted the railing and dropped down to a train passing beneath. Despite having him clearly in her sight, Moneypenny's repeated shots miss their mark, so Bond must make the same leap, engaging in hand-to-hand combat on the roof of the train with Silva's deadly mercenary.

This action sequence culminates with Moneypenny above the train tracks, where the film stresses her imperfect vision, as M's voice in her earpiece orders her to "take the bloody shot." Instead of hitting Patrice, though, Moneypenny's bullet sends Bond over the side of the bridge to freefall down to the river below. Kristen Shaw $(2015,72)$ points out that, in this moment, "Moneypenny's bad shot, and the disciplinary actions she must undergo as a result" reveals that "the presence of a powerful black woman at the center of this action narrative" is "out of place and unwelcome" (70) within the representational codes of the Bond franchise as it currently stands. Ultimately, we find that "Moneypenny has given up fieldwork to take over as his secretary and occupy a space that is on the periphery of power" (Parks 2015, 264). At the end of $S k y f a l l$, a wide shot shows James Bond overlooking the London skyline, surveying the city from a superior vantage point. This moment parallels the view available to him from the high rooftops of the Grand Bazaar during the film's opening chase sequence. His clear sight from these two rooftops establishes the connection between them to Britain's colonial Orientalist past and correlates such a superior range of vision with his dominant mobility through the Eastern bazaar. The embodiment of gaze and mobility is notably different in the Eastern bazaar spaces of Brosnan's Tomorrow Never Dies.

\section{“Who's Driving?": Navigating the Saigon Street Market in Tomorrow Never Dies}

During its central chase sequence, Tomorrow Never Dies imagines the two characters of James Bond and Wai Lin as one body. Their joining is not achieved through sexual union, as is the traditional Bond convention, but through the combined actions they take on a single motorcycle with assassins in pursuit. Bond and Lin initially work separately for their respective 
governments in investigating the media mogul, Elliot Carver (Jonathan Pryce), who wishes to foment war between Great Britain and China so that his global communications network may gain exclusive broadcast rights. They are both captured inside Carver's media headquarters in Ho Chi Minh City and find that they share a common goal to escape.

Handcuffed together in this endeavor, Bond and Lin briefly struggle over driving privileges for the motorcycle they are about to steal to make their getaway until Bond tells her to "get on the back." The subject of "balance" between them is physically demonstrated as well as embedded in subsequent dialogue and action stunts. It directly affects their shared ability to see clearly within this street market space as well as their trajectory through it. Seated behind Bond, Lin's left hand controls the bike's clutch as Bond's left hand works the accelerator on the other side. In learning to maneuver the bike as one body, they have a verbal exchange about the process. "Turn right," "No, left" and, finally, Lin counters with the whole point of this sequence: "Who's driving?" This is the question (and answer) that determines the outcome of their survival as the two pursuing Range Rovers proceed to have no less than three collisions with each other while the Bond-Lin pair flows through the street market with relative ease. The motorcycle drivers morph into a single hybrid entity (East-West, male-female) in the spirit of Bakhtin, whereby "carnival can now be seen as a model for the (parodic) performance of identity itself," allowing one to reject established social roles or take on other roles but also to embrace "the space between roles" (Hiebert 2003, 115). It is Bond-Lin's performance of this in-between self without boundaries that, likewise, dissolves the barrier between them and the city. As Moneypenny is depicted in Skyfall as being "out of place" by her collision-prone passage through Istanbul, here it is those who chase Bond and Lin that are marked as the outsiders. The two Range Rovers tear off the open door of a parked car, they hit street vendors' carts and rows of bicycles, they collide at various points with each other's front and rear ends, they crash through large stacked bags of grain, and they burst airborne water barrels only to drench their own windshields.

With increasing fluidity, Bond and Lin coordinate their skills in opening up the street market space to their hybrid gaze and to their immersive motion through it. This is visualized in the geography itself. They clear a maze of alleys and move en masse amidst other cyclists. Their movement is frictionless as they disappear into the flow of traffic, blending with the very spaces that the Craig-era Bond would disassociate with as an Orientalized, Othered environment. Rather than the touristic gaze we see in Skyfall's Grand Bazaar, the street market in Saigon is depicted without the colorful riot 
of consumer goods that characterize the Istanbul mise-en-scène. The street market is instead distinctly local—steaming woks for cooking, brief glimpses of green and yellow vegetables, and simple metal cookware-shaded by faded cloth awnings and umbrellas. Director Spottiswoode composes these street market shots with a muted color palette and a noticeable lack of exoticism; this is not the postcard Asia of Skyfall with its elaborate red and gold Macau Floating Dragon Casino.

It is Lin - with the action performance authenticity of Michelle Yeoh - who balances Bond's presence in this chase sequence. When he is unable to visually assess the speed and distance of their pursuers, it is Lin who improvises the hybrid body configuration that will enable them to have 360 -degree sight. She shifts from a straddling position behind him to stand up on one of the bike's footrests (while Bond re-balances the bike's center of gravity) and situates herself to sit in front of him and face backward. Lisa Funnell $(2012,176)$ points out that, in Tomorrow Never Dies, Lin "offers a new image of Asian femininity, based on physical abilities and achievements rather than (oriental) sexuality." As a result of Michelle Yeoh's early ballet training, action stunt choreography like this integrates her martial arts Hong Kong cinema background with the Bond franchise in a way that denies the detachment and separateness of Craig's Bond. The hybrid identity of Bond-Lin is in the vein of Bakhtin's carnival in which "social interaction [is] based on the principles of mutual cooperation, solidarity and equality" and is built on a more "egalitarian and radically democratic basis" (Gardiner 1992, 30-31). We see this clearly in the signature stunt of this sequence as the agents leap together on their motorcycle from one rooftop to another over the villains' hovering helicopter.

For the Bond of Skyfall, the rooftops above Istanbul's Grand Bazaar are a space where he leaves Moneypenny behind in the solitary pursuit of his target, while Brosnan's Bond is unequivocally joined with a woman of color; his success is made possible by their partnership. The rooftops of Ho Chi Minh City are depicted as a space where people live and work (vegetable gardens, clotheslines, TV antennas), not visualized as an explicit location for global tourism. Murat Akser $(2014,40)$ writes that Skyfall's “Orientalist approach to Istanbul is that it is a city of ancient monuments and not of people inhabiting it." Tomorrow Never Dies offers instead a chase through and above the Eastern street market where we see a "performative process" of "experiencing and constructing otherness [which] involves new constellation of identities that are both contested and collaborated, yet devoid of superior/inferior dialectics of gazing from afar" (Vicdan and Firat 2015, 23). The gaze of 007 in the Brosnan film is intimately interior to the space and, when joined with that of Lin, becomes a hybrid gaze. Their shared panoramic 
vision while on the motorcycle extends to the mobility it gives them. They pause inside a rooftop laundry shop where Bond asks Lin to move behind him because, he says, "I need to balance the bike." The success of their jump is a result of this balance, as is the conclusion of the chase. Back down on the street, they race toward the downward-angled helicopter and lean in unison to lay the bike over on its side so they can slide under the rotors above them, hooking an anchoring clothesline to the chopper's tail section. This maneuver is only possible if they act as a single body.

The unity of vision and motion exemplified in this chase sequence through the market spaces of Saigon culminates in a scene that functions to shift control from Bond to the woman of color with whom he is paired, disrupting the typical conventions of the franchise. Still handcuffed together, Bond and Lin rinse off the grime at an open shower located in a local bathhouse. Mothers bathe their children nearby as Bond and Lin engage in the kind of flirtatious interaction that would normally propel 007 and his Bond Girl to the nearest bed. However, the optics are telling: it is Bond who is topless while Lin remains fully clothed. As he runs a bar of soap through her hair, she covertly uses her metal earring to unlock the cuffs before slipping them onto a water pipe behind Bond, declaring, "I work alone" and walking away from him. Left standing there with his lean muscular torso streaming with water, Pierce Brosnan is already the erotic object of the camera's gaze, subverting Laura Mulvey's (1975) notion that the cinematic apparatus is gendered male by its active controlling gaze of the passive onscreen female. Brosnan further inverts Bond's typical subject position by shaking his head and sending bright droplets of water flinging from his dark hair into the deliberate, advert-sensuous backlighting. Hanying Wang $(2012,87)$ explains that, in Hollywood films, "the West has given itself the role of the male, and assigned the East the traditional female," something clearly at work in the bathhouse of You Only Live Twice, but iconographically not so in this scene. Not only is the Eastern bazaar location of Tomorrow Never Dies a space of hybrid identity (Bond-Lin), it imagines local life in terms of dailiness rather than tourism-its bathhouse is ordinary rather than exotic. The single close-up shot of a local resident ${ }^{2}$ during the chase sequence visualizes this, with Saigon as a space of interiors where people live, unlike the exterior, on-location spectacle that dominates Skyfall's mise-en-scène of iconic ancient monuments.

After Bond-Lin make their leap across the rooftops, they land on the other side and crash through into the domestic space below. In a mosquito-netted 
bed behind them is a pair of lovers. The film reinforces its Bakhtinian inversion of traditional power relations in the Bond franchise here by depicting Asian female sexuality as an active departure from the passive role celebrated in You Only Live Twice. The camera carefully frames the woman at shoulder height as she smiles down to her partner from a sexually-dominant position. Notably, we see not the barest glimpse of the person beneath her, leaving open possibilities for her sexuality, at least in the view of a queerly-positioned spectator. This possibility, located at the in-between spaces within Bakhtin's notion of carnival, is not seen again until Bond himself (in the Craig era) makes overt the homoeroticism - with Javier Bardem's Silva character in Skyfall - that has often been subtext between 007 and his villainous male counterparts. ${ }^{3}$

Zina Hutton (2015) further associates the cinematic subversion of sexual tropes with this film's characterization of Michelle Yeoh's Wai Lin by stressing that, "if women of color aren't hypersexualized in media, they're desexualized and taken completely out of the running as romantic partners. Wai Lin doesn't get that treatment. [...] And that's a good thing considering how terrible some of these films have been when it came to the male gaze and female bodies." The film, in other words, sees Lin, and not through the Orientalist gaze but "as a real person" (Hutton 2015) even as Michelle Yeoh simultaneously embodies what popular discourse proclaims "a real action hero" (nighthawk4486 2015). Indeed, Wai Lin is the first Bond girl to be featured in an independent fight scene, thereby blurring East-West and male-female boundaries as much as the Eastern bazaar, in its carnival aspects, blurs the line between self and Other.

\section{Conclusion}

There is a sequence in Skyfall, while Bond is recuperating from Moneypenny's bad shot along the shores of Calis Beach in Rethiye, Turkey, that illustrates

3 Skyfall screenwriter, John Logan notes that he and director, Sam Mendes, discussed the Bond franchise as a whole, in which there "were so many scenes where Bond goes mano-a-mano with the villain, whether it's Dr. No or Goldfinger or whatever, and there's been so many ways to do a cat-and-mouse and intimidate Bond, and we thought, what would truly make the audience uncomfortable is sexual intimidation," while actor Javier Bardem adds that they did not want it to be entirely clear to the viewer "if Silva's joking or not" (Rosen 2012). When Craig's Bond coolly remarks, "What makes you think it's my first time," to Silva, the queer spectator has an in-between space through which to read both text and subtext, a departure from traditional, hyper-heterosexual Bond canon. 
his resolutely un-blurred self. After making vigorous love to a local woman (who is not named and who never speaks) in a seaside dwelling, Craig's Bond lies on a bed with her curled beside him. She nestles her head into the crook of his neck, she strokes his chest with her hand, and she gazes up at his profile. Bond keeps his eyes averted away from her for the duration of the shot. Bond does not see the woman of color at his side. Orientalism is articulated through this kind of "physical, social, and psychological 'distancing"' (Wang 2012, 87), inflecting what we might think of as Bond's "license" to look (or, in this case, to not look). Edward W. Said $(1978,103)$ finds that "the European, whose sensibility tours the Orient" is "never involved, always detached" and, when he looks, he looks from a distance. Finding this same detachment in her examination of ethnicity, Orientalism, and the bazaar, Yolande Pottie-Sherman (2011, 20-21) acknowledges that "interaction in the marketplace is a social act" and is "not always positive-as it can reinforce difference, inequality, and 'Otherness." Such a dynamic plays out in Skyfall when Moneypenny joins Bond in Macau and, in a call-back to the bathhouse women of You Only Live Twice, attends to the upkeep of Bond's personal grooming — she shaves him while kneeling between his legs. During this intimate interaction, his gaze drops freely to her cleavage, visible in the deep $\mathrm{V}$ of her red dress. Now that she is no longer a fellow agent, his license to look is assured. Her domestication in this scene can be seen as a reinforcement of "racial and gendered hierarchies within an increasingly pluralized society in general and in postcolonial Britain more specifically" (Shaw 2015, 78). Therefore, through the "'traditional' Chinese architecture" of the Macau hotel and its reframing of Naomie Harris' character "within the conventions of the orientalized 'helper,' Skyfall effectively differentiates Moneypenny" from the other black women in the Bond series (Shaw 2015, 75). But it also associates her with the location where her failure as an agent was born: the Eastern bazaar.

On a contrasting note, Tomorrow Never Dies opens with a scene at the Russian border, labeled by title graphics as a "terrorist arms bazaar." In this purely male space - of tanks, fighter jets, and rocket launchers - the scene spectacularizes masculine conflict and the machines that enable it. That the film evolves from this point to a Saigon street market where an East-West/ male-female hybrid body brings down a heavily-armed military helicopter with a humble clothesline is surely a carnivalesque bookend to the film's first scene. It is perhaps ironic that locations such as "the Moroccan bazaar suggest how the presence of women in a traditionally male dominated area creates the space for cultural negotiation" (Pottie-Sherman 2011, 15) in light of Ian Fleming's views of women as men's significant Others. Robert A. 
Caplen $(2010,32)$ unearths the writer's early life to reveal that while, "Fleming often boasted about his conquests, he nonetheless always maintained a certain amount of distance, continually refraining from commitment, and preferred to view women as illusions in order to ensure that he would not give away anything of himself." However, when his alter ego instead closes that distance, a better Bond finds balance.

\section{Works Cited}

Akser, Murat. 2014. "From Istanbul with Love: The New Orientalism of Hollywood." In Whose City Is That? Culture, Design, Spectacle and Capital in Istanbul, edited by Dilek Özhan Koçak and Orhan Kemal Koçak, 35-46. Newcastle upon Tyne, Cambridge Scholars Publishing.

Bennett, Tony, and Janet Woollacott. 1987. Bond and Beyond: The Political Career of a Popular Hero. New York: Methuen, Inc.

Caplen, Robert A. 2010. Shaken \& Stirred: The Feminism ofJames Bond. Bloomington, Indiana: Xlibris.

Cheang, Sarah. 2007. "Selling China: Class, Gender and Orientalism at the Department Store." Journal of Design History 20, no. 1: 1-16.

Funnell, Lisa. 2012. "Fighting for a Hong Kong/Chinese Female Identity: Michelle Yeoh, Body Performance, and Globalized Action Cinema." In Asian Popular Culture in Transition, edited by Lorna Fitzsimmons and John A. Lent, 171-85. London: Routledge.

Funnell, Lisa. 2015. "Objects of White Male Desire: (D)Evolving Representations of Asian Women in Bond Films.” In For His Eyes Only: The Women ofJames Bond, edited by Lisa Funnell, 79-87. London: Wallflower Press.

Gilbey, Ryan. 2008. “All-Action Heroine.” The Guardian, December 31. Accessed May 15, 2016, https://www.theguardian.com/film/2009/jan/o1/bond-girlmichelle-yeoh.

Hiebert, Ted. 2003. "Becoming Carnival: Performing a Postmodern Identity." Performance Research 8, no. 3: 113-25. http://www.tedhiebert.net/site/downloads/ writings/Hiebert-BecomingCarnival.pdf

Hutton, Zina. 2015. "Bond Girls: Re-Watching and Re-Evaluating Tomorrow Never Dies.” The Mary Sue, August 17, Accessed May 15, 2016, http://www.themarysue. com/bond-girl-tomorrow-never-dies/.

Karlan, Ross. 2015. “The Spy Who Fooled Me: The Early Bond Girl and the Magician's Assistant." In For His Eyes Only: The Women ofJames Bond, edited by Lisa Funnell, 196-204. London: Wallflower Press.

Mulvey, Laura. 1975. "Visual Pleasure and Narrative Cinema." Screen 16, no. 4: 6-18. 
nighthawk4486. 2015. "For Love of Film: James Bond-Tomorrow Never Dies." Nighthawk News, November 1, Accessed May 15, 2016, https://nighthawknews. wordpress.com/2015/11/o1/for-love-of-film-james-bond-tomorrow-never-dies/

Öz, Özlem, and Mine Eder. 2012. "Rendering Istanbul's Periodic Bazaars Invisible: Reflections on Urban Transformation and Contested Space." International Journal of Urban and Regional Research 36, no. 2: 297-314.

Parks, Lori L. 2015. "'M' (O)thering: Female Representation of Age and Power in James Bond." In For His Eyes Only: The Women ofJames Bond, edited by Lisa Funnell, 255-64. London: Wallflower Press.

Pottie-Sherman, Yolande. 2011. “Markets and Diversity:' An Overview." Metropolis

British Columbia: Working Paper Series 11, no. 01: 4-35. University of British Columbia, Accessed May 15, 2016, http://mbc.metropolis.net/assets/uploads/ files/wp/2011/WP11-01.pdf.

Rosen, Christopher. 2012. "'Skyfall' Bisexual Scene: James Bond Screenwriter Reveals Impetus Behind Homoerotic Interrogation." Huffington Post, November 6, Accessed September 23, 2017, http://www.huffingtonpost.com/2012/11/o6/ skyfall-bisexual-james-bond-gay_n_2082845.html.

Said, Edward W. 1979. Orientalism. New York: Vintage Books.

Shaw, Kristen. 2015. "The Politics of Representation: Disciplining and Domesticating Miss Moneypenny in Skyfall." In For His Eyes Only: The Women ofJames Bond, edited by Lisa Funnell, 70-78. London: Wallflower Press.

Vicdan, Handan, and A. Fuat Firat. 2015. "Evolving Desire to Experience the Social 'Other': Insights from the High-Society Bazaar." Journal of Consumer Culture 15, no. 2: 1-29.

Wagner, Travis L. 2015. “'The Old Ways Are Best:' The Colonization of Women of Color in Bond Films." In For His Eyes Only: The Women ofJames Bond, edited by Lisa Funnell, 51-59. London: Wallflower Press.

Wang, Hanying. 2012. "Portrayals of Chinese Women's Images in Hollywood Mainstream Films-An Analysis of Four Representative Films of Different Periods." Intercultural Communication Studies 21, no. 3: 82-92.

Zahlan, Anne Ricketson. 1988. "City as Carnival, Narrative as Palimpsest Lawrence Durrell's The Alexandria Quartet." The Journal of Narrative Technique 18, no. 1: 34-46.

\section{About the Author}

Lorrie Palmer is an Assistant Professor of Film and Media Studies in the Department of Electronic Media and Film at Towson University (Baltimore, USA). Her scholarship on film history, film and TV genres (action, sci-fi, 
horror), race and gender in cinema/media, digital aesthetics, and city space appears in Cinema Journal, The Velvet Light Trap, Senses of Cinema, Jump Cut, Camera Obscura, the Journal of Popular Film and Television, Slayage, and the Journal of Science Fiction Film and Television; online at Pop Matters, Bright Lights Film Journal, and Mediapolis: A Journal of Cities and Culture; and in several anthologies (on Star Trek, Terminator: The Sarah Connor Chronicles, Supernatural, Lucy, The Punisher and James Bond). Palmer has a B.A. from the University of Missouri-Columbia, a M.A. from the University of Miami, and a Ph.D. in Film and Media Studies from Indiana University. Her fifteen seconds of fame occurred when she played a "third-class survivor" in Titanic (1997), a "performance" that now lives only on YouTube. 


\title{
9. Shaken, Not Stirred Britishness: James Bond, Race, and the Transnational Imaginary
}

\author{
Anna Everett
}

\begin{abstract}
This chapter examines discourses of race and of blackness in the James Bond film series, starting with post-imperial, Cold War-inflected "Negrophobic" themes in 1962's Dr. No; to the post-Civil Rights, Blaxploitation sampling deployed in 1973's Live and Let Die; to a black Amazonian, hypersexual badass vibe on display in 1985's A View to a Kill; to a new millennial, color-blind casting sensibility at work in 2012's Skyfall. Of particular concern are the Bond films' racist portrayals of black womanhood, and their aestheticized violence in depictions of the spectacularized annihilation of bodies of color. Simultaneously, this chapter acknowledges that Bond fans routinely derive pleasure from negotiating the strange spectatorial sublime of James Bond's troubling discourses on race and otherness.
\end{abstract}

Keywords: James Bond; intersectional cosmopolitanism; hypersexuality; aesthetics of destruction; badass black Bond babes; toxic masculinity

[Being] white is part of the character's specific makeup [...]. Bond's Britishness is an equally integral part of that makeup [...] [Thus,] a black Bond directly questions what it means to be British [...] (Fallon 2016).

I'm probably the most famous Bond actor in the world, and I've not even played the role.-Idris Elba (quoted in Fallon 2016)

Verheul, J. (ed.), The Cultural Life ofJames Bond: Specters of oo7. Amsterdam: Amsterdam University Press, 2020 DOI 10.5117/9789462982185_CHO9 
When rumors surfaced in 2013 that Sony Pictures Executive Amy Pascal wanted to cast British actor Idris Elba as the first-ever black James Bond and likely successor to Daniel Craig, the story "broke the Internet" (Boot 2014). Responding to the uproar, Elba himself commented, “I don't want to be the black James Bond. Sean Connery wasn't the Scottish Bond, and Daniel Craig wasn't the blue-eyed James Bond, so if I played him, I don't want to be called the black James Bond" (quoted in Boot 2014). Elba's hyperbolic colorblind assertion aside, the accomplished British actor of African descent was espousing a position out of sync with a larger trend occurring in both Hollywood and independent film, television, and theater industries wherein successful black performances in revivals of traditional and iconic white narratives have, over time, become all the rage. Additionally, the fact that the United States elected its first ever black-identified (but actually mixed-race) President, Barack Obama, in 2008 while the United Kingdom witnessed a mixed-race American actor, Meghan Markle, getting married to Prince Harry, Duke of Sussex, in 2018 toppled centuries of rigid and anachronistic Anglo-American racial identity politics. Cultural productions helped to lead this new socio-political reckoning, of which a transnational fandom advocacy for a black James Bond was clearly symptomatic.

It is crucial to grasp the significance of such shifting cultural terrain in terms of race, romance, and representation, and how plausible expectations for and attitudes about a twenty-first century black Bond get instantiated by hugely successful black-cast productions in traditional Eurocentric and classic American literary and theatrical works, such as the 2013 Broadway and cable television revival of The Trip to Bountiful (Sondheim Theater, Michael Wilson 2013; Lifetime TV, Michael Wilson, 2014) starring African American icon Cecily Tyson, who won the Tony Award for portraying the lead role established by Caucasian actors Lillian Gish on NBC TV in 1953 and Geraldine Page in the 1984 film adaptation, for which Page won the Academy Award for Best Actress. As promising - or cynically exploitative - as these successful transracial casting choices may be, the persistent hot potato of casting the next James Bond compels us to ask if imagining a black actor as 007 signifies a bridge too far for Bond-producers Barbara Broccoli and Michael Wilson at Eon Productions. Will it matter to Eon that each new Bond feature will henceforth be released in the wake of the unanticipated blockbuster success of Marvel Studio's Black Panther (USA: Ryan Coogler, 2018), or that its African American, megawatt co-star, Michael B. Jordan, is considered viable to replace Henry Cavill as DC Comics' penultimate white superhero, Superman (Fernandez 2018)? These questions are important because the socio-political impact of stardom can easily elevate or diminish 
any cinematic franchise's cultural capital and subsequent commercial viability.

The proven business success of black casting in traditionally white texts helps us to understand why global cinema's racially diverse fan communities prefer Idris Elba as the next 007. He is British. He is FINE! ${ }^{1} \mathrm{He}$ is charming. He oozes Bond-like masculine prowess, and more. Indeed, it seems fair to say that, across the globe, fans of the perennial Bond franchise were shaken and stirred by the prospect of a black 007, including American Right-wing political pundit Rush Limbaugh, who learned - in the wake of the Sony Pictures Studio email hack in 2014- that the studio's co-chair, Amy Pascal, was advocating for Elba as the next Bond (Gajewski 2014). As an expedient means to further the politics of America's toxic racialized culture wars, Limbaugh asserted, "I know it's probably racist to point this out, but [...] we had 50 years of white Bonds because Bond was white" (quoted in Zurcher 2014). Challenging the national and racial purism of Limbaugh's James Bond, reporter Ryan Gajewski reminds us of the identity malleability of the 007 signifier, stating that, "perhaps someone should let Limbaugh know that Bond hasn't actually been played by a person of Scottish descent since the first actor cast for the part, Sean Connery" (Zurcher 2014).

\section{Ian Fleming's Jamaica: The Birthplace and Ideological Center of James Bond's Invincible White Masculinity}

At the center of this exploration is the broader topic of race in the Bond films, focusing on the discussion of racial blackness because Bond-creator Ian Fleming crafted the James Bond spy persona while residing at his Goldeneye estate on the Caribbean Island of Jamaica. Trying to pin down the racial origin narratives for the Bond films can be a slippery undertaking, made more complicated by a narrative that belongs to a behemoth transmedia ecology comprised of novels, films, comics, television, and videogames. In turning our lens to Fleming's construction of Eurocentric masculine whiteness, we are able to recognize Britain's traumatic postwar collapse of its storied empire, and Fleming's negotiation of this irretrievable, often inglorious colonial past alongside the anxiety-ridden predicament that redefined everyday British life after the Second World War. This postwar

1 This is an old African American vernacular term affirming someone's exceptional attractiveness and charm. To be designated as "fine/FINE" means beyond good looking-essentially, it means drop-dead appealing. Idris Elba is all that, and then some, to his fans. 
existential tumult is a fractured ideological scaffold on which Fleming erected his subsequent literary fiction of super-sleuth James Bond in $195^{2}$ (Comentale et al. 2005, xxii; Metz 2004, 2). The numerous biographies and lore about how Fleming patterned his alter ego after his own feats of derring-do as a British Naval espionage specialist during the Second World War, as a journalist, and as a well-heeled member of the British upper-class do not bear reduplicating here. ${ }^{2}$ What does bear on our discussion from that period of creative ferment for Fleming are his contemporaneous literary encodings of racial ideologies, colonial and postcolonial sympathizing and rationalizing that arguably animate and motivate the endlessly self-replicating transmedia narrative plotlines and phantasmagorical storyworlds that keep the James Bond texts viable over decades, even when they have become largely anachronistic on registers of race and gender.

As The Atlantic's associate editor Katie Kilkenny (2015) posits in her book review of Matthew Parker's 2015 Fleming biography Goldeneye, Where James Bond Was Born: Ian Fleming's Jamaica: “Fleming loved Jamaica for its recreational activities, its Caribbean folklore (basically, his belief that it contained lots of buried treasures) [...] and the kinglike reception he got from the locals merely for being British (he arrived at the tail end of its time as a crown colony)." Kilkenny continues by rightly calling out Parker's untenable myopia; she writes, "Parker downplays the blatant offensiveness of the Bond books - to various ethnicities, women, carnivorous sea creatures, Americans_-by making the point that Fleming was prejudiced against anyone who wasn't British." One telling case concerns Fleming's schizophrenic attitudes about his second home, Jamaica, which was fighting for its independence from British colonial rule while Fleming was writing his Bond novels at Goldeneye: a discomfiting realpolitik that makes its way into the racist tropes at the heart of a number of Fleming's novels as well as their ensuing cinematic plotlines (Metz 2004, 5; Kilkenny 2015). In "Breaking the Cycle: Die Another Day, Postcolonialism, and the James Bond Film Series," Water C. Metz (2004, 4-5) offers a useful insight that bears quoting at length:

Dr. No is also a quintessentially colonialist film. Like Live and Let Die, it begins with the murder of a white agent by blacks. Its first image is a vicious, racist one: three black men, pretending to be blind (and

2 See Edward P. Comentale, Stephen Watt, and Skip Willman's Ian Fleming \& James Bond: The Cultural Politics of oo7; Walter C. Metz's “Breaking the Cycle: Die Another, Post-colonialism, and the James Bond Film Series;" and Lisa Funnell's "Negotiating Shifts in Feminism: The 'Bad' Girls of James Bond." 
"comically" accompanied by the song, "Three Blind Mice"), walk through Kingston, Jamaica, entering the grounds of the Queen's Club, where they proceed to murder Strangways, a British secret service operative. They then shoot his secretary in the chest [...]. This opening first ridicules the black men with emasculating Stepin' Fetchit racial stereotyping, but then reveals them to be dangerous murderers of white women. The moment thus contradictorily spans the gamut of colonialist treatment of black men-Coon and Buck-but coherently effects a vision of colonialism as an ordered, beneficent system threatened by the chaos perpetrated by its charges. This is, of course, terrible history: Jamaica became independent on August 6, 1962, two months before Dr. No's London premiere on October 5,1962 .

These themes and tropes of nineteenth-and-twentieth-century Negrophobia (or rabid anti-black racism) overlap with oo7's sexism and Orientalism and are crystallized in the first film adaptation of Fleming's Dr. No (UK: Terence Young) from 1962. More troubling, however, is the film producers' uncritical redeployment of these recurrent, abhorrent themes and their visual rhetoric throughout the franchise and during the American Civil Rights and Blaxploitation eras. In addition, these colonial significationswhich are arguably not reflexive of British and American societal attitudes equally — return spectacularly and trade opportunistically on New British Cinema's increasing representations of adult sexuality in the years following Fleming's death in 1964. By establishing the Eon production house in the United Kingdom in 1961, Bond-producers Albert Broccoli and Harry Saltzman availed themselves of the global film industry's changing censorship winds and identity politics in meeting modern audiences' expectations, belatedly creating a space for black performers in Live and Let Die (UK: Guy Hamilton, 1973) and View to a Kill (UK/USA: John Glen, 1985).

Significantly, these and sundry other big-budget film titles featuring black stars as well as other protagonists and antagonists of color have habituated identity-affiliated groups and diversity-minded audiences, non-racist spectators, and principally Bond-fans to imagine a black performer-Idris Elba - as a viable and desirable James Bond for the twenty-first century. This idea of transracial casting, unquestionably, is historically so far removed from the literary origins of Bond that a colonialist ideologue such as Fleming could hardly anticipate it, let alone embrace it. Of particular interest here is how the Bond films represented race and Britishness in Fleming's fecund escapist imaginary. As the cinematic Bond made its debut with the release of the colonialist Dr. No in 1962, Jamaica won its 
independence from the United Kingdom just as postwar British culture and society were becoming multiracial. While the US Marshall Plan for the reconstruction of a war-torn Europe created an intercultural bridge of international exchange that begat the commodification of such American cultural exports as African American-invented Blues and Rock-n-Roll music, the growing ranks of first- and second-generation postcolonial West Indian, Caribbean, South Asian, and African subaltern Britons - whose parents were often former colonial subjects conscripted in her majesty's military service during the Second World War, and who were subsequently relocated to the UK to help rebuild a war-torn Britain-contributed to the widespread architectural preservation and infrastructural reconstruction and modernization of the United Kingdom in the post-war era. Britain's growing postcolonial populations thus rightly staked their multigenerational claims to "Britishness" as their birthright or earned benefits as wartime patriots and veterans.

Against this backdrop, then, Dr. No's representational economies involving Jamaica and blackness become, at once, increasingly legible, complex, familiar, and above all racially suspect. Relatedly, the US Civil Rights Movement and other global African and African Diasporic liberation struggles need to be seen as another situational logic that informs if not fully enlivens the early Bond films' discursive address to racial blackness that delimits the texts' main characters and sensational plot points. Central here are the cinematic Bond's powerful constructs of black male arch villains and evil masterminds as main characters and even co-stars, most clearly evinced for the first time in 1973's Live and Let Die. In addition, the Bond films' address to the changing sexual mores and to the geopolitical shifts and transnational entanglements authorize Bond's womanizing and his transgressions of the "miscegenation taboo" with young, beautiful non-white women from across the globe as sexual playmates, conquests and antagonists - oftentimes simultaneously. Finally, another key area of interrogation concerns the Bond films' especially problematic portrayals of gratuitous and excessive violence in scenes that foreground the spectacular annihilation, evisceration and mutilation of bodies of color, both male and female, friend and foe. After all, the clichéd trope of the black guy dying first should not be continually reduced to innocuous comic relief or slapstick antics. And yet, apparently Bond fans routinely derive enormous pleasure as they negotiate the strange spectatorial sublime that is James Bond's complicated cinematic treatment of race and otherness, white male privilege and toxic masculinity, Anglo-American racial supremacy and cool Britishness. 


\title{
oo7, The Limits of Cosmopolitanism, and JFK's James Bond Fandom
}

\author{
Bond is "more a cosmopolitan man than a man of class[,]" and that \\ cosmopolitanism carries over to downplaying the "Britishness" of the Fleming \\ novels (even as Bond became an internationally recognized icon of Britishness [...]. \\ [Thus,] the threat to specifically British interests [...] is turned into a global threat \\ so that 007 is still a British agent, but a defender of the world
}

(Elhefnawy 2015, 40).

The cinematic Bond emerged in 1962 at a time when Europe's postwar national cinemas rebounded from the devastation of the Second World War (WWII). The revived national cinemas were of distinctive European art cinema movements (Italian Neorealism, French New Wave, New British Cinemas), which circumnavigated the globe with assistance from the US Marshall Plan, were provided with financial aid and infrastructure for their long-waited exhibition. Known as the European Recovery Program (ERP), which aimed to curtail the spread of state socialism, the Marshall Plan's cultural agenda required European film industries' acquiescence to screen a significant number of American films alongside homegrown products in order to expedite the recovery of Europe's domestic film industries. Clearly, this was not a purely altruistic arrangement, but the ERP boosted the circulation of European arthouse cinemas worldwide, which contributed to some extent to a mid-twentieth-century zeitgeist of cultural cosmopolitanism in the West. In this context, two cinematic movements defined British filmmaking in the postwar era: one consisted of post-WWII bleakness, characterized by the so-called "Angry Young Man" and "Kitchen Sink" dramas, while the other was comprised of a more hopeful, Swinging Sixties corpus, exemplified by James Bond's seductive construct of the suave and debonair British agent's masculine cool and mastery as embodied by 007 (Cook 1990, 589-99).

In the 1950s, European films, with their mature, sophisticated sexuality and highly stylized violence, were popular draws at American arthouse film theaters and cinematheques and helped augur a new American cosmopolitanism that resonated with the nation's burgeoning youth culture. America's generational shift was embodied most prominently by John F. Kennedy (JFK), who in 1960 and at the age of 43 was the second-youngest man ever elected to the US Presidency. Arguably, President Kennedy and his glamorous socialite wife, Jacqueline Bouvier Kennedy, projected an image of American cosmopolitanism that rejected the American isolationism of 
the interwar years. Indeed, art, fashion and literature were part and parcel of the Kennedys' contagious cosmopolitan allure. The Presidential couple was also affiliated with Hollywood glamor, and JFK aligned particularly well with Hollywood's leading-man-cool and with American pop culture more broadly. When President Kennedy subsequently listed Fleming's From Russia, with Love (1957) among his favorite novels, James Bond and "Britishness" had become idealized cultural referents in the United States (McDaniel 2012).

Matt McDaniel (2012) underscores JFK's immense influence and cultural capital by quoting a Bond insider: "Christopher Lee, who played 007's adversary in The Man With the Golden Gun [UK: Guy Hamilton, 1974], said JFK's endorsement of Bond was invaluable. 'What more could you ask for? If it's good enough for the President, it's good enough for me." However, cosmopolitanism is a double-edged sword in the age of global media culture. For scholar and cultural critic Kwame Anthony Appiah (2012), "Cosmopolitanism has always - at its best anyway-combined the respect for universality with the recognition that there are forms of difference that should be allowed to exist. Not everybody has to be the same for the world to be going well, going right. [...] Cosmopolitanism in the arts is an engagement with the cultural and literary and poetic life of other societies." Yet, if cosmopolitanism's allowance for human difference and engagement with diverse societies' cultures are mostly good things, the downside of Anglo-American cosmopolitanism is its destructive and counterproductive deployment in interactions or engagements with other societies and their particular cultures and peoples. In our focus on racial blackness in the Bond films, we often witness this benefit-threat dialectic of cosmopolitanism in effect.

Nader Elhefnawy (2015) understands On Her Majesty's Secret Service (UK: Peter Hunt, 1969) as the original signifier of Bondian cosmopolitanism. Elhefanawy's observation that James Bond represents British interests as somehow universal rather than uniquely beneficial to the British nation, is astute, especially during the Cold War of the 196os. In this context, "Bondian cosmopolitanism" concerns the cinematic Bond's daring approach to global interracial sexuality and its corresponding conversation with changing, postwar societal norms, expectations, and the representational taxonomies of race and gender. 


\section{Badass Black Bond Babes: Sexual Liberalism and Transgressing the Miscegenation Taboo}

By indiscriminately bedding "good" and "bad" women, Bond attempts to ensure the success of his missions [...]. When women act as independent agents expressing sexual desire, they are typically threatening, deviant, and "bad".

(Funnell 2011, 199-200)

Mainstream cinema in the post-WWII era was often conflicted about the depiction of power, predicament, and complexity of modern and postmodern femininity. Bond Girls and badass women were no exception. Torn between an enduring ideology of ideal white womanhood that was, well into the 1950s, predicated on neo-Victorian notions of sexual purity, "society expected women to remain virgins until their wedding night, but, paradoxically, they were also supposed to be sexually attractive" (Miller 1996, 46). In addition, Douglas T. Miller (46) reminds us that unprecedented numbers of women who worked in previously male-dominated factory jobs, and women who helped win WWII, especially on the home front, were none too pleased after the war to be told that a career was too masculine and no longer appropriate for these former Rosie-the-Riveters. To surmise that women of the era were either confused or downright distraught by such contradictory logics is to understate many intelligent and college-educated women's seething resentment at being relegated to housewives and mothers-as Betty Friedan's proto-feminist book The Feminine Mystique made crystal-clear in 1963.

Positioned outside of this emerging postwar ideal of womanhood were African American women and other women of color. After all, black women had historically been caricatured as the strong, emasculating black females that Sojourner Truth challenges in her "Women's Convention Speech" from 1851 - later dubbed as the "Ain't I a Woman? Speech." More than a century later, the badass black Bond babes made their vexed cinematic debut, which suggests an affirmative response to that age-old question about black femininity. Indeed, the predominant historical image of black women in western popular culture is "the mammy figure," who tends to be devoid of any feminine charms or characteristics. Hattie McDaniel's archetypal "Mammy" character in Gone with the Wind (USA:Victor Fleming, 1939) is the quintessential and most familiar stereotype of this representational ilk. These taxonomies of black femininity help us to push our discussion beyond James Bond's familiar womanizing in order to engage more pointedly with the little remarked-upon feature of 007's sexual exploits with black women-most notably—and other women of color across the film series' fifty-year run. 
Whereas mainstream postwar cinematic depictions of race, romance, and sexuality were slow to demand racial, gender, and sexual equality throughout all spheres of civil society, independent cinemas of the era, by contrast, challenged taboos on interracial relationships, as exemplified in Britain by Woodfall Films' A Taste of Honey (UK: Tony Richardson, 1961). In the US, the 1969 Supreme Court decision Loving v. Virginia struck down state laws banning miscegenation or interracial sex and marriage, thereby setting the stage for legal marriage between different races (and later same sexes). A major consequence of this monumental ruling was that the censoring of representations of sexual race-mixing on screen had sustained a fatal blow. Consistently and as if on cue, Hollywood replaced the racially and sexually restrictive 1934 Production Code with the more tolerant and less moralizing Ratings System in 1968. This shift meant that the Code's anachronistic antimiscegenation discourses, homophobia, and other exclusionary positions on hegemonic identity normativity became moot as the liberal segments of America's Baby Boom generation helped to recode the nation's cultural industries, which ultimately gave rise to the sensationalist ethos of New Hollywood Cinema with its new discursive freedoms and less censorious narrative dictates pertaining to sex and violence. Finally, US cinema had caught up with the European new waves in its representation of more explicit sexuality on screen.

Consequently, by the 1970s, mainstream filmmakers were no longer compelled to self-censor scenes of interracial sexuality. The Bond films, I suggest, led the way in this regard. Against the backdrop of the Loving $v$. Virginia decision, the Bond franchise's conscious transgression of the miscegenation taboo suggests a visual taxonomy, a specular forbidden fruit of sorts in which both the directors and the fans could indulge without censure. Beginning with Diamonds Are Forever (UK: Guy Hamilton, 1971), we have four Bond-stars (Sean Connery, Roger Moore, Pierce Brosnan, and Daniel Craig) "indiscriminately bedding 'good' and 'bad' women" (Funnell 2011, 199), signifying the film series' unapologetic equal-opportunity womanizing. Significantly, it should be noted that Bond's sexual couplings with women of color do not signify tender and romantic encounters as much as they naturalize Bond's masculine prerogative of accepting these women's lusty hypersexual offerings to him. In this way, oo7's white male sexual access to black and other women of color brings into full relief the hypocritical Western morality about who could and could not indulge in sexual racemixing. In "Negotiating Shifts in Feminism: The 'Bad' Girls of James Bond," Lisa Funnell situates the narrative centrality of the Bond Girl within actual societal reckonings with women's newfound power and agency during the 
social activism of the 1960 s and 1970s. This timing is coterminous with the rise and establishment of the James Bond film franchise. On the film series' instantiation of the "bad" cinematic Bond Girl, Funnell (2011, 200) notes,

Established during the "swinging-sixties" [...], [the Bond Girl was] liberated from the constraints of family, marriage and domesticity [...]. [By embodying] the liberal sexuality of the emerging women's movement[,] the 1960 s Bond Girl is, perhaps, more accurately described as a "model of adjustment," a dependent and derivative character that is tailored to fulfil the sexual needs of Bond.

Funnell's intervention provides a strong foundation for what I define as the cinematic Bond's "troubling intersectional cosmopolitanism" regarding the race and gender matrix of hypersexualized badass black Bond babes. Moreover, Cynthia Baron (2009) and Vivian Halloran (2005) remind us of the fact that these black Bond Girls and black Bond Girl-adjacents often originate from some fictionalized Caribbean island evocative of Fleming's beloved Jamaica, which should not be dismissed so easily because the cinematic value of these mostly bikini-clad would-be assassins inheres in their association with a sort of a libidinous island fever to which 007 succumbs. Conjoined, then, with a favorite setting for Fleming's literary Bond, which we recognize as a phantasmagorical or idealized Jamaica replete with oftentimes submissive and sometimes rebellious colonial subjects, badass black Bond babes convey the general limits of contemporary cosmopolitanism in cinema more broadly and in the James Bond films in particular.

Let us consider the earliest Bond film that makes the point. The 1969 entry On Her Majesty's Secret Service, with George Lazenby as 007, features a segment in which an array of young international, interracial beauties are being treated for an apparent food-borne allergy - the young women are of Asian, European, Indian, and black/African extraction. Most striking is the sequence's racialized associative editing structured on choices around racialized cultural differences, as evinced in the sequence's strong emphasis on gastronomical etiquettes. In the beauty pageant scene centered on a communal meal, race is foregrounded in a montage that juxtaposes the East Asian women eating with chopsticks with the lone black/African woman depicted peeling and eating a banana. This is striking because it does not associate the black beauty with some recognizable and non-demeaning black-identified cuisines eaten with the hands, such as Ethiopian food eaten with injera bread. Instead, On Her Majesty's Secret Service opts for the offensive and historic associational logic yoking this black contestant 
to the image of a monkey eating a banana, part of a familiar and reified racist representational economy.

In this vein, we should not forget Europe's embrace of the African American, Harlem Renaissance performer Josephine Baker and her nearly-nude, scandalous banana skirt dances, her dance-hall and cabaret acts, and her primitivist-themed films that all combined to make her a modernist rage across the continent during the 1920s and 1930s (Dalton and Gates 1998). An important complexity here is that Baker had agency in her creation and willing performance of her so-called "danse sauvage" ("savage dance"). In the French film Princess Tam Tam (France: Edmond T. Greville, 1935), Baker portrays the Tunisian tribeswoman Alwina, an "uncivilized" sheepherder who rapidly climbs a tree while being intercut repeatedly with a rambunctious monkey climbing that same tree. Princess Tam Tam's associational editing, which conflates Alwina and the monkey, exemplifies familiar racist tropes in Eurocentric and American white supremacist cultural production. If my calling out On Her Majesty's Secret Service for its foregrounding of a black woman eating a banana is not convincing enough, the blatantly racist scene in Diamonds Are Forever in which a black, Afro-wearing South African woman morphs into a gorilla surely brings the point across.

The troubling intersectional cosmopolitanism of the Bond films, and how it informs the film franchise's discourses on "dangerous black femininity" in On Her Majesty's Secret Service and Diamonds Are Forever, participates fully in what Moya Baily's has potently referred to as a "misogynoir" praxis of representation. Significantly, Bailey $(2018,763)$ is clear that the term "misogynoir" does not apply to all women of color but that it concerns instead a term "used to describe the unique ways in which black women are pathologized in popular culture. What happens to black women in public space isn't about them being any woman of color." Bailey (763) continues and argues that misogynoir "is particular and has to do with the ways that anti-blackness and misogyny combine to malign black women in our world." The unique and vivid misogynoir imagery of Diamonds Are Forever comes to the fore in the film's close-up two-shot of the facial expressions of two little girls watching the caged Zambora undergoing a "scientific" transformation from a beautiful black woman into a hulking black gorilla. In terms of spectatorship and primary identification, the little black girl is positioned differently from the little white girl in this scene's visual regime of racialized looking. As a result, this instance of maligning a black woman does not evoke the same visceral reaction or psychical violence for both girls: otherwise, what is the point of this associational edit or montage? It matters that Diamond's setting of this fictional circus foregrounds the promises 
of horror and terror while the scene was shot on location in an actual Las Vegas venue called "Circus Circus," with the film's mad scientist imploring the spectators to flee for their lives after Zambora-the-gorilla breaks free of her cage. This type of discursive slippage between fiction and reality functions to exacerbate Diamond's tropes of misogynoir.

The caged South African Zambora reminds us of Europe's ignominious history of human zoos as part and parcel of colonialism predicated on the invention of the so-called African "savage," which the tragic and barbarous treatment of the real-life South African Saartje "Sarah" Baartman, dubbed "the Venus Hottentot," revealed most shamefully as she was sexually abused and exhibited at "freak shows" across the continent during the nineteenth century. Zambora in this Bond film is visible evidence of the persistence of a uniquely virulent racism, targeting and damaging black women in particular. To watch, untroubled, as the camera centers briefly but pointedly on the skeptical and fearful-looking face of that little black girl witnessing the caged, beautiful black Zambora's metamorphosis into a dangerous animal is to be implicated in an aestheticizing of black trauma. As if Zambora's transformation into a gorilla is not bad enough, the fact that the scene implies that her species may be modified as a result of "a scientific experiment" evokes the horrific medical experiments performed on actual Africans and African Americans during the nineteenth and twentieth centuries.

By 1973, when Live and Let Die hit the screen, the Blaxploitation film cycle was a major box office trendsetter while its daringly transgressive portrayals of interracial sex were a game-changer in American independent and mainstream cinemas. As Christopher Sieving $(2005,16)$ points out, Coffy (USA: Jack Hill, 1973), the Blaxploitation film par excellence, "beat out the new James Bond film Live and Let Die - itself a sort of mainstream pastiche of the Blaxploitation phenomenon - for the number one position on Variety's August 22 listing of the nation's top moneymakers." With its nudity, simulated sexual intercourse, and profanity, Melvin Van Peebles' Sweet Sweetback's Baadasssss Song (USA: Melvin Van Peebles, 1971) had a catalyzing effect on Shaft (USA: Gordon Parks, 1971) and on Coffy's bold transgressions against America's miscegenation taboo, with its own flagrant iterations of mixed-race sexual encounters depicted on the screen. Live and Let Die, Sieving $(2005,16)$ indicates, was no exception. Crucially, Roger Moore's considerably less intense and rather campy and flippant enactment of 007 seemed to diminish any shock-value in seeing Bond "bed" his first badass black Bond babe, portrayed with equal camp and playfulness by Gloria Hendry as Bond-antagonist Rosie Carver. In testing the waters of interracial sex, both Bond and Carver perform their sexual relationship as a bit of comic relief. 
Twelve years after Live and Let Die, music artist and style icon Grace Jones took her turn as a Bondian badass black babe in A View to a Kill. Not officially considered a Bond Girl, Jones as May Day nonetheless fulfills, according to Lisa Funnel's (2011) typology, the function of the Bond Girl as an object of "sexual conquest" for 007-yet Jones does so to performative excess in correspondence with her own iconoclastic star persona. Jones's May Day posits a schizophrenic picture of powerful black womanhood in the post-Blaxploitation era. At one end of the representational spectrum, May Day's unquestioned physical strength and narrative agency - compromised to some extent by her ultimate self-sacrifice to protect Bond-defines Jones' badass black womanhood, while at the other end, her black henchwoman power is inextricably bound to her animalistic hypersexuality encoded in scenes of her sexual intercourse with both 007 and the film's Bond villain, Max Zorin (Christopher Walken).

One Grace Jones fangirl, Zina Hutton, suggests why it is necessary to assess these black Bond women with a measure of complexity and reflection. In her July 2015 editorial on "Bond Girl: Re-Watching and Re-Evaluating A View to a Kill," Hutton (2015) proclaims that

May Day stole the show for me [...]. May Day isn't a conquest. Not in the least [...]. While she does have sex with James Bond, it's absolutely on her terms [...]. [I]n the scene where May Day and Zorin go to May Day's room only to find James Bond naked in her bed but okay-I love that scene. May Day is in charge for the whole of it. She walks in and drops her dress to the ground without any shame and Bond is taken aback and intrigued by her boldness.

Most on point here is Hutton's observation that, "She takes the lead, stalking towards her bed and Bond as if she's on a hunter [sic] out for her prey. I feel as if May Day sees Bond as a conquest and not the other way around and that rather makes me wonder how she sees Zorin and how she views their relationship." While my assessment of May Day is less affirmative than Hutton's, it is useful to recognize how overdetermined and discursively slippery cinematic constructs of black womanhood in popular culture remain. And despite the fact that, like Rosie Carver, May Day as a darkskinned beauty presents counter-colorism images to those traditional or mainstream cinematic representations of black women as unattractive, unglamorous, and sexless mammy types, these earliest black Bond badasses are more aligned with the requisite sexual allure manifest in the white Bond Girls as well. 
Delving into the franchise's later offerings, it is important to emphasize that the inspired casting of black British actor Naomie Harris as MI6's valued staffer Eve Moneypenny in Skyfall (UK/USA: Sam Mendes, 2012) and Spectre (UK/USA/Austria/Mexico/Italy/Morocco: Sam Mendes, 2015) represents the film series' own move into the realm of black casting of traditional white roles discussed earlier. Pointedly, Harris's casting as Moneypenny positions this black badass Bond babe in a noteworthy liminal space between the unofficial and the official Bond Girls signified by May Day in the former register and by Rosie Carver in the latter. It is striking that the sexual tension between Daniel Craig's 007 and Naomie Harris's Moneypenny is heightened exponentially beyond the white Moneypenny incarnations that preceded her, whose constrained and unrequited romantic fantasies about Bond are an essential motif in the successful secret sauce of the conventional Bond-narrative. By contrast, Craig's Bond and Harris's Moneypenny actually do have sex. Additionally, this black Moneypenny garners significant screen time, which includes daring and dangerous action scenes: this marks an improvement in the representational taxonomy of black womanhood in the cinematic universe of Bond. As a bona fide black Bond Girl, we should recall that Halle Berry's screen time in Die Another Day (UK/USA: Lee Tamahori, 2002) was equal to that of her white peers. This fact provides a precondition for Naomie Harris's repeat performances as the black Moneypenny that audiences can accept and arguably celebrate.

Following Halle Berry's star turn as a black Bond Girl, Naomie Harris is able to and is comfortable with foregrounding the issue of race and blackness in her reflections on Spectre in an Ebony Magazine article entitled "Black Bond Girls Unite." Speaking fondly to her Bond trailblazer sisterhood consisting of Trina Parks, Gloria Hendry, Halle Berry, and Grace Jones, Harris commented:

You inspire me with your incredible performances and with your representation of black female beauty. Growing up in London, coming up in a little town, Finsbury Park [...] [,] there were not many representations of black female beauty[.] I really have to thank Bond and the franchise [...] for being one of the very few franchises at that time that actually presented black women [...]. I am so grateful and proud to represent this franchise, to continue the legacy you've all started (quoted in King 2015).

Ebony reporter Crystal Shaw King listened to these two generations of black female actors at the African American Film Critics Association's tribute to the "Black Women of Bond," and surmised that, "The black Bond Girl is 
definitely something to be celebrated [...], reflected on the big screen in a high-profile film with beauty, brains and power" (King 2015). For her part, Shaw King relished the contributions that these black Bond Girls have made to the franchise for over half-a-century. Of Parks, Hendry, Jones, and Berry, Shaw King observed, "They've either conspired with, slept with, or kicked 007's British butt." As innocuous and understandable as these disparate black women's voices appear on the surface, upon closer inspection the black badass Bond babes largely make sense as expressions of black empowerment because the black female body in mainstream and independent film and visual culture is historically essentialized, normalized, and reified as the personification of the grotesque, the subhuman, the violent and the sexually insatiable "Hottentot."

Against this representational taxonomy of explicit black pathology, any adjustment to such historic and persistent anti-black rhetoric is embraced with little to no critical pushback. I subscribe to Roxane Gay's $(2014,250)$ observation that we should resist "representational neediness," which follows an operational logic: "Here is popular culture about people who look like me. That's all I should need, right? Time and time again, people of color are supposed to be grateful for scraps from the table. There's this strange implication that we should enjoy certain movies or television shows simply because they exist." If there exists a discursive space for a Black Bond Girls tribute, so should critiques of colorism, lookism, and black hypersexuality and violence inscribed onto the signifying black body be circulated.

\section{Conclusion: Race and the Aesthetics of Annihilation in Bond}

Importantly, as an emblem of Western superiority in a rapidly changing global history, the figure of Bond gave expression to biases and anxieties that continue to shape our understandings of identity and belonging (Comentale et al. 2005, xxii).

As we conclude this interrogation of blackness in the James Bond film series, our interests also include how the racial encodings above have changed over the course of the franchise in order to track more closely with geopolitical realignments after the demise of the Cold War's raison d'etre that inspired Fleming's creation. What ties Fleming's Cold War discourse to this analysis of race, nation, and Britishness is the extent to which the scientific inventions of weapons of mass destruction-particularly lasers, satellites, atomic and nuclear energy — fired cinematic imaginings of the spectacular annihilation 
of 007 's arch villains. A special sort of total destruction was predictably reserved for Bond's non-white antagonists. Such racialized visual spectacles of bodily annihilation in the James Bond films recall Susan Sontag's (1965) formulation of "the aesthetics of destruction," which highlights important distinctions between science fiction literature and films. Sontag $(1965,2013)$ notes that, "the science fiction film [...] is concerned with the aesthetics of destruction, with the peculiar beauties to be found in wreaking havoc, making a mess. And it is in the imagery of destruction that the core of a good science fiction lies." Sontag's "aesthetics of destruction" readily applies to the Bondian spy genre as well, resonating powerfully as a heuristic device for understanding race and difference in the James Bond narrative universe.

The Bond films that most clearly illustrate the racist encodings of bodily destruction enacted upon characters of color are Live and Let Die, Diamonds are Forever, and Die Another Day. If black audiences have grown accustomed to the trope of the black villain or the black buddy-sidekick dying in mainstream films featuring interracial casting, the spectacular and total annihilation of the black body in the Bond series reflects a persistence of racial bias and intolerance as evinced in the franchise's anti-black racism (Diawara 1995). As I (Everett 2001) have pointed out, African American concerns about aestheticizing the destruction, pain, and suffering of black bodies date back to the beginnings of cinema. In 1909, New York Age newspaper editor and theatrical columnist Lester A. Walton penned a scathing condemnation of the Nickelodeons' deplorable practices of promoting moving pictures featuring the lynchings and burnings of black men with promises of "hearing" the sounds of black pain and suffering thrown in for a penny (Everett 2001, 19-21). Walton's legitimate fear that the new film industry was encouraging white spectators to enjoy such vile cinematic glorifications of the lynched and burned black body also applies to the Bond franchise, which sustains such racist tropes of black bodily annihilation by relying on more elaborate production values and computer-generated-imagery. Bondian on-screenexemplars include Live and Let Die, wherein supervillain Dr. Kanaga aka Mr. Big, portrayed by black, dark-skinned actor Yaphet Kotto, physically balloons out after Bond inserts a deadly object in his mouth until he literally blows up, exploding from the inside and leaving behind dispersed and disintegrated black bodily fragments. And in A View to a Kill, Grace Jones, the badass black Bond babe and villain May Day, meets her demise when she is blown up voluntarily while trying to save Bond.

The Bond films' especially venal aesthetics of destruction applied to its villains of color does not negate the central position of stylized violence and spectacular deaths in the action-adventure genre-formula and in the 
Bond films in particular: this includes white villains, arch nemeses, and henchmen. In Bond's Manichean realm of good versus evil, punishment and reward, key aspects of the franchise's spectatorial pleasures reside in viewing the excesses of the films' aesthetics of destroying planes, trains, and automobiles. Yet, while it seems that witnessing the transgressive bodies of bad guys getting their due punishment may be cathartic for audiences, the tendency of the Bond films to construct amoral, sinister and monstrous villains of color, befitting of an aesthetics of bodily destruction, nonetheless reflects the "imperial code" that Tony Bennett $(1982,13)$ identified at the heart of the Bond phenomenon's longstanding taxonomy of racist representation.

This chapter began with a discussion of the excitement and anxiety over the possibility of Idris Elba succeeding Daniel Craig in the role of James Bond. Part and parcel of Eon's inability to imagine Elba as 007 speaks to my analysis of the troubling intersectional cosmopolitanism that defines the limits of the Bondian universe. Thus, in 2019, we have come full circle by drawing our attention to the online reaction to rumors that a black woman, Lashana Lynch, may be the next 007. As expected, there is much controversy about this latest racialized conflagration over race, gender, and James Bond. As Aja Romano (2019) suggests in Vox, the deployment of race seems to have become a clever marketing ploy for Eon's twenty-fifth Bond feature, No Time To Die (UK/USA: Cary Joji Fukunaga, 2020). Romano accordingly concludes that, "Casting rumors aside, the Bond franchise still has a long way to go before it's meaningfully diverse." Romano's observation corresponds to my discussion of the intersectionality of race, gender, and nation in the James Bond film series. The box office-cred of Lynch's star turn in Captain Marvel (USA: Anna Boden and Ryan Fleck, 2019) as the badass Air Force pilot Maria Rambeau fits Eon's advertising and promotion bill neatly. As for me, the audacious casting rumor — even if a done deal-does not excuse Barbara Broccoli and Michael G. Wilson's inexplicable refusal to cast Idris Elba as a James Bond for the twenty-first century. Just sayin'! Now, millennial audiences and non-racist Bond superfans, what say you?

\section{Works Cited}

Appiah, Kwame Anthony. 2012. "Thought Leader Kwame Anthony Appiah on Cosmopolitanism." Carnegie Council for Ethics in International Affairs. Ethics Matter: YouTube.Com, November 12, 2012. Web, Accessed December 19, 2018. Bailey, Moya \& Trudy. 2018. “On Misogynoir: Citation, Erasure, and Plagiarism.” Feminist Media Studies 18, no. 4 (March): 762-68. 
Baron, Cynthia. 2009. "Dr. No: Bonding Britishness to Racial Sovereignty." In The James Bond Phenomenon: A Critical Reader, Second Edition, edited by Christoph Linder, 153-68. Manchester: Manchester University Press.

Bennett, Tony. 1982. "James Bond as Popular Hero." In U203 Popular Culture: Unit 21. Milton Keynes: Open University Press.

Boot, William. 2014. "Exclusive: Sony Emails Reveal Studio Head Wants Idris Elba For the Next James Bond." DailyBeast.Com, January 12, 2014. Web, Accessed March 16, 2016.

Child, Ben. 2014. "Rush Limbaugh: Idris Elba Can't be Bond Because He's Black." The Guardian, December 24, 2014. Web, Accessed March 20, 2016.

Cook, David A. 1990. A History of Narrative Film, Second Edition. New York: W.W. Norton \& Company.

Comentale, Edward P., Stephen Watt, and Skip Willman. 2005. "Introduction." In Ian Fleming and James Bond: The Cultural Politics of oo7, edited by Edward P. Comentale, Stephen Watt, and Skip Willman, xi-xxiii. Bloomington: Indiana University Press.

Dalton, Karen C.C., and Henry Louis Gates, Jr. 1998. "Josephine Baker and Paul Colin: African American Dance Seen Through Parisian Eyes." Critical Inquiry 24, no. 4 (Summer): 903-34.

Diawara, Manthia. 1995. "Black Spectatorship: Problems of Identification and Resistance.” In Black American Cinema, edited by Manthia Diawara, 211-20. New York: Routledge.

Elhefnawy, Nader. 2015. The Many Lives and Deaths ofJames Bond, Second Edition. Amazon Digital Services, LLC.

Everett, Anna. 2001. Returning the Gaze: A Genealogy of Black Film Criticism, 19o91949. Durham: Duke University Press.

Fallon, Kevin. 2016. "Cast Idris Elba as James Bond Already." DailyBeast.Com, May 20, 2016, Accessed January 10, 2018, https://www.thedailybeast.com/castidris-elba-as-james-bond-already?source=TDB\&via=FB_Page.

Fernandez, Alexia. 2018. "Who Should Replace Henry Cavill as Superman? From Michael B. Jordan to Henry Golding." People.Com, September 13, 2018. Web. Accessed September 14, 2018.

Funnell, Lisa. 2011. "Negotiating Shifts in Feminism: The 'Bad' Girls of James Bond." In Women on Screen: Feminism and Femininity in Visual Culture, edited by Melanie Waters, 199-212. New York: Palgrave.

Gajewski, Ryan. 2014. “Rush Limbaugh: Idris Elba Can't Play Bond Because He's Black." Hollywood Reporter, December 24, 2014, Accessed July 18, 2018, https:// www.hollywoodreporter.com/news/rush-limbaugh-idris-elba-cant-760356.

Gay, Roxane. 2014. Bad Feminist: Essays. New York: Harper Perennial. 
Halloran, Vivian. 2005. “Tropical Bond.” In Ian Fleming and James Bond: The Cultural Politics of oo7, edited by Edward P. Comentale, Stephen Watt, and Skip Willman, 158-77. Bloomington: Indiana University Press.

Hutton, Zina. 2015. "Bond Girl: Re-Watching and Re-Evaluating A View to a Kill.” TheMarySue.Com, July 20, 2015. Web, Accessed January10, 2019.

Kilkenny, Katie. 2015. "Was James Bond the Result of Ian Fleming's Midlife Crisis?" The Atlantic, March 22, 2015. Web, Accessed December 22, 2018.

King, Crystal Shaw. 2015. "Black Bond Girls Unite!.” Ebony, November 4, 2015. Web, Accessed January 10, 2019.

McDaniel, Matt. 2012. "007 at 50:JFK, James Bond's Biggest Fan." Movie Talk: Yahoo. Com, October 4, 2012. Web, Accessed December 22, 2018.

Metz, Walter C. 2004. "Breaking the Cycle: Die Another Day, Post-Colonialism, and the James Bond Film Series." ZAA:Zeitschrift fur Anglistik und Amerkanistik 52, no. 1 (Spring): 63-77.

Miller, Douglas T. 1996. On Our Own: Americans in the Sixties. Lexington, MA: D. C. Heath and Company.

Romano, Aja. 2019. "Lashana Lynch Will Reportedly Be the New 007. But She Probably Won't Be the Next James Bond.” Vox, July 15, 2019. Web, Accessed July 17, 2019.

Sieving, Christopher. 2005. 'She's a Stimulatin', Fascinatin', Assassinatin' Chick!:' Pam Grier as Star Text." Screening Noir 1, no. 1: 9-31.

Sontag, Susan. 1965. "The Imagination of Disaster." In Against Interpretation and Other Essays, 209-25. New York: Dell, 1979.

Zurcher, Anthony. 2014. "Rush Limbaugh and His 'Black Bond' Outrage." BBC News: Echo Chambers. December 29, 2014. Web, Accessed August 9, 2018.

\section{About the Author}

Anna Everett is a Professor of Film, Television and New Media Studies at the University of California, Santa Barbara. Her publications include Returning the Gaze: A Genealogy of Black Film Criticism, 19o9-1949 (Duke University Press, 2001), Learning Race and Ethnicity: Youth and Digital Media (MIT Press, 2007), New Media: Theories and Practices of Digitextuality (Routledge, 2003), Digital Diaspora: A Race for Cyberspace (SUNY Press, 2009), and Pretty People: Movie Stars of the 199os (Rutgers University Press, 2012). Dr. Everett is a two-time recipient of the Fulbright Senior Scholar Award (2005 and 2007), and currently serves a County Commissioner and Chair of the Santa Barbara County Commission for Women. 


\title{
10. Global Agency between Bond and Bourne: Skyfall and James Bond in Comparison to the Jason Bourne Film Series
}

\author{
Seung-hoonJeong
}

\begin{abstract}
Skyfall (2012) signals a crisis in global espionage in a post-9/11 era of schizophrenic digital terror. James Bond and his enemy are both internally excluded from their agency-MI6 — and this "abjection" leads to terrorist revenge and sovereign reaffirmation. The latter involves a survival test for 007's vulnerable body while simultaneously recovering a national identity for the United Kingdom. In this sense, James Bond mirrors Jason Bourne, the ex-CIA agent in the Jason Bourne film series. Bourne undergoes a similar abjection yet becomes neither terrorist nor sovereign but instead a symptom of perpetual mind-games. This chapter compares Bond to Bourne to enable a cognitive mapping of the twenty-first-century espionage genre and its global system of sovereignty and abjection.
\end{abstract}

Keywords: Jason Bourne; Skyfall; global cinema; sovereignty; abjection; agency

If the success of Skyfall (UK/USA: Sam Mendes, 2012) celebrated the fiftieth anniversary of the James Bond series and revitalized it for another halfcentury, this longevity could be viewed on two axes. First, synchronically, its brand power has already become "too big to fail" despite the ups and downs of individual entries in the series. Audiences know and repeatedly enjoy what they can expect from this longest film franchise. The Bondian narrative follows the flowchart of "moves" with archetypal characters: M's assignment of a mission to Bond, the Villain's threat, Bond's reactions, the

Verheul, J. (ed.), The Cultural Life ofJames Bond: Specters of oo7. Amsterdam: Amsterdam University Press, 2020 DOI 10.5117/9789462982185_CH10 
Woman's seduction, the Villain's capture and torture of Bond, Bond's escape and victory, and his convalescence with the Woman. Along this syntactic line, the semantic Manichean oppositions between characters, ideologies, and values are arranged in a quasi-mythical, structuralist fashion, with sexist, imperialist, and phallic codes crossing hermeneutically (Eco 1966, 37-39). Second, diachronically, the Bond series has never ceased evolving through the Cold War against the larger backdrop of the British Empire's decline and its global Anglo-American remodeling. As a "militainment" that meets societal expectations about war, media, and popular culture (Stahl 2009), it has flexibly adapted to the ages of the nuclear crisis, the Iraq War, 9/11, communist and post-communist militancy. Moreover, the agent with the "license to kill" has incarnated a modern fantasy of sovereign masculinity, stylish and high living as well as fast shooting and sexually liberated, while having been played by six actors. In short, 007 has been viable as "a variable and mobile signifier rather than one that can be fixed as unitary and constant in its signifying functions and effects" (Bennett and Woollacott 2003, 31).

Skyfall, however, leaves room for revisiting this general account in light of new challenges brought by both today's globalized world and the spy genre. Bond here, in the beginning, undergoes the symbolic death of being inadvertently but unsympathetically abandoned by M and MI6, whose role with murky methods is questioned in its turn and almost cast out of the government. The rest of the narrative unfolds the struggle of Bond, $M$, and MI6 at once to restore their endangered identity before their possible real death (thus all happens between the double death, symbolic and real). The mission given to Bond by $\mathrm{M}$ after his return is not just another countervillain operation, but a sort of "qualifying exam" to test their necessity in order to reconfirm their value. This self-reaffirmation is all the more tough yet urgent as the antagonist turns out to be a former MI6 agent, so to speak, an ex-child of M and a deserted brother of Bond. Moreover, this villain hacks the agency like an externalized insider who exposes its dirty business. In sum, the sovereign system generates its abject remnants, who may then become either a sovereign agent back or a terrorist one, either rejoining or rejecting the very system. The post-Cold War enemy of the digitally globalized agency is nothing but its double, and one's subjectivity precariously oscillates between sovereignty and abjection. Bond's unusually aging body materializes this vulnerability with little leisure for pleasure while trying to escape immaterial informatics and fight the enemy behind it physically in his Scottish childhood home to reclaim his identity as an MI6 agent. 
Indeed, Bond's self-reflection in this global backdrop is as desperate as timely. Now given the Brexit vote that revealed Britain's internal and external schisms, the final scene of Bond's return to London as a nationally reintegrated global hero may provoke all the more questions about his agency, nationality, and cosmopolitanism. However, these questions have been raised and addressed throughout the Bond series. What I propose then is to trace how Bond's sociopolitical subjectivity has resonated with the series' historically global nature, and to highlight the line between sovereignty and abjection that has become ever more blurred since Daniel Craig's introduction in Casino Royale (UK/Czech Republic/USA/Germany/ Bahamas: Martin Campbell, 20o6). Importantly, Craig's tenure has been influenced by the contemporary spy genre which has challenged 007 to renew its name value and differentiate its direction too. This interaction may tell much about today's global agency in both the senses of the term: the sovereign organization, and subjectivity in action for a mission.

\section{The Cold War as Already Post-Historical}

It is noteworthy that although Ian Fleming's early 1950s Bond novels emerged right in the wake of the Cold War, his 196os sequels introduced the swift shift to an imaginary post-Cold War world with sprouting effects of globalization. Hinting at a thaw in the Cold War, the source of enemies changed from SMERSH (Smiert Spionam [Death to Spies]), the most secret department of the Soviet Union, to SPECTRE (Special Executive for Counter-Intelligence, Terror, Revenge, and Extortion), an international criminal and terrorist syndicate. The latter is an NGO unaligned with any nation or political ideology, a borderless assembly of freelance villains only aiming to acquire power and wealth through terrorism. Exploiting the fragile relations between the East and the West, it holds them to ransom for private gain and carries out its threat to bring global catastrophes (Bennett and Woollacott 2003, 19-23). In a Marxist sense, SPECTRE then appears like the "spectre" of neoliberal terrorism or terrorist neoliberalism haunting the world as explicitly shown in Spectre (UK/USA/Austria/Mexico/Italy/Morocco:Sam Mendes, 2015). This fictional fusion of two oppositional facets of globalization, i.e., neoliberalism and terrorism, even betrays their real proximity in their pursuit of private greed through their supralegal modus operandi. In effect, the globally operating MI6 transcends the law in order to protect the order of neoliberal globalism. SPECTRE is thus like the mirror image of MI6 reflected from the outside of the latter's system. 
Interestingly, the Bond film series adopts the SPECTRE formula from the inception with Dr. No (UK: Terence Young, 1962) under the pressure of the film industry to depoliticize Bond, thereby maximizing worldwide profits. This widens the cultural spectrum of the Bond character with multiple access points, without ideologically pigeonholing him as the guardian of a big cause like freedom or equality. Above all, he appears as a traditional upper-class English gentleman: white, chivalrous, courteous, humorous, sporting, and patriotic. However, he is also a trans-Atlantic hero whose British origins are offset by American classlessness and openness, leading "the first truly global media phenomena of the modern age, crossing boundaries of language, social background, ethnicity, and culture" comparable to Coca-Colonization or McDonaldization (Chapman 2005, 138-40). While this "international Mr. Fix-It who just happens to be British" is still "a protector of Western interests" (141), the Westernized global hegemony seems to indicate not so much contradiction as mutual reinforcement between the national and cosmopolitan Bond, his Britishness and global appeal.

To amplify further, on the one hand, his Britishness lingers nostalgically on the conservative imagery of an elitist, nationalistic England: in Fleming's words, "a world of tennis courts and lily ponds, and kings and queens, of London, of people being photographed with pigeons on their heads in Trafalgar Square," and of people who "still climb Everest and beat plenty of sports and win Nobel Prizes" (Chapman 2007, 29). But on the other hand, Bond embodies an emerging fantasy of luxurious consumption in the society of the spectacle after the UK's imperial decline, breaking free from austerity and moving toward moral fluidity. He is a walking department store, displaying tasty food, nice clothes, brand-name goods, and technological gadgetry. He is a jet-setting free trader of sexual encounters and erotic adventures with multinational beauties in exotic locations. As if to watch a series of commercials or softcore porn, spectators are titillated to experience by proxy his capitalistic hedonism that is endlessly explored in a single global market of material splendor and sexual drives. That both Bond and Playboy were created in 1953 is coincidental yet convincing evidence to the cutting-edge "ethos of easy, free, open sexuality" in the backdrop of such easy, free, open consumerism (Chapman 2007, 31). In a nutshell, Bond is a playboy spy who transgresses laws and taboos while protecting the world as a global pleasure dome that represents his mindset and lifestyle shared or envied by his contemporaries.

The point is that Bond seamlessly mingles local anachronism with the global zeitgeist. Not rendered obsolete, his British legacy is updated as Anglo-American hegemony that sustains the global frame of transnational 
mobility and multicultural consumption. And yet it also underlies a new privileged place taken by the happy few in this classless frame. Capable but cruel in work and attractive but unattached in love, Bond is a winner in the modernity of meritocratic professionalism and sexual liberation. His hegemonic power typifies the collective spirit of the age precisely because it is desired by many but realized by few. Moreover, his "rebellious streak and less deferential attitude toward his chief" (Chapman 2005, 138) does not imply serious dissidence but just his free spirit, independence, and individualism which are allowed and even valued within the liberal democratic system-he is like "a cocky star student irritating his stuffy teachers" (Smith 2016, 153). His supralegal sovereignty for the cause of patriotic service and global policing - the essential motif of the spy genre-may then function as an umbrella for individual desires and gratifications, which he can pursue at liberty insofar as this capitalistic world system is defended from its spectral attackers. In this sense, the Bond films of the Cold War era prefigure the post-Cold War tendency of apolitical globalism. The global agent is already post-historical, with ideological seriousness left behind a capitalistic world of thrilling actions and teasing sensations.

\section{Increasing Globalism and Reflexivity Around the Millennial Turn}

In the 199os, Pierce Brosnan as Bond accelerates this "end-of-history" tendency after the real end of the Cold War. While a major threat still comes from Russia, it takes the form of the post-communist Russian mafia that exploits a flourishing black market as well as unstable local governments transitioning into global capitalism. Also, although China as the world's leading communist power is in conflict with Taiwan in Tomorrow Never Dies (UK/USA: Roger Spottiswoode, 1997), Bond teams up with a Chinese agent against the global villain who is a Western, power-mad media mogul. In short, the line between old friends and foes is blurred as ideological politics hardly matters. Enemies appear as the invisible hand of a global market for crimes, a power-controlling extra-legal Big Brother. And while Bond's patriotic and global sovereignty resonates with Tom Clancy's high-tech novels and films such as Patriot Games (USA: Phillip Noyce, 1992) and Clear and Present Danger (USA: Philip Noyce, 1994), global blockbusters that flexibly use the motif of espionage, even a comedy like True Lies (USA: James Cameron, 1994), trigger 007's depoliticization further in a spectacular fashion of media entertainment (Chapman 2007, 249). Bond's world now 
shows bungee jumping, computer hacking, new sports cars, and a female M, who even calls him "a sexist, misogynist dinosaur, a relic of the Cold War" in the way of recognizing the critiques of the Bond series from the liberal democratic perspective of "political correctness." In other words, the series has long been developed to the point of reflecting creative and critical challenges to it and co-opting them for its survival. To leave a self-critical room is even a marketing strategy as shown in an advertising copy: "Is there still a place in the modern world for a Secret Agent like 007" (Chapman 2007, 252)?

In the era of Craig's new millennial Bond, this self-reflexivity is not jokingly sprinkled but seriously embedded in the series' engagement with global terrorism. Casino Royale highlights the linked issues of global security and economy, showing that an international cabal led by stateless paymaster Le Chiffre (Mads Mikkelsen) finances terrorist organizations and African freedom fighters. So, while he is implied to have conspired with al-Qaeda in engineering $9 / 11$, what matters is not just a single bomb-maker but a big picture of terrorist networking backed by wealthy sponsors with connections to the world of high finance. This picture is all the more shadowy because the black market of terrorism is no longer detached from the official financial sector prospering through dynamic globalization. Sure enough, Le Chiffre means the cipher or the number, "a stand-in variable, a system of encoding that signifies meaning, but meaning that remains absent and undecipherable" (Omry 2010, 170). This spectral evil reflects the verso of globalization and its internalized external surplus, raising hysterical anxieties about the invisible complexity of the millennial world's operating system.

Bond's body is reformulated accordingly. He can cope with these anxieties technologically, but once stripped off tech gear, his body is all the more natural and raw, tough and gritty, showing off hegemonic masculinity realistically. Conversely, he is exposed to globally erupting danger, with the scar of technology inscribed on his flesh and its masculinity becoming vulnerable. Le Chiffre's sadistic torture poses castration threat to Bond's well-trained male body which is taken out of the law as if it were abandoned like "waste," in Le Chiffre's word, by his agency and country that might consider him as expendable. He is degraded, as Giorgio Agamben (1998) would say, to the animal-like "bare life" that is deprived of the right to protect biopolitical subjectivity and thus can be killed with impunity in the state of exception to normal law, which is suspended. His body is no longer the slick, classy, unharmed container of a stable identity secured by the state sovereignty, but a "precarious life" disposable any time. If Bond's law-bound submission to M's authority is masochistic in a socially acceptable way, his 
law-escaping surrender to Vesper is masochistic in the opposite way of opting out of that social structure which does not necessarily guard him (Johnson 2010). He loves her enough to quit his precarious job and social subjectivity when saying, "I have no armor left. You've stripped it from me. Whatever is left of me, whatever I am, I'm yours." Of course, after her death, all this self-skeptic deviation turns back into the reconfirmation of his name as "Bond, James Bond," but this reaffirmation itself draws delicate attention.

\section{Skyfall, The Self-Reaffirmation of the "Dark Knight"}

Now let us return to Skyfall. Ironically, it is in this most successful Bond film that Bond undergoes the most existential crisis along with $\mathrm{M}$ and the entire MI6. The motif of falling suggested in the title is manifested at the beginning when Bond's colleague Moneypenny (Naomie Harris) obeys M's ruthless order to shoot from long range Patrice, a villain fighting with Bond on the roof of a train, but instead Bond is hit and falls into the river below (Bond's revenge is done later by making Patrice fall from a building). Accidentally abandoned by his agency, Bond is then presumed dead; M writes his obituary later. This symbolic death happens in a "teaser sequence," which conventionally shows Bond's climactic action and resolution of an undetailed mission before the opening credits with title music followed by the main narrative. Moreover, Skyfall's title sequence does not titillate with the usual exhibition of girls, guns, and travels, but unfolds an experimental perspective of the camera falling into the abyss of expressionist, partly animated imagery as if it dug inside 007's dying mind, ending up with a vertiginous zoom into Bond's iris. The implication is his social abjection, cast off from subjectivity yet not dead like an object, thus stuck between life and death. After this prologue, Bond reappears as an aging, grudged alcoholic, spending a time of depravity in a tropical town, no longer as the hegemonic agent but as an abject whose loss of belongingness leads to physical and moral dilapidation. This period is brief as he soon returns to London upon the news of a terrorist attack on MI6, but his full re-subjectivation is completed only by the end of a whole new mission. Meanwhile, M's weakened operational edge and moral authority confronts her with the pressure to retirement as well as the criticism of the entire agency for lacking democratic transparency and strategic capability. So, the film will be about the quasi-postmortem redemption of both the agent and agency.

Such identity crisis becomes all the bigger as globalization renders global systems and subjects increasingly precarious. The post-historical 
systems of inclusion based on liberal democracy, multicultural commerce, and social networking inevitably generate symptoms of exclusion, the abject in various forms who are deprived of global citizenship, and whose revengeful return to the systems may be catastrophic. Also, due to the collapse of political barriers like the Iron Curtain that separated ideological oppositions, enemies are hard to detect, germinating in the systems as internally excluded byproducts. Criminal and financial forces mingle; schizophrenic terrorism and transnational neoliberalism mirror each other in their expansion. Skyfall updates this situation, staging the hacking of MI6's global network by its former agent as cyberterrorist. The post-911 globalism is more complicated in the backdrop of the digital revolution. The World Wide Web is ubiquitous, and information flows omnidirectionally. Warfare is net-centric, and satellite cartography casts an inescapable web of global surveillance. The leaks of computer data and the loss of network control are riskier than any physical military action; the IT infrastructure of daily life offers a broad platform for hostile attacks; global networks of opportunities are those of threats. The more connection, the more contagion. Not the gun but the computer as weapon renders Bond's physical action anachronistic, while the civilian overseers' demand of clear accountability harshly questions the dysfunctional role of MI6.

Raoul Silva (Javier Bardem), the ex-agent terrorist connected to SPECTRE, is an up-to-date villain in this regard, a master computer hacker who steals and leaks MI6's agent identities on YouTube. While hacktivists and whistleblowers such as Julian Assange and Edward Snowden are even revered as freedom fighters for the public right to know the suspicious power mechanism, Silva, though evoking these digital heroes, is nothing but a public enemy doing a renegade activity (Smith 2016, 147-50). The conservative logic of stigmatizing displacement works here: civil protest is externalized as a national security threat, and the inner problems of the state apparatus are singularized into an individual's abnormality. Silva appears like a sadistic monster when torturing Bond and killing Bond girl Sévérine; a psychopathic predator when caged in his turn; and an insane warmonger when flying to the last battlefield in a military helicopter playing loudly The Animals' rock number "Boom Boom." In short, he is a subject of jouissance who enjoys surplus pleasure beyond normalcy, obsessed with "a maniacal desire for revenge rather than any higher notions of transparency or democratic duty" (Smith 2016, 152).

This revenge results from Silva's backstory: an MI6 agent in Hong Kong, he was caught for hacking China beyond his brief (another sign of excessiveness), then tortured by the Chinese as $\mathrm{M}$ gave him up and got six agents in return 
upon Hong Kong's retrocession to China. That said, his hatred for M's complicity with the Chinese in torturing him appears as too traumatically twisted whereas it turns out that $\mathrm{M}$ made an inevitable decision, which is aligned with her justification of some "reasonable" cases of torture. Consequently, on the one hand, Silva's message to M ("Think of your sins") signals the return of the repressed, the punishment by the "undead" abject who cannot die since "life clung to me like a disease" after the torture as symbolic death. He recalls the horrors committed for imperial interests and mocks Bond's patriotic loyalty to M. On the other hand, Silva's resentment only turns into the active nihilism of pure destruction without any alternative idea, ideal, or ideology. He is oriented to no future but the past, just as his island kingdom is nostalgically associated with a ruined empire-a counterpart to Bond's Scottish home. The cyber war entailing actual torture and terror characterizes the dystopian closed circuit of post-historical globalism and abjection.

The dilemma of Bond's body is intensified accordingly. To upgrade it as a human interface with an embedded positioning device and info-processing capabilities is crucial for countering new enemies. When Silva escapes capture into the London Underground in the disguise of a policeman - the visualization of his ghostliness as a hacker-Bond chases him with the live guide of the control tower mapping their changing routes. However, as Silva still causes a massive train accident recalling the 2005 London terror, such risks literally make Bond "bare life:" vulnerable, suffering, bloody and sweaty unlike earlier Bond incarnations, who fights without dirtying his suit. Now, he must survive with technical proficiency for intelligent tasks as well as the self-healing power for body recovery (pulling out heart-screwing pins), flexibly adapting to volatile situations which test his superhero-like status to be retained despite its disposability by and in the system. From the socio-economic standpoint, this new working condition of Bond reflects the nature of post-industrial late-capitalist labor. One is required to acquire technical skills for handling knowledge and information as immaterial assets that overwhelm physical assets in cognitive capitalism, along with corporeal tenacity, mapping ability, flexible mobility, and useful adaptability in a globally expanded workspace and limitless competitive market. Work is relational, communicative, boundless, continuous, when workers become easily hurt, casualized, fired, and dehumanized in an economic "war of all against all" - a new Hobbesian state of Nature in which the social safety net to protect precarious labor from aggressive capitalization disintegrates to the extent that social abjection is no longer exceptional but normalized.

Likewise, Bond is put in the war on terror during the state of emergency, which is now all the more normalized as aggressive terrorization is 
omnipresent, even invisibly networked and internally generated. The Bond series indicates a historical shift in this regard. In the past, as described in Fleming's Moonraker (1955), Bond would venture only two or three times a year, and was basically "an easy-going senior civil servant" who would enjoy a routine of "elastic office hours from around ten to six" with "evenings spent playing cards in the company of a few close friends" and "weekends playing golf for high stakes at one of the clubs near London" (Smith 2016, 153). That is, disciplined work and pleasurable leisure were separated in his normal life while risky missions were given only exceptionally. The state of exception in which he worked as a secret agent was, like the "dark knight," hidden under the surface of his official life as "white knight" (mirroring Christopher Nolan's Dark Knight trilogy [UK/USA, 2005-2012]). To the contrary, this distinction is blurred in Daniel Craig's impersonation of Bond, whose status and environment are continuously unstable and modulable due to the infernal fusion of belongingness and abjection, loyalty and betrayal, peace and crisis, sovereign and terroristic agencies, and normal and bare lives. His world tour is no longer hedonistic but breathless with unpredictable widespread threats; the only sexual moment of taking a shower with Sévérine, who is soon to be killed, is very short. Even $\mathrm{M}$ is nothing but a replaceable boss; her desk is cleaned for a successor right after her death, which receives no official acknowledgment.

This precarious condition of life and work may underlie Bond's bitterness over $\mathrm{M}$ and her would-be successor Mallory, the "bureaucrat." Bond is no longer a loyal servant of the state with some rebellious attitude, but a twin of Silva, who tells that they are M's two kids, two caged rats tested to survive from cannibalism. Their bifurcation into the opposite sides seems contingent, thus reversible - it suggests Bond as a seeming renegade antagonistic to the state. However, skepticism about the system also appears as the official interrogation of MI6 by civil servants and government ministers in parliamentary committees who stand for the very system more comprehensively and so require more democratic transparency, global efficiency, and neoliberal competitiveness in operation. For them, MI6 is a "bunch of antiquated bloody idiots fighting a war [they] don't understand and can't possibly win," and M is responsible for the "monumental security breaches and dead operatives" (Skyfall). No longer a denied or obscured taboo, the agency is asked to be a collective "white knight," publicly named and openly advertised on the web with official histories.

For M (Judi Dench), however, those civilians and non-combatant bureaucrats are too naïve since new enemies are no longer nations but unknown individuals without a face, uniform, or flag. M says in Skyfall, "Our world is not 
more transparent now. It's more opaque. It's in the shadows. That's where we must do battle. So, before you declare us irrelevant, ask yourselves, how safe do you feel?" This logic renews the Cold War rhetoric of fearmongering politics in the post-historical (and post-911) age in which global networks generate the schizophrenic multitude of stateless hackers and ghostlike terrorists. In this world which itself lacks transparency, secret agencies would become more vulnerable and ineffective under open scrutiny and public interference. $M$ thus advocates for the secrecy of MI6 with "dark knight" elite agents as inevitable and even invaluable in the global fight against dark enemies. The terms of criticism are then inverted; it is not the citizen or politician but the agency that is "the true defender of democracy" against ubiquitous threats (Smith $2016,156)$. The agency is not oppositional to, but rather protective of the open democratic system from behind. It works like a hidden underlying principle of the system, like the dark Real of the symbolic order. The transparent efficacy of legitimate reality does not function without this bloody invisible hand for dirty yet necessary businesses. The ideological effect is the conservative perpetuation of supralegal sovereignty that enables the justified perpetration of panoptic surveillance, unrestrained violence, and state-sponsored crimes. Now MI6's headquarters are moved to one of Churchill's war bunkers, and there, M quotes a verse from Alfred, Lord Tennyson's poem "Ulysses" (1842): "One equal temper of heroic hearts/ Made weak by time and fate but strong in will/ To strive, to seek, to find, and not to yield."

Bond's excursion with $\mathrm{M}$ in an old car (the canonical Aston Martin from Goldfinger [UK: Guy Hamilton, 1964]) to his family estate of Skyfall, following Silva's brutal attack on M's inquiry hearing, is no other than Ulysses' homecoming, a journey to reclaim their identity with "heroic hearts" as well as the identity of the spy genre. The itinerary from London to the Scottish Highlands, recalling Alfred Hitchcock's The 39 Steps (UK: Alfred Hitchcock, 1935), suggests a nostalgic return to the origin and heyday of the spy thriller in the way of escaping from the tech-web of digital networks and surveillance apparatuses. Skyfall is in the middle of nowhere, of nearly sublime Scottish nature. It is a dark old place for traditional physical actions of bare lives. Bond uses conventional firearms with no computer; he fights, hurts, and "falls into water" (again) to almost die before finally killing Silva with a knife. Only after this experience of going down to the bottom of life does he resurge and reconfirm himself. The entire sequence indeed indicates Bond's selfrecovery. It is told that he was orphaned very young - his parents' tombstone shows their names, Andrew and Monica Delacroix Bond-and now M and Kincade, estate gamekeeper, symbolically take the place of his parents. This quasi-family triangle forms a minimal unit of agency temporarily 
bonded for the mission of action, grounding Bond's pseudo-Oedipal quest to protect the matriarchal M from Silva. But the death of both Silva and M, for whom he mourns in a chapel, alludes to Bond's final overcoming of his revisited past. In fact, he expresses his hatred of his childhood, and Skyfall is destroyed while he escapes the explosion through a tunnel. Like these repetitions of falling and escaping, Bond lives his past again as if to work through the trauma of orphanage which led him to MI6, whose recruiting target was "maladjusted young men who give little thought to sacrificing others in order to protect Queen and country" (Casino Royale, film version). In other words, this past in which he became an adult as an agent is re-lived in order to reaffirm the sublimation from the lost primary identification with his concrete family to the higher secondary identification with the abstract nation. It is the classical double step of identity formation.

Back in London, the iconic rooftop scene of Bond contemplating the skyline dominated by Union Jacks repositions him as an adult son of the Queen and a loyal servant of the country. By extension, he is a heroic guardian of its imperial nostalgias; the locations of Shanghai, Macau, and some islands evoke the sunset-less Empire and its loss of colonies like Hong Kong. J.M.W. Turner's painting The Fighting Temeraire (1839), on display in the National Gallery where Bond meets Q, shows a gunship that led the Trafalgar victory, being tugged to her last berth to be broken up upon the British navy's transition from sail to steam. Silva hits the spot: "England. The Empire. MI6. You're living in a ruin. It's over. Finished. What are you doing clinging to this notion of nation?" The recovery of MI6, therefore, operates as a reassuring fantasy of the national Empire's postmortem resurrection as a global empire in which London is (again) the center, maintaining the imperial legacy—Bond's victory over Silva valorizes traditional physical and mental strength over postmodern techy smartness. However, this fantasy is not smoothly sutured. The problem is not simply that the nostalgia of shadowy anti-terrorism may involve "the use of unaccountable and extreme violence in our battles with cyberterrorists" (Hasian Jr. 2014, 585). More profoundly, the new global empire is like the Empire without emperor in Antonio Negri and Michael Hardt (2000)'s terms, full of post-historical symptoms related to cognitive capitalism and precarious labor, already cyber-networked and ready to abject its own agents. Bond's coolness barely hides insecurity and terror, and his harsh actions infinitely inscribe fatigue and pain on his body. The agency's self-reclaim of its raison d'être is the desperate attempt to find an ideological frame in which what is lost is self-illusively retrieved. Bond's traumatic past is called for back here, not to be affirmed in itself so much as to reaffirm his present identity in crisis. Abject subjectivity regains agential sovereignty in this way. 
In Spectre, Sam Mendes again stages the UK's political hazard and physical insecurity in central London and on British soil where the state appears as a significant threat to itself. But again, it is noteworthy to read global symptoms in the national framework as the title explicitly designates SPECTRE. Bond is networked into a collective working unit as never before, while his and MI6's relevance to the new world order is critiqued again within the government - hence, Bond's realization that "the best way to protect the country is to protect oneself from the country's government." Leading the sinister global SPECTRE, Ernst Stavro Blofeld (Christoph Waltz) taunts about Bond's one-person show, telling him like Silva: "Everything you stood for... is a ruin." His torture, using computer-controlled micro-drills to penetrate Bond's skull, looks almost like a psychotic play for sadistic jouissance, again evoking Silva. Facing this bodily pain as bare life in abjection, Bond performs his mission against SPECTRE as his self-imposed mission of identity reaffirmation too. The doubly Proustian name of Madeleine Swann, his love interest, suggests that the Craig films are "ostentatious and extended Remembrance of Things Past": Skyfall goes back to the time "before Bond" and Casino Royale to the time of "becoming Bond" (Murray 2016, 6). The ironic opening intertitle, "The Dead Are Alive," is then not only about SPECTRE but also about Bond himself. The Self finds himself through the encounter with the Other, while both are floating around the world like undead phantoms of the past and intermingled shadows of the present. Of course, the film ends up with the neat separation between them and the Self's triumphant elimination of the Other. This separation is reaffirmed every time the franchise struggles to reposition itself.

\section{Abject Agency from Bond to Bourne}

At this point, Bond's self-reaffirmation can be seen as the series' survival strategy in the contemporary context of the action spy genre and the global film market. The new millennial reflections of post-911 espionage, surveillance, security and precarity have blossomed in the Jason Bourne (2002-Present) and Mission: Impossible (1996-Present) franchises, political thrillers such as Syriana (USA: Stephen Gaghan, 2005) and Rendition (USA: Gavin Hood, 2007), and high-budget TV serials including 24 (USA: Joel Surnow, 2001-2014), The Wire (USA: David Simon, 2002-2008), Spooks (UK: David Wolstencroft, 2002-2011), and Homeland (USA: Howard Gordon, 2011). For example, Ghost Protocol (USA: Brad Bird, 2011), the most successful Mission: Impossible film, maximizes the crisis of secret agencies during the post-Cold War 
disintegration of the distinction between friends and foes, the Self and the Other. In the Fox television series 24 , a counterterrorism agent must cope with an enemy's ticking-time-bomb-scenario as well as inner critics' disapproval of his ruthless methods. Typically, global agents undergo the symbolic death of abjection, then restore or transform their suspended subjectivity before probable biological death by carrying out a traumatically (self-)imposed mission. It is often fulfilled through a double cognitive-corporal mapping under lethal threat: the temporal reconstruction of their pathological mind/ memory and the spatial reorientation of a disastrous and apocalyptic territory. In this narrative bracketed by double death, global abject-subjectivity emerges as both reflecting and performing cognitive capitalism as well as its catastrophic imagination. However, the forking point appears here. Although the Bond series reboot to reflect the socio-physical vulnerability of agency beyond its old fantastical luxurious escapism, Bond is sutured back into the system as a sovereign agent like the Dark Knight. By contrast, Jason Bourne, among others, becomes a new type of terroristic agent who refuses this reterritorialization of old subjectivity and leaves open the gap between the global system and its inherent inconsistency. ${ }^{1}$

Undoubtedly, "Jason Bourne" intends to reconfigure "James Bond" in a continuous sage up to the latest segment titled just Jason Bourne (USA/ China: Paul Greengrass, 2016). The only enemy of the CIA is its own ex-agent Bourne (Matt Damon), who thus fights with his former agency. However, unlike Silva's pure revenge or SPECTRE's terror for capital and power, Bourne becomes a terroristic agent only to discover who he is and why the agency threatens him. The beginning marks his failure in a mission of assassination, after which he is shot and presumably turns amnesiac. The rest of the film chronicles his nomadic struggle to recover his memory, under attack from unknown assassins, whom he defeats while discovering secret CIA operations that involve and target him. As in the Bond series, the beginning is the end of the hero's normal life, his symbolic death as traumatic abjection from his psychological, sociopolitical subjectivity. His quasi-dead body floating in the sea visualizes a rootless bare life deprived of identity in Agamben's sense of homo sacer, whose murder by sovereign CIA agents is to be done in the state of exception with no due regard to any legal system.

Indeed, the CIA functions as a supralegal global network agency. The US headquarters connect to international branches; local agents carry out

1 Elsewhere (Jeong 2019), I have compared James Bond to Jason Bourne to discuss sovereignty and abjection as reflected in Source Code (USA/Canada/France: Duncan Jones, 2011), among other post-Jason Bourne action thrillers. 
remotely delivered missions in global metropolises. Using private planes and satellite surveillance, they intervene in the entire world under the Geographic Information System. Moreover, information is corruptly capitalized and traded by senior CIA officials with Russian magnates in the global black market of private greed. This dirty business implies "disaster capitalism" on the level of power elites who monopolize the control over security and industry, taking benefits from real or potential crises. They are enemies within who suppress uncomfortable truths and engineer illicit execution for "our" security at the cost of bare lives, including their own ex-agents who might debunk the system. That is why Bourne is trained and then threatened by them, treated like a potential terrorist, "a known unknown," as Donald Rumsfeld posited, in the sense that we know we don't know his location, which is a security risk. The CIA is a global ideological apparatus of neoliberal information capitalism and neoconservative patriotic vigilantism.

Bourne is defined in this system as "government property," but also as "a malfunctioning \$30 million weapon," and therefore "a total goddamn catastrophe." He is a corporeal program that merits high investment by removing threats from the info-market, but he would otherwise turn into the system's own disaster. Bourne is therefore both a product and byproduct of the global system, embodying its cognitive capitalism and precarious labor, terror and war on terror at once. His pistol, money, and multiple passports symbolize his physical, financial, and intellectual qualifications for working like a global freelancer. He is an all-around professional with neoliberal abilities for success: quick decision, swift movement, high intelligence, and risk-taking. His cognition perfectly maps new places at first sight, while a traumatic sense of déjà $v u$ brings him some lost memory. His action is fast enough for flexible adjustment to unstable situations, particularly during acrobatic chases. This competitive worker, however, suffers from endless labor without leisure, and from constant insecurity without protection in a perpetual state of emergency. Far from Bond's bourgeois bohemian lifestyle, Bourne enjoys no consumerist relaxation, no exotic tourism, no hedonistic liberation. His only sexual partner becomes his romantic girlfriend, who is subsequently killed. All this precarity, worse than in Skyfall, characterizes Bourne's body which is shot, drifting, strangled, wounded, and stabbed. However, this bare life equips itself with the endurable agency, the causative force to act for a mission, the self-imposed task of self-rediscovery through his continual self-recovery.

The Bourne series indeed combines James Bond's efficiency with Noam Chomsky's politics, renewing the 1970s paranoid thriller-such as The Conversation (USA: Francis Ford Coppola, 1974) and The Parallax View (USA: 
Alan J. Pakula, 1974) - that reflected cynically on the US government and articulated conspiracy theories about the Vietnam War and the Watergate scandal. The Iraq War and the war on terror provoke a new paranoiac view in which our corrupt elites might create terrorists who could be internalized more dangerously. The sovereign system intensifies global surveillance and supralegal violence while violating democratic procedures, wreaking havoc on civilians, and convoluting terror and counterterror. Suggestive are Bourne's chases, as well as Bond's, in what Marc Augé (2009) calls "non-places," spaces of transition without identities like a motorway and a supermarket. The Waterloo Station scene in The Bourne Ultimatum (USA/ Germany/France/Spain: Paul Greengrass, 2007) particularly shows how a public place becomes claustrophobic under surveillance when cameras lurk everywhere to locate Bourne, but also how both the CIA and Bourne use their remotely controlled agents — for Bourne, a journalist as proxy — to play a hide-and-seek role-playing game with each other between the visible and the invisible. The hidden cameras maximize the visual field in which Bourne remains a mobile blind spot, a phasmid-like ghostly shadow-a terrorist by nature. The tension between the system and the terrorist then turns mutual fear into "dread," the ubiquitous fear for unpredictable attack immanent in daily life. Normalcy is an emergency.

Each Bourne film comprises such discrete sequences as if they were levels in a video game that the player completes with increasing difficulty while exploring unknown non-places. This double game-narrative of "leveling-up" and "navigation" also applies to the entire series. Also, as secret files play the role of a plot developing archive, all physical actions are driven by the cognitive desire for valuable information. Bourne's body functions here as a sensorimotor system, with the self-backup function embodying a certain undeadness, while his mind is a self-investigating cerebral system that restores damaged memory for identity rebooting. The film series thus appears as a "mind-game" (Elsaesser 2009) road movie in which a traumatized abject-agent has to follow an undetermined itinerary along contingent spatiotemporal shifts in both fractured memory and disoriented movement. It unfolds a cognitive-corporeal mapping of horizontal global space and vertical subjective time; a struggle of today's pathological subjectivity as abject to orient itself in the threatening world. The terrorist becomingagent of the abject is then a survival strategy against the global system by reappropriating qualities and skills that are required and trained within the very system - as already noted, this aspect is shared with Daniel Craig's Bond films and harkens back to Licence to Kill (UK/Mexico/USA:John Glen, 1989) as well. 
The origin of this antagonism is, however, not merely the corruption of the system. Bourne fails in the initial mission because of his hesitation about killing an African leader in the presence of his children; Bourne takes revenge for the murder of his girlfriend who was shot instead of him; Bourne apologizes to the daughter of a Russian reformist politician he killed, after discovering the grubby operation and business of his boss who ordered this murder; Bourne always uses violence in a restrained manner, protecting and never really killing others except for the case above. All these suggest Bourne's guilt and responsibility for (possibly) killing (decent) people, his atonement and redemption through paying off this guilt as debt. In The Bourne Ultimatum, he finally reaches the CIA training center in New York where, he remembers, he was forced to kill a masked terror suspect as an initiation ritual into a secret team; killing a bare life in the state of exception gained him supralegal sovereignty. The ultimate scene of self-discovery recalls the original sin of killing the Other, whose face was covered to prevent the Levinasian encounter with the "face of the Other" that commands, "You shall not kill," in its absolute vulnerability, which may conversely reveal the potential sanctity of life. At last, the post-traumatic restoration of his identity, its ontological and epistemological recovery, ends up with the traumatic revisit to its initial formation, as in Skyfall and Casino Royale. But upon knowing the truth of who he was, Bourne, unlike Bond, decides to abandon this identity, the license to kill, the system of mechanizing sovereignty and abjection. He is then shot and falls into New York's East River. Real death? We see him swimming away.

It is clear where Bond and Bourne meet and part. Secret agencies as a protective gear of global systems driven by info-capitalist tech-networking inevitably generate symptoms of precarious labor and bare life, and agents as competitive professionals, once excluded, can turn into dangerous hackers or whistleblowers. Bond, particularly in Skyfall, undergoes abjection too (evoking On Her Majesty's Secret Service [UK: Peter Hunt, 1969], For Your Eyes Only [UK: John Glen, 1981], and especially Licence to Kill), but fights against such terrorist abject-agents by reaffirming the sovereign agency of supralegal power repeatedly. On the contrary, while Bourne's former network agency is more globalized and corrupted at once, his traumatic abjection puts him under harsher conditions of bare life in a radically normalized emergency with no room for the hedonistic privileges of the early Bonds. His cognitive-corporeal struggle with a lost memory and threatening space nonetheless unfolds as a convoluted journey for selfdiscovery in the form of terrorist resistance to the unethical system that trained him. In sum, the continuation of the Bond and Bourne series, in 
opposing ways, tells us that the sovereign system and the abject agent are inseparable and that their antagonistic hide-and-seek network has no outside. This cinematic logic allegorizes the impossibility of one's ultimate release from the global system, leaving only the fantasy of choice: Bond or Bourne? A blue pill or a red pill?

\section{Works Cited}

Agamben, Giorgio. 1998. Homo Sacer: Sovereign Power and Bare Life, translated by Daniel Heller-Roazen. Stanford, CA: Stanford University Press.

Augé, Marc. 2009. Non-Places: An Introduction to Supermodernity, translated by John Howe. London; New York: Verso.

Bennet, Tony, and Janet Woollacott. 2003. "The Moments of Bond." In The James Bond Phenomenon: A Critical Reader, edited by Christoph Lindner, 13-33. Manchester: Manchester University Press.

Chapman, James. 2005. "Bond and Britishness." In Ian Fleming and James Bond: The Cultural Politics of oo7, edited by Edward P. Comentale, Stephen Watt, and Skip Willman, 129-43. Bloomington: Indiana University Press.

Chapman, James. 2007. Licence to Thrill:A Cultural History of the James Bond Films, Revised Edition. London: I. B. Tauris.

Eco, Robert Angus. 1966. "The Narrative Structure in Fleming." In The Bond Affair, edited by Oreste Del Buono and Umberto Eco, translated by Robert Angus Downie, 35-75. London: Macdonald \& Co.

Elsaesser, Thomas. 2009. "The Mind-Game Film." In Puzzle Films: Complex Storytelling in Contemporary Cinema, edited by Warren Buckland, 13-41. Chichester: Wiley-Blackwell.

Hardt, Michael, and Antonio Negri. 200o. Empire. Cambridge, MA: Harvard University Press.

Hasian Jr., Marouf. 2014. "Skyfall, James Bond's Resurrection, and 21st-Century Anglo-American Imperial Nostalgia." Communication Quarterly 62, no. 5: 569-88. Jeong, Seung-hoon. 2019. "A Thin Line Between Sovereign and Abject Agents: Global Action Thrillers with the Sci-Fi Mind-Game War on Terror." CLCWeb: Comparative Literature and Culture 21, no. 7 (December): 1-13.

Johnson, Audrey D. 2010. "Male Masochism in Casino Royale." In Revisioning oo7: James Bond and Casino Royale, edited by Christoph Lindner, 115-27. New York: Wallflower Press.

Murray, Jonathan. 2016. "I've Been Inspecting You, Mister Bond': Crisis, Catharsis, and Calculation in Daniel Graig's Twenty-First-Century 007." Cineaste 41, no. 2: $4^{-11 .}$ 
Omry, Keren. 2010. "Bond, Benjamin, Balls: Technologised Masculinity in Casino Royale." In Revisioning oo7:James Bond and Casino Royale, edited by Christoph Lindner, 159-72. New York: Wallflower Press.

Smith, James. 2016. "'How Safe Do You Feel?': James Bond, Skyfall, and the Politics of the Secret Agent in an Age of Ubiquitous Threat." College Literature 43, no. 1: 145-72.

Stahl, Roger. 2009. Militainment, Inc.: War, Media, and Popular Culture. New York: Routledge.

\section{About the Author}

Seung-hoon Jeong is an Adjunct Assistant Professor at Columbia University in the City of New York and a Visiting Professor at Yonsei University, as well as a Lecturer at Korea National University of Arts and Seoul National University. He received the SCMS Dissertation Award and wrote Cinematic Interfaces: Film Theory after New Media (Routledge, 2013). He co-translated Jacques Derrida's Acts of Literature into Korean (Moonji, 2013), co-edited The Global Auteur: The Politics of Authorship in 21st Century Cinema (Bloomsbury, 2016), guest-edited a special double issue of Studies in the Humanities, "Global East Asian Cinema: Abjection and Agency" (2019), and is writing Global Cinema: A Biopolitical and Ethical Reframing (Oxford University Press, forthcoming in 2020). 



\section{Part III}

Beyond the Films:

The Transmediality of the James Bond Franchise 



\title{
11. James Bond and Art Cinema
}

\author{
Christopher Holliday
}

\begin{abstract}
The James Bond films are an enduring example of "escapist" popular cinema seemingly at odds with the filmmaking traditions of European modernism. However, this chapter offers the 007 film series as a candidate for Britain's contribution to the European Art Cinema tradition. From Maurice Binder's opening credits for Dr. No (1962), reminiscent of experimental filmmaker Len Lye, to the discontinuous editing patterns and jump cuts of $\mathrm{On} \mathrm{Her}$ Majesty's Secret Service (1969), 196os Bond cinema formally registers the violation of the classical norms and stylistic traits upon which art cinema was predicated. This chapter accordingly identifies how the stylistic transformation of the early Bond films can be woven into the art cinema traditions and political modernism of post-war European filmmaking.
\end{abstract}

Keywords: art cinema; European; style; modernism; British; James Bond

I'd just seen a very pretentious picture called L'année dernière à Marienbad, where everybody was wandering down moonlight paths with sculptures and Christ knows what, so we put Sean in there. - Terence Young, director of From Russia with Love (1963)

Part-Hitchcock and part-Hollywood in their "double" identities, the James Bond films express a shared occupancy within both the British imperial spy thriller and American blockbuster filmmaking traditions. However, the 007 film series also counts among its multitude of push-pull relationships the adventure serial, film noir, the British New Wave, the B-movie, Italian comic books and pulp fiction, and 196os Eurospy cinema; a mixed pedigree that, when taken together, reveals the myriad of influences and afterlives that underscore the most commercially-successful film series in post-war

Verheul, J. (ed.), The Cultural Life ofJames Bond: Specters of oo7. Amsterdam: Amsterdam University Press, 2020 DOI 10.5117/9789462982185_CH11 
British cinema. Taking into consideration the multiple genealogies of Eon's official Bond films, this chapter introduces modernist—and particularly European-art cinema traditions as often overlooked points of intersection with 007 's big-screen adventures. Brian Hoyle $(2009,407)$ is not alone in asserting that "British cinema did not have an indigenous equivalent to the modernist European art cinema of countries such as France, Italy and Germany in the 196os and 1970s." However, despite the Bond series' status as an enduring example of "escapist" popular cinema seemingly at odds with the realisms, looser narratives and languid stylings of European modernism, this chapter offers the 007 films as a potential candidate for the presence of a British art cinema tradition. With particular focus on the striking narrative and formal elements of sixties Bond cinema that foregrounded "narrational acts" (Bordwell 2008, 155), this chapter identifies how the stylistic transformation of Bond cinema, in spite of its popularist appeal and pervasive "Britishness," can be productively woven into multiple art cinema traditions (British, European, and North American) and political modernisms of post-war filmmaking.

\section{The Specter of Europe}

The visible absence of a clear-cut art cinema tradition within British film has been a mainstay of its critical narrative, culminating in what Thomas Elsaesser $(2005,14)$ calls British cinema's "many false dawns as an art cinema." Despite several protestations-most notably by Peter Wollen (1993) and Alan Lovell (1997) — against traditions of British social realism as embodying a native art cinema in Britain, many scholars have suggested that an art cinema was able to develop through mid-century realist conventions just as it had done so in the concurrent national filmmaking traditions of the French Nouvelle Vague, Italian Neorealism and Young German cinemas. The naturalism and verisimilitude of "Free Cinema" and, later, the British New Wave with its "authentic" socially-purposive sentiments and political poeticism staked a strong claim to be considered Britain's contribution to a global art cinema. Although British cinema has typically been omitted from European-centric critical studies of auteurism, Britain "was at least intellectually at the very core of the domination of the European art cinema in the 1950s" (Hedling 2003, 23). While perhaps lacking a coherent set of figures to rival Ingmar Bergman, Federico Fellini, Roberto Rossellini and Luchino Visconti, it was filmmaker Lindsay Anderson and his co-founding of the Sequence film journal that propagated a radical British 
"art cinema credo" (Hedling 2003, 24). Sown in the pages of a specialist publication devoted to transmitting the individualism of the filmmaker (thereby anticipating French auteurism by several years), what might be termed British art cinema was intellectualized in the 1950s prior to the emergence of a distinguishable body of "socially-realist" films towards the end of the decade and into the sixties.

The prevailing assumption, however, has been that social realist traditions cannot quite be reconciled as the fullest realization of an indigenous art cinema in Britain. Hoyle (2009, 407-08) suggests that any notion of a "British" art cinema exists only sporadically in the work of filmmakers such as Anderson, Joseph Losey, Ken Russell and Nicolas Roeg (in addition to expatriates Michelangelo Antonioni and Roman Polanski), and ultimately did not achieve full coherency until the early 1980s through figures like Derek Jarman, Peter Greenaway, Peter Watkins, Terence Davies and Sally Potter. In the work of these later filmmakers, prior social realist traditions would merge more readily with European art cinema to form "social art cinema," in which social and political engagement was delivered more explicitly through strategies of formal hybridity and a self-conscious narrative style (Williams 1996; Hill 1999). This broader critical uneasiness around the legitimacy of "Free Cinema" and the British New Wave as art cinema movements further explains the consistent critical turn toward any separate "deviant, non-realist British cinema" (Street 1997, 188) as a way of qualifying the existence of a true British art cinema more in line with the aesthetic traditions, formal radicalism and political critique of post-war European cinema. Marked by the work of experimental animators Len Lye and Norman McLaren, the earlier 1920 s and 1930 s period of British avant-garde practices has been credited with "nurturing a cultural appreciation for art cinema, particularly amongst the intelligentsia" (McFarlane 2016, 29). For Sarah Street (1997), it was the later formal experiments of filmmakers Michael Powell and Emeric Pressburger in the 1940s-at a time when continental art cinema was gesturing primarily towards a realist aesthetic — that ultimately served to push British domestic production towards a more conspicuously modernist style. Street $(1997,200)$ argues that Powell and Pressburger offered, under the guise of their production company The Archers, "exciting and significant contributions to the corpus of national cinemas," which constituted clear "aesthetic experiments" in the "commercial feature industry" of the United Kingdom. These were films that therefore rejected the naturalism of the British Documentary Movement of the late-1930s while anticipating the later, hardened period of modernist "art cinema" in Britain during the 1970s and 1980s. 
Whether paperback hero or big-screen British Intelligence agent, the figure of James Bond seems immediately incompatible with discussions of a "British interest in non-narrative experimental art cinema" (Street 1997, 188) in particular, and European art cinema more broadly. Circulating within the global market and firmly in the mainstream, the 007 film series is an international filmmaking phenomenon and an exemplar of post-war popular cinema. The series is far removed from "art cinema" as both an industrial and aesthetic category, not outwardly defined by the "modes and circuits of production, distribution and exhibition" (Neale 1981, 13), or the formal conventions (ambiguous endings, rejection of classical storytelling, "open" narratives) that traditionally position "art cinema" outside the mainstream Hollywood style. Beyond the divisions of high/low or art/commerce that normally structure categories of the popular, Bond films similarly operate at a distance from a specific kind of "authored" or auteur art cinema. Despite a regular coherency of British directors (Terence Young, Guy Hamilton, Lewis Gilbert and, later, John Glen), as Sinclair McKay $(2010,27)$ playfully put it, "being a director on a Bond film is not so much a job for an auteur as a circus ringmaster."

However, a closer examination of the Bond series illustrates that rather than enforce traditional dichotomies between "art" and "popular" filmmaking, or indeed classical and modernist cinemas, these two strands are more in dialogue with one another than is often assumed. This is because the Bond series occupies something of a missing link between two historical moments in British art cinema's chronology. The birth of the official series with $D r$. No (UK: Terence Young, 1962) comes towards the end of the early-196os British New Wave movement, but before the 1970 s and 1980 s when British cinema strayed from its naturalist style to consolidate a recognizable art film aesthetic cut to the pervasive European model. The 007 of these sixties' films was (to a degree) congruent with the anti-authoritarian "Angry Young Man" social type of the British New Wave (often played by regional actors), even if the Bond narratives themselves were outside the mold of "kitchen sink" realism that supported these Free Cinema successors. At the same time, there was certainly something about the 007 film series that marked them out as a radical break from contemporaneous British cinema of the period.

It was in their Modernist production design (typified by the work of Berlin-born Ken Adam) for their elaborately engineered set pieces that the Bond films eschewed the primacy of location shooting and levels of realism that became the hallmark of multiple New Wave and art cinema movements. The architectural splendor of Adam's set designs, including spacious command centers, cavernous control rooms and elaborate underground lairs 
evoking the mid-century architectural form of Frank Lloyd Wright, Albert Kahn, Pierre Koenig and Charles-Édouard Jeanneret, provided a suitable backdrop for the lofty aspirations of the Bond villains, if not a startling counterpoint to the moderate Georgian-style interior of oo7's home first glimpsed in Dr. No. It has also not been outside the remit of Bond villains to appropriate pre-existing modernist structures for their sinister operational bases. John Lautner's futuristic Elrod House and the minimalist Moroccan villa designed by Algerian architect Imad Rhamouni-a protégé of French designer Philippe Starck - were used by Ernst Stavro Blofeld in Diamonds Are Forever (UK: Guy Hamilton, 1971) and Spectre (UK/USA/Austria/Mexico/ Italy/Morocco: Sam Mendes, 2015), respectively, as a suitable accompaniment to his hyperbolic megalomania.

Modernist architecture certainly supports the identity of sixties Bond as a "colorful fantasy" (Chapman 2005, 9) that marked a wider shift within British film culture away from a fifties cinema committed to social realism. Yet the cleaving of 007 from British filmmaking of the period is often underscored by the series' degrees of attachment to popular American cinema. Filmmaker François Truffaut's criticisms of the 007 films (as nothing more than parodies of Hitchcock) bears out the dislocation of Bond from the social and political reality of post-war Europe through the character's anchorage in mainstream Hollywood culture. Truffaut argued that with 007 "mass audiences were exposed to what amounts as a degradation of the art of cinema" (quoted in Bergan 2008, 130). Bond thereby represented American "decadence," with an identity as a Hollywood product that betrayed Bond's presumed "Britishness" as defender of the Empire. At the same time, the Bond movies did trade in a strong(er) European flavor, bearing the stamp of a particular kind of European sensibility largely defined in opposition to the North American entertainment cinema.

Produced outside any recognizable studio system by American Albert "Cubby" Broccoli and Canadian Harry Saltzman for their London-based company Eon Productions, the 007 films were UK/US co-productions and trans-Atlantic products, aided by a distinctly European flavor from the outset. Tim Bergfelder $(2000,149)$ argues that 007 was "indebted to popular European genre traditions" more so than they were to contemporary American genres of the sixties period. The Bond films further "replicated the attractions of the European adventure film," bringing globe-trotting expanse, stunts and action together with "escapist pleasures" that offered a low-brow appeal to the European market. Elsaesser (2005: 47) suggests the Bond films should actually be considered "part of European cinema," aligning the series with a diverse range of more typically European post-war 
products, from the rural sentimentality of the Heimat films in Germany to the Italian Spaghetti Western. The strong intercontinental casting of the 1960 s Bond films also marked a concerted effort by Broccoli and Saltzman to target European audiences. Kim Newman argues $(1986,51)$ :

Although to many, the James Bond films represent the epitome of AngloAmerican movie-making, they were expressly aimed at a multi-national audience from very early on. The casting of guest stars from the German (Gert Fröbe, Lotte Lenya), French (Claudine Auger) and Italian (Ursula Andress, Daniela Bianchi, Adolfo Celi, Luciana Paluzzi) popular cinema did much to give the series an international feel. ${ }^{1}$

Despite Andress (Dr. No) and Auger (Thunderball [UK: Terence Young, 1965]) having their voices dubbed by English actresses, the presence of these foreign-born performers were "the perfect example of the type of woman the producers like to cast [...] in the early 007 thrillers-European, large-breasted, and very sexy" (Rubin 2002, 333). Many of these stars of the early Bond films inhabited European cinema both before and after their roles in the 007 series. Prior to Thunderball, for example, Auger (a runner-up in the 1958 Miss World contest) had featured in European auteur Jean Cocteau's The Testament of Orpheus (France:Jean Cocteau, 1960), and would remain predominantly a star in Europe. Indeed, with the spy film genre "among the high points of their careers," many former Bond Girls went "back to Italy, France or Germany for international films of dubious merit" (Lisanti and Paul 2002, 18-19). Once there, such starlets routinely featured in those European (commonly Italian) spy films that parodied the official 007 series. Andress and Auger appeared in Anyone Can Play (Italy: Luigi Zampa, 1968), Bianchi in O.K. Connery (a.k.a. Operation Kid Brother) (Italy: Alberto De Martino, 1967) and Shirley Eaton in the Germany/Spain/ US co-production The Girl from Rio (West Germany/Spain/USA: Jesús Franco, 1968), roles that developed the 007 mythology across the interstices of multiple national cinemas.

Supported by the casting of European females, perhaps the strongest identifier of the Bond series' Europeanness was ultimately their portrayal of sex, sexuality and erotic display. The risqué nature of the 007 films certainly had more in common with the frank sexual content of European art cinema of the period than it did with either the political and social economy of the British New Wave, or the conservative ideology of Hollywood 
still largely marshalled by the restrictions of the Hays Code. Sex would go on to solidify the presence of the 1970s British art cinema, just as the "graphic tendency" and bankable eroticism of the "sex kitten" would serve to distinguish European art cinema's striking violation of code-era Hollywood throughout the 196os (Betz 2009, 42). But if the European (and, later, British) art cinema casualized images of sex in ways that blurred ideological distinctions with soft-core pornography, then similar charges were leveled at Bond films. Since spy author John le Carré first described Fleming's original novels as "cultural pornography," the status of the source material as an early form of mass-produced pornography, if not Bond's historical links to the publication of Playboy, have been well-documented (Hines 2018). However, the ideological vision of Britishness signified by Bond within (and for) American culture was complemented by particular views of sexual behavior. In spite of the character's patriotic conservatism and indelible Britishness, British audiences celebrated 007's masculine promiscuity and guiltless sexual authenticity as strongly "European" (Ginneken 2007, 159). If the modest naturalism of the British New Wave typically dressed its women "in a dressing gown" (to quote the title of J. Lee Thompson's 1957 feature film), then the durable image of the alluring Bond Girl is one tied to her traditional appearance in the bikini (Andress, Eaton, Auger and Mie Hama in You Only Live Twice [UK: Lewis Gilbert, 1967] all appear in swimsuits) as a way of defining the boundaries of female glamor. Even when considering the contemporaneous British sex films and bedroom farces of the late-196os/early-1970s — such as Mary Had a Little... (UK: Edward Buzzell, 1961), No Sex Please-We're British (UK: Cliff Owen, 1973) and the Confessions series (UK: Val Guest et al., 1974-77)— the Bond series still provides a stronger evocation of the lubricious and luxurious eroticism of art cinema that flourished in many European cinemas following break-up of the Hollywood studio system.

Unlike these British-shot comedies that presented sex as "eccentric, peculiar and ambiguous" (Conrich 1998, 93), Bond films glorified their sexual content through a more European image of the sex symbol. Chris Darke $(2003,440)$ explains that in the post-war European context, sex was highly bankable as "a sophisticated yet earthy sexuality was important in opening up foreign markets for European art cinema abroad." European art cinema's array of female sex symbols obtained their impact from a shared cultural capital as curvaceous, combining excessive and voluptuous physicality with an enigmatic psychology of character that remained erotically mysterious. The 196os Bond films traded specifically on these constructions of the "sex kitten" and European starlet, most famously embodied by Brigitte Bardot 
and Sophia Loren, as well as Gina Lollobrigida and Silvana Mangano in Italy. The fact the role of Tracy Di Vicenzo in On Her Majesty's Secret Service (UK: Peter Hunt, 1969) was originally intended for both Bardot and Catherine Deneuve, star of Belle de Jour (France/Italy: Luis Buñuel, 1967) reflects the kinds of sexually "sophisticated" European femininity desired by Broccoli and Saltzman. A symptom of his assertive bachelorhood and a marker of his freedom from British class relations, Bond's sexual mobility was regularly matched to the sexually promiscuous image of the ultra-feminine European women, whose socially transgressive pre-marital romances became a strong current of post-war continental Europe. This entwining of male and female sexuality certainly allowed for more modern representations of gender. Fitting strongly the "sex goddess" type of European art cinema, Paluzzi in particular (as villainous Fiona Volpe in Thunderball) conveys a eroticized rebelliousness and "conspicuous nudity" that reprises the Bardot-inspired undressed image of "nude sunbathing, soaked dresses clinging to her body as she frolics in the surf" (Betz 2009, 122) made famous in And God Created Woman (France: Roger Vadim, 1956).

The often sensationalist promotional material for the sixties Bond films shored up the series' relationship to more European art cinema standards of sexual content. Designed by American illustrator Mitchell Hooks, Dr. No's poster campaign depicted Bond (listed as "gentleman spy") outnumbered four to one by his sexual conquests in the film, who are pictured in various states of undress. In the international posters for From Russia with Love (UK: Terence Young, 1963), this ratio is maintained. Bond is surrounded by lead Bond Girl Tatiana Romanova, as well as the two fighting girls Vida and Zora, and the unnamed belly dancer played by Leila Guirat. With artwork by Italian commercial artist Renato Fratini (who would also move between art and popular cinemas, designing the poster for Anderson's This Sporting Life [UK: Lindsay Anderson, 1963]), the US design of From Russia with Love's poster art is clearly intended to re-conjure the glamour of the European sex symbol, while also evoking pulp magazine covers. In 1972, United Artists re-released all seven Bond films across Europe under the banner of the "Viva James Bond Film Festival." Illustrator Yves Thos' new posters for this "Viva" campaign bear a striking resemblance to Bardot's Le Mépris (France/Italy: Jean-Luc Godard, 1963), including an unidentified blonde woman kneeling at the feet of 007 reminiscent of the buxom Bardot, and tap into an image of female sexual behavior that supported "the art and commerce of the art cinema" (Bordwell 2008, 153).

Le Mépris is a film that for Bordwell $(2008,153)$ "works on the very problem of erotic spectacle in the art cinema." Such a "problem" is wholly rooted in 
the new sexual realisms and liberal sexual politics of art cinema. Godard's antagonism towards the feminine sexuality of Camille Javal-played by Bardot-in Le Mépris (translated as "Contempt") both punishes abundant eroticism through Camille's climactic death, while simultaneously evoking the expendability of those transgressive "bad" women across the Bond franchise equally marked by liberal, even deviant sexualities, including Volpe in Thunderball and Helga Brandt in You Only Live Twice. Seduced by Bond and, consequently, diverted from their villainous allegiance, both Volpe and Brandt fit the sixties template of oversexed European siren, yet their elimination as adversaries almost immediately following an erotic encounter with 007 connects promiscuity to disposability (unlike the "Good" Bond Women, whose initial resistance and self-declared immunity to Bond's sexual advances are typically assuaged by the films' end).

These emergent points of contact and overlap between the James Bond films of the 1960 and the category of modernist art cinema serves to muddy the art/popular binary that has (politically, culturally, institutionally) separated many European cinemas from the Hollywood system. In this way, Bond finds a natural companion in Hitchcock, a filmmaker with which the series shares "common ideological and cultural ground" (Chapman $2014,154)$, as well as certain visual motifs and narrative patterns. So too the Bond films - alongside Hitchcock as a figure of joint British and North American sensitivity - can be equally understood as intersecting with a self-conscious and highly distinctive European style. Many of the sixties Bonds embraced the art cinema as a set of stylistic conventions, adopting several of the alternative formal practices flourishing across European film through the 1950 and 1960 s that Hitchcock would himself adopt in "his attempts at a European-style art film" (Haeffner 2005, 99). Indeed, as the next section of this chapter examines, the first decade of Bond cinema (1962-1969) seemingly recalled the earlier British "art" cinema period of experimental animation, with a clear formal expressivity more in line with the modernist credentials of the British and even mid-century American avant-garde cinemas.

\section{Shaking and Stirring? Bond's Modern Style}

Notable among critical responses to the atmospheric pre-credits sequence that begins From Russia with Love was its alleged connections to an exemplar of post-war European art cinema, L'année dernière à Marienbad (France/ Italy: Alain Resnais, 1961). Many reviewers of From Russia with Love noted the 
striking parallels between villain Red Grant's pursuit of 007 in the grounds of a moonlit garden, and the geography and mood of Resnais' film (Gilliatt 1963; Bennett 1964). Penelope Houston (1964, 28) — who was the inaugural editor and co-founder of the Sequence film journal in Britain with Anderson and Reisz-wrote that Bond and Red Grant's "stalking match" (resulting in Bond's fake[d] death) takes place in the "formal gardens of a Marienbad chateau." The Marienbad reference would appear in another of Houston's reviews of the palatial setting in From Russia with Love for Monthly Film Bulletin in November 1963. However, Marienbad was not the only allusion to continental art cinema of the 1960 s to find its way into popular responses to Young's film. A review of From Russia with Love published in The Times on the October 10, 1963 suggested that its depiction of the Turkish capital Istanbul "set one wondering inevitably if this is what was really happening to the enigmatic heroine of L'Immortelle" (anon. 1963). ${ }^{2}$

Filmed on the evenings of April 16 and 17, 1963 at Pinewood's Renaissance garden, From Russia with Love's opening sequence is, for Chapman (2007, 76), a "deliberate reference to European Art cinema which establishes the very European style of the film." Flanked by Dr. No (Jamaica), Goldfinger (United States), Thunderball (the Bahamas) and You Only Live Twice (Japan), From Russia with Love is certainly the most European of all the sixties Bonds, taking in as part of its global expanse a variety of European cities-London, Istanbul, Belgrade and Venice - all networked together by the Orient Express that hosts the film's standout set piece. However, From Russia with Love balances references to art cinema with popular cinema, containing intertextual gestures to Marienbad and, more explicitly, Call Me Bwana (UK: Gordon Douglas, 1963) during the sequence in which SPECTRE agent Krilencu is shot by Kerim Bey while escaping through a billboard for the Broccoli-produced British comedy. Starring Anita Ekberg, who had herself become an international icon with art-house film La dolce vita (Italy/France: Federico Fellini, 1960), Call Me Bwana's presence in the second official Bond film narrativizes the series' vexed relationship to the popular. Hidden behind o07's façade of commercial cinema lies another, altogether more latent, identity of art cinema that prefigures the expatriate British filmmaking of the 1970s. Yet this duality does not void Bond's status as an exemplar of popular entertainment, but rather begins to place it in conjunction with the international profile of European art cinema.

2 L'Immortelle (France/Italy/Turkey: Alain Robbe-Grillet, 1963) director Alain Robbe-Grillet was a novelist and filmmaker, and as a key figure within cerebral art cinema collaborated (as screenwriter) with Resnais on Marienbad. 
Three of the next four Bond films released after From Russia with Love in the 1960s-Thunderball, You Only Live Twice and On Her Majesty's Secret Service - also make use of fragmented, discontinuous editing patterns and jump cuts, thereby formally registering something of European art cinema's violation of classical norms and stylistic traits. All edited by Peter Hunt, the climactic fight in Thunderball between Bond and Emilio Largo (Adolfo Celi) aboard the Disco Volante yacht, and the pre-credits sequence to $\mathrm{On}$ Her Majesty's Secret Service in which Bond disarms an assailant, present their violent action through frenetic editing patterns. In You Only Live Twice, however, jump cuts are used only briefly during the sequence in which autogyro Little Nellie is constructed by Q branch in front of Bond and a disbelieving Tiger Tanaka. Barry Langford $(2010,136)$ calls Hunt's radical use of such formal devices in the George Lazenby film as "unremarked jump cuts [...] [that] energize a violent fistfight," drawing parallels with the self-conscious fragmentation of time and space in the earlier $\grave{A}$ bout de souffle (France: Jean-Luc Godard, 1960). Most significantly, however, is Langford's (136) admission that the co-option of a European art cinema style by popular film (as represented here by Bond) marked the "mainstreaming of disruptive devices."

As a technique primarily the reserve of European modernist filmmaking, the jump cut has been widely theorized, typically in more conventional auteurist accounts of aesthetic meaning within the context of the French Nouvelle Vague. The intention of jump cuts was to destabilize the forward momentum of classical storytelling by disrupting the legibility of diegetic space and time. While anticipating the dizzying effect of intensified editing patterns in contemporary Hollywood action cinema, the fight sequences in both Thunderball and On Her Majesty's Secret Service upturn spatio-temporal coherency in ways that owe a debt to the stylistic repertoire of post-war French cinema. However, as Mark O'Connell (2012) notes, Hunt's editing patterns also evoked contemporaneous British art cinema of the period too, drawing from the "real/unreal stylings of British fare like Performance [UK: Nicolas Roeg, 1970], If... [UK: Lindsay Anderson, 1968] and Blow-Up [UK/USA/Italy: Michaelangelo Antonioni, 1966]," and exemplifying how the techniques of "Godard, Polanski, Bertolucci, Truffaut and Antonioni" were all "filtered down" into sixties Bond cinema. From a rhetorical use of mise-en-scène and temporal ellipses to radical shifts in compositional principles via reflexivity and abstraction, the experimental register of the modernist generation of international art auteurs shattered the classical style and narrative arrangement underwriting popular cinema's formal grammar. The momentum and visibility of jump cuts in Thunderball, You 
Only Live Twice and On Her Majesty's Secret Service thus offer an explicit narrational act that similarly counterpoints the long-take naturalism of British social realism and Classical Hollywood via the formal vocabulary of European space-time continuity.

Just as one of the commonalities of European art cinema is the mirrored return of the look via direct address, which as Tom Brown $(2012,17)$ argues features in such films "more often at the end [...] than at any other point," the address of the Bond films has likewise always been rooted in discourses of looking. At its most declamatory, the opening gun barrel motif in which 007 is glimpsed through the interior of a .38 caliber weapon awards spectators a point-of-view shot, before Bond himself turns to "shoot" directly into the camera. The moving white iris is simultaneously a gun barrel, a bullet hole, a camera lens, a microdot and a human eye, but ultimately a constellation of gestures denoting the many ways of seeing and being seen. As a formal device, it functions as a visual rhyme to the traditional ending disclaimer that "James Bond Will Return" which, unusually, gestures to a particularly open-ended narrative while at the same time intensifying spectatorial engagement through an acknowledgement of our presence by the fiction. As Bordwell $(2008,156)$ notes of European art cinema, "With the open and arbitrary ending, the art film reasserts that ambiguity is the dominant principle of intelligibility." The "open" endings to Bond films through the promise of 007 's return functions against more classical restraint, marking out the Bond film's aesthetic distinctiveness. The disclaimer operates as another intriguing moment of self-reflexivity that (as with the opening gun-barrel motif) recurs across the series, not only evoking art cinema's predilection for the "pensive ending," but inviting a particular form of spectatorship rooted in the power of a deviation from classical narrative conclusion through the assurance of a connecting sequel.

As one of the series' key signifiers, and a strong point of connection with "Hitchcockian" modernism, the seductive formal arrangement of the Bond title sequences are fleeting spaces of radical possibility and bravura heterogeneity that further stress the Bond series' modernist credentials. In the hands of designers like Maurice Binder and Robert Brownjohn (who designed the Dr. No, From Russia to Love and Goldfinger credits sequences, respectively), alongside their (mostly North American) contemporaries Saul Bass, Richard Williams and Pablo Ferro, the 1950s emerged as a time of "major change for the title sequence" (Stanitzek 2009, 54). With an increased turn towards metaphor and symbolism, Binder's 007 titles were a space where spatial montage and typography in motion provided a graphic match to the thrills, exoticism and affluence of oo7's big-screen adventures. 
Designed by Binder and animated by Trevor Bond (who began his career at the British cartoon film studio W.M. Larkins specializing in abstract modernist form), Dr. No is the first - and until Casino Royale (UK/Czech Republic/USA/Germany/Bahamas: Martin Campbell, 2006) the only-Bond film to segue directly from the gun barrel motif into the opening bars of the title song, in this case Monty Norman's arrangement of the James Bond Theme. Playing over Dr. No's gun barrel are a series of electronic pulses and a xylophone refrain. In the style of the experimental technique of musical composition known as musique concrète, Dr. No is the only film in the series to use such an abstract sound arrangement. The piece was allegedly composed by electronic musician Daphne Oram in July 1962 (three months before $D r$. No's October release) and titled "Atoms in Space." Dr. No frequently returns to electronic audio effects, notably in the soundtrack that accompanies o07's escape from his cell in the eponymous villain's futuristic lair, which have been attributed to Oram's Oramics system (a machine that translated drawings made on glass slides into sound effects). Later Bond films would further mine the variance of auditory experience. The disjunctive editing patterns in $\mathrm{On}$ Her Majesty's Secret Service are similarly matched to a remarkably dissonant soundtrack. John Barry's score for the film was the first by a major studio to incorporate a Moog synthesizer in what was a "daring" and "groundbreaking application of electronic music" (Burlingame 2012, 85). Developed by New York-born engineer Robert Arthur Moog in the mid-196os, the Moog was a voltage-controlled synthesizer system that utilized "oscillators, keyboards, filters and modulators to generate unusual musical sounds" (84). The sonic possibilities of Oram's techniques and the Moog system showcased in Dr. No and On Her Majesty's Secret Service suggests the modernist credentials of several early Bond films extend to their soundscapes, musical techniques and acoustic effects, just as the wide-ranging impact of European modernism was to be found in North American product design, graphic design, commercial advertising and architecture.

Featuring minimalist graphic animation and the rhythmical movement of multi-colored dots, the title sequence for $\mathrm{Dr}$. No remains largely atypical of the series insofar as it utilizes visually abstract circles of variant scale, size and geometry of forms. The animation of colored dots evokes artist Roy Lichtenstein's popular Ben-Day printing process (a visual hallmark of the Pop Art movement), though Binder's more abstract visual design for Dr. No would gradually cede to the image of the female body. Within the context of British national cinema, Chapman $(2007,63)$ notes that through its "kaleidoscope of brightly colored dots which flash on and off in rapid succession," Dr. No "is at pains to distance itself from the sober, restrained visual style which was 
so prevalent in British cinema, especially through its insistence on color." But if the Pop Art-style design of Bond's debut situated the film outside the kitchen-sink realism of British cinema of the period, it simultaneously aligned Binder's work with both the pictorial modernism of European avant-garde traditions and the earlier period of 1920 and 1930s British art cinema.

The designer of fourteen credits sequences for Bond films between 1962 and 1989 (as well as several 007 trailers), Binder was a "ceaseless experimenterwith color (emulsions, filters), optical effects, underwater shots, slow motion, animation, electronic movement, superimposition and ways to blend or overlap images" (Kirkham 1995, 12). His titles were ingenuous surrealist collages, replete with moving typography, abstract imagery, and graphic colors that entwined humor with exotic sexuality, most obviously embodied in the silhouetted female nudes that became a staple of the series' highly-gendered discourse. Given his exploratory testing of composite imagery, distorting graphics, multi-images and fluid typography, it comes as little surprise that Binder's name regularly appears next to eminent experimental animation pioneers like Lye, Norman McLaren and Oskar Fischinger in wider histories of animated typographies, motion design and musical visualization (Betancourt 2016).

In his treatment of abstract motion, image overlaying and pictorial fluidity in Dr. No and his next film Thunderball, Binder can be further connected to the innovative, non-objective "absolute film" tradition of 1920 s Germany anchored to the work of Fischinger, Walter Ruttmann, Viking Eggeling and Hans Richter. Taken together as forms of experimental animation, Binder's 007 titles are no less examples of what Fischinger himself termed "absolute color work, born quite of music" (quoted in Leslie 2002, 189), insofar as they trade in colorful, abstract and erotic imagery with a strong emphasis on rhythm and tempo. Fischinger's 1933 film Kreise (Germany: Oskar Fischinger, 1933; translated as "Circles"), for example, involves a remarkably similar molecular movement of colored dots synchronized to rousing orchestral music. One of the very first color films to be produced in Europe, and manufactured using the new Gasparcolor process (founded a year earlier by the Hungarian chemist Bela Gaspar), the notational pulsations in Fischinger's two-minute Kreise finds a corollary in Binder's beating circles that would begin the titles for Dr. No. Set to Franz Liszt's Second Hungarian Rhapsody, Fischinger's later film An Optical Poem (Germany: Oskar Fischinger, 1938) also experimented with the excessive and sporadic behavior of red dots fluctuating in size and scale, while Len Lye's A Colour Box (UK: Len Lye, 1935) made two years after Kreise also involves abstract colored circles and vertical lines as part of its visual patterning. McLaren's 1940 film Dots (Canada: Norman McLaren, 1940), which was produced by the animator scratching and painting directly 
onto the film strip, offers a further analogue to Binder's sequences that are no less a psychedelic experimentation with color and movement.

However, it is another of Lye's films, Rainbow Dance (UK: Len Lye, 1936), also made at the General Post Office that seems an obvious comparison to Dr. No, and connects Binder more directly to these historical traditions of British art cinema. With music by Filiberto Rico's Cuban-inspired Creole Band, Rainbow Dance is an abstract color advertisement produced once more with the Gasparcolor film stock, which in its striking design of silhouetted human forms parallels the middle section of Binder's titles for Dr. No. During the Bond film's opening title sequence, the design shifts from the multitude of flashing circles to the silhouettes of female dancers in red, purple, green and blue, who rhythmically gyrate to a calypso drum-beat. Each anonymous figure is layered over one another in a dizzying visual dance of overlapping colors. The psychedelic silhouettes of (often nude) female bodies engaged in a form of seductive striptease would become an icon of Binder's eroticized 007 titles. These female silhouettes in motion (signifying Bond-as-womanizer and international playboy) in $\mathrm{Dr}$. No, coupled with the formal experimentation of the preceding "dot dance," suggests multiple points of comparison with the contemporary (typo)graphic design of experimental animation in both Britain and across Europe.

Complementing the modernism of Ken Adam's bravura set designs, the abstract patterns of Binder's title sequences for the Bond series and his synchronization of sound and image would certainly not have looked out of place in a 196os period in which Lye and McLaren were still making experimental shorts. The non-narrative flavor of Binder's 007 title sequences suggests a shared lineage with the "absolute film" tradition popularized across Central Europe, but also American counterculture that would borrow its practices. Indeed, Kirkham $(1995,11)$ acknowledges the historical connections between Dr. No's titles and the "mind-blowing light, sound and multi-media shows [that] were spreading from the USA to Europe at this time." Binder's use of cutting-edge laser effects drew from this vibrancy of modernist moving image culture in sixties America, including liquid light shows accompanying avant-garde theater performances, holograms and laser installations.

Beyond the excitement of irregular "flashing dots and lights" (Kirkham 1995, 11) in Dr. No, Brownjohn's subsequent title sequences for From Russia with Love and Goldfinger provide further connections between 007 and continental art cinema. Brownjohn was strongly indebted in his visual style to Fischinger, but equally to the light filming projections of Hungarian László Moholy-Nagy, who had screened Fischinger's work to the Bauhaus art school in late-1920s Germany. In fact, Brownjohn was a protégé of Moholy-Nagy, 
under whom he studied painting and design throughout the forties at the Illinois Institute of Technology (formerly the New Bauhaus and founded by Moholy-Nagy in 1937), having previously been taught by German graphic designer Will Burtin at New York's Pratt Institute. Influenced by Soviet constructivist cinema, Moholy-Nagy's manipulation of light (he invented the Light-Space Modulator lighting equipment in 1930) and his experimental testing of light displayed onto clouds at the IIT Institute of Design are recalled in the title sequences for both the second and third Bond films. Beams of colorful light and film footage are projected by Brownjohn directly onto the female body-as-screen, positioned midway between the scandal of a peepshow parlor and light projection body art. ${ }^{3}$ Well-versed in the formal logic of European modernism and the potential for filmic abstraction, both Binder and Brownjohn therefore provide something of a connective between mid-century American avant-garde film, European art cinema practices and British cinema of the 196os. A closer look at the design of their undulating titles sequence ultimately illustrates the extent to which 1960 s Bond cinema evidently reflected back the audiovisual language of rhythm in light popular across European and North American art cinemas.

\section{Conclusion}

The received narrative of British cinema is one that has regularly outlined its compromise position between a Hollywood style and the cultural standing of Europe's art cinema. For Christopher Williams $(1996,193)$, it is a national cinema "caught between" these two alternatives, "unconfident of its own identity, unable to commit or develop strongly in either direction." Against the backdrop of Hollywood as a cinematic institution and post-war European cinema, the James Bond film series offers the study of British national cinema a new birthright, rather than a false dawn. This chapter has reconsidered the place of the James Bond films in relation to the formation of (popular) British national cinema, and suggested they function as something of a blind spot within the many possibilities and potentials of British, European and North American art cinemas. The genesis of the 007 film series in the 1960 , if not Bond's cultural currency as a popular hero, can certainly be connected to the liberation of the "Swinging" period, which would surrender as Bond

3 Emily King $(2005,204)$ argues that Brownjohn's erotic titles for From Russia with Love in which colored light is projected onto a belly dancer's body is "an extremely open-ended and positively experimental piece of film." 
entered into the 1970s and its new cultural and ideological terrain. But as very much a post-war film series, Bond cinema's popular appeal potentially obfuscates a discussion of their (at times) radical form and visual style. The sixties' Bond films are remarkably heterogeneous, not yet shaped by the weight of New Hollywood and its most popular genres, whether the emergence of Blaxploitation (Live and Let Die [UK: Guy Hamilton, 1973]) and science-fiction (Moonraker [UK/France: Lewis Gilbert, 1979], or the increased international visibility of martial arts and kung-fu cinema (The Man With the Golden Gun [UK: Guy Hamilton, 1974]) that would define the Roger Moore-era.

The distinct qualities of the early sixties' Bonds therefore lie in their own chronological place between the wave of socially-realist films in the $1950 \mathrm{os}$ and 1970s British social art cinema. Terence Young's admission that he had watched L'année dernière à Marienbad, and his subsequent desire to "put Sean in there," certainly points to the possibility that European art cinema directly influenced the conceptualization and production of big-screen Bond. Given Binder and Brownjohn's further associations with American and European print artists and graphic designers, alongside connections to British animation and European modernism, it also seems likely that the boldly ambitious title sequence designs were envisioned to recall the modern European graphic aesthetic. Despite their exemplary standing as examples of popular filmmaking and their enjoyment by mass audiences, the early-196os Bond films are ultimately rich case studies within which it is possible to trace many historical and cultural waves of British art cinema, and similar streams manifest across Europe and North America, while smoothing over the persistent duality between art and popular cinemas. So as the history of Bond cinema continues to evolve and the franchise extends beyond its fiftieth anniversary, it might be in the recesses of European modernism that this most enduring example of British film harbors something of its own secret identity.

\section{Works Cited}

Anon. 1963. "Four Just Men Rolled into One." The Times, October 10, n.pag. Bennett, Colin. 1964. "Thrills and Tricks." The Age, April 23, n.pag.

Bergan, Ronald, ed. 2008. François Truffaut: Interviews. Jackson: University Press of Mississippi.

Bergfelder, Tim. 200o. "The Nation Vanishes: European Co-Productions and Popular Genre Formula in the 1950 s and 196os." In Cinema and Nation, edited by Mette Hjort and Scott Mackenzie, 139-52. London: Routledge. 
Betancourt, Michael. 2016. Beyond Spatial Montage: Windowing, Or the Cinematic Displacement of Time, Motion, and Space. London: Routledge.

Betz, Mark. 2009. Beyond the Subtitle: Remapping European Art Cinema. Minneapolis: University of Minnesota Press.

Bordwell, David. 2008. Poetics of Cinema. New York: Routledge.

Brown, Tom. 2012. Breaking the Fourth Wall:Direct Address in the Cinema. Edinburgh: Edinburgh University Press.

Burlingame, Jon. 2012. The Music ofJames Bond. New York: Oxford University Press. Chapman, James. 2005. Past and Present: National Identity and the British Historical Film. London: I.B. Tauris.

Chapman, James. 2007. Licensed to Thrill: A Cultural History of the James Bond Films. London: I.B. Tauris.

Chapman, James. 2014. "Hitchcock and Bond." Hitchcock Annual 19: 153-80.

Conrich, Ian. 1998. "Forgotten Cinema: The British Style of Sexploitation." Journal of Popular British Cinema 1, no. 1: 87-100.

Darke, Chris. 2003. "The French New Wave." In An Introduction to Film Studies Third Edition, edited by Jill Nelmes, 421-50. London: Routledge.

Elsaesser, Thomas. 2005. European Cinema: Face to Face with Hollywood. Amsterdam: Amsterdam University Press.

Gilliatt, Penelope. 1963. "Laughing it off with Bond." The Observer, October 13, n.pag. Ginneken, Jaap van. 2007. Screening Difference: Screening Difference: How Hollywood's Blockbuster Films Imagine Race, Ethnicity, Culture. Lanham: Rowman and Littlefield Publishers, Inc.

Haeffner, Nicholas. 2005. Alfred Hitchcock. London: Routledge.

Hedling, Erik. 2003. "Lindsay Anderson: Sequence, and the Rise of Auteurism." In British Cinema in the 1950s: An Art in Peacetime, edited by Ian MacKillop and Neil Sinyard, 23-31. Manchester: Manchester University Press.

Hill, John. 1999. British Cinema in the 1980s: Issues and Themes. Oxford: Clarendon Press. Hines, Claire. 2018. The Playboy and James Bond: oo7, Ian Fleming, and Playboy Magazine. Manchester: Manchester University Press.

Houston, Penelope. 1963. "From Russia with Love." Monthly Film Bulletin 30, no. 358 : 155.

Houston, Penelope. 1964. "Whose Crisis?" Sight and Sound 33, no. 1 (Winter): 26-28, 50. Hoyle, Brian. 2009. "Radio On and British Art Cinema." Journal of British Cinema and Television 6, no. 3 (December): 407-23.

King, Emily. 2005. Robert Brownjohn: Sex and Typography. London: Laurence King Publishing.

Kirkham, Pat. 1995. "Dots and Sickles." Sight and Sound 5 (December): 10-13.

Langford, Barry. 2010. Post-Classical Hollywood: Film Industry, Style and Ideology since 1945. Edinburgh: Edinburgh University Press. 
Leslie, Esther. 2002. Hollywood Flatlands: Animation, Critical Theory and the Avantgarde. London: Verso.

Lisanti, Tom, and Louis Paul. 2002. Film Fatales: Women in Espionage Films and Television, 1962-1973. Jefferson, North Carolina: McFarland \& Company, Inc., Publishers.

Lovell, Alan. 1997. “The British Cinema: The Known Cinema?” In The British Cinema Book, edited by Robert Murphy, 235-43. London: BFI Publishing.

McFarlane, Brian, ed. 2016. The Encyclopedia of British Film, Fourth Edition. Manchester: Manchester University Press.

McKay, Sinclair. 2010. The Man with the Golden Touch: How The Bond Films Conquered the World. New York: The Overlook Press.

Neale, Steve. 1981. "Art Cinema as Institution." Screen 22, no. 1 (May): 11-40.

Newman, Kim. 1986. "Thirty Years in Another Town: The History of Italian Exploitation, Part II." Monthly Film Bulletin 53, no. 625 (February): 51-55.

O'Connell, Mark. 2012. Catching Bullets: Memoirs of a Bond Fan. Hampshire: Splendid Books.

Rubin, Steven Jay. 2002. The Complete James Bond Movie Encyclopaedia, Third Revised Edition. New York: McGraw-Hill.

Stanitzek, Georg. 2009. "Reading the Title Sequence (Vorspann, Générique)." Cinema Journal 48, no. 4 (Summer): 44-58.

Street, Sarah. 1997. British National Cinema. London: Routledge, 1997.

Williams, Christopher. 1996. "The Social Art Cinema: A Moment in the History of British Film and Television Culture." In Cinema: The Beginnings and the Future, edited by Christopher Williams, 190-200. London: University of Westminster Press.

Wollen, Peter. 1993. "The Last New Wave: Modernism in the British Films of the Thatcher Era." In British Cinema and Thatcherism: Fires Were Started, edited by Lester Friedman, 35-51. London: UCL Press.

\section{About the Author}

Christopher Holliday teaches Film Studies and Liberal Arts at King's College London, specializing in film genre, international film history and contemporary digital media. He has published widely on digital technology and computer animation, including work in Animation Practice, Process \& Production and animation: an interdisciplinary journal. He is the author of The Computer-Animated Film: Industry, Style and Genre (Edinburgh University Press, 2018), and co-editor of Fantasy/Animation: Connections Between Media, Mediums and Genres (Routledge, 2018) for Routledge's AFI 
Film Readers series that examines the historical, cultural and theoretical points of intersection between fantasy and animation. He has also published articles on the performance of British actors in contemporary US television drama, and on the James Bond film franchise. 


\title{
12. Branding 007: Title Sequences in the James Bond Films
}

\author{
Jan-Christopher Horak
}

\begin{abstract}
The James Bond series has maintained its brand identity through the James Bond character, recurring plot elements, and its film design, in particular the credits sequences of Maurice Binder, Robert Brownjohn, MK12, and Daniel Kleinman. This chapter will examine the work of Binder, who created fourteen of the first eighteen Bond titles and has been rightly singled out as one of a new generation of title designers who utilized modernist aesthetics to create a specific look for the James Bond franchise. The chapter also asks how the digital turn, which coincided with the transition from Binder to Kleinman in the 1990s, has impacted the design and aesthetics of the James Bond title sequences.
\end{abstract}

Keywords: Maurice Binder; Daniel Kleinman; title sequences; modernism; branding

The James Bond film series is one of the longest running and most successful film franchises in the history of the movies, now encompassing twenty-four plus two films that have been produced over more than fifty-five years. Having featured no less than six different actors (Sean Connery, George Lazenby, Roger Moore, Timothy Dalton, Pierce Brosnan, and Daniel Craig), the Bond series has maintained its brand identity through the character of James Bond as conceptualized by Ian Fleming, through rigorously recurring plot elements-Bond chasing international bad guys and bedding down a number of beautiful young women-and through the films' design, in particular the credits sequences of Maurice Binder, Robert Brownjohn (briefly), MK 12 (one film) and Daniel Kleinman. Maurice Binder, who created fourteen of the first eighteen Bond titles, starting with $\operatorname{Dr}$. No (UK: Terence

Verheul, J. (ed.), The Cultural Life ofJames Bond:Specters of oo7. Amsterdam: Amsterdam University Press, 2020 DOI 10.5117/9789462982185_CH12 
Young) in 1962, has been rightly singled out as one of a new generation of title designers who utilized modernist design to create a specific look for the Bond franchise, and who influenced the creation of music videos through his marriage in the title sequences of abstract images and catchy pop music tunes. Binder made the latter claim himself in 1991, noting that his sequences "were really the fore-runners of today's pop videos: the song came first and we'd illustrate it" (King 2004; Cork and Scivally 2002, 193).

Maurice Binder's death in 1991 coincided with the end of both the analog era and the Cold War, leading the franchise's producers to hire Daniel Kleinman for 1995's GoldenEye (UK/USA: Martin Campbell), whose seven titles in the Bond series are interrupted only by MK12's equally accomplished title design for Quantum of Solace (UK/USA: Marc Forster, 2008). The titles by Kleinman and MK12 have been praised for their redesign for the digital era, creating dense montages that brand the films and the series while relinquishing the simplicity of modernist design for post-modern pastiches. Kleinman and MK12 conceptualize their titles as surrealistic dreamscapes that incorporate the visual themes of the film that follows. In contrast, Binder's titles promoted the Bond brand, obsessively repeating motifs and technologies but always within the framework of a modernist grid-based design whose goal is the simplification of form. Indeed, after the first half dozen Bond films, Binder's titles were seemingly produced by rote. Ben Radatz (2012), co-director of Quantum of Solace's titles, excuses the repetition of tropes, themes, and technologies, preempting any reservations or negative interpretations:

In spite of the tropes, the Bond titles are not formulaic - they have become a genre unto themselves, and as such they hold a certain immunity from criticisms aimed at its format. To criticize a Bond title for featuring silhouettes is to criticize a Tolkien novel for featuring hobbits.

Ironically, while there has been praise for the Bond titles in some quarters, much of the popular literature on James Bond fails to even mention, much less analyze the work of Binder and Kleinman. Other commentators, including John Brosnan, touch on the themes found in this laudatory statement by John Cork and Bruce Scivally (2002, 48): "Binder's titles, like the films themselves, were marked by elegance, wit and sex. His use of rich color and nude female silhouettes quickly became a celebrated design motif, imitated but never equaled."

Only recently have academics critiqued the deep misogyny of Binder's images. In their discussion of Goldfinger (UK: Guy Hamilton, 1964), Tony Bennett and Janet Woollacott $(1987,152-3)$ discuss the sexism of Brownjohn's 
title sequence, citing Laura Mulvey and connecting it to a "long tradition in mainstream Hollywood cinema, whereby women are constructed in terms of erotic spectacle"-but their analysis excludes typography and spatial design. Kristin Hunt (2011, 62), in her Freudian-feminist analysis of dance in the Bond films, goes one step further, comparing Binder's title sequences to a striptease spectacle. Finally, Sabine Planka (2015) and Eileen Rositzka (2015), respectively, zero in on the inherent misogyny and objectification of women in the Binder, Brownjohn, and Kleinman credits sequences.

There is general agreement that Binder's gun-barrel opening was a stroke of genius as a branding device, and as an extended, time-based logo for the series. Binder, following the lead of Saul Bass and other modernist designers in Hollywood, reconceptualized credits sequences as not just a way to identify the studio and its personnel, but also as a movie within a movie that visualized the film's narrative or thematic elements. Whereas classic studio credits were standardized to identify the studio rather than the film, Bass in the 1950s created specific title sequences for specific films, which influenced the whole industry. Robert Brownjohn and Saul Bass were both trained by students of László Moholy-Nagy, the Hungarian modernist designer, painter, photographer, filmmaker, sculptor and scholar who had brought Bauhaus design to the United States in the 1930s. Like Bauhaus designers, Bass organized his design elements asymmetrically on a mathematically precise grid, preferring sans serif type, and utilizing right and/or left justification (mirroring the screen's frame). The basis for a mathematical screen grid was the establishment of a horizontal and vertical axis, cutting the frame into four equally sized rectangles, which would allow Bass to create architectural structures within the two-dimensional screen space. Furthermore, modernist designers relied mostly on primary colors and blocks of color both to abstract the image and guide the viewer in the reading of text, even when title sequences were presented within a diegetic space (Horak 2014,122). Like Bass and Brownjohn, Binder was one of the first to demand credit for his work in titles, and, like them, he employed stylistic flourishes from modern and pop art, such as abstraction and psychedelic colors, to connote $1960 \mathrm{~s}$ modernity with its sexual liberation and visualization of violence.

This chapter analyzes the Bond titles, as well as providing a necessary ideological critique. Such an analysis will demonstrate that in keeping with modernist aesthetics, Binder utilized an extremely limited palette of formal devices, colors, and images. Furthermore, Binder's and Brownjohn's titles must be read for both their overt sexism through the objectification of woman's bodies, and for their utilization of disturbing racial stereotypes. While the titles of Kleinman and MK 12 are not free of charges of sexism, 
I argue that digitality abstracts their female bodies, de-eroticizing them and thereby limiting their voyeuristic spectacle. Furthermore, digital tools allow them to create post-modernist pastiches that brand both individual films and the series as a whole.

\section{The Opening}

The opening image of $\mathrm{Dr}$. No, a point of view shot through a gun barrel during which James Bond shoots at the audience, was considered so successful-along with Monty Norman's theme music - that it became the signature for the entire series. Indeed, nothing has contributed more to the branding of James Bond films than this opening image. Except for the very first Bond, $\mathrm{Dr}$. No, all other Eon Bond openings are structured as a three-part overture: the gun barrel, a narrative teaser sequence and the main titles. Varying in length between four and eight minutes, the action teaser is often only minimally connected to the film's main plot, sometimes ending as a kind of joke or surprise (Bennett and Woollacott 1987, 152), as when in From Russia with Love (UK: Terence Young, 1963) and You Only Live Twice (UK: Lewis Gilbert, 1967) Bond is seemingly killed. Other action sequences set up the villain, who Bond will be assigned to kill.

While the three-part opening sequence now seems conventional, given its continual repetition in the Bond canon, it was a completely new and original in the mid 196os, and effectively grabbed the viewer's attention. Common to all the films, the three-part opening focused obsessively on two themes: violence and sex, both addressing the audience viscerally and emotionally. The white dot that first appears on a black background and then finds James Bond walking along the screen's horizontal axis initially suggests either a camera, a spyglass or a gun scope. Bond seems to be in the cross hairs, and therefore subject to the viewer's control through the cinema's inherent scopic regime. The audience as voyeur-the circular view is surrounded by what looks to be a shutter-sees without being seen but is also placed in the subjective position of a potential Bond assassin. However, when James Bond turns, pulls his gun and fires at the audience, the tables are suddenly turned. The circle shakes a bit then slides vertically down the frame and fades out, with red blood filling the screen, as if the subject - the viewer-has been killed. The audience becomes the victim of violence, rather than the potential perpetrator, disarming them and making them pliable for further manipulation. The device recalls a trick in The Great Train Robbery (USA: Edwin S. Porter, 1903), where as a coda to the 
film, "Broncho Billy" Anderson shoots at the camera - the audience-as if to say that no one is safe even though the bank robbers have been caught. Highlighting the audience's voyeurism, and immediately punishing them for it, sets the stage for another motif that will become ever more prominent in subsequent titles: erotic titillations are often promised, but then frustrated by a fade out before the "action" begins.

\section{Dr. No-Main Title Design}

Unlike almost all subsequent Bond films, Dr. No's title sequence begins immediately after the gun barrel sequence: the black background is populated with a mosaic of flashing dots in various colors, green, baby blue and yellow. A somewhat larger red dot anchors the design, as "IAN FLEMING'S," appears in the right half of the frame. The smaller white dots below are then replaced with text on the vertical axis in pink and red that is four times larger: "DR. NO." The full title, then, forms a block that covers the whole lower right quadrant of the frame. In color and form, the block text resembles a Chinese chop or signature seal, implying that the villain of this piece is of East Asian extraction. As with a few other Bond villains, Dr. No (Joseph Wiseman) is subject to racial stereotyping.

The film's title then moves around the frame flashing on and off in different colors, as do colored dots around subsequent credits. The flashing dots not only mirror the gun barrel opening but also reference computer technology. Furthermore, the changing primary colors have a feel of pop art that, like the computer references, give the sequence a modernist look that was in keeping with much of the modern design work in the 1960 . Two-thirds through the sequence, Binder cuts from the red dot to a red silhouette of a female dancer, followed by two more silhouetted dancers in orange and purple, accompanied by a vaguely African drum beat on the track. Unlike all subsequent Binder titles, the dancers are dressed, but the music marks them as Jamaican, changing colors from red hues to blue-green, their silhouettes overlapping as more major technical credits fade in and out. Planka $(2015,143)$ argues that the two women are Bond girls, while the male dancer, standing for Bond, asserts male control over the women.

They are replaced by black silhouettes of three blind men walking across the bottom of the screen, while the children's song, "Three Blind Mice," is sung with a calypso beat. After the director's credit, the silhouettes dissolve to live action shots of three black Jamaican blind men. Like Saul Bass, Binder understood that the titles "could act as a prologue," communicating 
both diegetic and non-diegetic information about the film to come (Horak 2014,94), although Binder eventually preferred generic rather than filmspecific references. However, the $D r$. No's titles are oddly bifurcated between animated graphics - designed by Trevor Bond, who drew on his experience as a modernist animator-and moving images, between the modernity of computers and the implied racial Otherness of figures who prove to be a danger to Bond.

\section{Typography}

Another difference to Saul Bass's work can be found in Binder's and Kleinman's relation to the logocentricism of the titles. The primary raison d'etre for title sequences is to list the names of the creative personnel involved in a film, and the goal of the title designer is to make those words as legible as possible while holding the viewer's interest with visuals, which may at times overpower the typography. Bass conceptualized titles as a combination of visual elements, including typography, composition and layout, movement, color, and design, all of which contributed to the overall design of his film titles. Binder and Kleinman, on the other hand, seemingly eschew ascribing semantic meaning to their typography, the chop-like design of $D r$. No being the rare exception. Indeed, Binder's and Kleinman's typography and text placement remain unchanged throughout the Bond series: only MK12 innovates here in the titles for Quantum.

It becomes clear that while adhering to the geometry of modern graphic design, Binder was relatively uninterested in typography as a creative element. This may have been a function of Binder not having been trained as a graphic artist, unlike Saul Bass and Robert Brownjohn. As Pat Kirkham $(1995,12)$ notes, Binder used neither storyboards nor did he draw his own letters, instead relying on Letraset, a prefabricated rub-down typography. Like modernist designers, Binder composed his titles within a grid that divided the frame into four quadrants, placing his typography in relation to a central vertical and horizontal axis. Binder adheres rigorously to this grid for all of his Bond titles. While the titles to Dr. No still utilizes some left and right justification, Binder's later Bond titles avoid this design variable, creating credit blocks that are center justified. While left/right justification tends to stabilize the text within the frame, center justification tends to destabilize compositions, another method of manipulating the viewer. A constant in all the Bond titles was the use of small lettering on the left or above for credits, while names appeared in caps below or to the right of the 
center justified axis. Utilizing caps for names gives them a block quality that stands out from the busy background, especially since Binder relied exclusively on white typography for reasons of legibility, given that his live action and animated backgrounds were densely composed and filled with action. In keeping with the modernity of the James Bond project, Binder's use of clean, simple sans serif fonts, like Helvetica, Futura or Univers, mimics 196os American design.

It is Robert Brownjohn who first connects typography to voyeurism, when he projects credits on the gyrating body of a female belly dancer in From Russia with Love. Like Binder, he uses a modern sans serif type, but in various pastel shades rather than white, possibly to reflect the gypsy colors of the dancer. Brownjohn's Goldfinger returns to white typography on a black background, while a semi-naked woman in gold acts as a projection surface for images from the film. The titles promise eroticism and violent action, for example, in the scene where we see a gun go off in close-up: a sexualized trope for ejaculation.

\section{Color}

In keeping with modernist design, Maurice Binder used a limited palette of colors for his James Bond title sequences, consisting almost exclusively of primary colors: blue, red, yellow/orange, and green, plus black. Pastel shades are almost completely absent, except for a rare purple hue. Highly saturated primary colors are not only more visible, they also elicit stronger emotional responses, which is in keeping with the dramatic narratives. Binder utilized broad swatches of color, often filling the screen with monochromatic color, and then dramatically shifting from one color to another. These color fields act as a background for his moving silhouettes or other patterns, highlighting the movement of objects and persons while allowing Binder's uniformly white typography to pop off the screen, increasing legibility.

Of all the colors in the rainbow, Binder preferred blue. Indeed, twelve of fourteen Binder-titles are dominated by blue. In some sequences-Thunderball (UK: Terence Young, 1965), Moonraker (UK/France: Lewis Gilbert, 1979) or For Your Eyes Only (UK: John Glen, 1981) — blue reflects the blue of the sky or the sea, but in most cases, Binder's blue light communicates coolness, as in Octopussy (UK:John Glen, 1983) and A View to a Kill (UK:John Glen, 1985). James Bond films were nothing if not signposts for post-World War II modernity and cool. Given the on-going Cold War and the negative reputation of spies in the public imaginary in the early 1950s due to the 
Julius and Ethel Rosenberg trial in the United States and the defection of two British spies, Guy Burgess and Donald Maclean, in the United Kingdom, Bond offered a suave, modernist alternative. As a sexually liberated figure and a government licensed assassin, the Bond figure became an icon of modernity. Bond remains blasé to cheeky, depending on the actor, whether disposing of enemies or bedding resistant women. Blue encapsulates Bond's underlying coldness of emotion, masked by exuding calmness and tranquility in the face of mortal chaos. The blue titles for On Her Majesty's Secret Service (UK: Peter Hunt, 1969) and The Spy Who Loved Me (UK: Lewis Gilbert, 1977) refer to the Union Jack featured in the opening frames, but also communicate attributes such as loyalty, trust, and intelligence. "True blue" goes the phrase, representing qualities necessary for a secret agent.

If blue is often connected to "cool imagery," then red-oranges are hot colors, denoting fire, explosions, and gun fire. In Thunderball, for example, red fills the screen with every explosion and then returns to blue, while You Only Live Twice is primarily held in red-orange oranges to mimic the flowing lava while adding a touch of Orientalism. The red-oranges of fire also dominate Live and Let Die (UK: Guy Hamilton, 1973) and are associated with violence, death, and superstition. As a hot color, reds are connected to fire and blood, eliciting strong and even violent emotions such as passion and lust but also rage and danger. Red appears when Binder inserts explosions and fires but also indicates the danger of sexuality, as in his depiction of a backlit red hydra in Moonraker, or in the female bodies shooting from a gun in Octopussy. Bond's cool blue modernity, then, is juxtaposed to a red death, which is marked feminine.

Interestingly, red's complimentary opposite, green, makes a single appearance in almost every Binder-authored Bond title, beginning with Thunderball. Green is the color of spring, of the renewal of life, the color of the earth; it connotes youth, health, and vitality, but also projects safety and spiritual serenity. This might be Binder's reminder to his audience that in the unnatural world of Cold War espionage - a world of the violence and sexuality, of blue and reds-nature's green is not writ large but it does persevere.

The absence of all color is black, which Binder uses liberally in his palette. Obviously, black's primary utility is in silhouettes, Binder's most obsessive visual trope, as will be discussed below. Black hides details or highlights objects, creating uncertainty, as when black marks a gun barrel. Beginning with You Only Live Twice, however, Binder conceptualizes black as a field of color; first as a moving matte, then, in Diamonds Are Forever (UK: Guy Hamilton, 1971), as a full screen background: the diamonds on luxurious black velvet are 
replaced by specimens of naked young women, half-hidden in the darkness of the background. Every other Binder title, except The Spy Who Loved Me, utilizes black backgrounds, often to frame the women on display, contributing to the objectification of female bodies and to the furthering of audience scopophilia, just as the use of a limited palette of primary colors prepares the audience for further promises of violent action and sexual titillation.

\section{Film Techniques}

Given the obsessive sameness of many of the Binder produced title sequences, we can see these sequences as simple variations on a theme which carries over from one Bond film to the next, functioning primarily to brand the series. In each iteration, Binder works with the same set of visual themes but plays with their presentation by varying film techniques. As Pat Kirkham $(1995,12)$ notes, Binder got a lot of pleasure out of technology: "He was a ceaseless experimenter — with color (emulsions, filters), optical effects, underwater shots, slow motion, animation, electronic movement, superimposition and ways to blend or overlap images." However, these experiments are tested within a very limited formal parameter, including typography and color. There is also virtually no variation in the length of title sequences. The opening gun-barrel ran exactly 30 seconds, followed by the opening teaser scenes, and then the main title sequence, which was rigorously restricted to about three minutes, the median length for film titles in Hollywood. Interestingly, Daniel Kleinman's titles would average twenty-five seconds longer (as does MK 12's Quantum), except for GoldenEye, which at 2:54 minutes matches the Binder-title-average.

For Thunderball, Binder creates what appears to be a continuous singleshot-underwater-sequence, which utilizes animation to move silhouettes of swimming female nudes over live action bubbles exploding up to the surface, while the women are pursued by armed male scuba drivers, also in silhouette. You Only Live Twice adds graphic representations, multiple exposures, and traveling mattes to create a visual montage of naked women and flowing lava. On Her Majesty's Secret Service returns to animation and a martini-glass-matte, which features a montage of images from all the previous Bond films, allowing Binder to secure brand identity by connecting Sean Connery to George Lazenby. All other Binder titles utilize a combination of these techniques to create montages of naked women and guns.

The one technique that Binder employs in every one of his fourteen Bond titles is the animation of silhouettes. Binder had first applied silhouettes 
in his titles for Damn Yankees (USA: George Abbott and Stanley Donen, 1958), and colored silhouettes for $D r$. No, while all subsequent titles exploit black silhouettes. A dressed Bond in occasional silhouette contrasts with the habitual use of silhouetted naked women, emphasizing their erotic intent. Silhouettes made of black cut-out paper first became popular in the eighteenth century as an inexpensive form of portraiture, but the tradition of black figures in art goes back to ancient Greek pottery. Until the advent of photography, they were one of the few ways of creating an image of a person, other than having an artist paint or draw a portrait by hand. In photography, silhouettes created by the backlighting of persons and objects lose their function as portraiture and become methods to create atmosphere or to physically hide details. Silhouettes simplify and abstract compositions, a primary goal of modernist design, as evident in Man Ray and László Moholy-Nagy's camera-less photograms and Lotte Reininger's shadow animations. Furthermore, full-body silhouettes of naked women allow Binder to emphasize female anatomy without running into trouble with the censors, while also referencing nineteenth-century traditions of female portraiture (LeFever, 2009), turning what might be considered a tawdry voyeuristic moment into an aesthetic experience.

\section{Girls and Guns}

Maurice Binder famously summarized his credits sequences for the Bond films as "girls, guns, smoke, and steam" (King 2002; Raddatz 2012). In point of fact, it had been Robert Brownjohn's credits sequences for From Russia with Love and Goldfinger which set the sexual tone for all subsequent Bond titles. In almost all of the consecutive Bond title sequences by Maurice Binder, the dual tropes of female flesh and guns and of sex and violence become the obsessive poles around which the sequences are structured. Close-ups of hand-guns, invariably held by women, signal danger for the hero, but also remind viewers that Bond will not be afraid to bed them, even if they are working for the enemy.

A female hand points a gun directly at the credit "Sean Connery" in Diamonds, at the credit "Roger Moore as James Bond," in Live and Let Die, and at the credit for "Timothy Dalton" in The Living Daylights (UK: John Glen, 1987), while in The Spy Who Loved Me a silhouette of a Russian female points a gun at Bond's silhouette. These titles tell us: women with guns are dangerous and must be neutralized. In A View to a Kill, Grace Jones' screen credit seems to be shot from a gun, foreshadowing her role as May Day, 
the villain's deadly companion. Grace Jones is first seen wearing bright red outfits, again connecting the color to death and femininity. Girls with guns appear prominently in most other Binder titles as well. In fact, only three sequences do not feature close-ups of guns: You Only Live Twice, On Her Majesty's Secret Service, and Moonraker. In The Man With the Golden Gun (UK: Guy Hamilton, 1974), as befits the title, the golden gun points at Roger Moore's name above the title. Thus, guns in female hands function as a fetish for danger, death, sexual deviancy, and the violence that invariably ensues in James bond films. Every James Bond film features beautiful, young, gun-toting women who are themselves killers or working for the enemy, some of whom Bond can turn to after sex, some of whom he kills after off-screen penetration. The visual trope finds its tongue-in-cheek iteration in the image of a naked woman exercising on the horizontal bar of a gun barrel in The Spy Who Loved Me.

Binder's iconography consists of for more than go percent of images of naked women. As we have seen, Binder puts women on display and encourages a voyeuristic relationship to his sexualized images (Planka 2015,142 ). His ubiquitous silhouettes of female nudes never seem to tire of dancing, jumping, running, engaging in gymnastics, skiing, showing off breasts and hips. Binder's other strategy for the depiction of women is photographic, shooting frontal portraits, at times slightly distorted, or letting his camera caress body parts with slow moving pans, all of which recall the conventions of classic nudes in art production and centerfolds in Playboy, where Ian Fleming serialized On Her Majesty's Secret Service in 1963 (Hines 2018).

Furthermore, Binder's repeated use of tropes of sight and vision communicate and sanction a voyeuristic relationship, such as the close-ups of eyes in seven Binder titles, or the circular images of naked women (Moonraker), some seen through gun sights (Licence to Kill [UK/Mexico/ USA: John Glen, 1989]). In A View to a Kill, the woman knowingly looks at the camera - the audience - and thus exposes the viewer's voyeurism, but such moments are exceedingly rare. Binder reinforces erotic entanglement even further by guiding the audience's gaze to credits via eroticized body parts: in Diamonds Are Forever, a huge diamond covers a close-up of female genitalia behind Sean Connery's screen credit; in For Your Eyes Only John Glen's directorial credit is visible on a naked breast; Maude Adams' credit rests on the naked breast of a lying female nude (also holding a gun) in Octopussy; a female hand reveals half-naked breasts directly under the opening title credit in A View to a Kill. Here the audience as voyeur is guided by the typography. 
Beyond the undeniable sexism of the Binder titles, there is also the troubling aspect of racialized and racist images of women. Conceived in the era of 1970s "Blaxploitation," Live and Let Die's title sequence is particularly egregious, being structured as a "voodoo horror film." Cutting from the death of a British agent at the hands of some seemingly "primitive" black Jamaican cult-recalling countless racist Hollywood “jungle films" like Tarzan the Apeman (USA: W.S. van Dyke, 1932), where a white man is burned or cooked to death-Binder lays images of fire over naked and painted black women. In reference to James Snead's $(1994,4)$ notion of mythification, the white Bond needs black villains to highlight his whiteness:

Mythification involves the realization that film codes describe the interrelationship between images. American films do not merely feature this or that debased black image or this or that glorified white hero in isolation, but rather they correlate these images in a large scheme of semiotic evaluation [...]. This device engages audiences on the level of their racial allegiance, social background and self-image.

There is also the specific danger of women of color. One black female head becomes a wick for a torch of red fire, her eyes buggering out of her head-another well-worn racist trope (Snead 1994, 4) - the image intercut twice with a human skull. The fire motif continues over the silhouette of a naked black woman and multi-colored disembodied arms reaching for the sky, their silhouettes dancing, visually reinforcing references to "the occult." Black women are not portrayed as erotic but as signifiers of death. Binder's credits thereby undergird the mise en scene of the "voodoo rituals" in the teaser. Ironically, the only other time when Binder utilizes fire imagery as a design element (and not just for explosions) is in You Only Live Twice, where again women of color predominate: close-ups of Japanese women are juxtaposed to lava flows, conveying danger even in the silhouettes of naked geishas.

In $A$ View to a Kill, we see an olive-skinned woman with red lips, who suddenly, after a lighting change to blacklight, appears in blackface with neon-red lips and colored body makeup, just as subsequent actresses appear in blackface with neon make-up. Their Otherness emphasizes the whiteness of the single woman in gun sight, while tropes of fire are connected to black female bodies to conjure up images of hell_-in keeping with the red-clad villain, played by Jamaican-American Grace Jones. The blacklight technology thus undergirds racist iconography. 
By the mid-1980s, at the height of the HIV/AIDS pandemic, when Binder completed his final Bond titles, the free and easy eroticism of the $1960 \mathrm{~s}$ was no longer modern. As British film critic Tom Shone $(1992,24)$ noted, Bond's obsolescence "was nowhere more lovingly observed than in the films' title sequences, shot by Maurice Binder." The availability of digital tools created a whole new universe of formal possibilities but also opportunities for Daniel Kleinman and MK12 to abstract the gun-and-girls tropes, their digital unreality undercutting any voyeuristic eroticism.

\section{Digital Shift}

Maurice Binder had used animation, traveling mattes, and superimpositions to layer his images of girls and guns behind the typography. Producing such montages necessitated careful planning and continual experimentation with exposures, since $35 \mathrm{~mm}$ negative film had to be exposed repeatedly for superimpositions. Mattes covered up parts of the frame while exposing others, again leading to multiple exposures. Setting exposure levels too high risked over-exposure, setting them too low left portions of the frame too dark. Furthermore, Binder's modernist methodology meant that he was composing for a two-dimensional frame, while multiple exposures further flattened out space.

By the time Daniel Kleinman was given the assignment to produce the titles for GoldenEye, computer generated imagery (CGI) had matured enough to create the first computer animated feature length animation, Toy Story (USA: John Lasseter, 1995). CGI allowed Kleinman, who had made a career for himself producing music videos and advertising films, not only to layer an almost infinite number of images without worrying about exposures, but also to grant him the ability to compose his titles in deep space. While multiple exposures of analog images were a matter of time consuming trial and error, digital tools allowed for image manipulations with a touch of the keyboard. Digitality engendered a post-modernist turn as well. Rather than simply juxtaposing iconic images composed within a mathematical grid, Kleinman created atmospheric sequences in highly synthetic spaces without regard for the rules of photographic realism or narrative logic: a phantasmagoria of floating objects. The digital paint-box also gave Kleinman and MK12 the freedom to manipulate color at 1000 points within the frame. They therefore eschewed broad color swatches for an ever-changing palette, depending on the moods they were trying to create. 
In GoldenEye, Kleinman's backgrounds of clouds and smoke change colors from bright orange to blue, grey, yellow and purple without influencing the objects in the foreground - another advantage of digitality. And while the titles for GoldenEye still feature a preponderance of nude women and guns, Kleinman's overall montage is focused on the visualization of the end of the Cold War. However, Kleinman's typography remains uninspired and monotonous, repeating similar fonts, sizes, and design. Except for GoldenEye, where Kleinman uses a yellow font, his standardized sans serif-typography sticks to standard white for legibility. There is indeed little variation in the overall text design of the post-Binder titles, except in MK12's titles for Quantum of Solace, which have a unique look. After a six-year hiatus in the series following Licence to Kill, Kleinman helped to reboot the Bond franchise in two ways. First, he updated Binder's gun-barrel-opening by reshooting the sequence in digital, adding much more detail to the previously dark interior of the barrel. More importantly, his titles for GoldenEye illustrate the new geopolitical context for Bond's secret agent work, symbolically visualizing the dissolution of the Soviet Union and thus mirroring the film's post-Cold War plot.

Kleinman's utilization of CGI technology becomes apparent from the very first image of his credits for GoldenEye, when the camera zooms out from inside a gun barrel, a bullet hurling forward towards the audience; then followed by a completely artificial, digital image as the camera turns into space: an impossibility in analog. The naked women posing in the fore, middle and background also originate in the digital, their bodies seemingly suspended in an orange-yellow cloud, possibly referring to the Soviet banner. These women are clearly products of computer animation, their focus sharp regardless of their distance from the implied camera, their contours and skin having the plasticine quality of CGI. Kleinman then suspends Communist sickles horizontally, transforming them into walkways for Bond and his naked women while hammers float through the frame, as if in a surrealist painting by René Magritte. Toppled statues of Vladimir Lenin and other Soviet leaders are destroyed with sledge-hammers by semi-clad women as far as the eye can see. Later, a woman in profile opens her mouth, releasing a gun barrel that fires: a digital image that Planka $(2015,145)$ mentions in her discussion of dangerous women, but it may also refer to such surrealist photography as Jaromir Funke's image of a man with a lightbulb in his mouth. A shower of hand-guns rises up with women dancing on their muzzles.

Just as the titles for GoldenEye are structured around visual tropes for the fall of Communism, so too do Kleinman's subsequent Bond titles develop 
visual motifs that reference film narratives playing out in an artificial digital space. As Kleinman (Radatz 2012) noted in an interview: "I am really riffing on a language already invented [...] but I do feel I've brought some individual creative input of my own to the titles and tried to make them more narrative and less just collage-like sequences." I would argue that Binder's collages of guns and girls have been supplanted by digitally sophisticated collages that return individualized narrative threads and a clear thematic focus to the Bond titles: their post-modernity references other Bond titles rather than the real world.

Thus, Tomorrow Never Dies (UK/USA: Roger Spottiswoode, 1997) opens with a homage to the stained glass warriors in Young Sherlock Holmes (USA: Barry Levinson, 1985) - the first feature-length film to incorporate CGI—and then continues as a meditation on digital technologies and on the media conglomerates controlling them, zooming through a matrix of numbers and creating human female forms from solid-state computer boards-all referencing the cyber war that ensues in the film. Indeed, Tomorrow Never Dies begins with an analog tail shot of what could be a Soviet-era MIG aircraft — reminding us of Bonds gone by — and then turns to digital to shatter the image before a rollercoaster ride on the logorhythmic highway ends with a seemingly analog image of (wo)men as insect-sized specimens on a slide, connecting the sequence to Binder's Bonds but also inferring that, in a virtual reality, humans have become insignificant.

The World Is Not Enough (UK/USA: Michael Apted, 1999) is structured around images of oil in keeping with a plot about an assassinated oil tycoon, whether visualizing partial female bodies sinking into or rising up from oil or depicting bodies dripping with crude. Kleinman's titles resemble a Binder title on steroids, erotically suspending female bodies in space, interrupted by firey explosions, yet these titles-impossible without CGI-use that technology to distance the viewer from affect. Die Another Day (UK/USA: Lee Tamahori, 2002) intercuts photorealistic images of Bond being tortured and beaten with CGI images of female bodies in fire and ice. Excerpts from the film—a strategy not seen since On Her Majesty's Secret Service-are shown and then digitally distorted in CGI sequences, which signify the villain's use of solar energy as a weapon of mass destruction.

For the series reboot with Daniel Craig, Casino Royale (UK/Czech Republic/USA/Germany/Bahamas: Martin Campbell, 20o6), Kleinman chooses a purely graphic representation of playing cards and roulette wheels, morphed from gun sights, which also reference the original cover design of Fleming's source novel (another return), while digital silhouettes of fisticuffs and gunplay between Bond and his adversaries result in guns firing black 
clubs and red hearts and corpses bleeding red hearts. It is a masterfully constructed space, featuring Lissajous spirals and other graphic elements that defy spatial orientation, recalling the ornate design of a deck of cards, which is then violated by flat red-and-black-silhouetted combatants who float in their own three-dimensional digital bubble. It is the only Bond sequence that eschews the visualization of naked women, focusing instead on card games and on Bond firing his weapon as a trope for Bond's poker game with the villain, Le Chiffre (Mads Mikkelsen). It is also the only title sequence that is wholly graphic rather than photographic, but its construction could only be achieved digitally.

For Quantum of Solace, MK12 created titles at the insistence of director Marc Forster. Founded in 200o, the design collective consisted of Jed Carter, Tim Fisher, Matt Fraction, Ben Radatz, Shaun Hamontree, and Chad Perry. Like Kleinman's titles, MK12's title relies on CGI technology, reprising GoldenEye's opening with a bullet shot from Bond's gun before moving through a desert landscape. However, MK12's titles are the first to rethink the presentation of the credits, utilizing moving graphic typography and a unique font. As in the Kleinman titles, the logic of digital animation-objects and scenes constantly morph into something else-rather than analog's realistic space-time coordinates guide the design. Interestingly, MK12's white, animated typography_lines form letters and words — is completely original, its sans serif-style mimicking the bullet's path. Likewise, MK12 significantly eliminates the voyeurism of female bodies, presenting mere apparitions of naked women that dissolve almost as soon as they appear, threatening only because of their size in relation to a CGI Bond moving or falling through amorphous desert landscapes. When naked female bodies appear that the end of the title, they are abstracted into kaleidoscope and silhouetted forms, referencing Binder as indeed virtually every MK12 image in some way refers to previous Bond title sequences, such as the parasol design in You Only Live Twice, the red moving dots from Dr. No. or the kaleidoscope image of women in On Her Majesty's Secret Service, with all of these now spectacularly reimaged as a digital praxinoscope.

Daniel Kleinman returned to the franchise for Skyfall (UK/USA: Sam Mendes, 2012). At the end of the prologue, Bond is shot and falls into a river, which allows Kleinman to structure his titles as a nearly continuous forward track through a CGI riverbed and other landscapes filled with objects of death and decay, some in stark black and white, others in flaming red (the bullet hole in Bond's chest) which again connotes death. Guns and girls do make an appearance but are abstracted in kaleidoscope images that include a skull morphing into a grave. Bond's impotent state is visualized through 
images of falling and shooting wildly at unseen targets without any effect other than to shatter mirrors, the fragmented glass a trope for schizophrenia or identity loss. Both Adele's theme song and Kleinman's dark, moody visuals reflect the many defeats Bond suffers in the movie, beginning with his own near-demise to the death of $\mathrm{M}$ (Judi Dench).

Finally, Kleinman's titles for Spectre (UK/USA/Austria/Mexico/Italy/ Morocco: Sam Mendes, 2015) feature for the first time a naked James Bond along with the proverbial nude Bond Girls. The credit sequence also animates a giant octopus, taken from SPECTRE's logo, as well as environments presaging the rogue syndicate's dark headquarters in an evocation of Ken Adam's modernist set designs for the 1960 s Bond films. As in Skyfall, Bond falls through space, his nakedness a sign of vulnerability but also strength-fire can't touch him -, thus revitalizing the weak 007 of Skyfall. Kleinman's titles, then, construct a Freudian nightmare with images that are both erotic and horrific, the black octopus enveloping a woman's naked body like a giant phallus, which is subsequently contrasted with images of fire and death. It is another surrealistic dream filled with dark shadows, the camera traversing empty spaces that evoke Giorgio de Chirico and M.C. Escher while a montage of eyes carries strong connotations of Fritz Lang's Metropolis (Germany: Fritz Lang, 1927).

Except for Die Another Day, none of the Kleinman titles incorporate shots from the films, but even there, the images of Bond's torture are highly stylized and abstracted by digital electronic females dancing while conjuring up a simulacrum of eroticism. Kleinman and MK12 prefer a set of iconic images in order to brand the series and individualize each film. Digital female forms appear as transparent liquids, as oil, as computer circuits, as molten steel or as disembodied parts for moving kaleidoscope designs. In doing so, they frustrate the voyeuristic male gaze. Planka (2015, 147) argues that these female bodies are surfaces for the projections of the male gaze, but I would suggest that the lack of flesh and blood negates their erotic appeal. The overt voyeurism of Binder's titles is eliminated by placing a heavier emphasis on violence and on the threat of a death of the hero.

While Kleinman moves beyond the simple binary of Binder's guns and girls, his and MK12's titles employ iconic images to introduce themes and codify plots. When guns and girls do appear, they are imbedded in dreamscapes, with objects floating freely in digital spaces that have no visible coordinates but only exist in a digital no-man's land, thereby robbing them of any erotic power. The utilization of CGI and digital post-production allows Kleinman and MK12 to create densely composed, $3 \mathrm{D}$-like views of unreal 
spaces that morph with a speed that leaves the audience overwhelmed, thus making them vulnerable for further manipulation in a vein similar to Binder's gun barrel sequence. Rather than manipulating the viewer with photographically realistic images of eroticized female forms, these digital titles recreate the sensory overload of music videos to reproduce their excitement and reference their modernity. After all, the goal of the Bond franchise continues to be to entertain the audience by allowing them to identify with a hero who has a license to kill but is also continuously under mortal threat.

\section{Conclusion}

This chapter has addressed the aesthetics and cultural politics of the James Bond title sequences and their repeated use of technologies, techniques, and imagery as well as their tenuous depictions of gender and race. Working in the analog realm and repeating recognizable tropes and images, Maurice Binder's work stands out against countless other films from the period, which simply begin the plot behind the titles, in that Binder's sequences function to brand the series rather than individual films. In that endeavor, Binder utilized a limited number of visual tropes of young women in sexualized positions and of guns leading to violence. His overt use of sexualized and racialized imagery was presented in primary pop art colors as a montage in a two-dimensional space, which marked his titles as modernist. Individual films were branded by giving each title sequence its own theme song that could be sold in conjunction with the film. Such a strategy seems to have been in the interests of the Eon producers, who were always thinking beyond the production of a single film. In that sense, the Bond titles are successful as series branding.

Digitality has allowed for a much more complex layering of images, undergirding the branding of the film series as well as the referencing of film-specific narratives and themes. Kleinman and MK12 imbue each title with a specific mood and utilize iconic visual images and scenes that refer to the specific storylines that follow. In particular, digital tools have completely altered the construction of space. Rather than maintaining realistic space-time coordinates, the post-analog titles construct free-floating spaces where metaphoric and real objects and persons appear and disappear, creating the violent and erotically charged dreamscapes that Binder always aspired to. In the process, the voyeurism of Binder's nudes is mitigated, de-eroticizing female bodies into post-modern algorithmic visual surfaces. 


\section{Works Cited}

Bennett, Tony, and Janet Woollacott. 1987. Bond and Beyond: The Political Career of a Popular Hero. New York: Methuen.

Brosnan, John. 1981. James Bond in the Cinema, Second Edition. San Diego: A.S. Barnes \& Co.

Cork, John, and Bruce Scivally. 2002.James Bond: The Legacy. New York: Harry N. Abrams.

Hines, Claire. 2018. The Playboy and James Bond: oo7, Ian Fleming and Playboy Magazine. Manchester: Manchester University Press.

Horak, Jan-Christopher. 2014. Saul Bass: Anatomy of Film Design. Lexington: University Press of Kentucky.

Hunt, Kristin. 2011. "Beyond the Spiral Barrel: A Critical History of Dance in the James Bond Films.” In James Bond in World and Popular Culture: The Films are Not Enough, edited by Robert G. Weiner, B. Lynn Whitfield, and Jack Becker, 6o-75. Newcastle upon Tyne: Cambridge Scholars Publishing.

Kirkham, Pat. 1995. "Dots and Sickles." Sight and Sound5, no. 12 (December): 10-12. LeFever, Gregory. 2009. "Faces in Black and White." Early American Life, June, 6o-9. Planka, Sabine. 2015. "Female Bodies in the James Bond Title Sequences." In For His Eyes Only: The Women ofJames Bond, edited by Lisa Funnell, 139-45. New York: Wallflower.

Radatz, Ben. 2012. "James Bond: Fifty Years of Main Title Design." Art of the Title, Accessed September 6, 2017, http://www.artofthetitle.com/feature/james-bond50-years-of-main-title-design/.

Rositzka, Eileen. 2015. "Random Access Mysteries. James Bond and the Matter of the Unknown Woman." In For His Eyes Only. The Women ofJames Bond, edited by Lisa Funnell, 146-6o. New York: Wallflower.

Shone, Tom. 1992. "It's Time To Junk Bond." In The Sunday Times, October 25, 24.

Snead, James. 1994. White Screens/Black Images: Hollywood From the Dark Side. London: Routledge.

\section{About the Author}

Jan-Christopher Horak received his PhD. from the Westfählische WilhelmsUniversät in Münster, Germany, his MS from Boston University, and a BA from the University of Delaware. He was previously Director of UCLA Film \& Television Archive, Director of Archives \& Collections, Universal Studios, Director, Munich Filmmuseum, and Senior Curator, George Eastman Museum. He has held professorships in Rochester, Munich, Salzburg, and 
Los Angeles. An Academy Scholar in 2006, he is recipient of the Katherine Singer Kovacs Essay Award (2007), SCMS Best Edited Collection Award (2015), the Andor Kraszna-Kraus International Film Book Award (2016), and the Reinhold Schünzel Prize (2018). His books include: Saul Bass. Anatomy of Film Design (2014), L.A. Rebellion: Creating a New Black Cinema (2015), and Hollywood Goes Latin. Spanish-Language Filmmaking in Los Angeles (2019). 


\title{
13. "Unlike Men, The Diamonds Linger:" Bassey and Bond Beyond the Theme Song
}

\author{
Meenasarani Linde Murugan
}

\begin{abstract}
This chapter directs attention to Shirley Bassey's voice as both constituting and contesting the white male gaze of the James Bond franchise. I consider Bassey in relation to the politics of race and gender as she sonically invokes a long tradition of racial mimicry by both black and white women singers. Bassey furthers this tradition in that her influence can be traced beyond her various theme songs for the Bond films in the more recent performances by white artists. As Bassey's Welsh and mixed-race identity gives a different contour to our understanding of what and who constitutes "Britishness," her synecdochal relationship to the James Bond film series also allows us to reconsider the possibilities for black women's voices in cinema.
\end{abstract}

Keywords: theme song; Shirley Bassey; voice; race; gender; Black Atlantic

In commemorating fifty years of James Bond, the 2013 Academy Awards focused on the music of the series. The celebratory montage was later complemented by Adele's performance of "Skyfall," which was given an Oscar by the end of the broadcast. While the tribute was introduced by Halle Berry (Jinx, Die Another Day [UK/USA: Lee Tamahori, 2002]) and featured sequences from the many Bond films, Dame Shirley Bassey's performance of "Goldfinger" (1964) stood in for the iconic James Bond of the past fifty years. In her first-ever performance at the Academy Awards, Bassey commandingly belts out the theme song. Though her voice has more of a baritone thickness to it now than it did in 1964, she sings the tune with force. Her breathing is so well hidden that the last note, which she holds for 6 seconds, surreally

Verheul, J. (ed.), The Cultural Life ofJames Bond: Specters of oo7. Amsterdam: Amsterdam University Press, 2020 DOI 10.5117/9789462982185_CH13 
emanates from her. In her almost sixty-year musical career, she is the only artist to have performed three theme songs for the Bond franchise, with "Goldfinger," "Diamonds Are Forever" (1971) and "Moonraker" (1979). Her synecdochal relationship to the Bond film series allows us to consider the possibilities for resistance and incorporation found in black women's voices in cinema.

In this chapter, I first situate Bassey's performance in the cultural circulation of the Black Atlantic. Secondly, I consider Bassey's voice within the discourses of authorship and gender that circulate around the Bond films. Finally, while Bassey certainly has iconic status, I show how the power of her voice does not necessarily amount to an enunciation of resistance to the politics exhibited in the Bond film series.

\section{The Girl from Tiger Bay}

Shirley Bassey was born on January 8, 1937 in Cardiff, Wales. Specifically, she was born and raised in the area of Tiger Bay. This neighborhood by the Cardiff docks housed many sailors that migrated from Portugal, Norway, Malaysia, Afghanistan, Sierra Leone, Nigeria, Barbados, Trinidad, Jamaica, Spain, Egypt, and Greece (Little 1948, 108). Many of these sailors would then marry white Welsh women, creating a unique multiracial population (Tackley 2014, 44-47). Tiger Bay, while definitely part of Wales, had a distinct identity as both multiethnic and multiracial. Strikingly, in Ross Cameron's history of Tiger Bay, he (1997, 87-88) notes how "racism within the community does seem to have been absent; K. Little, S. Collins and L. Bloom all speak of a racially integrated community in the decades after 1945. External racism was likewise unchanging" as the neighborhood "failed to become integrated into the wider city and remained geographically and socially isolated." This created an insulated community that would protect their own, but it also stigmatized Tiger Bay as a poor and dangerous neighborhood in relation to the rest of Wales and the United Kingdom.

Despite this uneasy relationship with the rest of the country, the isolation of Tiger Bay produced a distinct musical culture. While jazz was part of the repertoire of many bands that played in dance halls and clubs, "musicmaking in Tiger Bay was dominated by plucked string instruments; banjo, guitar, mandolin, cuatro (a small four-stringed lute) and ukulele" (Tackley 2014, 47). While the presence of a Hawaiian ukulele in Cardiff may seem odd, the fact that Cardiff was a port meant that musical fashions from abroad - even oceans away_ came there first. Despite the latest fashions 
however, "plucked string instruments were also suitable for rendering the calypso repertoire most in demand by the community of which West Indians represented a significant proportion" (47). While there was a large West Indian population in Tiger Bay, black American soldiers came to Britain during World War II, adding to the audience for jazz music that already made up the popular music scene, while also contributing knowledge, records, and musicianship of black American musical traditions (Tackley 2014, 57; Sinclair 2003, 66; Doffman 2014, 111-32).

Writing several decades later, Paul Gilroy would remark upon this circulation of black cultural production. He $(1993,109)$ notes that as "a child and a young man growing up in London, I was provided by black music with a means to gain proximity to the sources of feeling from which our local conceptions of blackness were assembled. The Caribbean, Africa, Latin America, and, above all, black America contributed to our lived sense of a racial self." While Gilroy in this instance is writing about London in the 1950 and 196os, key to his assertion is both the specificity and hybridity of black music. It is specific in that it is produced by black artists and provides a means by which Afro-descendant people can come into an understanding of a "lived sense of racial self." However, it is hybrid in that these black artists were from various locations in the African diaspora and also borrowed from various musical traditions. This contributed to, as Gilroy (109) notes, "local conceptions of blackness [that] were assembled," meaning racial identity was produced through a collective combination of black cultural practices and products and not simply a direct correlation to one's lineage, skin color, or physiognomy. Specifically, in the neighborhood of Tiger Bay, records from Paul Robeson, Lena Horne, and other black American jazz and blues artists mixed with jitterbug dancing and calypso performances to not only create a unique hybrid black musical culture but also contribute to the racial identities of its inhabitants.

While Bassey is not often put into the context of the cultural production of the Black Atlantic, this is a generative contextualization as Bassey herself cites Horne as an influence (Williams 2010, 75). Furthermore, hearing Bassey within the sonic space of black music demonstrates how Bassey's voice came to be heard not only as powerful but also emblematic. In an analysis of various black American singers, Farah Jasmine Griffin $(2004,104)$ meditates on "the way the black woman's voice can be called upon to heal a crisis in national unity as well as provoke one." Though she is studying singers in a US context, the power of and that is culturally attributed to black women singing can be fruitful to take note of in the case of Bassey, as she has become revered as a British national treasure and a symbol aligned with 
the James Bond film series - an imperial and largely white movie franchise. Ros Jennings $(2012,37)$ notes:

In the same way that other great Dame Commanders of the Order of the British Empire (for example, the actresses, Judi Dench and Helen Mirren), have as they have aged, gone on to play/perform the roles of great British queens (Elizabeth I, Victoria and Elizabeth II) on screen and to assume the mantles, respectively, of national treasure and one of the world's sexiest older women, Dame Shirley Bassey has come to embody both these aspects (she is a national signifier and from my perspective, still most definitely sexy).

These signifiers of nationalism, royalty, sex appeal, and Bond neatly came together when Bassey performed "Diamonds are Forever" at Queen Elizabeth II's Diamond Jubilee Concert at Buckingham Palace in 2012. Fashion designer, former Project Runway (Bravo, 2004-2008; Lifetime 2009-2017; Bravo 2019-present) contestant and TV personality Nick Verreos (2012) blogged, "she looked DIVINE in an ivory gown with chiffon capelet sleeves that flowed in the London wind and made for dramatic effect as she belted out one of her iconic songs. She looked AMAZING and the gown was a Lesson on How To Dress In Front of THOUSANDS of people!!! Go on Miss Shirley Bassey!" The theatricality she employs in collapsing all these signifiers demonstrates how Bassey's performance is always addressed to a mass — and often a mass that is both national and exhibited for international consumption.

Though the Diamond Jubilee aligned her with Great Britain, other media events demonstrate her pride in being Welsh. In 1999, Bassey, "draped in a Welsh flag and accompanied by a traditional harpist, took centre stage for their updated version of the rugby World Cup anthem-World in Union" ("Rugby" 1999). Despite these moments of explicit British and Welsh pride, the class, racial, and ethnic identity of Tiger Bay are effaced in these moments of national symbolism. While Bassey is framed as a "national treasure," her race and ethnicity are unacknowledged or only understood as something that must be overcome. Jennings $(2012,37)$ notes, "She is of mixed race (English mother and Nigerian father) and is simultaneously black and not black in her cultural presence; she has risen above her impoverished childhood in the Docklands of Cardiff's Tiger Bay to reside as a tax exile in that exclusive European playground of the rich, Monte Carlo." As Monte Carlo and its casinos are pivotal to the imaginary of Bond, Bassey in her real life lives in the cinematic world of Bond, where her mixed-race identity just adds to her glamour and exoticism. She has 
divorced herself from any markers of class, ethnic, and racial specificity. Part of the reason why Bassey's blackness is not often taken into account in discussions of her performance is not only her being primarily raised by her white Welsh mother but also her fraught relationship with racial identity and black liberation politics. In a profile of the singer from the March 1963 issue of Ebony, the article shows Bassey "at a family reunion after first triumph, Shirley gives performance for Bassey clan. Her Welsh mother (seated) divorced star's Nigerian father when Shirley was three. They had seven children" ("Shirley" 1963, 112). Bassey says, "despite initial fears, US race problem 'hasn't affected me so far" ("Shirley" 1963, 110). While Ebony frames her with her family, it is clear from Bassey's interview that she has not considered why race would matter in her transatlantic debut. It is referred to merely as a hindrance. This kind of ambivalence toward race and racism continued after the dismantling of US legal segregation in the 1960 s and ' 70 s.

In 1984, she was listed on a register of performers who had ignored a cultural boycott of South Africa. This document, which was addressed to the United Nations, noted how each of these performers were being discussed "as a collaborator with a racist regime," since "South Africa is the only country left in the world where it has written segregation-where it is legal to discriminate by race" (Wilson 1985). Despite many performers-especially black artists - refusing to go to South Africa even before the register, Bassey continued to perform at the height of apartheid. In a 2009 interview, moreover, she decried the rise in immigration to the United Kingdom. "We're letting in too many people. We're an island, for God's sake. And the Britishness seems to have gawwwnnne.' She enunciates the word "gone" so poshly that it takes a while to work out what she's saying” (Hattenstone 2009). Interviewer Simon Hattenstone (2009) tried to challenge her on this perspective, but she seemed unable to see the irony. He writes, "I can't help wondering what her Nigerian father would make of her assessment of modern Britain.” Despite Bassey's complicated relationship to her ethnic and racial identity, race did impact the audiences she interacted with and the kinds of opportunities she was given while trying to be a recording artist in the 1950 os and ' 60 s.

\section{The Heat in Hot from Harlem}

Bassey got her start in 1953 when she signed her first professional contract with Cliff Gordon to be a performer in the touring revues Memories ofJolson (1953) and Hot from Harlem (1954). Gordon had previous success with black 
American influenced music productions, such as the successful radio show The Kentucky Minstrels (1950). Bassey's biographer, John L. Williams (2010, 84-85) notes, however, that "while The Black and White Minstrels featured an all-white cast, Memories ofJolson was, in the parlance of the time, an almost all-coloured show." Unsurprisingly, this black-cast show had a much smaller budget than Gordon's other work. The black musical revue, especially in its British instantiation, was a hybrid entertainment form. Shane Vogel (2008, 98) notes, "These revues, with scores of cast members, showcased black performance and choreography primarily scripted, designed, and staged by white writers, composers, and directors." As indicated by titling a black musical revue Memories ofJolson (a reference to US blackface performer Al Jolson), black music in these contexts was always tied to white minstrel show performances of blackness. Originating in the US in the early nineteenth century, minstrel shows featured white performers in blackface makeup performing music comedy acts of black people as buffoonish. Even after emancipation and Reconstruction, the minstrel show endured in several US entertainment forms and sometimes featured black performers in blackface makeup, playing racist caricatures of black people. While Vogel focuses his analysis on black musical revues in New York in the 1930s and 1940s, Howard Rye draws attention to the longer history of trans-Atlantic travel for the black musical revue.

The first all-black musical revue to come from the United States to play in London was In Dahomey, which played from 16 March, 1903 at the Shaftesbury Theatre, and subsequently toured in the provinces. The tradition thus started was carried on by touring shows which were often organized by Americans, but relied in part for their casts on non-American members of the African diaspora recruited in Britain (Rye 2006, 169; Green 1983).

Here, in the British tours of black musical revues, the productions were twice-removed from black Americans but then re-appropriated and rearticulated by black British artists via the Black Atlantic. Gilroy notes how minstrel performance was the standard by which all black performers were measured, from the spirituals of the Fisk University Jubilee Singers to rock star Jimi Hendrix. Yet, while the Fisk Singers in the 1870 s took great pains to distance themselves from the minstrel language that was used to market them abroad, Hendrix's "updated minstrel antics" reinvented him "as the essential image of what English audiences felt a black American performer should be: wild, sexual, hedonistic and dangerous" (Gilroy 1993, 
88-93). It was in the space of the black musical revue that Bassey honed her craft, and in the larger context of Black Atlantic cultural production that she navigated remediations of blackness and minstrelsy.

These touring shows would re-present, mostly to white audiences, different musical essentialisms of US blackness. Part of this would be a display of the Harlem nightlife and jazz performances that had catered to white audiences since the 1920s. Other numbers would be minstrel performances with songs done in blackface and with backup dancers playing cotton pickers. Bassey's experience as a mixed-race Welsh Nigerian was divorced from this particular American iconography of slavery and of the various racialized remediations of minstrelsy and the Harlem cabaret. Despite this, the space of the black musical revue schooled Bassey's raw talent. Joe Collins, producer of Hot From Harlem (1954) commented on how he had to transform Bassey "to look feline and seductive. She's only a scrap of a kid" (Williams 2010, 96). Later, however, he was appreciative of his foresight:

You could say I got a bargain. Shirley Bassey put the heat into Hot from Harlem [...] fingers snapping, hips working overtime. She was a right little tease, with a seductive, growling voice. Sometimes the wolf whistles from the audience drowned her singing. Both the audience and the rest of the cast went wild over her (Williams 2010, 100-1; Collins 1986).

The black musical revue provided the site from which Bassey became a sexy and sexualized chanteuse, further enmeshing her in a transnational history of black musical production for both black and white audiences. In particular, Joe Collins' account of Bassey's performance demonstrates how the black musical revue trafficked not only in white-produced commodifications of US blackness but also a titillation, in which an always sexually available femininity was inextricable from black women performers. In writing about the Cotton Club, Vogel $(2008,18)$ states, "The intimacy of the segregated cabaret was predicated on the promised display and exposure of black female interiority, an expectation that informed the different but related racial discourses of primitivism and exoticism shaping representations of black performance in the 1930s and 1940s." Here, then, Bassey's "exposure" isn't just about seduction but an assumption that her "black female interiority" is being communicated through this overly sexualized performance. This navigation of sex appeal and emotional torch singing became key to her rise as a musical artist in the US and UK. In March 1963, she was on the cover of Ebony. Positively reviewed for her Las Vegas and New York performances as a "tawny tigress" or a "high priestess of soul 
and sex," it was clear that her racialized sex appeal was integral to her act ("Shirley" 1963, 108-9).

Though playing in New York and Las Vegas was her first foray into US entertainment, her singing of the title song, "Goldfinger," for the 1964 Bond film, cemented her as a pop star with international fame. In 1963, John Barry was both scoring Goldfinger (UK: Guy Hamilton, 1964), his third Bond film, and conducting a 23-piece orchestra for Bassey's December 1963 concert tour (Burlingame 2012, 39). Because of their work together, Bassey was selected to sing the theme song. In the words of Barry, she had "great dramatic sense," adding that "when it came to the studio, she didn't know what the hell the song was about, but she sang it with such total conviction that she convinced the rest of the world" (Burlingame 2012, 39). From an industrial perspective, Bassey was also a well-suited choice for the film because she was then signed to United Artist (UA) Records, whose film division was handling both the film distribution and music rights and the licensing for the Bond film series (Smith $1998,104-5,110)$. Jeff Smith $(1998,110)$ notes how "Bassey was already a star in England and was on the verge of stateside stardom as Goldfinger was being produced." For the rather young film series, "Bassey's name recognition would help gain attention for the film during the buildup to its world premiere in London. For UA Records on the other hand, the film would be just the thing to propel Bassey to stardom in the States." Here, then, it is Bassey's stardom that is seen as a key asset in majorly promoting this fledgling film series.

This cross-promotion proved to be a winning combination as the film "went on to earn nearly $\$ 50$ million in domestic and foreign rentals. The soundtrack album, released by UA Records in October 1964, eventually topped both Billboard's and Variety's album charts [...] Bassey's single was issued in December 1964 and climbed to number 8 on the singles chart" (Smith 1998, 110-11). Goldfinger, as a film as well as a soundtrack album and single, proved to be a global hit that catalyzed a "Bondmania" that included copycat albums, film and television parodies and homages, and inspired merchandise from golf jackets to "alarm clocks that played the 'James Bond Theme"" (Smith 1998, 111; Chapman 2007, 89-122). Key, then, to the Bond franchise's global ascendance was Bassey's stardom and dramatic vocal performance. While Bassey's singing of "Goldfinger" is often credited to Barry for choosing her for the role of theme song singer, the role she played has far outlived the initial run of the film. Her iconicity over several decades as a popular artist is due to the fact that her on and off-screen performance, while it features a powerful voice, emotive face, and extravagant costuming, is also inextricable from the Bond franchise. Her most successful songs as a recording artist have been the ones for Bond soundtracks: "Goldfinger," 
"Diamonds Are Forever," and "Moonraker." Furthermore, she is the only artist to have performed more than one theme song.

\section{The Voice of Bond}

Before Bassey, Bond's sound was most associated with the musical theme composed by John Barry and Monty Norman that features in every film score of the series, beginning with Dr. No (UK: Terence Young, 1962). In The Music ofJames Bond, Jon Burlingame $(2012,2)$ notes:

The Bond sound was an accident, really: Monty Norman had a tune in mind that John Barry arranged into something that would suit a dangerous spy and also work as a pop instrumental record with both rock and jazz elements (highly unusual in 1962). Editor Peter Hunt liked it so much he kept repeating the piece throughout that first film. The success of the "James Bond Theme" both dramatically and commercially, led to future Bond movie assignments for Barry-11 in all.

This musical theme provides a strong sense of continuity and definition to the series and more largely to the espionage genre in film and television. Even the more recent Bond film scores by Thomas Newman and David Arnold reflect the "Theme." Arnold says, "John Barry was one of the few people that created a genre of film music: He uniquely, single-handedly, created the spy genre" (Burlingame 2012, 2). While Barry's music production is significant, Bassey's vocal performance must also be understood as being equally integral to sonically defining the series and genre.

Following the Bondmania of Goldfinger, Bassey was also considered for the theme song to the next Bond film, Thunderball (UK: Terence Young, 1965). Both she and Dionne Warwick were asked to record a version of "Mr. Kiss Kiss Bang Bang," "a nickname by which Bond was known in Japan," and the possible new title for the film (Smith 1998, 111). However, the title reverted back to Thunderball with the theme song having the same name. Rather than having Bassey's version of "Mr. Kiss Kiss Bang Bang” for the closing credits, producers Harry Saltzman and Albert Broccoli, "decided to leave Bassey's number out of the film completely" as they followed the same musical template of Goldfinger (Smith 1998, 111). Though another Welsh singer, Tom Jones, was eventually chosen, the influence of Bassey's powerful vibrato can be heard as Jones crescendos to reach the last high note and hold it for a full nine seconds (Burlingame 2012, 53). 
Similarly, Lulu's “The Man with the Golden Gun" (1974) and Tina Turner's "Goldeneye" (1995) recapture the bizarre dramatics of "Goldfinger." Nancy Sinatra's "You Only Live Twice" (1967) and Sam Smith's "Writing's on the Wall" (2015) are more like the wistful and oddly phrased laments of longing heard in "Diamonds Are Forever" and "Moonraker." While Gladys Knight's "Licence to Kill" (1989) directly cites the opening brass musical motif of "Goldfinger," it pushes Bassey's powerful timbre towards an R\&B style. Knight's vocal flourishes recall a needing and pleading for love found in gospel music, with which she was more immediately familiar than Bassey. Significantly, even when the theme song is sung by a man such as Jones or Smith, there is a "feminine quality" to these songs, which, as Anna G. Piotrowska $(2015,172)$ argues, "was introduced as an aural compensation for the visual portrayal of women on screen as well as a musical counterpoint to the male themes (e.g. Bond, oo7, villain)." However, as these "feminine" themes play and revise Bassey's version of "Goldfinger," they demonstrate how not only song composition but also her specific vocal performance has left an enduring impression on the series.

Despite this claim for authorship, I am hesitant to label her voice as always resistant to the sexist visuals of the various films. Jeff Smith (1998, 122) does an extensive reading of Goldfinger's opening, noting the lusty power of Bassey's voice. “The song appears to address an unidentified female subject, one who we might assume is any or all of the film's major women characters." She brings forth a female presence in a title sequence where women's bodies are static and rendered as screens. Catherine Haworth $(2015,162)$ notes, "she brings her own identifiable stardom to bear on the sequence and thereby adds weight and emphasis to the title song's tale of female experience, solidarity, and warning." While the song is explicitly about the villain Goldfinger (like other Bond theme songs, such as "Thunderball"), the lyrics could easily be construed as to why Bond is not a safe sexual partner. After all, women characters in Bond films often end up killed post-coitus.

Given this treatment of many Bond Girls, it is easy to hear Bassey's song as one of resistance. Yet, while the lyrics warn us of about the treachery of men, the powerful sensuality of her siren-like voice also lures us further into the narrative. While the gold-painted women's bodies may be rendered as screens to project the film on, the camera's caressing pans over the lines of the model's legs are designed to titillate the viewer. Here, then, Bassey's voice is not simply a contestation and alarm, but rather a complicated seduction. While her words warn pretty girls about dangerous men, her voice is what carries us into the narrative. 


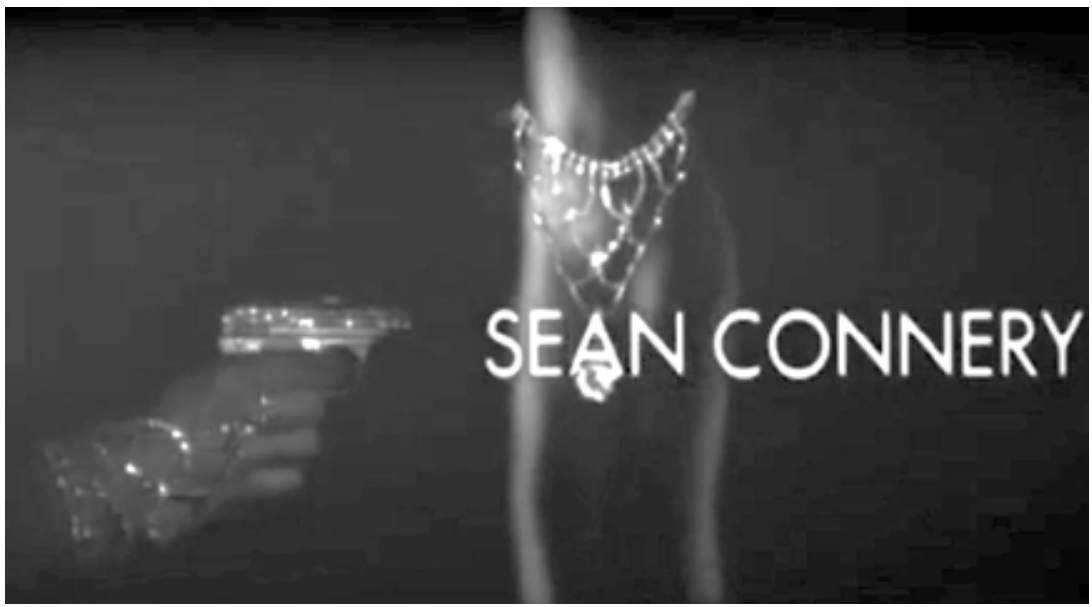

3. Title Credits from Diamonds Are Forever (UK: Guy Hamilton, 1971). Copyright of Eon Productions, United Kingdom; and Danjaq, LLC, United States of America.

A similar contradiction occurs in the opening credits for Diamonds are Forever (UK: Guy Hamilton, 1971). An extreme close-up of a white cat's eye is used as a graphic match to wipe to a diamond against a black background as two black silhouetted palms in a praying position appear over the diamond and slowly part. The diamond descends into the background and diminishes in size as it appears to almost be held by the two palms, but then a lightskinned hand with manicured red nails and a diamond costume jewelry cuff emerges from the upper left corner of the screen to pick up the diamond between their thumb and index finger. We then cut to two naked women's bodies silhouetted in black with accents of reddish amber light. The body closer to us is on the left and we only see her back and what appears to be a diamond belt slung on her waist. She turns her right arm into the frame as the camera appears to dolly slightly right and zoom in. Her right hand and wrist has an ornate diamond bracelet-cuff-ring combination and holds a shiny platinum gun. As we get closer to the frontally nude women in the background of the frame, she appears to put her hands up as the title "Sean Connery" appears on the screen cutting across her knees. We can see vague outlines of the curves of her breasts and shadows between her thighs. She also appears to be wearing an ornate diamond belt across her waist, in which a lattice-work of diamonds adorns her flat lower torso with a low hanging diamond pendant, appearing as if it was hanging right between the lips of her labia. As we zoom further into this pendant, the suggestion of a crotch is further obscured as parted legs just become shadowy red spots amidst a black background. The elaborate diamond waist belt now looks 
more like a diamond necklace as the film's title appears in blue font right above the pendant.

Sonically, all we have heard is a minor key musical motif in a more classical film score orchestration. The only slight difference is the tambourine-heavy mix, which "gives the cue (and the theme itself) a modern, Motown-ish sound" (Smith 1998, 119). However, this more modern and current musical style is then met not with the airy falsetto of Diana Ross or the gospelinflected voice of Martha Reeves, but rather the full-throated and rounded tones of Bassey in a lower register intimating, "Diamonds are forever." Though the song is a lament about men and love, it has a brazen sexuality in its performance. While Bassey's initial tone in this song is more slyly seductive than powerful, she still eventually crescendos to her clear and resounding vibrato. Like the credits of Goldfinger, visuals and sound are brought together to titillate and seduce. While the plot here is not directly projected on women's bodies, the credits collapse the Bond film into its key components: glamour, intrigue, violence, women's bodies and the double entendres they produce - we see two kinds of pussies within the first 30 seconds.

The lyrics also add to the sensuality, with lines like "touch it, stroke it, and undress it." John Barry's songwriting collaborator, Don Black, explained, "Seediness is what we wanted" (Burlingame 2012, 95). Barry advised Black to "write it as though she's thinking about a penis" (95). By substituting the word diamond with penis, the tune has a very conflicted meaning about the importance of sex, love, men, and jewelry. Despite the writer's intentionality, however, Bassey's performance, especially as it has reverberated throughout her career, carries multiple interpretations. Her voice relishes the pronunciation of "undress it." In performances, she coyly looks at the audience to suggest the original meaning of the lyrics.

On "The Christmas Show" episode of The Morecambe \& Wise Show (BBC, December 25, 1971), in a slinky, full-length sequin gown with crystal straps and cutouts on both sides of her torso, Bassey delivers the song with the same polish of the soundtrack recording. She knowingly smirks at the camera as she sings "undress it" and then glances at her hand as she flirtatiously unfurls and presents her fingers, which all have a garish diamond ring on them. She is seductive in her visual presentation and vocal performance, but also quite literal. While the lyrics suggest a forlorn attitude towards love and time, it is interpreted in its most concrete sense and performed with humor. "This literal realization of the song's words," Vogel (1998, 99, 95) reminds us, is "in line with [the] nightclub revue's dominant aesthetic," meaning Bassey not only learned torch singing in the black musical revue 
but also a way to both literalize and poke fun at songs written by white men to be most often performed by black women for white audiences. ${ }^{1}$

Specifically, in this performance, the literalization of the lyrics occurs not by way of massive sets and props but rather via flashy costuming. Her jewel-encrusted gown carries with it, as Adele Patrick $(2005,131)$ notes, "a Hollywood-inspired glamorous aura using costumes freighted with signification and pleasure for female audiences." Similarly, Bassey playfully gesturing to her bevy of large diamonds rings is in strong contrast with the solitaire diamonds dangling from a woman's labia, which we see in the title sequence to Diamonds Are Forever. While Bassey is extremely hetero and femme in her presentation of sexuality, she is also excessive in her performance, giving space for feminine and queer audiences and pleasures. Like the svelte Bond Girls, Bassey is also fit but fashions her sexiness in garish costume jewelry and low-cut embellished gowns as opposed to bikinis. This meticulously constructed diva-excessiveness has contributed to her simultaneous endurance as both a national treasure and a gay camp icon - though her questionable racial and gender politics perhaps make her less queer-friendly ${ }^{2}$ (Guilbert 2018, 26-29). By listening to the music in the credit sequences and by looking at subsequent performances by Bassey, it becomes clear, then, that camp and excess are integral to Bond. This is not to say that camp in Bond only occurs because of Bassey, but it demonstrates how camp is tied up in the endurance of Bond as a cultural text.

This coupling of camp and the Bond franchise as synthesized in Bassey's voice becomes most prominent in the various knockoffs and parodies of Bond. Following the Bondmania of Goldfinger, Bassey sang the titular theme song for The Liquidator (UK: Jack Cardiff, 1965), a spy film with Rod Taylor as a multi-talented lover and man of action. While the song is more upbeat than "Goldfinger" it is equally dastardly and sung with Bassey's usual brassiness. Even in a less direct Bond parody or knockoff, a Bassey-inspired theme song becomes key to the spy film genre. Spy (USA: Paul Feig, 2015), starring Melissa McCarthy as the unlikely intelligence operative who is now in the field, provides a delightful mix of action, comedy, and gender critique that is very-much its own CIA-based espionage story. In keeping with the genre, however, its opening credit sequence features a Shirley Bassey-inspired

1 "Most crucially in this tradition, Billie Holiday sonically inscribed Tin Pan Alley love songs with a blues modernism that, through her vocal performance, rewrote their commodifiable narratives of gender, sex, and romance" (Vogel 2008, 95; Davis 1998, 161-80; Denning 1996, 338-48). 2 "In an interview with the Daily Mail in 2015, Bassey expressed horrendous anti-feminist sentiments: she believes women should not be pilots, firefighters, policewomen or soldiers, among other appalling ideas" (Guilbert 2018, 29; Shakespeare 2015). 
theme song, "Who Can You Trust" (2015) by Ivy Levan, which can be heard over an animated gunplay sequence.

Even in the absence of a film, Bond is always invoked through Bassey. In the January 7, 2001 episode of Rock Profile (UK Play, 1999-2000; BBC Two, 2000-2001; Funny or Die UK, 2009), a spoof of music chat shows, comedians Matt Lucas and David Walliams play the Welsh singers Shirley Bassey and Tom Jones, respectively, as they argue about who has had more success. After lustily hitting on the presenter (Jamie Theakston), Lucas as Shirley proclaims in a hilariously posh accent "Yes, I am the voice of Bond, darling," as she flourishes a hand into the air for added emphasis and proceeds to sing the titles "Diamonds Are Forever," "Goldfinger," and "Moonraker" - all to the tune of "Diamonds Are Forever." Poking fun at Bassey's diva-excessiveness, Lucas' Shirley is in a gold-beaded gown and white taffeta boa and reclines on a chaise behind Tom, who is seated on the ground. She then proceeds to sing the remaining Bond theme songs to the melody of "Diamonds Are Forever," stressing that every Bond-singer from Tina Turner to Shirley Manson to Gladys Knight to Paul McCartney “doesn't have the range.” The joke is that, as far as Lucas's Bassey is concerned, there is only one person in the world who could be the "voice of Bond," and that is not any man, but rather her.

\section{Having the Range}

While Bassey's theatricality might lend itself to parodies of both her and the Bond franchise, her voice also provides a central nodal point for the series to return to as its more recent entries, Skyfall (UK/USA: Sam Mendes, 2012) and Spectre (UK/USA/Austria/Mexico/Italy/Morocco: Sam Mendes, 2015), strive to keep the franchise fresh, sexy, and relevant while still faithful to its 196os imaginary of international glamour. In particular, "Skyfall" (2012), performed by Adele, is deeply indebted to Bassey's style. The way Adele elaborates and nostalgically waxes on Bassey's vocal performance demonstrates some of the racial and gendered tensions found in Bassey's star text. With a detached delivery somewhere in between Shirley Bassey and Dusty Springfield, Adele's contralto swoons. While she shows off her range, it is clear that her voice does not have the same throaty sensuality as Bassey — a fact made very apparent after the two performed at the 2013 Academy Awards.

Yet, while both Adele and Bassey are remarkably talented singers, I wonder what is lost in Adele's detached earnestness as opposed to the sexuality that is loudly displayed in Bassey's performances. What happens 
when nostalgia is divorced from excess and becomes more sincere? Adele's blue-eyed soul performance is controlled and elegant. Her bouffant hair and winged black eyeliner pay tribute to Dusty Springfield and 196os girl group singers by way of Amy Winehouse. In writing about this borrowing of ' 60 s style, Daphne A. Brooks $(2010,39)$ notes, "Winehouse traffics in the sound as well as the look of 1960 os girl group pioneers such as the Supremes and the Ronettes, as well as the vocal stylings of $\mathrm{R} \& \mathrm{~B}$ and jazz greats—from Dinah Washington and Sarah Vaughan to across-the-pond Afro-Welsh pop legend Dame Shirley Bassey." The range of black women's artistry that these white British women singers draw from encompasses several genres and decades. Adele further effaces these citations as Winehouse's "bouffant, satin gowns, vintage cocktail dresses and little black gloves clearly reference the styles of everyone from Lena Horne to the Shirelles" (Brooks 2010, 39-40). Adele, in simple but elegant dresses, in no way indulges the costuming excesses of Winehouse and Bassey. Yet, in comparing the two and calling attention to Adele's cultural appropriations, I am cautious of equating blackness with authenticity, sexuality, emotional excess, and the body. To do so would be to follow the well-worn tradition of using the essentialisms derived from minstrelsy to measure the "authenticity" of black performers. Rather, a comparison of both performances demonstrates Bassey's ability to take these racial essentialisms and play with them and manipulate them.

Although Bassey's "Goldfinger" set the standard for all subsequent Bond theme songs — as it stands in as iconic for the heyday of the franchise- - her musical style was out of step for her time. In examining both vocal styles and recording charts, Vincent Stephens $(2010,39)$ classifies Bassey along with Astrud Gilberto, Robert Goulet and Barbra Streisand as early 196os rock era crooners that would appear on the adult-oriented easy listening charts as well as the general pop music charts of the time. Addressing more of an adult contemporary or easy-listening market, Bassey's work in the '5os and 6os was not like the pop girl group sounds (Shirelles, Supremes, Ronettes) or even the rock'n roll or soul music of women like Tina Turner and Dusty Springfield. Adrian Daub and Charles Kronengold $(2015,96)$ frame Bassey's successful Bond theme songs as a "profound shift in mainstream pop: middle-of-the-road, easy listening, and adult contemporary had drifted inexorably toward black music." They (96) elaborate:

Soulful singing, grooving rhythm sections, and jazzy harmonies were now part of pop's lingua franca. This blackening of grown-up pop meant that Bassey, a showbizzy Anglo-Nigerian Welsh belter who was never associated with the soul-music tradition, fronting a bunch of British 
studio hacks, could count as a soulful—yes, "black" — singer asserting African American musical authority over what was a very White film.

While Daub and Kronengold critique Bassey's version of "Diamonds Are Forever" for its "Tin Pan Alley construction," they $(2015,97)$ commend her for pushing further towards soul, "bending notes, varying her vibrato, playing with the beat, getting a bit breathy, even adding a little grit." They (100) frame this effort of her singing "as if the song, the film, and early 70 culture at large need her to be black. But somehow the film doesn't hear her." What is striking in their assessment is the equation of blackness with not only Americanness but also soul music and a particular 1970s black liberation politics. Rather than seeing "black" as something fixed to a particular decade, nation, or musical style, however, listening to Bassey as the "showbizzy Anglo-Nigerian Welsh belter" reveals a different constellation of black music and cultural politics.

As Adele owes much of her success to reworking cultural nostalgia for singers like Springfield, Bassey capitalized on nostalgia for the blues, jazz, and cabaret singers of the 1920 s and ' 30 - a skill she honed in her beginnings in the black musical revue and cabaret. In describing black women's musical performance in the ' 20 s and ' 30 s, Hazel V. Carby $(1998,474)$ notes that it "articulates a cultural and political struggle over sexual relations: a struggle that is directed against the objectification of female sexuality within a patriarchal order but which also tries to reclaim women's bodies as the sexual and sensuous subjects of women's song." Carby (476) details how the songs of Clara Smith, Bessie Smith, and Ida Cox were about the frustrations of heterosexual relationships but sounded a gendered agency and autonomy. "The sound of the train whistle, a mournful signal of imminent desertion and future loneliness, was reclaimed as a sign that women too were on the move." This being "on the move" not only brought new opportunities for autonomy and work but also lent itself to indulging in fashion and sex. As Carby (481) elucidates,

They had broken out of the boundaries of the home and taken their sensuality and sexuality out of the private into the public sphere [...]. Their physical presence was a crucial aspect of their power; the visual display of spangled dresses, of furs, of gold teeth, of diamonds, of all the sumptuous and desirable aspects of their body reclaimed female sexuality from being an objectification of male desire to a representation of female desire. 
Bassey's performance, though of a different period, is conversant with a similar contradiction and struggle over sexual relations and self-involved adornment. As she imparts these politics into her vocal laments heard in the Bond theme songs, she nuances the largely patriarchal visual relations constructed in these films.

Hearing Bassey within a Black Atlantic route of black cultural production, then, complicates how we consider authorship. While she certainly defines the sound of Bond as much as John Barry, it is reductive to simply claim that she too-to borrow from David Arnold - "uniquely, single-handedly, created the spy genre" (Burlingame 2012, 2). Though her voice, like other black women's voices - as Griffin reminds us - is often called upon to represent a collective of texts and peoples - be it Bond, Wales, or Great Britain - the power performed by that voice does not necessarily generate a closed unified body. Rather, the voice carries with it the complications of migration, displacement, racial mimicries, and vexed sexual relations. To challenge Daub and Kronengold's assessment of Bassey's "Diamonds Are Forever" as insufficiently soul or as "black" as it could be for the 1970s, our understanding of Bassey must account not for what "showbizzy" fails to live up to but for what it redirects our ear toward; be it different cities and sites - the cabarets of London, New York, and Las Vegas as opposed to the music studios and clubs of Detroit and Philadelphia — or different periods and genres.

Bassey's "Diamonds Are Forever" is not impressive in spite of its "Tin Pan Alley construction;" rather, it is precisely this kind of pop song that Bassey can inflect with her black music revue-honed sense of humor and seduction. In wanting to isolate all the tracks that come together to make the sound of Amy Winehouse, Brooks (2010, 48-49) implores that "the exigencies of excavating this history are crucial, especially if one considers how rarely black women are scripted as racial masqueraders of any sort," and "the extent to which popular music culture constructs and depends on black women as static nurturers who, as Farah Griffin [2004, 103-4] demonstrates, are called upon so often to 'sin[g] rather than spea[k],' to 'heal' and give 'life and love' to 'the majority culture." In a similar spirit, this chapter has elaborated on Shirley Bassey's vocal citations, mimicries, and innovations as she moves between genres, audiences, nations, and decades of popular music, both as a black woman and as a "showbizzy" singer. To challenge the claim that "somehow the film doesn't hear her," Brooks' invocation of Griffin compels us to ask, what is it that we expect to hear when we listen to black women? At an even lower frequency, the question reverberates: Are we even fully listening? Perhaps, then, Bassey's most important contribution as an author 
comes not from her enduring influence on the James Bond film series, but rather from the ways she urges us to fully listen to Bond and comprehend the transnational circulations of black musical performance enlisted in an imperfect project of both empire and patriarchy.

\section{Works Cited}

Brooks, Daphne A. 2010. "This Voice Which Is Not One:" Amy Winehouse Sings the Ballad of Sonic Blue(s)face Culture." Women \& Performance: A Journal of Feminist Theory 20, no. 1 (March): 37-60.

Burlingame, Jon. 2012. The Music of James Bond. Oxford: Oxford University Press.

Cameron, Ross. 1997. "The Most Colourful Extravaganza in the World': Images of Tiger Bay, 1845-1970." Patterns of Prejudice 31, no. 2 (Summer): 59-90.

Carby, Hazel V. 1998. "It Jus Be's Dat Way Sometime: The Sexual Politics of Women's Blues." In The Jazz Cadence of American Culture, edited by Robert G. O'Meally, 469-82. New York: Columbia University Press.

Chapman, James. 2007. Licence to Thrill: A Cultural History of the James Bond Films, Revised Edition. London: I. B. Tauris.

Collins, Joe. 1986. A Touch of Collins. London: Columbus Books.

Daub, Adrian, and Charles Kronengold. 2015. The James Bond Songs: Pop Anthems of Late Capitalism. Oxford: Oxford University Press.

Davis, Angela Y. 1998. Blues Legacies and Black Feminism: Gertrude "Ma" Rainey, Bessie Smith, and Billie Holliday. New York: Vintage.

Denning, Michael. 1996. The Cultural Front: The Laboring of American Culture in the Twentieth Century. New York: Verso.

Doffman, Mark. 2014. 'What You Doin' Here?:' The Sounds, Sensibilities, and Belonging(s) of Black British Jazz Musicians." In Black British Jazz: Routes, Ownership and Performance, edited by Jason Toynbee, Catherine Tackley, and Mark Doffman, 111-32. Burlington: Ashgate.

Gilroy, Paul. 1993. The Black Atlantic: Modernity and Double Consciousness. Cambridge: Harvard University Press.

Green, Jeffrey P. 1983. "In Dahomey in London in 1903." The Black Perspective In Music 11, no. 1 (Spring): 23-40.

Griffin, Farah Jasmine. 2004. “When Malindy Sings: A Meditation on Black Women's Vocality." In Uptown Conversation: The New Jazz Studies, edited by Robert G. O'Meally, Brent Hayes Edwards, and Farah Jasmine Griffin, 102-25. New York: Columbia University Press.

Guilbert, Georges-Claude. 2018. Gay Icons: The (Mostly) Female Entertainers Gay Men Love. Jefferson: McFarland. 
Hattenstone, Simon. 2009. "Interview: Bassey is Back." The Guardian, October 23, 2009, https://www.theguardian.com/music/2009/oct/24/shirley-basseyinterview.

Haworth, Catherine. 2015. "Pussy Galore: Women and Music in Goldfinger." In For His Eyes Only: The Women of James Bond, edited by Lisa Funnell, 157-66. New York: Wallflower Press.

Jennings, Ros. 2012. "It's All Just a Little Bit of History Repeating: Pop Stars, Audiences, Performance and Ageing-Exploring the Performance Strategies of Shirley Bassey and Petula Clark." In “Rock On:” Women, Ageing and Popular Music, edited by Ros Jennings and Abigail Gardner, 35-51. Burlington: Ashgate.

Little, Kevin. 1948. Negroes in Britain: A Study of Racial Relations in English Society. London: Routledge.

Patrick, Adele. 2005. “Queening It: Women's Taste for Jewelry Excesses in Post-War Britain." Women \& Performance: A Journal of Feminist Theory 15 , no. 2 (Summer): 119-46.

Piotrowska, Anna G. 2015. "Female Voice and the Bond Films." In For His Eyes Only: The Women ofJames Bond, edited by Lisa Funnell, 167-75. New York: Wallflower Press.

“Rugby World Cup Kicks Off With Roof-Raising Hymns.” 1999. The Guardian, October 1, 1999, https://www.theguardian.com/rugbycup/Story/o,,202590,0o.html.

Rye, Howard. 2006. "Showgirls and Stars: Black-Cast Revues and Female Performers in Britain, 1903-1939." Popular Music History 1, no. 2 (Summer): 167-88.

Shakespeare, Sebastian. 2015. "Dame Shirley Bassey Says Women Should Not Be Pilots or Police Officers and Should 'Stop Trying To Be Cleverer Than Men." The Daily Mail, November 19, 2015, https:/www.dailymail.co.uk/femail/article-3324822/Dame-Shirley-Bassey-says-women-not-pilots-police-officers.html.

"Shirley Bassey." 1963. Ebony, March, 1963.

Sinclair, Neil M. C. 2003. Endangered Tiger: A Community Under Threat. Cardiff: Butetown History and Arts Center.

Smith, Jeff. 1998. The Sounds of Commerce: Marketing Popular Film Music. New York: Columbia University Press.

Stephens, Vincent. 2008. "Crooning on the Fault Lines: Theorizing Jazz and Pop Vocal Singing Discourse in the Rock Era, 1955-1978." American Music 26, no. 2 (Summer): 156-95.

Tackley, Catherine. 2014. "Tiger Bay and the Roots/Routes of Black British Jazz." In Black British Jazz: Routes, Ownership and Performance, edited by Jason Toynbee, Catherine Tackley, and Mark Doffman, 43-62. Burlington: Ashgate.

Verreos, Nick. 2012. "ROYAL COUTURE..... Diamond Jubilee: Queen Elizabeth, Kylie, Grace Jones, Dame Shirley Bassey." Nick Verreos: Where Style Happens, June 2012, http://nickverrreos.blogspot.com/2012/o6/diamond-jubilee-concert-fashion.html. Vogel, Shane. 2008. “Lena Horne's Impersona.” Camera Obscura 23, no. 1 (Spring): 10-45. 
Vogel, Shane. 2008. “Performing 'Stormy Weather:' Ethel Waters, Lena Horne, and Katherine Dunham." South Central Review 25, no. 1 (Spring): 93-113.

Williams, John L. 2010. Miss Shirley Bassey. London: Quercus.

Wilson, John M. 1985. “UN`S 'REGISTER' OF PERFORMERS RAISES BLACKLIST SPECTRE IN S. AFRICA BOYCOTT." Chicago Tribune, May 19, 1985, https://www. chicagotribune.com/news/ct-xpm-1985-05-19-8501310597-story.html.

\section{About the Author}

Meenasarani Linde Murugan is an Assistant Professor in the Department of Communication and Media Studies at Fordham University. Her research focuses on television, popular music and theories of race and visuality, with special attention to fashion and diaspora. She has written on contemporary Asian diasporic pop culture aesthetics and politics for the Los Angeles Review of Books and The Platform. Her book, Gender and Race in Postwar Variety Television: Colorful Performance, is under contract at Routledge. 


\title{
14. Skyfall and Global Casino Culture
}

\author{
Joyce Goggin
}

\begin{abstract}
This chapter analyzes the signifying potential of gambling and casino culture as a seminal feature of James Bond-ness and the o07-universe. It argues that gambling and casinos, both of which are updated with every new outing of James Bond, have important cultural, political and economic ramifications. In particular, the chapter asks how and what casino gambling signifies as it is updated in Skyfall (2012), in terms of the film's mise-en-scène as well as its geopolitical configuration as a colonizing industry in a global economy that is increasingly dependent on various forms of gambling. Finally, the chapter connects various aspects of what has been referred to as "cinematic revisionism" to the politics and economics of neoliberalization, 007 , and global casino culture.
\end{abstract}

Keywords: Skyfall, gambling, casinos, globalization, finance, Macau

The notion that a particular logic and dynamic reside at the heart of the 007 franchise, lending it durability as a function of its capacity to project hipness, newness and traditional "Britishness" all at the same time, has become something of a truism in popular and scholarly writing on Bond. For example, in The Man Who Saved Britain, commercial author Simon Winder has outlined the many ways in which Bond has been rebooted to serve the economic and political aims of various parties involved in the production of the series over time. Similarly, Charlie Higson $(2012,37)$, on the fiftieth anniversary of the release of Dr. No (UK: Terence Young, 1962) and the twenty-third outing of Bond in Skyfall (UK/USA: Sam Mendes, 2012), writes that "[e]ach new incarnation of Bond (very loosely) fits a decade and speaks to each new generation" so that it is "fascinating to chart how each Bond cleverly manages to personify an era and even define it."

Verheul, J. (ed.), The Cultural Life ofJames Bond: Specters of oo7. Amsterdam: Amsterdam University Press, 2020 DOI 10.5117/9789462982185_CH14 
In scholarly work on 007, much has been made of the British spy's ability to trend-set, and to inform the periods in which the films were produced, hence Tony Bennett and Janet Woollacott's $(1987,13)$ argument that James Bond functions as a mobile "sign of the times," who is "capable of taking up and articulating quite different and even contradictory cultural and ideological values," often rearticulating these values in such a way as to enunciate new, or at least revamped versions thereof, that also resonate with tradition. Likewise, James Chapman $(2005,129)$ offers a detailed compendium of numerous "moments of Bond," following how each installment is updated stylistically and ideologically so as to appeal to viewers over time, from the Cold War, through the era of "swinging Britain", to the threat of cyberterrorism. In a related vein, Craig N. Owens $(2005,107-8,110)$ explains how the franchise and the character manage to sustain the "nasty habit of surviving" by serving as a "kind of ontological blank" whose name-007-suggests "a blank at the center of his identity" so that his "mixable, dilutible essencelessness seems to confirm the sense that he [...] is a real cipher." And Michael Denning $(2009,58)$ has argued that "each set of attributes" and characteristics that we might ascribe to this essence-less cipher comprise a "figure who has been accented in a number of ways," so that Bond is - and is not - the collection of accoutrements by which we know him, such as the Aston Martin, martinis, sophisticated gadgetry, exotic destinations and so on.

In what follows, I subscribe to the notion that the 007-concept serves as a base that may be updated and reconfigured handily and often in order to keep up with differing tastes and viewer demands. In doing so, I will focus my argument on casino culture, which holds a prominent place in the Bond universe, while simultaneously revealing how gaming and the greater economy work in tandem as represented in the myriad of James Bond casino scenes, beginning with the very first one in Ian Fleming's Casino Royale (1953). My specific aim is to unpack the casino scene in Skyfall and, to a much lesser extent, the casino scene in Man with a Golden Gun (UK: Guy Hamilton, 1974) in order to discuss what these scenes and their settings tell us about various styles of economic management, regulation or the lack thereof, and the underlying political systems which enabled them when the films were made.

\section{Backing Up to Move Forward}

Given the body of popular and academic work that focuses on the adaptability and perpetual novelty of Bond within the purview of tradition, I want 
to discuss $S k y f a l l$, a film that likewise situates itself in relation to tradition as a means of innovating, seemingly in reverse of many of the previous Bond films. In this regard it is notable that $S k y f a l l$ belongs to a prequel quartet that includes Casino Royale (UK/Czech Republic/USA/Germany/Bahamas: Martin Campbell, 2006), Quantum of Solace (UK/USA: Mark Forster, 2008), and Spectre (UK/USA/Austria/Mexico/Italy/Morocco: Sam Mendes, 2015), which quartet is marked by a number of features also common to other film franchises to which the term "revisionist" is frequently applied. Various authors have used the term "revisionist" to describe some of the more salient features of this predominantly American trend in cinema that began in the late 1990s, including a "gritty noirish" aesthetic and feel (Lindner 2009, 2); a "more realistic look" and a "certain 'retro' style" (Chapman 1999, 249), a "total disavowal of previous titles and events in the series" (Lindner 2009, 2); a repositioning of Bond "at the start of his career as if the events in previous films had not taken place" which often goes hand in hand with a reinvigoration of the series accomplished by going back to basics or "bare essentials" (Chapman 1999, 249); and Bond's new-found capacity to age which includes "fallibility and vulnerability" (Lindner 2009, 2).

In the Bond prequels, revisionism offers us insights into Bond's life as "the orphan child recalled in Casino Royale" and affords us an opportunity to sympathize with "the death of his lover that hardens [007's] sense of purpose as exhibited in Quantum of Solace" (Dodds 2014, 118). We also become acquainted with a damaged yet rehabilitated Bond in Skyfall, along with "a substitute father figure;" in this case the gamekeeper of the Scottish Bond mansion in Skyfall (Dodds 2014, 118). This dual temporal movement belongs to what Monika Gehlawat $(2010,131)$ has characterized as a "dialectic of old and new [...] crystalized in the latest Bond film[s] where Daniel Craig presumably represents 007 in his originary form and, in so doing, shows him at his most contemporary."

While revisionism fills in the backstory, it also adds a layer of grit and historical authenticity — at least where the Bond franchise is concerned — to a series that was threatening to lose its capacity to impress viewers with special effects. At the same time, revisionism is political as well as aesthetic because it rewrites the past through the addition of explanatory plot twists or visual and aesthetic clues which support a particular stamp of, in this case, conservative or retrogressive leaning. One such detail in Skyfall is M's old-fashioned china bulldog that Bond inherits at the close of the film, painted to look like the Union Jack and therefore, to signal Empire. As I will argue, however, there is more at stake in metonymically connecting an aging James Bond to signifiers of Britain's past such as J. M. W. Turner's 
portrait of a gunship being towed away to a scrapyard, captured in his The Fighting Temeraire (1839), which also makes an appearance in Skyfall. As Q meets Bond by the painting in the National Gallery, he quips that it always makes him "feel a little melancholy [to see] a grand old warship being ignominiously hauled away to scrap." The deeper significance of such details has been noticed by critics commenting on the politics of this film, who tend to concur that it is impossible to view Skyfall independently of markers of Empire and earlier times, and to not "think back to a time when one-quarter of the globe was painted imperial red" - in other words, it is well-neigh impossible to overlook the film's political implications and innuendos (Hasian 2014, 580).

In what follows, I will read the film's aesthetics, and its many nostalgic references to some purportedly more "authentic" past when the nation was "great," as political gestures aligned with, and on occasion perhaps critical of, what is known as neoliberalism. The term "neoliberal" was coined to describe the behavior and policies of "free marketers," and is often used as a blanket term to describe "free trade' or simply 'globalization" while it invariably involves "the elimination of the public sphere, total liberation for corporations and skeletal social spending” (Klein 2007, 14-15). Neoliberalism also entails a shift away from "government action in the form of fiscal policies (taxation) and federal expenditures, to monetary policies [whose] faith in the market [leads] to suspicions about too much government intervention," while "promoting policies to deregulate and privatize banking, financial services, information and network technology and telecommunications" (Taylor 2004, 6-7). Neoliberalism is also distinguished by the imposition of "flexible labor markets so as to get longer working hours and more intensive production" from workers, combined with "cut[ing] back on welfare expenditure" in favor of "marketization and privatization" (Harman 2009, 240). Given the above, neoliberal policies have consistently supported the destruction of much of what until recently still belonged to the present (the publicly funded maintenance of infrastructure, the social safety net, liberal politics, the freedom of certain kinds of speech), ostensibly as a means of returning to, or convincing citizens that it is possible to return to, an idealized, largely fictional, past era of greatness.

Skyfall's relationship to neoliberalism is apparent in numerous aspects of the film, such as its "distressed or decaying aesthetic," mirroring the results of neoliberal economic policies that erode government expenditure in the public sphere, or the film's depiction of the reigning, purportedly global, "world view" (Gehlawat 2010, 133). In describing what that world view might look like when depicted in a Bond film, Gehlawat $(2010,131)$ explains_-in 
the context of Casino Royale - that this world view is evidenced in an "unexpected but logical turn" to "the destructive character [that] stands in the front line of traditionalists." "Simply put," writes Gehlawat (2010, 134), Bond's "destructive character, in clearing away all that came before, represents the advent of a new tradition," wiping the slate clean in order to establish a new order and to erect new institutions that paradoxically claim a special, direct relationship to tradition and to the past.

Therefore, various aspects of $S k y f a l l$, such as the presentation of a fallible 007 who abandons high-tech weaponry at the close of the film in favor of good, old-fashioned booby-trapping of the Scottish manor where he grew up, may be at least tangentially linked to the politics of neoliberalism. While such vintage details, together with Bond's own avowal that he is an "old dog" who can't be taught "new tricks" may be charming and quaint, the devil is in the details. My goal is to connect the franchise's characteristic projection of newness and tradition, in combination with the tenets of revisionist cinema and various characteristics commonly associated with the economics and politics of neoliberalism, to the representation of gambling and casino culture in Skyfall — as indeed economics and politics have resonated through the Bond franchise as a whole.

\section{"Bond Has Always Been a Gambler"}

In one of his more poetic moments, Fleming (1953) wrote that 007 had never "been made to suffer by cards or by women," and that Bond equates luck with "women, to be softly wooed or brutally ravaged." Just as the Bond Girl has been a standard feature of the franchise since its beginnings, so too the spy's steely-eyed proficiency as a gambler has become a standard signifier of Bond-ness. Therefore, as Klaus Dodds $(2014,123)$ has noted, 007's "impeccable appearance in a dinner jacket" as he arrives on the casino floor in various instalments of the franchise are part and parcel of the "long-standing trademark of his gambling prowess" and masculinity. Hence, as the Vegas Master website (Vegasmaster) would have it, "[a]lthough you won't find Bond at a casino in every movie, casinos are commonly associated with the fictional secret agent, about as much as 'shaken, not stirred' dry martinis." From the first novel, named after a casino, to scenes set in Las Vegas in Diamonds are Forever (UK: Guy Hamilton, 1971), to the Macau casino featured in The Man with the Golden Gun (UK: Guy Hamilton, 1974), and the CGI Macau casino created for Skyfall, gambling, as a sign or mobile signifier, blends seamlessly into the ambient texture of fast cars, easy women, 
and shaken martinis. The question that remains to be answered, however, is how casinos and gambling signify at various moments in the history of Bond, and why this is politically and economically significant.

As I have argued elsewhere (Goggin and Glass 2010), one good example of how gambling signifies in the Bond universe may be read in the shift from Baccarat in Fleming's Casino Royale (1953) to Texas Hold'em in the 2006 film adaptation. The shift is indicative of various cultural and economic developments that were underway in 2006 , such as the global popularity of Texas Hold'em at the time of the film's release. Therefore, changing the game from Baccarat to Texas Hold'em in the film effectively adds a modern detail to the story for contemporary viewers who would have been familiar with Texas Hold'em from televised tournaments, the internet and countless other sources, whereas they might not have been familiar with the older game of Baccarat. One might also conjecture that the switch was intended as a subtle reference to the Texan-George W. Bush-who was occupying the White House in 2006 (Goggin and Glass 2010). In other words, Texas Hold'em was substituted in order to update the novel written in 1953 for audiences viewing its cinematic adaptation in 2006 - a game much more familiar to audiences than Baccarat.

To delve deeper into the seemingly minor gesture of changing a card game from novel to film adaptation and what it might mean, I want to unpack some of the signifiers of gambling culture in which the Bond franchise abounds, along with what these signifiers may communicate to viewers. Take, for example, a somewhat less obvious historical dimension of Poker of which viewers may not be consciously aware, but which comes to light if one considers the significance of updating Baccarat in Casino Royale by replacing it with Texas Hold'em in the 2006 film adaptation. One of the reasons that Poker is so often represented in film and television is connected to the game's popularity and tenaciousness across recent history, due in part to poker's peculiar adaptability. Poker owes its malleability to its origins as a nineteenth-century American hybrid of older European card games including Primero, Brag, Bouillotte, Poch, and Poque that entered the United States with various waves of immigrants (Parlett 1992, 208). Since its invention in the United States two centuries ago, Poker has morphed into numerous variants that reflect the historical juncture and the economic context in the nineteenth or twentieth century in which the variants developed, such as industrial capitalism or our current, largely finance-driven economic order. Hence, as Ole Bjerg (2011, 5, 222-3) has argued, "the evolution and succession of different forms of poker, Flat poker, Draw poker, Stud poker, and Texas Hold'Em, corresponds to the evolution and succession of different 
paradigms of capitalism," with the recent Texas variant closely resembling "postindustrial capitalism, where financial markets tend to constitute a reality of their own decoupled from the sphere of the productive economy" so that the game is now so closely aligned with the economy that playing it has become an "unimaginative", "mechanical" and "disciplined job." Likewise, the "no limit" feature of Texas Hold'Em is misleading because the continuance of both the game and the market must logically and finally depend on the availability of funds which, even though one can borrow, eventually run out.

More recently, Ed LiPuma (2017) has adopted Bjerg's argument to argue for the existence what he has called "poker nation," which describes life in the global speculative economy based on market models that got their start in Western Europe in the eighteenth century and were further developed in the United States. According to LiPuma (2017, 256), because the global economy is now reliant on the financial markets and therefore on speculation which has only been divorced from gambling by the introduction of various laws such as the Gambling Act of 1774 in England, "speculation has gone public and global." Citizens of the said poker nation constitute "a community whose self-defining act and determination is the risk driven wager" (257), whether the wager in question is taken voluntarily and at leisure on the green felt, or involuntarily in the form of one's pension which is now invested in the market whether one cares to speculate or not. The poker nation is ultimately a social imaginary that entails a "shared understanding and habitus" in which "gambling and speculation have come out of the back room and assumed [...] a visible and marketable place in the public sphere" (257), be it in the form of gambling narratives, 007 movies, gambling vacations taken in places like Las Vegas, or in popular events like poker tournaments.

The Bond novels and films that contain gambling scenes extend the card-playing logic - the level of risk involved, maximum bets as opposed to no limit, the amount of information concealed, revealed, or bluffed - from specific card games such as Baccarat, Poker, and Gin Rummy, and from how they signify in the worlds of Bond, to the larger scene of the casino. The card-playing logic to which I refer also informs economic and cultural developments such as the tremendous expansion of the gambling industries over the last several decades as a key driver in the global economy, in which the industries themselves also rely on a form of entertainment involving on risk taking and speculation. Indeed, the current post-industrial capitalist paradigm has given rise to an economy that relies heavily on all of those things that make Bond special: risk taking, speculation, entertainment, excitement, sensation, and travel. 
Hence, as in my previous example from Casino Royale, updating and Americanizing the novel's older European game of Baccarat by replacing it with Texas Hold'em in the film is symptomatic of a significant shift in gambling cultures that we see reflected in casino décors and the games on offer, as well as in the economic paradigms in which the films and novels are set. This shift is likewise visible in the ways in which casinos are depicted in other Bond films, from Las Vegas - a place that Fleming both ridiculed and venerated - in Diamonds are Forever (1956) and Thrilling Cities (1957), to the nineteenth-century style Casino Royale in Montenegro in Casino Royale, the Casino de Macau in The Man with the Golden Gun, and the stupendous CGI "Macau casino" in Skyfall with its retro-oriental theme.

\section{Casino Cultures}

As I have been arguing, 007 is a gambler and many if not most of the novels and films contain a significant gambling scene, while at the same time, the global economy has become increasingly financialized — that is, dependent on investment banking and the financial markets. In order to understand the full significance of Macau and its CGI representation in Skyfall in light of these observations, I will now turn to a discussion of the history of casino cultures as represented in the worlds of Bond.

Importantly, Fleming himself paid particular and prescient attention to the gambling industries which would come to form such an important part of the global economy, evidenced in everything from the spread of Las Vegas themed franchises, casinos on First Nations reservations, and televised poker tournaments, which in turn are all part of how the global speculative economy generates wealth. Fleming's prescience is particularly evident in Diamonds Are Forever, which contains a segment set in Las Vegas, a city which itself was updated over a period of time spanning the publication of Fleming's novel in 1956 to the film adaptation released in 1971. The relationship between 007 the gambler, the gambling scenes depicted in Fleming's narratives, and the role of gambling as an industry becomes clear in the novel as Bond enters the city via the emerging Strip, described by Fleming (1956) as a road that "was beginning to sprout gas stations and motels" in the desert, empty "except for occasional hoardings advertising the hotels." Along this textual trajectory, Bond's cab driver points to new casinos that were springing up - the Flamingo, the Sands, the Desert Inn, the Sahara, the Last Frontier and the Thunderbird - all of which would have seemed slightly dated by the time the film adaptation was released in 1971, when 
Fleming's description of the Strip as still being largely undeveloped would no longer have been accurate (Goggin 2010; 2015).

In the film adaptation of Diamonds Are Forever, as in the example of the card game in Casino Royale, the way in which this scene and the casino setting are updated represents more than an architectural face-lift or a switch to a trendier Vegas theme (Goggin 2011). While Fleming presents a bleak view of the desert capital and the largely deserted yet developing Strip, he also foresaw fiscal policies that loomed large, such as the Gambling Act of 1967 , and which began to take hold in the 1970s at about the same time that Sean Connery arrived in Vegas to begin filming Diamonds are Forever. By 1971, for example, the city had made considerable advances toward going straight and courting wider middle-class recognition, some of which is attributable to Howard Hughes, who took up residence in Las Vegas in 1967, and bought the Desert Inn, followed by the Sands, the Landmark, Castaways, the Silver Slipper, and the Frontier, thereby contributing significantly to the further development of the Strip (Rothman 2003, 20). More importantly, Hughes used his political influence to help push through the Corporate Gaming Act in 1967, making the gambling industry a legitimate public offering that could attract corporate investment and the kind of large scale financing not previously available through "mob" channels (Schwartz 2003, 133).

Ultimately the Gaming Act would lead to the repackaging of gambling as "gaming:" a government-endorsed, normalized and, to a certain extent, sanitized product, as reflected in Fleming's (1956) novel Diamonds Are Forever, in which Felix Leiter's asserts that the hoodlums are increasingly in charge and beginning to "run governments. State governments like Nevada." Therefore, while Fleming was writing the novel, Las Vegas was learning to frame gambling as an acceptable, government-approved, middle-class leisure activity, presented in a more diversified package that included family activities. While in the novel, catering to middle America is lamented (for example, Fleming has Bond sarcastically take note of a pool sign that reads, "LIFESAVER: BOBBY BILBO—POOL SCOURED DAILY BY HYDROJET"), Hollywood backers worked together with Vegas developers on the 1971 film adaptation of Fleming's novel to showcase Circus Circus, the first casino-hotel on the Strip to feature a family theme. Shot precisely to highlight every aspect of this casino on offer to family guests when it opened, the film is more like an adaptation of Circus Circus' own advertisements in the 1970s, which announced the "[W]ORLD'S LARGEST GAMING AND ENTERTAINMENT CENTER," with "GIRLS! GIRLS! GIRLS! ELAPHANTS, 14 BARS AND RESTAURANTS, SHOWS, CLOWNS, PRIZES GALORE [...] FOOD, ENTERTAINMENT, AND FUN FOR THE ENITRE FAMILY! SPECIAL NURSERY CENTER FOR YOUR CHILDREN" (Schwartz 2003, 135). 
More importantly however, by the 1970s, famous hotel chain Ramada Inns, Incorporated had entered the scene and purchased the Tropicana, declaring that this would mark a "new era for corporate growth" and that they were eager "to join the fast-growing casino gaming industry" and get a piece of what "appears to be [a] recession-resistant if not recession-proof" industry (Schwartz 2003, 163). The entry of a large hotel chain for the middle classes on the Strip took the management of Las Vegas' casino industry out of the hands of organized crime and transferred it to large, faceless corporations. Hence, Ramada Inns' faith in the power of gambling as a "recession-proof" economic driver and generator of wealth was accompanied by increased efforts to sanitize and expand Las Vegas and its gambling industries, which impacted radically on the geography of the city through the intense development of the Strip and its many themed casinos that mimic desert oases, medieval jousting rings, and pirate ships.

Beginning late in the 1980s, moreover, developer Steve Wynn began to dramatically reshape the economic landscape of Las Vegas again, this time by aggressively selling the city and its diversified leisure industries (theme parks, music venues, convention centers, shopping malls) on the market, and garnering the kind of capital investment needed to build mega resorts with thousands of rooms. This involved moving the industry overwhelmingly into the kind of elaborate mega theming whereby casinos are modelled as replicas of famous places such as Bellagio, New York, Paris, and Venice. These mega complexes, featured in films like Ocean's Eleven (USA: Steven Soderbergh, 2001), make Las Vegas a resort full of mini-destinations, as well as a convention and family entertainment center with multiple facilities such as shopping, swimming pools, various forms of gambling, as well as meeting rooms (Goggin 2010).

The corporatization of gambling - that is, the transfer of casino ownership from private developers like mafia boss Bugsy Siegel, who created The Flamingo on the Strip in 1946, to corporations made up of faceless investors and stockholders - as well as the view of gambling as a recession-proof industry are linked to what Susan Strange (1986) famously called "casino capitalism." This is to say that, where previously gambling was either illegal or sequestered, since the 1970s the casino industries are public offerings on the market. Or, put differently, whereas gambling was once prophylactically sealed and segregated from ostensibly legitimate economic practices, on river boats and in heterotopic centers like Reno and Vegas, it is now seen as an important economic driver around the globe. At the same time, the global market is driven by speculation, an activity that closely resembles gambling and is likewise based on risk taking. The two-gambling and 
speculation; the market and the gambling industries in which one may buy shares on the market - have become so fully merged that they are difficult to tell apart. Indeed, progressive deregulation of the financial markets in the twentieth century has made way for increasingly risky speculation, while neoliberalism has emerged as both a market force and "a cultural phenomenon expressing itself in casinopolitan culture as well as a particular political-economic constellation at work" on the global scene (Luke 2010, 397).

Hence, if Steve Wynn remarked in the 1990s that "Las Vegas exists because it is a perfect reflection of America [...], journalists and academics alike have debated whether the rest of the country is becoming more like Las Vegas [...] [given] its status as the capital of the post-industrial economy" (Dow Schüll 2012, 7). What is more, where the gambling industries dominate, the tendency is to level anything on the extant landscape in typically neoliberal fashion, and remake it by erecting simulacra of Vegas-style simulacra of famous cities such as the Venetian, which has now spawned a fake twin Venice in Macau. In the following section, therefore, I want to extend this line of reasoning and turn my attention to some of the consequences entailed in the export of 007 and Las Vegas-style gaming to Macau.

\section{Skyfall and Macau}

Choosing a CGI simulation of Macau as the setting for the Bond franchise's trademark casino scene in Skyfall, rather than "Little Macau" as Las Vegas is sometimes called, parallels the current industrial migration of gambling from an American center, with its most important themed environments mimicking world cities, to a new, global arena. But the significance of setting Skyfall's casino scene in a simulated Macau becomes all the more evident when one considers the fact that most of the action in the movie takes places in the United Kingdom, resulting in a Bond film remarkably lacking in exotic tourist destinations. In this regard, the CGI oriental gambling palace in Skyfall is called upon to do double-duty by standing out as the film's most memorable and exotic location on the one hand, and supporting the franchise's need to project newness on the other while, as part of one of the revisionist prequels, signaling tradition by calling up the past in the form of references to Empire and the nostalgic Orientalism of Macau.

As Jen Hui Bon Hoa $(2012,1)$ argues, Skyfall's depiction of an "aging hero [...] no longer equal to the physical rigors of his job" parallels the film's 
portrayal of "an empire after the last colony has been surrendered" through its representation of the casino among an array of other signifiers of the past, such as M's China Bulldog. Hence, whereas previously Bond often operated and asserted his British superiority in (former) colonies, by the time Skyfall was made, Hong Kong (where the film's villain Silva [Javier Bardem] is stationed prior to the action of the movie) had been returned to the People's Republic of China. As a consequence, writes Hoa (2012, 6), the film treats Hong Kong with "coy indirection," featuring "no Hong Kong natives or locations nor any mention of Hong Kong's special status as the last bastion of the British Empire." Rather, Bond's pursuit of Silva in Skyfall takes him around the "geographical fringes of Hong Kong, to three different cities [sic.] in East Asia: Shanghai, Macau, and an unnamed island," with each of these places appearing "almost as encryptions of Hong Kong" through hints and inside jokes (6). In other words, Hong Kong is implicitly present yet largely absent from Skyfall in comparison to Macau and Shanghai. According to Hoa, then, Skyfall's portrayal of Hong Kong by innuendo suggests that Britain's former colonial glory, as well as the kinds of portrayals of the colonies and colonial life that typify both Fleming's novels and the earlier film adaptations, is communicated in Skyfall by means of subtle suggestion and revisionism.

Like Hong Kong, Macau, a former Portuguese colony, was returned to the People's Republic of China in 1997. Yet, as Hoa $(2012,7)$ points out, once in Skyfall's "Macau," Bond finds himself in an environment saturated with signifiers of the island's colonial period, "beginning with the series of dragon-shaped arches through which he approaches the casino, [...] pet komodo dragons in a pit by the entrance, dragon sculptures inside the building, standard-issue cheongsams embroidered with dragons for the staff and, of course, a sinuous, chain-smoking femme fatale." In other words, the Macau casino in Skyfall has been retro-fitted to nostalgically recall old-time colonial casinos with the kinds of trappings that Hoa describes, now reproduced as mega-simulacra of a bye-gone era, ostensibly by the same Las-Vegas-based franchises that have established themselves in Macau and which are currently colonizing the much of the rest of the globe. The scenes that represent Macau also serve as an excellent example of how "Bond has successfully managed to acclimate to the changing social and political issues of the time [in which the film in question was being made, such as the Cold War in the earlier films and novels, or the shift from largely industrial capitalism to postindustrial capitalism] while being presented as the unattainable pinnacle of cool" (Wagner 2015, 51). This same strategy also "allows for Bond's oppressive colonizing and patriarchal behaviors to 
remain unchecked" (51) through, in this case, revisionism which involves the retro-feel and referencing of the casino.

The kinds of casinos that one would have encountered in Macau before the arrival of Vegas franchises following the colony's return to the People's Republic of China in 1997, such as the Casino Macau Palace, which housed only six baccarat tables, two blackjack tables, and two tables for sic-bo and dai-siu, were small scale affairs, the likes of which were featured in the 1974 film adaptation of The Man with the Golden Gun. In that earlier Bond film, the casino is filled with signifiers of the colonial period, such as the kind of dragon-festooned arches also featured in the CGI retro-themed Floating Dragon casino from Skyfall, while the street scenes in The Man with the Golden Gun are replete with rickshaws and impoverished children who attempt to sell 007 cheap souvenirs. The establishments we see in The Man with the Golden Gun, hosting largely local crowds, belonged to a "small traditional stretch of casinos" along the cargo wharves that held onto a "pretense of upper-crust European nightlife with white dinner jacket and formal dress" (Luke 2010, 397). These old casinos were run by "Macau monopoly holder Stanley Ho [who] turned over management of VIP gaming rooms in his casinos to Chinese triad operators who began violent campaigns to protect their turf, creating an increasingly lawless atmosphere" (Simpson 2012, 15). However, with the transfer of sovereignty from Portugal to the People's Republic in 1997, the Macau government decided to refashion its urban space around allegedly "larger, more wholesome Las Vegas-style operations" (Kurlantzick 2005, 286; Luke 2010, 399), as reflected in the digitally designed Floating Dragon created in the Pinewood Studios and featured in Skyfall.

The "real" Macau now boasts a number of mega complexes that replicate Las Vegas casinos such as The Rio, Wynn Vegas, The Riviera, The Sands, MGM, and The Flamingo, the importation of which signals deep structural, economic and cultural changes, such as the shift from being a colony of one country to another; entering the global economy; the restructuring of the island's economy to one predominantly based on gambling; a much-changed landscape full of neon-themed casino complexes; a major restructuring of the job market; and the necessity of a late-night work force.

Ironically, the processes of legitimizing and sanitizing the gambling industries, initiated by casino operators and state legislators in Las Vegas with the 1967 Gambling Act, has resulted in Vegas casinos being regarded as a quasi-policing mechanism. Hence, as Tim Simpson has written, by the twenty-first century, the Las Vegas gaming industries had become so legitimized that the Macau government awarded gaming concessions to 
Steve Wynn and Sheldon Adelson-Las Vegas kingpins, casino developers and operators-hoping that their investment would develop the economy and restore law and order. "Knowing that casino operators in Vegas were bound to follow the regulations of the Nevada Gaming Commission or risk losing their license in Nevada, Macau bet on the fact that the rule of law in the United States would work indirectly to police Macau" (Simpson 2012, 15). This applies to issues such as surveillance, security, and financing, and includes the Las Vegas rule that casinos must hold enough cash in reserve to cover every marker on the floor at any given time.

American casino industries inject soft forms of governance around issues concerning employment, business practices and surveillance into the local economy of countries where they set up shop, acting as regulatory industries and policing measures. This is no small feat if one takes into account Steve Wynn's ("Steve Wynn" 2016) own confession in a CNN interview that the kind of large-scale, industrial colonialization that he has undertaken in Macau has "political ramifications and political consequences" as "the leadership of Macau wrestles with all of the competitive forces at work." When coupled with Wynn's obsession with security and his work on radio frequency identity (RFID) chips, which help to identify counterfeit chips, rate players for bonuses that will keep them at the slots, and deter casino cheats, the implications are staggering if not yet fully realized.

Quite obviously, at least one peculiar irony arises here from the consideration that importing Las Vegas franchises amounts to importing US law. Like Bond, a secret agent who famously polices the globe, American gambling franchises have been brought into various global destinations with the surreptitious purpose of policing the local population and economy as outlined above. Unlike the older Macau casinos which I described previously, the casino in Skyfall retains something of a "glocal" oriental flavor yet it is still decidedly Americanized, which suggests that, just as various signifiers of Bond are known and mobilized around the globe, so too is the Western practice of industrializing gambling that dramatically transforms the cultures into which it is imported. At the same time, what was previously Macau has now been raised and refitted with casinos

1 One such consequence is the restructuring of the island's economy to operate through Las Vegas franchises which are famous for negative externalities such as gambling addiction, public drunkenness and rowdy behavior and violence, as well as indolence caused by this negative cluster of outcomes in the local population. As yet, there is little or no work available on the Americanization of Macau's local cultures and Wynn is notably vague in the interview about whatever "political ramifications and political consequences" there are now or may be in the future. See "Steve Wynn: A true showman." 2016. CNN Talk Asia. 
with names like "The Sands" that recall old-fashioned establishments from the "Rat-Pack" hay days of Las Vegas, thus rehearsing the logic of neoliberalism that erases the past in order to reinstate some odd, newlyminted form of tradition. But given that, in this case, the tradition being referenced comes from Las Vegas, the kind of casinopolism taking hold in Macau is more aptly described as "Vegas-ization," since it amounts to the full-scale importation of the feel and landscape of one city (Las Vegas), itself comprised of simulacra of other cities (Paris, New York, Bellagio, Venice). This shift has significant consequences, which, I suggest, will include the shrinkage of what were previously Macau's pillar industries (manufacturing, construction and real estate, financial services), increased gambling addiction, an economy almost entirely based on service industries, increased prostitution, tourist debauchery, and, ironically, increased lawlessness (Mingjie Sheng and Chaolin Gu 2018).

Furthermore, the neoliberal logic of levelling whatever is perceived as standing in the way of economic "progress" in order to (re)establish a largely fictional, nostalgic, and revisionist version of the past, while impacting on everything from the political system to the indigenous culture and economy, is bizarrely redoubled in Skyfall. The film's Macau casino, which suggests a sort of vintage Vegas-style oriental gambling resort, is non-existent and was created to reflect the kind of image that viewers might conjure up if asked to imagine an oriental casino in an exotic location. True to the Las Vegas tradition, the mock-up casino is themed to represent an urban location out of the past, much like the Paris, Venice or New York, New York casino complexes in Vegas, but the "order of simulacrum" (to borrow Jean Baudrillard's [1983] term) is enhanced by the fact that this is a non-existent casino. This gesture is all the more radical considering that none of the scenes in Skyfall were actually shot on location in Macau: rather, Macau itself was entirely created with CGI for the film, with one blogger (Sterling 2013) suggesting that "most likely [the producers] felt that Macau would be more exotic portrayed like something from the colonial era." In other words, neoliberalized societies and the economies in which they operate are, it would appear, more comfortable with sentimental - if gritty - revisionist simulations of an imagined past world that never existed than they are with the "real" world of the Global South. The casino scene in Skyfall, and the kinds of signifiers and the politics of contemporary, global casino culture that it depicts, is an excellent example of how the neoliberalized global economy is expressed in revisionist cinema. 


\section{Conclusion}

Umberto Eco $(2009,45)$ wrote of his "suspicion that [Fleming] does not characterize his creations in such and such a manner as a result of ideological opinion but purely for rhetorical purposes" by exploiting endoxa or "the common opinions shared by the majority of readers," which ultimately made him "an expert in tale engineering." Whether or not, as Eco suggests, Fleming himself was as cynical about the inherent ideology of what he was up to, the result is a fictional universe with the capacity to make a serious, real-world impact. In keeping with these observations, I have argued that $S k y f a l l$, as a post-Fleming revisionist outing of a franchise calculated to communicate "nowness," expresses, directly or indirectly, a neoliberal ideology and gives voice to particular economic practices such as deregulation, corporatization, casinofication, Lasvegasization, and financialization. The film does all of this by negotiating its relationship with the past and the future from its situation in the present through the many signifiers of Bond, in particular by way of its representation of gambling and casinos. In so doing, the film — and indeed the Daniel Craig quadrilogy more generally — shares a number of features with wider trends not only in blockbuster cinema but also with specific aspects of neoliberal (geo)politics and economics: first and foremost, the practice of erasing or eradicating the past in order to (re)create a present that references an imaginary past, which itself answers to the demands of current neoliberal ideologies. In other words, when Silva asks Bond if he has a hobby, his answer- "resurrection"-is more than just an amusing quip. As we know, Bond has a nasty habit of surviving, but it is the how of his continuance that keeps us watching and waiting for the next instalment. In the current moment of Bond, it would seem that to innovate means going "back in time, where we have the home field advantage," as 007's dredged up father figure, Kincade (Albert Finney), explains in Skyfall.

\section{Works Cited}

Baudrillard, Jean. 1983. Simulations, translated by Paul Foss, Paul Paton and Philip Beitchman. New York: Semiotext(e).

Bennett, Tony, and Janet Woollacott. 1987. Bond and Beyond: The Political Career of a Popular Hero. New York: Routledge.

Bjerg, Ole. 2011. Poker: The Parody of Capitalism. Ann Arbor: The University of Michigan Press. 
Chapman, James. 1999. Licence to Thrill: A Cultural History of the James Bond Films. London: I.B. Tauris.

Chapman, James. 2005. "Bond and Britishness." In Ian Fleming and James Bond: The Cultural Politics of oo7, edited by Edward P. Comentale, Stephen Watt, and Skip Willman, 55-63. Bloomington: Indiana University Press.

Denning, Michael. 2009. The James Bond Phenomenon: A Critical Reader, Second Edition, edited by Christoph Lindner, 56-75. Manchester: Manchester University Press.

Dodds, Klaus. 2014. "Shaking and Stirring James Bond: Age, Gender, and Resilience in Skyfall (2012)." Journal of Popular Film and Television 42, no. 3: 116-30.

Dow Schüll, Natasha. 2012. Addiction by Design: Machine Gambling in Las Vegas. Princeton: Princeton University Press.

Eco, Umberto. 2009. The James Bond Phenomenon: A Critical Reader, Second Edition, edited by Christoph Lindner, 34-55. Manchester: Manchester University Press.

Fleming, Ian. 1953. Casino Royale. London: Jonathan Cape.

Fleming, Ian. 1956. Diamonds are Forever. London: Jonathan Cape.

Gehlawat, Monika. 2010. Revisioning oo7:James Bond and Casino Royale, edited by Christoph Lindner, 131-44. New York: Wallflower.

Goggin, Joyce. 2010. "From Remake to Sequel: Ocean's Eleven and Ocean's Twelve." In Second Takes: Approaches to the Film Sequel, edited by Caroline Jess-Cooke and Constantine Verevis, 105-21. Albany: State University of New York Press.

Goggin, Joyce, and René Glas. 2010. "It Just Keeps Getting Bigger: Bond and the Political Economy of Huge.” In Revisioning oo7:James Bond and Casino Royale, edited by Christoph Lindner, 50-70. New York: Wallflower Press.

Goggin, Joyce. 2011. "007 Does Vegas: The Diamond Standard and the Experience Economy." The Cultures ofJames Bond, edited by Joachim Frenk and Christian Krug, 65-81. Trier: Wissenschaflicher Verlag Trier.

Goggin, Joyce. 2015. "Opening Shots and Loose Slots.” Screen 56, no. 2, Special Issue on "Opening Pages, Opening Shots," edited by Christine Geraghty and Shannon Wells-Lassagne: $245^{-5}{ }^{2}$.

Harman, Chris. 2009. Zombie Capitalism: Global Crisis and the Relevance of Marx. Chicago: Haymarket Books.

Hasian Jr., Marouf. 2014. “Skyfall, James Bond's Resurrection, and 21st-Century Anglo-American Imperial Nostalgia." Communication Quarterly 62, no. 5:569-88.

Higson, Charlie. 2012. "James Bond: Nobody Does It Better." The Daily Telegraph, October 19.

Hoa, Jen Hui Bon. 2012."'That Which We Are, We Are': Hong Kong and Post-Colonial Identity in Skyfall." Situations 6 (Winter): 1-11.

Klein, Naomi. 2007. The Shock Doctrine: The Rise of Disaster Capitalism. London: Penguin. 
Kurlantzick, Joshua. 2005. “The Decline of American Soft Power.” Current History 104, no. 686 (December): 419-24.

Lindner, Christoph. 2009. "Introduction." In The James Bond Phenomenon: A Critical Reader, Second Edition, 1-13. Manchester: Manchester University Press.

LiPuma, Ed. 2017. The Social Life of Financial Derivatives: Markets, Risk and Time. Durham: Duke University Press.

Luke. Timothy W. 2010. "Gaming Space: Casinopolitan Globalism from Las Vegas to Macau". Globalizations 7, no. 3: 395-405.

Owens, Craig N. 2005. “The Bond Market." In Ian Fleming and James Bond: The Cultural Politics of oo7, edited by Edward P. Comentale,, Stephen Watt, and Skip Willman,107-29. Bloomington: Indiana University Press.

Packer, Jeremy. 2009. Secret Agents: Popular Icons Beyond James Bond. New York: Peter Lang.

Parlett, David. 1992. A Dictionary of Card Games. Oxford: Oxford University Press. Rothman, Hal. 2003. Neon Metropolis: How Las Vegas Started the Twenty-First Century. London: Routledge.

Taylor, Mark. 2004. Confidence Games: Money and Markets in a World without Redemption. Chicago: The University of Chicago Press.

Schwartz, David G. 2003. Suburban Xanadu: The Casino Resort on the Las Vegas Strip and Beyond. New York: Routledge.

Sheng, Mingjie, and Chaolin Gu. 2018. "Economic Growth and Development in Macau (1999-2016): The Role of the Booming Gaming Industry." Cities 75 (May 2018): 72-80.

Simpson, Tim. 2012. “Tourist Utopias: Las Vegas, Dubai, Macau." Asia Research Institute Working Paper Series 177, National University of Singapore: 1-27.

Sterling, R. 2013. "Portuguese Macau." James Bond Locations, Last Accessed on August 1, 2019, https://jamesbondlocations.blogspot.nl/2013/05/portuguesemacau.html).

“Steve Wynn: A true showman." 2016. CNN Asia, Accessed January 14, 2019, http:// edition.cnn.com/videos/world/2016/10/o6/talk-asia-steve-wynn-spc-a.cnn.

Strange, Susan. 1986. Casino Capitalism. Oxford: Blackwell.

Vegasmaster. 2016. “The Best Scenes in Casinos in James Bond Movies”. Last Accessed October 21, 2016, http://www.vegasmaster.com/the-best-scenes-in-casinos-injames-bond-movies/.

Wagner, Travis. 2015. "The Old Ways are Best: The Colonization of Women of Color in Bond Films." In For His Eyes Only: The Women ofJames Bond, edited by Lisa Funnell, 51-59. New York: Wallflower.

Winder, Simon. 2006. The Man Who Saved Britain: A Personal Journey into the Disturbing World ofJames Bond. New York: Picador. 


\section{About the Author}

Joyce Goggin is a Senior Lecturer in Literature at the University of Amsterdam. She has published widely on gambling and finance in literature, painting, film, television, and computer games. Her recent publications include a co-edited collection of essays entitled The Aesthetics and Affects of Cuteness (Routledge 2017), and she is currently completing a translation of two eighteenth-century Dutch comedies by Pieter Langendijk on the South Sea Bubble, forthcoming with Liverpool University Press in 2020. A book chapter on the novelizations of The LEGO Movie has also been published in Cultural Studies of LEGO: More Than Just Bricks (Palgrave 2019). 



\title{
15. Three Dimensions of Bond: Adaptive Fidelity and Fictional Coherence in the Videogame Adaptations of GoldenEye
}

\author{
Ian Bryce Jones and Chris Carloy
}

\begin{abstract}
Rare's 1997 game GoldenEye ooz redefined the first-person shooter genre not only through its mission-based gameplay, improved enemy AI, and architecturally believable level designs, but also how it combined these features to create an internally consistent, believable Bond experience. When the game was remade in 2010, new developers Eurocom had to negotiate intellectual property restrictions and new genre developments to create a game that was both faithful to the beloved original and successful on its own terms. We explore the relationship between these games via the rubrics of adaptive fidelity (how faithfully each game operates as an adaptation of the GoldenEye film) and fictional coherence (how well their own components collaboratively encourage role-play as the character of Bond).
\end{abstract}

Keywords: first-person shooter; adaptation; GoldenEye oo7; role-play; transmedia; James Bond

In 1995, Nintendo approached videogame development company Rare, Ltd. about designing a game based on the then in-production James Bond film GoldenEye (UK/USA: Martin Campbell, 1995) as a platform-exclusive title for their Nintendo 64 console. While the resulting game, GoldenEye oo7 (1997), first appeared to be a routine production, comparable to releasing action figures or other merchandise to accompany a movie release, it would ultimately become a surprise critical and commercial success and a landmark both of film-to-videogame adaptation and of the emerging first-person shooter

Verheul, J. (ed.), The Cultural Life ofJames Bond: Specters of oo7. Amsterdam: Amsterdam University Press, 2020 DOI 10.5117/9789462982185_CH15 
genre. While its multiplayer mode created the biggest stir, its single-player levels are remembered today not only for their innovative mission objectives, enemy behavior, and level design, but for the way these features worked to create an internally consistent, believable Bond experience.

In 2010, another videogame adaptation of GoldenEye appeared, this time developed by Eurocom for the Nintendo Wii. The motivations behind this re-adaptation have very little to do with any lingering popularity for the then fifteen-year old Pierce Brosnan vehicle-instead, it had been the enduring, nostalgia-enriched reputation of the original game that prompted the return of this particular storyline from the Bond canon. A curious double-adaptation, the 2010 game serves as a case study in the adaptation and mutation of intellectual property, as well as the development of the first-person shooter genre, particularly as a medium for storytelling.

Untangling each of these issues requires a careful re-assessment of Rare's original game alongside a careful examination of its remake, with an eye toward the latter's mixture of borrowing and re-invention. To the extent that videogame adaptations are addressed at all within discussions of popular media franchises, they tend to be discussed as emblems of "transmedia storytelling," defined by Henry Jenkins $(2008,97)$ as narrative that "unfolds across multiple media platforms, with each new text making a distinctive and valuable contribution to the whole." Indeed, the late 199os were a fertile era for licensed videogames that genuinely extended and expanded the stories of their source material, including such examples as Star Wars: Shadows of the Empire (LucasArts, 1996), released on the Nintendo 64 console roughly contemporaneously with GoldenEye oo7. The two GoldenEye games, however, do not make unique narrative contributions to their Bond-branded source material so much as adapt them. As such, the games-as well as the various legal and brand-related considerations that shaped their development - are best investigated through critical frameworks of adaptation, particularly adaptation across media.

This chapter undertakes such an investigation, combining a historical overview of the generic and business developments that lead to the creation of each game with a formal analysis of their game design (with a narrow focus on a small cluster of levels in each game) to address how they function as manifestations of the Bond brand. Two terms that will help us along the way are adaptive fidelity and fictional coherence, which refer, respectively, to how faithfully each game operates as an adaptation of the GoldenEye film, versus how well their own components hold together and collaboratively encourage role-play as the character of Bond. 


\section{7: Innovation and the Guiding Logic of Fictional Coherence}

When GoldenEye 007 went into production in 1995, the videogame medium was facing a moment of great transition. More powerful hardware had opened the possibility of real-time three-dimensional graphical rendering, significantly changing spatial representation and the possibilities of level design. The first-person shooter (FPS) genre, to which GoldenEye oo7 belonged, had been on the forefront of this technological transition when it first emerged in the early 1990 .

The classic form of the FPS, established by Wolfenstein ${ }_{3} D$ (id Software, 1992) and popularized by Doom (id Software, 1993), consisted of navigating a series of corridors that were interconnected into maze-like environments, searching said environments for inventory items and keys, and shooting enemies. A level of Doom was, in effect, a large spatial puzzle, the goal of which was to make it to the exit alive. Although gameplay could be slow as players learned a level, a player who had mastered a level could move quickly through the space, solving puzzles and killing enemies without much thought.

By 1996-1997, the popularity of the genre had been cemented, but its basic formula had not evolved much beyond the template first pioneered by Wolfenstein ${ }_{3}$ D and Doom (It is telling that the moniker "Doom-clone" was frequently affixed to the genre during this period). Critical reception of games such as Kileak: The DNA Imperative (Genki, 1996) and PO'ed (Accolade, 1996) reveal fatigue among popular-press reviewers toward the genre's increasing staleness (Glide 1996; Baran et al. 1996b). However, despite widespread perceptions of stagnation, new signs of life were emerging. Turok: Dinosaur Hunter (Iguana Entertainment, 1997) abandoned the darkened corridors of Doom in favor of large, open spaces. The level design of Alien Trilogy (Probe Entertainment, 1996) bore the hallmarks of the landmark production design of its source film franchise (Baran et al. 1996a). Meanwhile, as previously noted, Star Wars: Shadows of the Empire (LucasArts, 1996) pioneered games' entrance into transmedia storytelling, weaving previously-unseen story threads between two Star Wars feature films (Nintendo Power Staff 1996a).

In tandem with these designers working concurrently on other games, Rare used GoldenEye 007 as an opportunity to experiment with the FPS genre. Taken in this full context, GoldenEye oo 7 is perhaps not the singular beacon of innovation it is sometimes made out to be. As an Electronic Gaming Monthly (Funk 1997) editorial acknowledges, "Most of what you see in the game has been in other games." What, then, explains the game's critical and 
popular success - its re-drawing of the boundaries of what a licensed game could be, and how the Bond franchise could be adapted into other media?

We propose that the "secret ingredient" here is fictional coherence. Although experiments at this time in FPS level design and AI programming were manifold, GoldenEye oo remains notable in the degree to which these components are unified, in a manner that seems motivated. Upon release, the game was lauded for (and its popularity likely boosted by) its successful evocation of the James Bond character and universe. It included objectives beyond pure shooting. It sported intricately-designed enemy behavior, and took place in relatively large and open space. Its historical importance, however, is cemented not just because it contains all of these components-although that is, to be clear, a feat in and of itself. It is the fact that it does all of these things while also presenting a Bond-inspired fictional world to players that feels intuitive, rather than arbitrary. The actions the player undertakes are clearly motivated. They feel less like puzzles for puzzles' sake (as could sometimes be the case with Doom and its many clones), and more like analogues to behaviors that make sense within the context of Bond's objectives. This fictional coherence was an ideal that was aspired to by many videogame developers working in this moment of transition, often referred to under the guise of creating more "realistic" virtual experiences. GoldenEye ooz ended up being the right game at the right time.

Critically re-assessing GoldenEye oo7 two decades after its original appearance, then, requires a careful eye — one geared less toward its individual "innovations" - which, again, are less original than sometimes portrayed, having been pioneered by other games around the same time - than toward the overall gestalt of how they fit together into a coherent play-world. To best examine this, we will now take up a close analysis of the game's early moments. The game's first three levels - "Dam," "Facility," and "Airfield"function as an augmented and extended adaptation of the GoldenEye film's pre-credits sequence, with players taking the role of Pierce Brosnan's Bond as he infiltrates and disrupts a chemical weapon facility hidden in the Arkangelsk Dam, before escaping on an airplane as it explodes. The game's opening level, "Dam," will be the primary focus here.

As in the opening scene of GoldenEye, "Dam" follows Bond's attempts to covertly enter a well-guarded weapon facility by bungee jumping from the top of the Arkangelsk Dam. The first portion of the level consists of a succession of open spaces, functioning as a route to the top of the dam. Fictionally, the spaces serve as storage and staging areas for the dam, and as a guarded access point to the dam's top. The level design is linear in the 
sense that there is ultimately only one direction to go; each main area must be passed through, in order, to reach the top of the dam. That said, there is a significant amount of freedom to move around in the large areas, and the way players choose to navigate the open spaces has a significant impact on gameplay-determining, for example, how covertly the player moves through the space, and thus the frequency and intensity of combat.

"Dam" begins as all GoldenEye oo levels begin, with players first reading a description of its mission objectives, in the form of a classified briefing from MI6. One genuinely unique feature of the game is the manner in which the chosen difficulty setting changes each level's objectives. For "Dam," the only objective on the level's easiest setting is to make it alive to the end of the level-an objective familiar to players of Doom or its many clones. At the other end of the difficulty spectrum, however, players' objectives include "neutralize all alarms," "install covert modem," "intercept data backup," and "bungee jump from platform." No details are provided as to the locations within the level these objectives can be accomplished, and the game provides no map. The successful completion of these additional objectives requires close environmental observation and exploration on the part of players - a taxing task, to be sure, but one aided by a coherent net of clues provided by the game.

Once players have clicked through the mission objectives, "Dam" greets them with an establishing shot of the level, and then a fly-through of the initial area as the virtual camera seems to move from the far corner of the space up to Bond. This sweeping virtual crane shot conveys the size and openness of the space, while allowing attentive players to note the positions of enemies. Upon the conclusion of this shot, the game switches to Bond's first-person perspective, and the player is granted control. To Bond's back is a dead end. In front, a corridor bordered by towering grey cliffs curves to the left. Rounding this curve, players can catch a view along the length of the first area. At the far end, a guard tower rises on the left, and a tunnel opens on the right. Each is guarded by a pair of soldiers. If players charge out from cover, firing their weapons (a stereotypically Doom-clone-like tactic), they will draw the attention of all of the soldiers, forcing them to fight them simultaneously, likely taking damage in the process. Careful and attentive players, on the other hand, will find that they can silently kill a guard who is walking around the tower, move to the tower's rear, silently shoot a second guard, climb to the top of the tower (where they will discover a sniper rifle), and snipe the two tunnel guards from a distance.

Passing through the tunnel, players enter a second area with similar gameplay features. Stacks of boxes, towers, and bunkers form a ring around 
a central open space. Again, if players run directly into the open space, they will find themselves surrounded, and fired upon by enemies using the environmental features for cover. Having learned from the experience of the previous area, however, players can also pass behind the stacks of boxes and use them for cover as they work their way around the space killing enemies, or even stay at the far end of the tunnel and clear out the space with the sniper rifle. As these first two rooms demonstrate, successful gameplay requires attention to the risks and affordances of the game's spaces, while different players may exploit these spaces in unique but equally successful ways.

Moving forward, players enter a third open space that provides a variation on enemy behavior, as well as housing the first two mission objectives. The space is relatively empty, with a tower on the right and a gate and gatehouse on the far end. Upon entering the space, players may notice an enemy who (unlike any they have seen in the level thus far and unusually for the FPS genre up to this point) does not shoot, but rather turns and runs towards a red mark on a distant wall. If players fail to shoot the guard before he reaches this mark — which turns out to be an alarm - more enemies will emerge from a gatehouse to the right. If, alternately, they do shoot this guard before the alarm is tripped, the additional guards will remain ensconced within the gatehouse, oblivious to the presence of an intruder. Thus, the action of the running guard not only introduces a novel enemy behavior, it also leads players to their first objective, "destroy all alarms." Upon being shot several times, the alarm will explode. Checking the list of objectives will reveal that this objective is not yet marked as "complete," indicating that there must be other alarms. Moreover, players who have read their mission briefing carefully and have seen that they are supposed to connect a covert modem to a "satellite link" may notice a satellite dish on the roof of the gatehouse. If they explore around back of the gatehouse, players will find that the dish is connected to a small screen. Completing the mission requires the player to attach the modem to the screen by equipping the modem, aiming at the screen, and pressing the action button. If, however, players put the modem somewhere else or (following stereotypical Doom-clone gameplay), fire upon anything that can be blown up, including the screen, they will fail the mission objective, and will have to restart the level.

Readers familiar with the GoldenEye film —in which the "Dam" sequence consists of a grand total of 105 seconds ( 16 shots), in which Pierce Brosnan's Bond springs out and very quickly bungee jumps down the vertical face of the Arkangelsk Dam, shooting precisely no one in the process-will have noticed a significant amount of embellishment of both setting and action in the level thus far. This embellishment continues even after the player 
reaches the precise setting of the film's opening sequence, the top of the dam. Three guard towers are now present on the rim's right lip, as well a series of docks off of the right side of the dam. If players dash straight towards the bungee jumping point — acting, in other words, exactly as Bond does in the movie - they will miss multiple gameplay objectives. Rather, completion of the level on its highest difficulty setting requires entering each of the guard towers to destroy more alarms and descending into the interior of the dam to "intercept data backup" by interacting with a computer. While not drawn from the film, these mission objectives provide the player with more opportunity to act as Bond in the fictional space- that is, to do the types of things Bond might believably have to do while infiltrating a military facility — while the "realistic" distribution of mission objectives throughout the level (alarms in guard towers, important computers in the heavily-guarded interior of the dam) provides a believable spatial context for roleplaying. Thus, we see that in Rare's adaptation of the scene adaptive fidelity to the source material is subsidiary to internal fictional coherence.

This is not to suggest that GoldenEye ooz is entirely without fidelity to its source material. Indeed, the fidelity that it does exhibit is strikingly important to its overall reception as a successful adaptation and expansion of the film. In terms of space, industry press reported, in 1996, that the design team had been given access to the film's sets and were basing the game's level design on them (Nintendo Power Staff 1996b). As a result, many of the levels - particularly "Facility" and "Tank" — contain architecture that is readily recognizable from the film, fulfilling an immersive dream of "stepping into" the world of Bond. In terms of story beats, action sequences reappear either in the form of major dramatic scenes to which players are witness (the shooting of Agent oo6/Alex Trevelyan in "Facility," for example), or in the form of mission objectives (protecting the computer scientist Natalya while she tries to disable the satellite at the game's climax).

Other aspects of the film, however - and of the Bond franchise, as a whole - get lost in translation. Bond, as a character, is considerably warped from his more familiar incarnations. Videogame scholars have rightly pointed out that only one side of James Bond's character is on display in the game - the secret agent, rather than the playboy-and the absurdly large body count of the game is out of keeping even with the Brosnan era's usual violent standards (Stein and Weise 2010). (This, of course, maps onto the usual biases of the medium, as shaped by historical factors of censorship and target audience). Those actions that players do engage in beyond shooting are heavily abstracted, to a degree that reveals the limits of the game's innovations. Already in Doom, players were called upon to 
press buttons in the environment to open doors and progress, and had to search the environment to collect keys, weapons, and health upgrades. Much of GoldenEye oo7's non-shooting environmental interaction likewise merely involves pressing a single button on the controller. Objectives such as "neutralize all alarms" or "intercept data backup" may initially sound robustly interactive, but ultimately they boil down to destroying some of the level's scenery, or pressing a button.

However, this lack of adaptive fidelity to the larger, transmedial fictional personage of Bond is balanced out by the game's remarkable coherence when it comes to the internal logic of its own fictional diegesis. Much of this has to do with enemy behavior and the construction of the game's spaces. For example, much was made at the time of the game's release of its relatively advanced hit detection - shooting an enemy in the leg, for instance, does less damage than shooting them in the head, but causes them to stagger, slowing them down (Nintendo Power Staff 1996b). Beyond this, though, there are additional components to the enemy's AI that together have a pronounced influence on player behavior. Enemies won't notice players if they approach from behind, and once they do notice them, they will not run straight at the player, but rather attempt to evade them, or hide behind cover. Additionally, if an alarm is near, they will run to trigger it, causing further waves of enemies to appear and attack.

The combined effect of these behaviors is that the game rewards stealthalthough a different sort of stealth of the sort being pioneered concurrently in games such as Thief: The Dark Project (Looking Glass Studios, 1998) or Metal Gear Solid (Konami, 1998). Unlike the latter games, stealth in GoldenEye oo is not about hiding for lengthy stretches of time, but rather moving quickly and efficiently_cleaning up messes, as it were, by taking enemies out quickly with headshots (preferably with a silenced pistol) before they have a chance to retreat, regroup, and add their allies to their ranks.

The game's environmental design, meanwhile, is tightly integrated into its systems of objectives. As previously established, players do not have to solve complicated puzzles to complete objectives. But they do have to discover the locations of these objectives, without the aid of written clues or an included map. Here, the design of the game's levels-particularly, the way that, in being recognizably inspired by the film's sets, they hew closer to real-life analogs than to pure mazes-provides a strong basis for environmentally-guided inferential reasoning. In the above description of the "Dam" level, this took the form of noticing the satellite dish on the top of the gatehouse, recalling that an objective was to hack the satellite network, and deducing that access to the network will likely be nearby. It could also 
mean that, having discovered an alarm in one guard tower, it is worth searching other towers to see if there are alarms to destroy in them, as well.

The interplay of these features creates an internally coherent play-world, which in turn shapes player behavior, by rewarding certain actions and punishing others. We can say that, from the encouraged player behavior, a variation on the Bond character emerges. It is not precisely the Bond of the films, nor precisely the Bond of the novels, given the aspects of adaptive infidelity at work. But this Bond is not completely unrecognizable, either. This Bond is much more of a violent killer than his analogs in Fleming's books or Eon's films. However, he is not on a rampage. He kills as quickly and as silently as possible. He is a consummate professional, aiming for stealth and efficiency. His goal is, above all, not to be seen, and he kills people first and foremost to achieve this goal. He is clever and observant, able to deduce the locations of mission-relevant items and materials based off of logical intuition. He is resourceful, both carrying standard-issue $\mathrm{MI}_{5}$ equipment (including a special watch that serves as the game's requisite "Bond gadget") and procuring weapons and ammunition from the field. He is cool, collected, and violently psychotic - but he is able to fold his violent streak into service for England ("always for England"). The construction of the game's mechanics, through their internal fictional coherence, encourage players to role-play as this variation on the Bond character-one that shares crucial overlaps with the character's other incarnations elsewhere, while not being identical.

\section{0: Nostalgia and Evolution}

During the seventh generation of videogame consoles (consisting of the Nintendo Wii, Microsoft Xbox 36o, and Sony PlayStation 3, hardware released between 2005 and 2006, and retired between 2012 and 2013), the videogame industry discovered that its history - so often relegated to the dustbin in the constant march of planned obsolescence-could, in fact, be profitable. The advent of internet-based digital game distribution on consoles opened up the opportunity for games with low profit margins to remain available, leading to a gradual re-assessment of the commercial potential of gaming's past on the part of both console manufacturers and game publishers. Nintendo inaugurated this trend with the Wii's Virtual Console, a set of emulators of that allowed for Wii owners to download and play games from a wide variety of past game consoles, from the Nintendo Entertainment System's Super Mario Bros. (Nintendo, 1985) and Final Fantasy (Square, 1987) up through the Nintendo 64's Sin and Punishment (Treasure, 
2000). Sony and Microsoft eventually followed suit with their "PSClassics" and "Xbox Originals" programs, respectively. Across all three platforms, it became clear that players' nostalgia was a powerful economic force.

No-frills emulated versions of games from past generations of hardware were only one possibility in this new commercial exploitation of gaming's history. Another possibility was the enhanced port - a version of an older game that had been thoroughly re-worked as to fully take advantage of the new possibilities of modern hardware. On the Xbox 360 and PlayStation 3 , the reigning mode of enhanced port was the "HD remake," older games re-worked to run at resolutions of $720 \mathrm{p}$ or 1080p, so as to scale better to contemporary high-definition televisions. Nintendo's Wii, lacking the high-definition graphics of its peers, instead relied on the introduction of motion controls as the raison d'être for its enhanced ports.

Given the hallowed place of GoldenEye oo 7 in the history of console firstperson shooter games, it was perhaps inevitable that, during this particular moment, demand would be high for the game's commercial re-release, either in the form of legal emulation via Nintendo's Virtual Console, or as some sort of enhanced remake. By February 2008, rumors that such developments were in the works reached enough of a fever pitch that the gaming magazine Xbox 360 World reported that the game was, in fact, slated for a re-release on Microsoft's console (Gapper 2008).

Sadly, for fans, the report was erroneous: in fact, there were considerable hurdles to such a re-release actually ever coming to pass. ${ }^{1}$ Following a close partnership with Nintendo during the Nintendo 64 era, Rare had been acquired by Nintendo's competitor Microsoft in 2002, leaving the intellectual property rights to several of their games in a complicated morass. Eon Productions' control over its intellectual property presented an additional hurdle. Although Nintendo held the publishing rights for GoldenEye oo in 1997, by 2007 Eon had granted the exclusive publishing rights for all official licensed James Bond games to Activision, meaning that any re-appearance of GoldenEye would have to include Activision's involvement as a publisher. Together, these hurdles proved insurmountable, and by 2009 both Microsoft and Rare had put forward statements announcing that that any attempt to re-release the original game on contemporary hardware was dead in the water (Purchese 2008; Purchese 2009).

1 This is not to say that the $X_{b o x_{3}} 6$ o World report was a hoax. Subsequently leaked materials have confirmed that Rare was, in fact, experimenting with porting GoldenEye oo to the Xbox 360 (monokoma 2010). It was simply erroneous to suggest that the legal hurdles to its release had been cleared, and that the game's release was imminent. 
Although the obstacles to a four-way agreement between Microsoft/Rare, Nintendo, Eon, and Activision proved overwhelming, the excited burst of fan nostalgia surrounding the possibility of a re-release demonstrated the continued viability of the GoldenEye brand - even as licensed Bond games had moved into their own respective Daniel Craig era, following the film franchise, with the actor's visage and voice appearing in the game adaptation oo7: Quantum of Solace (Treyarch, 2008). Soon after, Activision set out on its own to completely remake the game from the ground up, for exclusive release on the $\mathrm{Wii}^{2}{ }^{2}$ Creating an entirely new game, with development duties handed over to Eurocom (who had previous experience developing licensed Bond games in the long interim between the two Goldeneye games, having made 2002's James Bond oo7: Nightfire), neatly sidestepped the legal hurdles of re-releasing Rare's original game, leveraging a powerful license while abandoning the quagmire of the game's particular history.

The Bond franchise is certainly no stranger to remakes, and the twisty games of legal give-and-take that can result. Most famously, Kevin McClory's IP disputes with Ian Fleming gave the world Never Say Never Again (UK/USA/ West Germany: Irvin Kershner, 1983), the Sean Connery-starring remake of Thunderball (UK: Terence Young, 1965) that stands as the most high-profile non-Eon Bond film. The McClory estate successfully kept Ernst Stavro Blofeld from Eon's hands until 2013, but Never Say Never Again was denied Monty Norman's iconic James Bond theme music and Maurice Binder's equally-iconic opening "gun barrel" sequence — arguably much stronger assets when asserting the Bond brand (Gardner 2013).

The GoldenEye remake enacts a very different dance between deference to the brand and strict adherence to IP restrictions, between nostalgia and re-imagining. Two major components of the original game remained legally out of reach for Activision and Eurocom: the original game's level design, and the visage of Pierce Brosnan. The geometry of the original game's levels, as well as the placement and behavior of the AI denizens that populated them, had been Rare's signature contribution to the GoldenEye license, and therefore could not survive adaptation. Meanwhile, from a licensing perspective, the contract to play Eon's Bond had transferred from Brosnan to Craig, meaning that the latter's likeness had to be substituted for the former.

Beyond these mandated changes, however, Eurocom remained acutely aware that nostalgia was the primary currency of the GoldenEye brand, and

2 The 2010 GoldenEye 007 was eventually ported to the Xbox 360 and PlayStation 3 as GoldenEye oo7 Reloaded in 2011, adding yet another wrinkle to this saga of remakes and re-releases. For the purposes of this article, however, only the Wii release of GoldenEye oo 7 is being considered. 
therefore aimed for fidelity in other areas. The 2010 GoldenEye's screenplay (penned by Bruce Feirstein, one half of the screenwriting team that produced Eon's original GoldenEye screenplay) thoroughly reworks both the original film's and game's events, transplanting them from the 1980 s and 1990 s into the 2010 (Leader 2010). But it pointedly retains the major set pieces of the original game, even if this means tossing the (relatively) gritty and grounded persona of Craig's Bond into scenarios borrowed from the more excessive Brosnan era, including a tank chase through St. Petersburg (Although the intricate contrasts that can be drawn between Brosnan and Craig's star personas-and the shift in tone that marked Eon's Bond franchise during the transition from the former to the latter-are not the primary concern of this chapter, this particular subject is handled in greater detail by David McGowan (2013)).

From a gameplay perspective, the game remains a first-person shooter through and through, influenced by other major milestones in the genre that had appeared in the dozen years since the original's debut, but containing no attempts to re-invent the license. Game cutscenes are now fully voiced acted (by Craig and Judi Dench, alongside less-famous voice performers), replacing the text-based exposition of the original game, and adding an extra dimension of adaptive fidelity to the Eon film franchise that the original GoldenEye oo lacked. However, dialogue options of the type pioneered by espionage role-playing game Alpha Protocol (Obsidian, 2010), released months earlier, are notably absent. Also absent is any real attempt to leverage the rougher physicality of Craig's particular take on Bond. Craig's debut in the Bond role, Casino Royale (UK/Czech Republic/USA/Germany/Bahamas: Martin Campbell, 2006) held a key role in the introduction of le parkour into contemporary action cinema, with its fluid chase scene through a construction site standing as one of the high points of the discipline's representation in film. Parkour experienced a roughly contemporaneous burst of popularity in action videogames such as Assassin's Creed (Ubisoft Montreal, 2007) and the first-person Mirror's Edge (DICE, 2008), and one could imagine a more ambitious take on the license integrating such elements. Eurocom's GoldenEye, however, is resolutely not that game. It is, instead, an adaptation that prioritizes fidelity to Rare's original game-including all of the leeway said game had with its license - over any genuine attempt to re-imagine the possible fidelity an updated Bond game could show toward its cinematic source material.

Tasked with remaking beloved levels, with a certain amount of change necessitated by legal mandate, what does one do? Eurocom chose what is perhaps the most obvious route: to re-evaluate the decisions Rare's original design team made in terms of the needs and expectations of contemporary 
game design. The gap from 1997 to 2010 had been a long one, and the expectations of players had changed drastically in the interim. Rare's GoldenEye 007 is a series of mid-sized levels that must be scoured patiently and cautiously, as players struggle to maintain a finite pool of health until they achieve their objectives and reach the designated exit point. Eurocom's levels are much longer, but they are also much more modularly designed. Frequent checkpoints in which the game auto-saves players' progress allow for shorter play sessions, and player health that re-generates as long as players can avoid being fired upon for a small amount of time removes the possibility of a tough firefight at the end of a level evaporating all of one's progress. This leads a distinct "pause/burst/pause" rhythm to the proceedings: Players walk down an empty hallway, in which their health regenerates and their game auto-saves; they then enter and clear out a large, arena-sized room full of enemies; following this, they discover another long, safe hallway where the game again saves, and their health again regenerates. As several reviewers noted at the time of the game's release, it is a rhythm and pace that owes much more to 200os-era first-person shooters such as Call of Duty 4: Modern Warfare (Infinity Ward, 2007) than to the original GoldenEye 007.3

Along with adding distinct architectural pauses to the tenser flow of the original game, Eurocom also punctuate their GoldenEye with moments of cinematic spectacle. The basic components of moving and shooting are broken up, at irregular intervals, by more elaborate sequences in which control is partially wrested from the player, and the possibilities of interaction are narrowed so as to better allow a very particular action set piece to take place.

To fully understand the way these modifications are set upon the blueprint of Rare's original GoldenEye 0o7, game, it is perhaps best to begin at the beginning — that is, "Dam," the very first level of Eurocom's GoldenEye 007, and a clear analogue to the opening "Dam" level of Rare's game. Following our mission briefing (which, here, is delivered in video form, complete with voice acting by Judi Dench as M and Rory Kinnear as Bill Tanner, in contrast to the original's comparatively sparse text screens), we are greeted with a fly-through view of a level that, initially, looks strikingly like its Nintendo 64 counterpart. The bridge, the guard tower, the mountain tunnel: each is exactly where one would expect it to be. However, rather than simply drop players into space as a single

3 Previewing Eurocom's game, Christian Donlan of Eurogamer writes, "[D]oes it feel like GoldenEye? Actually, it feels more like Modern Warfare: the pace of the encounters is very reminiscent of some of Soap's adventures" (Donlan 2010). In a full review of the game, Jon Wahlgren likewise notes that, "It's a game much more in line with Call of Duty in both feel and pace [...]" (Wahlgren 2010). 
figure surrounded by hostiles, "Dam" instead eases them into the character of 007 by making them privy to a first-person conversation with oo6, with voice acting by Daniel Craig and Elliot Cowen (filling in for Sean Bean as oo6/ Alex Trevelyan). Control is granted to players gradually — the game initially handles movement for them, with interaction initially limited only to making the necessary gesture with the game's motion controls on cue when a guard is to be silently subdued. Once players finally gain complete control of Bond, Cowen's voice remains on the soundtrack, offering advice, alerting players to converging enemies, and generally giving a sense of genuinely working with a partner that was entirely absent from the 1997 game's opening levels. In the original game, players' "guide" to the level was simply an inanimate truck, the seemingly unmotivated movement of which serves as the game's primary instruction to players of where to go, and where to look. By 2010, the possibilities of voice acting and much more advanced character animation have allowed a non-player character to much more organically take this role.

This allows for the truck itself to serve a different function. After an auto-save checkpoint (a distinct "pause" in the game's pause/burst/pause pacing), players are invited to climb into its passenger seat, at which point control of movement is again wrested away from them. For a few beats, the player is invited to sit and listen as Trevelyan, driving the vehicle, delivers exposition. Then, upon being recognized by guards, the game launches into a distinct "spectacle" phase. With forward movement still controlled by the game, rather than the player, the game transforms into a busy shooting gallery, with players tasked with taking out the gunmen of various trucks that swerve into view, with explosions and other bits of miscellaneous action happening at the margins of the screen. Throughout this brief section, players are given a precise prescription of what to do by the various means the game has at its disposal, either via audio (at one point, when a gas tanker is backing up in front of the truck, Trevelyan barks "shoot the tanker!") or visual cues (when a Russian soldier jumps onto the side of the truck and attempts to pull Bond out of it, the game offers up an explicit icon instructing players to shake the Wii remote). The proceedings are entirely scripted, and players' inability or refusal to play their part on cue will result in swift failure.

Given that this sort of elaborately-scripted spectacle, with the game frequently using non-player characters to tell players what to do, is very much the bread and butter of the Call of Duty franchise, a question arises. The elaborate feats of fictional coherence on display in Rare's GoldenEye oof lead it to rightly be recognized as something other than a "Doom clone." Is the 2010 GoldenEye 007 content with being a Call of Duty clone? As has already been noted, this seems to have been the consensus of contemporary 
reviewers. Martin Hollis, director of the original Rare GoldenEye, has laid down similar charges. ${ }^{4}$ Do the charges stick? To fully investigate the validity of this accusation, it is useful to move on from "Dam" to the following level-here, as in Rare's original, named "Facility."

Whereas Eurocom's re-imagining of "Dam" leaned heavily on recognizable landmarks from Rare's original level, "Facility" finds the team striking out on their own. Gone is Rare's indebtedness to the chemical weapon facility set from the film. Also gone is the residual indebtedness to Doom-like mazes that marks Rare's design. If Rare's game was already a milestone in the generic transition from mazes toward more recognizable, intuitive architecture, the functional (even boring) walkways and cubicles of Eurocom's "Facility" mark a moment further down that evolutionary path.

Along with being less twisty, Eurocom's "Facility" is also more rife with alternate routes. Air vents-a mainstay of stealth games such as Tom Clancy's Ghost Recon: Chaos Theory (Ubisoft Montreal, 2005), but not something used to any real effect by Rare-consistently present less direct, but also less risky paths through enemy-populated areas. Compared to its predecessor, players wandering through Eurocom's "Facility" are more encouraged to find routes through the level that keep them out of patrolling enemies' lines of sight, to sneak up behind them and take them out with a quick melee attack, or perhaps simply avoid them altogether. This play style becomes a particularly feasible option — even, arguably, the most encouraged option —immediately following the level's fifth checkpoint. Here, cameras and patrolling guards dot the central hub room, but the smaller rooms around its perimeter are occupied by staff distracted by their computers, rendering them easy to sneak up on from behind. Linked together by air vents, these perimeter rooms allow cautious players a chance to explore safely, gradually winnowing down the facility's personnel and take control of the map before they enter the center, shoot out the cameras, and make their final strike at the patrolling guards.

This is not to say that Eurocom's GoldenEye ooz is a stealth game. Longrunning stealth franchises such as the aforementioned Metal Gear Solid and Splinter Cell generally rely on a varied array of AI alertness states, for instance allowing guards to lose interest in finding they player if they have hidden well enough, for long enough. GoldenEye oo lacks such robust AI. If a hostile NPC detects the player, the player has a few seconds to kill them as silently as possible, or else all enemies in the area will immediately become

4 In an interview, Hollis reports of the remake, "I thought that it is really close to Call of Duty, more, in its gameplay [...] the rhythm of the enemies, the rhythm with which they come to you, the way you approach them [...]" (Hollis 2013). 
alert and open fire. As in Rare's original, the emphasis here is not on patient hiding, but on the careful isolation and quick dispatching of enemies. The end result is a hybrid of contemporary stealth level design tricks with the original game's "ruthless efficiency" version of stealth.

The fictional coherence on display in Rare's GoldenEye 007 was one of that game's most striking innovations. Any expectation that Eurocom's GoldenEye 007 would be equally bold in its innovations would have been naïve. After all, Activision's entire motivation for funding Eurocom's endeavor was the commercial exploitation of nostalgia - by no means the best of circumstances for inspiring progressive design. Ultimately, however, Eurocom's GoldenEye 007 does at least distinguish itself from contemporaries such as Call of Duty. It does so by utilizing the same trick that allowed Rare's game to distinguish itself from its own contemporaries: the creation of a fictionally-coherent interlocking systems that gradually encourage players to adopt Bond-like behaviors.

\section{Conclusion}

At the outset of this chapter, we announced an intention to avoid leaning too heavily on the framing of "transmedia storytelling," and to focus instead on the broader frame of adaptation. Part of the reason for this is that neither of the two GoldenEye games contribute genuine expansions to the narrative tapestry of the Eon Bond franchise, and therefore fail to meet Henry Jenkins' $(2008,97)$ definition of texts that make a "distinctive and valuable contribution to the whole."

More broadly, we can also say that the frame of "transmedia storytelling" is limiting because of its explicit focus on "storytelling." Rare's GoldenEye oo is, indeed, an adaptation of the story of the 1995 GoldenEye film. But, more broadly speaking, it operates as an adaptation of the Bond character-as persona, and as attitude. Through elements such as the spatial design of levels, mission objectives, and the behaviors of AI opponents-elements contributing to a "fictional coherence" that goes beyond the mere recounting of causally-related events-Rare's GoldenEye encourages play styles that bring player behavior in line with the fictional Bond. Moreover, Rare's approach to these elements suggests a concern not only with the unique affordances of the videogame medium but with contemporaneous genre-wide trends-both of which contributed to the 1997 game's commercial, critical, and artistic success.

Tasked with designing an adaptation of Rare's GoldenEye, Eurocom had to evoke the experience of the original enough to capitalize on fan 
nostalgia - the ultimate purpose of the adaptation - while doing without prominent features of the original to which they lacked the rights thanks to the breaking down of industry negotiations, and deciding how to manage changes to genre conventions that had taken place since the original game's release. While the finished product did encourage fan nostalgia through the recreation of particular story beats, objectives, and set pieces from 1997's GoldenEye, Eurocom successfully adapted Rare's game-as opposed to merely recalling it - by remaining faithful to the original's emphasis on fictional coherence and role-playing the "James Bond character." In doing so, Eurocom's game-like Rare's before it—-demonstrates that the toolbox of adaptation in games extends far beyond fidelity to story beats.

\section{Works Cited}

Baran, Andrew, Mark Lefebvre, Mike Desmond, and Sushi-X. 1996a. "Review: Alien Trilogy." Electronic Gaming Monthly, No. 81, April.

Baran, Andrew, Mark Lefebvre, Mike Desmond, and Sushi-X. 1996b. "Review: PO'ed." Electronic Gaming Monthly, No. 83, June.

Donlan, Christian. 2010. “GoldenEye oo7 Preview." Eurogamer. July 22, http://www. eurogamer.net/articles/goldeneye-007-preview.

Funk, Joe. 1997. “Editorial.” Electronic Gaming Monthly, December.

Gapper, Michael. 2008. "Special Feature: GoldenEye World Exclusive!” Xbox 360 World Magazine, February.

Gardner, Eriq. 2013. “MGM, Danjaq Settle 50-Plus Year Legal Fight Over James Bond Rights." The Hollywood Reporter, November 15, http://www.hollywoodreporter. com/thr-esq/james-bond-mgm-danjaq-settle-656432.

Glide, Tommy. 1996. "Review: Kileak: The DNA Imperative." GamePro, June.

Hollis, Martin. 2013. "Video: The Making of GoldenEye oo7." Gamasutra, June 21, http://www.gamasutra.com/view/news/194784/Video_The_making_of_GoldenEye_0o7.php.

Jenkins, Henry. 2008. Convergence Culture: Where Old and New Media Collide, Updated and with a New Afterword. New York: NYU Press.

Leader, Micheael. 2010. "Bruce Feirstein Interview: James Bond, Blood Stone and Modernising GoldenEye." Den of Geek!, August 2, http://www.denofgeek.com/ games/james-bond/12014/bruce-feirstein-interview-james-bond-blood-stoneand-modernising-goldeneye.

McGowan, David. 2013. "Some of This Happened to the Other Fellow: Remaking GoldenEye ooz with Daniel Craig." In Game On, Hollywood!: Essays on the 
Intersection of Video Games and Cinema, edited by Gretchen Papazian and Joseph Michael Sommers, 115-28. Jefferson, NC: McFarland \& Co.

monokoma. 2010. "GoldenEye oo7 Remake [Xbox 36o - Cancelled]." Unseen64: Beta, Cancelled \& Unseen Videogames, July 2, https://www.unseen64.net/2010/o2/07/ goldeneye-007-remake-xbox-360-xbla-cancelled/.

Nintendo Power Staff. 1996a. "Feature: Star Wars: Shadows of the Empire." Nintendo Power 83, April.

Nintendo Power Staff. 1996b. "Preview: GoldenEye oo7," Nintendo Power 85, June. Purchese, Robert. 2008. "MS Rubbishes GoldenEye XBLA Talk.” Eurogamer, February 25, http://www.eurogamer.net/articles/ms-rubbishes-goldeneye-xbla-talk. Purchese, Robert. 2009. "Rare: GoldenEye Revival Long Dead.” Eurogamer, September 21, http://www.eurogamer.net/articles/goldeneye-revival-long-dead/.

Stein, Abe, and Matthew Weise. 2010. "All Bang Bang, No Kiss Kiss? The Bond Figure and Video Games." In James Bond in World and Popular Culture: The Films Are Not Enough, Second Edition, edited by Robert G. Weiner, B. Lynn Whitfield, and Jack Becker, 23-39. Newcastle upon Tyne: Cambridge Scholars Publishing. Wahlgren, Jon. 2010. "Review: GoldenEye oo7 (Wii)." Nintendo Life, November 5 , http://www.nintendolife.com/reviews/2010/11/goldeneye_007_wii.

\section{About the Authors}

Ian Bryce Jones lives in the Chicago area, where he has taught at the University of Chicago, De Paul University, and the School of the Art Institute of Chicago, and also serves as a grant writer for Storycatchers Theatre. His previous writings and video essays on videogames and the player/ character relationship have been published in New Review of Film and Television Studies, The Velvet Light Trap, and [in]Transition. He blogs at intermittentmechanism.blog.

Chris Carloy received his PhD in Cinema and Media Studies from the Uni-

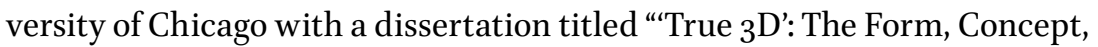
and Experience of Three-Dimensionality in 199os Videogames." His research focuses on videogame history and theory, theories of space and place, genre history and theory, reception studies, and the embodied experience of play, and aims to place videogames within longer traditions of art, media, and architecture. He currently teaches at the University of Chicago. 


\section{Index}

24 (television, 2001-2014) 220

39 Steps, The (film, 1935) 30, 217

Á bout de soufflé (film, 196o) 239

A Colour Box (film, 1935) 242

A Gentleman (film, 2017) $\quad 76$

A Hard Day's Night (film, 1964) 82

A Taste of Honey (film, 1961) 196

A View to a Kill (film, 1985) 151, 175, 191, 258-6o

Abjection 132, 208, 213, 215-16, 218-20, 222-24

Adele $\quad 265,269,282-84$

Adaptations

Book to film $42-43,81-82,85,93,133,136$, 294

Book to television $17,27,31-32,34,37$ see Casino Royale (television, 1954)

Film to video game 21, 309-10 see Goldeneye oo7 (videogame, 1997)

Adam, Ken $\quad 20,129,134,232,243,265$

Agamben, Giorgio $\quad 212,220$

Agent Vinod (film, 2012) $\quad 73-76$

Akdeniz, Ali $\quad 87-88$

Allen, Irving 82

Ambler, Eric 33

Amis, Kingsley 13,36

Amores Perros (film, 2000) 90

An Optical Poem (film, 1938) 242

And God Created Woman (film, 1956) $\quad 236$

Andress, Ursula $107,153,162,164,234$

see also Bond Girls

see also Dr. No (film, 1962)

Ankhen (film, 1976) 62, 64, 66, 74-76

Anyone Can Play (film, 1968) 234

Apted, Michael $86,139,158,263$

see also World is Not Enough, The (film, 1999)

Argo (film, 2012) 86

Arnold, David 277, 285 see also Soundtracks

Arteton, Gemma $\quad 156$ see also Bond Girls see also Quantum of Solace (film, 2008)

Audiences 16, 207

and class 13,112

and race $\quad 203,274-75,280-81$

in Britain $\quad 95,106,115,118,235,274-75$

in Europe $18,42,45,49,52,57,104,113$, 115-16

in North America $\quad$ 14, 30-31, 35, 95

see also Fan Cultures

see also Spectatorship

Augé, Marc 97, 222

Auger, Claudine 234

see also Bond Girls

see also Thunderball (film, 1965)

Avengers, The (television,1961-1969) 162
Baker, Josephine 198

Bakhtin, Mikhail $\quad 172-73,179-180,182$ see also Carnivalesque

Bardem, Javier $\quad 108,117,182,214,300$

Bardot, Brigitte $\quad 235-37$

Barry, John 15, 20, 135, 241, 276-77, 280, 285 see also Soundtracks

Barrymore, Ethel 29

Bass, Saul 240, 251, 253-54 see also Title Sequences

Bassey, Shirley $\quad 20,269-78,280-85$ see also Black Atlantic, the

Baudrillard, Jean $127,135,303$

Belle de Jour (film, 1967) $\quad 236$

Bellucci, Monica 153,155 see also Bond Girls see also Spectre (film, 2015)

Bennett, Charles 30

Benvenutial nord (film, 2012) 115

Berry, Halle $\quad 155,162,175,201,269$ see also Bond Girls see also Die Another Day (film, 2002)

Beswick, Martine 153 see also Bond Girls see also Thunderball (film, 1965)

Bhaba, Homi K. 97

Bianchi, Daniela 234 see also Bond Girls see also From Russia With Love (film, 1963)

Binder, Maurice $\quad 20,240,242-43,249-51$, 254-55, 257-61, 266, 319 see also Title Sequences

Black Atlantic, the $271,274-75,285$ see also Bassey, Shirley see also Gilroy, Paul

Black, Don 280

Black Panther (film, 2018) 188

Blackman, Honor $\quad 15,155,164$ see also Bond Girls see also Goldfinger (film, 1964)

Blow-Up (film, 1966) 239

Bogart, Humphrey 30

Bollywood $62-65,67-77,86$ see also India

Bonanza (television, 1959-73) 45

Bond Girls

and fashion $161-62,281$

and feminism $149,151,154,157,197$

and lesbianism $\quad 15$

and race $176,195,197$

and seriality $19,126,15^{2}, 155,165$

and sex $47,109,126,150,181,200,235,237,278$

and stardom $\quad 91,108,234$

Bond, Samantha 174 see also Bond Girls see also Goldeneye (film, 1995) 
Bond, Trevor $\quad 241,254$ see also Title Sequences

Bordwell, David $230,236,240$

Bourne Ultimatum, The (film, 2007) 222-23

Boyle, Danny 16

Britain

British empire $35-36,174,208,233,286$, 292, 299-300

British film industry 14

British new wave $81,191,193,229-32,234$

"Britishness" 99, 105-106, 115, 118, 192, 194, 210, 230, 233, 235, 273, 289

Broccoli, Albert R. $38,81-83,85,109,132,191$, 233-34, 236, 277

See also Eon Productions

See also Warwick Films

Broccoli, Barbara $\quad 16,109,188,204$

Brosnan, Pierce $\quad 108,116,129,132,211,249,310$, 314,320

and masculinity $\quad 137-39,181$ see also Masculinity

and race $19,172,180,196$

Brown, William H. 17

Brownjohn, Robert $\quad 20,89,240,243-45,249-51$, $254-55,258$

see also Title Sequences

Buchan, John 33

Call Me Bwana (film, 1963) 238

Campbell, Martin $\quad 15,21,95,103,126,137,155$, 209, 241, 250, 263, 309, 320 see also Casino Royale (film, 2006) see also Goldeneye (film, 1995)

Captain Marvel (film, 2019) 204

Carnivalesque $173,182-83$ see also Mikhail Bakhtin

Casablanca (film, 1942) 30

Casino culture $\quad 31,159,293-99,301-04$ and globalisation 296 and masculinity 293 and the law 295, 297-98, 301

Casino Royale (television, 1954) 17, 25-31, 33-38 see also Climax!

Casino Royale (film, 1967) 14

Casino Royale (film, 2006) 15, 34, 69, 105-108, $110,112-13,126,155,212,263,291,320$

Casino Royale (novel, 1953) 13, 28, 290, 294

CBS 25-26, 28-29, 32-35, 37

Celi, Adolfo $\quad 234,239$

Chandler, Raymond $\quad 29,35,131$

Charas (film, 1976) 62,66-67

Chayefsky, Paddy 28

China 68, 106, 179, 211, 214-15, 301

Chomsky, Noam 221

Christian, Linda 30

Chopra, Priyanka 72

CIA 19

Clear and Present Danger (film, 1994) 211

Climax! (television, 1954-1958) 25, 28-30, 32
Communism $\quad 34,44,54,134,262-63$

Anti-communism 43, 58, 127

see also Cold War

see also Germany, Democratic Republic of see also Poland

see also Soviet Union

Coffy (film, 1973) 199

Cold War $53,68,86,97,128-29,217,290,300$ as narrative device $13,31,34,36,93-94$, 262

as geopolitical context $\quad 52,58,61-62$, $136-37,151,194,202,208-09,211,255$

"iron curtain" $18,43,57,214$

"post-Cold War" 95, $25^{\circ}$

Confessions (film series, 1974-77) 235

Connery, Sean $\quad 20,116,129,163,188-89,297$ and masculinity $107,134,136,138$ see also Masculinity

and orientalism 126, 135-36, 175 see also Orientalism and sexuality 133

Connolly, Cyril 133

Conversation, The (film, 1974) 221-22

Craig, Daniel $15-16,18,62,69-70,73,76,88-89$, $96,103,115-16,129,188,201,216,291,320$ and masculinity $\quad 72,109,126,138,174-75$ see also Masculinity

and nationalism $\quad 99,105^{-06,119}$

and neoliberalism 304 see also Neoliberalism

and orientalism $\quad 93,96,172,183$ see also Orientalism

and transnationalism 105-06, 112, 209, 212, 222 see also Transnationalism

Cremona, Alessandro 89

Crouching Tiger, Hidden Dragon (film, 2000) 175

D'abo, Maryam 155 see also Bond Girls see also The Living Daylights (film, 1987)

Dalton, Timothy $94,107,129$

Damn Yankees (film, 1958) 257-58

Danger (television, 1950-1955) 32

Dark Knight trilogy (film, 2005-2012) 216

Davi, Robert 95

Dench, Judi $\quad 99,150,216,265,320-21$

Diamonds are Forever (film, 1973) 41, 132, 136, 196, 233, 279, 297

Diamonds are Forever (novel, 1956) 33, 297

Die Another Day (film, 2002) 139, 153, 175, 201

Disney, Walt 110-11

Don (film, 2006) 62,69

Don 2 (film, 2011) 62, 72

Dots (film 1940) 242

Douglas Fairbanks Jr. Presents (television, 1953-1959) 29

Dr. Kildare (television, 1961-66) 45 


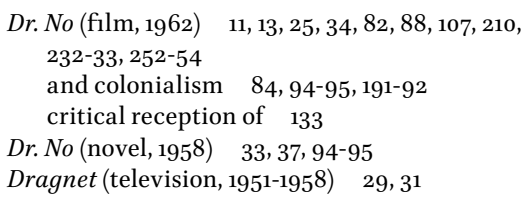

Eady Levy $\quad 82-85$

Easton, Sheena 165

Eaton, Shirley $\quad 134,234,-35$

see also Bond Girls

see also Goldfinger (1964)

Ebert, Roger 127

Eco, Umberto $13,15,304$

End of Agent $W_{4} C$, The (film, 1967) 42

Enforcer, The (film, 1952) 30

Elba, Idris $188-89,191,204$

Elizabeth II 16, 106, 272

Ellis, Antony 30

Elsaesser, Thomas $\quad 222,230,233$

Eon Productions $11,14,27,38,41,83-85,98$, $109,188,191,204,266,318$

Espionage and Cold War 13, 18-19, 34, 93, 256, 277 see also Cold War

and Second World War 190 see also Second World War as film genre $42-43,46,55,58,86,93,108$, 130, 203, 208, 211, 219, 234, 277

Exoticism 54, 84-85, 89-9o, 93, 96-98, 106, 162,

$173,177,275$

see also Imperialism

see also Orientalism

Fall of Berlin, The (film, 1949) $5^{1}$

Fan cultures 26-27

Farz (film, 1967) $\quad 62-65,68$

Fascism 4, 53

Anti-fascism $\quad 51,53$

Fay Grim (film, 2006) 86

Feirstein, Bruce $\quad 320$

Feminism 149-57, 163-65

Post-feminism $156-58$

Ferro, Pablo 240 see also Title Sequences

Finney, Albert 304

Fleming, Ian $11,13,15-16,28,33-34,37,81-82$, $107,125-26,131,189-91,197,296-97,304$ and anti-communism 43, 93-94

and "Britishness" 202, 210

and class 127,129

and colonial nostalgia $\quad 36,93,95-96$

and sexism 183-84, 293

For Eyes Only (film, 1963) 55

For Your Eyes Only (film, 1981) 94, 109, 223

Foreign Correspondent (film, 1940) 30

Formalism 32

Forster, Marc 103

see also Quantum of Solace (film, 2008)
Frankenheimer, John $\quad 32$

Fratini, Renato 236

French New Wave (Nouvelle Vague) 193, 230, 239

Friedan, Betty 195

Fröbe, Gert 135, 234

From Russia With Love (film, 1963) 13, 34, 89, 93-94, 153, 237, 255 critical reception of 238 production of 84,86

From Russia, With Love (novel, 1957) 13, 33, 35, 194

Fukunaga, Cary Joji $\quad$ 11, 104, 204 see also No Time to Die (film, 2020)

Galeano, Eduardo 127

Garland, Judy 159

Gayson, Eunice $\quad 133,153,164$

see also Bond Girls

see also Dr. No (film, 1962)

see also From Russia With Love (film, 1963)

Genre 45, 50, 62, 130

action 69, 203-04

Blaxploitation $\quad 245$

comedy 49,

first-person shooter $310-11,314,320$

genre hybridity 69

martial arts 245

science fiction 245

spaghetti western 233-34

thriller $17,5^{\circ}$ see Espionage (as film genre)

Germany

Democratic republic of $18,41,45,53$, $5^{6-58,134}$

Federal republic of $\quad 41-42,51,53-54,57-58$

"Germanophobia" 42, 44

Ghost Protocol (film, 2011) 219

Gilbert, Lewis $16,64,85,106,159,232$ see also Moonraker (film, 1979) see also Spy Who Loved Me, The (film, 1977) see also You Only Live Twice (film, 1967)

Gilroy, Paul 271, 274 see also Black Atlantic, the

Girl from Rio, The (film, 1968) 234

Glen, John $\quad 61,85,94,109,232$ see also A View to a Kill (film, 1985) see also For Your Eyes Only (film, 1981) see also License to Kill (film, 1989) see also Living Daylights, The (film, 1987) see also Octopussy (film, 1983)

Global South $\quad 56,96,98$ and exoticism $84-85,97,27$ see also Galeano, Eduardo see also Exoticism

Goldeneye (film, 1995) 21, 95, 137, 261, 309-10, $312,314,324$

Goldeneye oo7 (video game, 1997) 309, 311, $315^{-16}, 318,321-25$ 
Goldfinger (film, 1964) 13-15, 134, 159, 217, 238, $243,255,276$

critical reception of $129-30,134,250-51$

Goldfinger (novel, 1959) 33

Gone with the Wind (film, 1939) 195

Goodyear Television Playhouse (television, 1951-1957) 29

Gramsci, Antonio 131

Great Train Robbery, The (film, 1903) 252-53

Green, Eva 126, 155, 165

see also Bond Girls

see also Casino Royale (film, 2006)

Gunsmoke (television, 1955-1975) 29

Hall, Stuart 128

Hamilton, Guy $13,41,85,232$ see also Diamonds are Forever (film, 1973) see also Goldfinger (film, 1964) see also Live and Let Die (film, 1973) see also Man With the Golden Gun, The (film, 1974)

Hammett, Dashiell 35

Harris, Naomie $\quad 19,107,155,172,174-75,183$, 201, 213

Head, Edith 31

Heimat series (film, 1984-2013) 234

Hendry, Gloria 199, 201 see also Bond Girls see also Live and Let Die (film, 1973)

High Noon (film, 1952) 45

Hill, George Roy 32

Hitchcock, Alfred $30,229,237,240$ Alfred Hitchcock Presents (television, 1955-1962) 29

Hollywood 48, 82, 194, 229, 232, $25^{1}$

and censorship 196, 235

and classical form 33,240

and transnationalism $\quad 62,69,85,110$

Homeland (television, 2011) 219

Homoerotics 182

Hooks, Mitchell 236

Huerta, Tenoch 91

Hughes, Ken 14

Hunt, Peter 20, 34, 239

see also On Her Majesty's Secret Service (film, 1969)

I, The Jury (film,1947) 36

If... (film,1968) 239

Imperialism

and Britain $\quad 17,84-85,94-95,106,136$, 190-91, 208, 210, 218

and Europe 199

and the Soviet Union $\quad 5^{0}$

Post-imperialism 131-32

see also British Empire

India $12,18,61$

"Indianization" 62-64, 66-67,70

see also Bollywood
Invisible Gun Sight, The (television, 1973-

79) $42-43,53-55,57$

Italian Neorealism $\quad 230$

James Gunn-Secret Agent

(television,1956) 37

Jason Bourne (film, 2016) 220

Jenkins, Henry 310,324

Jones, Grace $\quad 151,162,175,200-202,258-60$

See also Bond Girls

See also A View to a Kill (film, 1985)

Jones, Tom $\quad 277-78$

Kael, Pauline $\quad 128,135$

Keemat (film, 1973) 62,65

Kennedy, John F. 94, 193

Khan, Shah Rukh $\quad 62,68-69$

Kinescope 26

Kleinman, Daniel $\quad$ 20, 249-51, 254, 257, 261-65

Knight, Gladys $\quad 278,282$

Kraft Television Theatre (television, 1951-1958) 29

Kreise (film, 1933) 242

Kurylenko, Olga 155 see also Bond Girls see also Quantum of Solace (film, 2008)

L'Immortelle (film, 1963) $\quad 238$

La dolce vita (film, 1960) $\quad 238$

Lang, Fritz 30

Last Year at Marienbad (film, 1961) 237-38, 245

Lautner, John 233

Lazenby, George $\quad 129,163$

Le Carré, John 235

Le Mépris (film, 1963) 236-37

Lenya, Lotte 94,234

Lesbianism 15, 128, 164

License to Kill (film, 1989) 85, 90-91, 94-96, $165,222-23$

Liquidator, The (film, 1965) 281

Live and Let Die (film, 1973) 85, 191

Live and Let Die (novel, 1954) 28, 33, 94-95

Living Daylights, The (film, 1987) 94

Llewellyn, Desmond 107

Lollobrigida, Gina $\quad 235-36$

Look Back in Anger (film, 1959) 81

Loren, Sophia $\quad 235-36$

Lorre, Peter $\quad 26,30,33$

Lulu 278

$M$ (film, 1931) 30

Main Hoon Na (film, 2004) 68-69

Maltese Falcon, The (film, 1941) 30

Man from U.N.C.L.E, The (television, 1964-68) $\quad 37-38$

Man on Fire (film, 2004) 90

Man With the Golden Gun, The (film, 1974) 85, 301

Man With the Golden Gun, The (novel, 1965) 13 
Man Who Knew Too Much, The (film, 1934) 30

Mangano, Silvana $\quad 235^{-3} 6$

Manson, Shirley $\quad 282$

Marlohe, Berenice Lim 155

see also Bond Girls see also Skyfall (film, 2012)

Marshall, Zena 153 see also Bond Girls see also Dr. No (film, 1962) see also Orientalism

Marty (television, 1953) 28, 32-3

Mary Had a Little... (film, 1961) 235

Masculinity $\quad 70-71,127-28,134-35,208,212,293$ and imperialism $17,131-32,136,183,189$ and race $172-73,189,192$ and sexuality $\quad 72,125^{-2} 6,137$ Metrosexuality $137-38$

Mask of Dimitrios, The (film, 1944) 30

Matrix, The (film, 1999) 69

Maxwell, Lois 174

McCarthyism 34

McCartney, Paul 282

McClory, Kevin 37

McRobbie, Angela $\quad 156$

Melodrama 69

Mendes, Sam 15, 86, 97, 108, 117 see also Skyfall (film, 2012) see also Spectre (film, 2015)

Metro-Goldwyn Mayer (MGM) 109-10

Metropolis (film, 1927) 265

Mexican, The (film, 2001) 91

Mexico 18

MI6 19, 93, 127, 175, 208, 213

Mikkelsen, Mads $108,212,264$

Miner, Worthington 32

Mission: Impossible (film, 1996) 69, 219

MK12 20, 249-50, 254, 257, 261, 264-66 see also Title Sequences

Modernism

and architecture $\quad 233$

and cinema $\quad 20,232,237,239$

and set design $\quad 243$

and title sequences $\quad 240,249-50,255,261$

Moholy-Nagy, László $\quad 243-44,251,258$ see also Modernism

Moonraker (film, 1979) 85, 159, 162

Moonraker (novel, 1956) 13, 33, 36, 216

Moore, Roger $\quad 61,85,108,127,129,163,175$ and comedy 62,73

More Than Life at Stake (television, 196768) $42-43,45-49$

Morgenthau III, Henry 37

Mulvey, Laura 181, 251

Munk, Andrzej 44

Murder, My Sweet (film, 1944) 29

NATO 37,93

Negra, Diane 157

Nelson, Barry $\quad 30,33$
Neoliberalism $\quad 20,61-62,156,209,216,221$, 292-93, 299, 302-03

Never Say Never Again (film, 1983) 319

Newman, Thomas 277 see also Soundtracks

No Country for Old Men (film, 2007) 117

No Sex Please-We're British (film, 1973) 235

No Time To Die (film, 2020) 11, 104, 109, 204

Norman, Monty $16,25^{2}, 277,319$ see also Soundtracks

O.K. Connery (film, 1967) 234

Oceans Eleven (film, 2001) 298

Octopussy (film, 1983) 61, 159

On Her Majesty's Secret Service (film, 1969) 34, 194, 197-98, 223, 239

On Her Majesty's Secret Service (novel, 1963) 33, 259

Oram, Daphne 241

Orientalism $126-28,135-36,172,174,179$, $182-83,191,256,299$ see also Said, Edward

Osborne, John 81

Paluzzi, Luciana $\quad 135,234,236$ see also Bond Girls see also Thunderball (film, 1965)

Parallax View, The (film, 1974) 221-22

Parks, Trina 153, 201

Pate, Michael 31

Patriot Games (film, 1992) 211

Paz, Adriana 91

Performance (film, 1970) 239

Péteri, György 57

Pinewood Studios $\quad 84-85,238$

Playboy 17, 210, 235, 259

Poland $18,41,5^{8}$

Polish School 44, 46

Ponzanesi, Sandra 97

Powell, Dick 29

Princess Tam Tam (film, 1935) 198

Purvis, Neal 108

Quantum of Solace (film, 2008) 103, 113, 156, 264,291

Race: $\quad 162,175,188-89,192,194,196-97,199$, 202-03, 272 see also Black Atlantic, the see also Bond Girls and race see also Orientalism

Radatz, Ben $25^{\circ}$

Rainbow Dance (film, 1936) 243

Rand, Ayn 128-29

Rapace, Ola $\quad 176$

Ratoff, Gregory $\quad 28$

Reagan, Ronald $\quad 58,127$

Red Beret, The (film, 1953) 82

Red Dawn (film, 1984) $5^{8}$ 
Rendition (film, 2007) 219

Requiem for a Heavyweight (television, 1956) 28

Rhamouni, Imad 233

Richards, Denise 158 see also Bond Girls

see also World is Not Enough, The (film, 1999)

Richardson, Tony 81

Rigg, Diana 153,162

Romeo+Juliet (film, 1996) 90

Runaway Productions $\quad 81-86,88,90,98$ see also Skyfall (film, 2012), production of see also Spectre (film, 2015), production of see also Transnationalism

Sabotage (film, 1936) 30

Said, Edward 172,183 see also Orientalism

Saint, The (television, 1963-69) 45

Saltzman, Harry $38,81-83,109,191,233,236,277$ see also Eon Productions

Sartre, Jean-Paul $15^{2}$

Schaffner, Franklin 32

Second World War 19, 43, 45, 47, 50, 95, 189-90, 192-93, 255

Secret Agent (film, 1936) 30

Serling, Rod 28

Seventeen Moments of Spring (television, 1972) $\quad 42-43,49-5^{2}$

Seydoux, Léa $\quad 108,155^{-5} 6,158-59$

see also Bond Girls see also Spectre (film, 2015)

Seymour, Jane 155

Shaft (film, 1971) 199

Sigman, Stephanie 91,153

see also Bond girls see also Spectre (film, 2015)

Simpson, Mark 137

Sinatra, Nancy $\quad 278$

Skyfall (film, 2012) 15-16, 86, 99, 172, 176-78, 201, 207-08, 213, 264-65, 282, 291-93, 299-301, 304 and exoticism 93, 96-97 see also Exoticism

and globalisation $\quad 214,299$

and nationalism $\quad 106$

critical reception of $105,112-16$

production of $87-89,108,303$ see also Runaway productions

Smith, Sam $\quad 278$

Sontag, Susan 19, 203

Soundtracks $61,63,158,241,277,280,285,319$ see also Arnold, David

see also Barry, John see also Newman, Thomas see also Norman, Monty see also Theme Songs

Sovereignty 130, 208-09, 211-12, 216-18, 220, $222-24,301$
Soviet Union $\quad 13,42-43,50,93-94,262$

Spectatorship $53,198,204,240$

and race 203

and sexuality $126,182,210$

see also Audiences

"tourist gaze" 96

Spectre (film, 2015) 89, 96-97, 99, 106, 156, 158, 201, 219, 233, 265, 282, 291

and neoliberalism $\quad 209$

critical reception of 91,113

production of $86,90,92,109$ see also Runaway productions

Spigel, Lynn 157,160

Spillane, Mickey 36

Spooks (television, 2002-2011) 219

Spottiswoode, Roger $\quad 19,180$ see also Tomorrow Never Dies (film, 997)

Spy (film, 2015) 281

Spy Who Loved Me, The (film, 1977) 16, 106, 159

St. John, Jill 153 see also Bond Girls see also Diamonds Are Forever (film, 1971)

Stardom 175-76, 188-89, 191, 200, 276, 278, 282

Strange, Susan 298

Studio One (television, 1948-1958) 29, 32

Sweet Sweetback's Baadasssss Song (film, 1971) 199

Syriana (film, 2005) 219

Tarzan the Apeman (film, 1932) 26o

Tengo ganas de ti (film, 2012) 115

Terrorism 208-09, 212, 214, 216, 220-22 and Neoliberalism 209 see also Neoliberalism

Cyberterrorism 108, 214, 217-18, 290

Testament of Orpheus, The (film, 1960) 234

Tinker Tailor Soldier Spy (film, 2011) 86

Title Sequences 20, 164-65, 213, 240-41, 242-45 see also Bass, Saul see also Binder, Maurice see also Bond, Trevor see also Brownjohn, Robert see also Ferro, Pablo see also $\mathrm{MK} 12$ see also Williams, Richard

Thatcher, Margaret 96

Theme Songs $269,272,276-82,283-84$ see also Adele see also Bassey, Shirley see also Black, Don see also Knight, Gladys see also Lulu see also Manson, Shirley see also McCartney, Paul see also Sinatra, Nancy see also Smith, Sam see also Soundtracks see also Turner, Tina see also Warwick, Dionne 
This Sporting Life (film, 1963) 236

Thos, Yves 236

Thunderball (film, 1965) 13, 128, 135, 153, 239, 277, 319

Thunderball (novel, 1961) 33-34, 37

Tomorrow Never Dies (film, 1997) 19, 137, 165, 172-73, 178-81, 211, 263

Total Recall (film, 1990) 90

Toy Story (film, 1995) 261

Transnationalism $62,84,104,110,188,192$, 210-11, 214, 286

True Lies (film, 1994) 211

Truffaut, Francois 233

Turkey $18,86-89$

Turner, Tina $\quad 278,282$

United Artists $\quad 38,82-83,109$

United Nations $37,127,273$

United States 12

American cosmopolitanism 193-94

Anti-Americanism $\quad 5^{2}$

Untouchables, The (television, 1959-63) 29

van der Zyl, Nikki $\quad 164$

Veiller, Bayard 29

Video Games 21, 309-11, 315-16, 318, 321-25 see also Adaptation (film to video game) see also Goldeneye oo7 (video game, 1997)

Wade, Robert 108

Wagon Train (television, 1957-1965)
Wajda, Andrzej 44

Walken, Christopher $\quad 175,200$

Waltz, Christoph 99, 219

Warner Bros. 88

Warwick, Dionne 277

Warwick Films 82

Whishaw, Ben 107

Williams, Richard 240 see also Title Sequences

Wilson, Michael G. $\quad$ 16, 87, 109, 188

Windust, Bretaigne 30

Wire, The (television, 2002-2008) 219

Wiseman, Joseph $\quad 253$

Wizard of $\mathrm{Oz}$, The (film, 1939) 159

Whittingham, Jack 37

Woodfall Film Productions 81

World is Not Enough, The (film, 1999) 86, 139, 158,263

Yeoh, Michelle $\quad 19,172,175^{-7} 6,180,182$ see also Bond Girls see also Tomorrow Never Dies (film, 1997)

You Only Live Twice (film, 1967) 64, 67, 85, 126, $135,175,181-82$

You Only Live Twice (novel, 1964) 33

Young, Iris Marion $15^{2}$

Young Sherlock Holmes (film, 1985) 263

Young, Terence $11,13,82,84,232,245$ see also Dr. No (film, 1962) see also From Russia With Love (film, 1963) see also Thunderball (film, 1965) 

The release of No Time To Die in 2020 heralds the arrival of the twenty-fifth installment in the James Bond film series. Since the release of Dr. No in 1962, the cinematic James Bond has expedited the transformation of Ian Fleming's literary creation into an icon of western popular culture that has captivated audiences across the globe by transcending barriers of ideology, nation, empire, gender, race, ethnicity, and generation. The Cultural Life of James Bond: Specters of 007 untangles the seemingly perpetual allure of the Bond phenomenon by looking at the non-canonical texts and contexts that encompass the cultural life of James Bond. Chronicling the evolution of the British secret agent over half a century of political, social, and cultural permutations, the fifteen chapters examine the brand of Bond beyond the film series and across media platforms while understanding these ancillary texts and contexts as contested sites of negotiation with the Eon franchise.

Jaap Verheul is a Lecturer in Film Studies Education at King's College London, where his research focuses on the regulation of transnational flows of cultural production in European media industries.

"One of the permanent gains we owe to 'new Bond studies' is the notion that James Bond is far more mobile a signifier than previous generations of critics imagined. The Cultural Life of James Bond makes an invaluable contribution to this widened view of 007. Situating the films in a range of new contexts, this trove of essays uncovers previously ignored and even unexpected connections between Bond and such phenomena as black casting and performance, postfeminism, modernism, transnational geographies and taste cultures, and the development of film, television, video game, and music industries across the globe. This book doesn't just remind us that Bond matters. It reminds us that Bond scholarship matters." - Colin Burnett, Washington University in St. Louis, author of The Invention of Robert Bresson: The Auteur and His Market (2017)

"This book brings together a supremely talented group of scholars to interrogate 007 in new and innovative ways. The result is a fresh and timely re-examination of the James Bond phenomenon's complicated relationship with popular culture, global media, and transnational geopolitics. The Cultural Life of James Bond is a must-read for 007 scholars and fans alike." - Christoph Lindner, University College London, editor of The James Bond Phenomenon: A Critical Reader (2009) 